\title{
AN EXAMINATION OF HOW WOMEN AND UNDERREPRESENTED RACIAL/ETHNIC MINORITIES EXPERIENCE BARRIERS IN BIOMEDICAL RESEARCH AND MEDICAL PROGRAMS
}

\author{
A Dissertation \\ Presented to \\ The Faculty of the Curry School of Education \\ University of Virginia \\ In Partial Fulfillment \\ of the Requirements for the Degree \\ Doctor of Philosophy \\ by \\ Devasmita Chakraverty, B.Sc., M.Sc., M.P.H.
}

August 2013 
(C) Copyright by

Devasmita Chakraverty

All Rights Reserved

August 2013 


\begin{abstract}
Women in medicine and biomedical research often face challenges to their retention, promotion, and advancement to leadership positions (McPhillips et al., 2007); they take longer to advance their careers, tend to serve at less research-intensive institutions and have shorter tenures compared to their male colleagues (White, McDade, Yamagata, \& Morahan, 2012). Additionally, Blacks and Hispanics are the two largest minority groups that are vastly underrepresented in medicine and biomedical research in the United States (AAMC, 2012; NSF, 2011). The purpose of this study is to examine specific barriers reported by students and post-degree professionals in the field through the following questions:
\end{abstract}

1. How do women who are either currently enrolled or graduated from biomedical research or medical programs define and make meaning of gender-roles as academic barriers?

2. How do underrepresented groups in medical schools and biomedical research institutions define and make meaning of the academic barriers they face and the challenges these barriers pose to their success as individuals in the program? These questions were qualitatively analyzed using 146 interviews from Project TrEMUR applying grounded theory. Reported gender-role barriers were explained using the "Condition-Process-Outcome" theoretical framework. About one-third of the females (across all three programs; majority White or Black between 25-35 years of age) reported gender-role barriers, mostly due to poor mentoring, time constraints, set expectations and institutional barriers. Certain barriers act as conditions, causing gender-role issues, and gender-role issues influence certain barriers that act as outcomes. Strategies to overcome 
barriers included interventions mostly at the institutional level (mentor support, proper specialty selection, selecting academia over medicine).

Barrier analysis for the two largest URM groups indicated that, while Blacks most frequently reported racism, gender barriers, mentoring, and personal barriers, Hispanics most frequently reported economic barriers, language barriers, institutional and workplace environment barriers, and gender-role barriers. Examining barriers using the "Individual-Institutional" theoretical framework indicated that barriers do not occur in isolation, but due to an interaction between the individual and its institution.

Additionally, the barriers of the two groups are qualitatively different and the "one size fits all" approach may not be suitable for interventions. Implications and recommendations were stated. 


\section{Department of Curriculum, Instruction and Special Education \\ Curry School of Education \\ University of Virginia \\ Charlottesville, Virginia}

\section{APPROVAL OF THE DISSERTATION}

This dissertation, "An Examination of How Women and Underrepresented Racial/Ethnic Minorities Experience Barriers in Biomedical Research and Medical Programs", has been approved by the Graduate Faculty of the Curry School of Education in partial fulfillment of the requirements for the degree of Doctor of Philosophy.

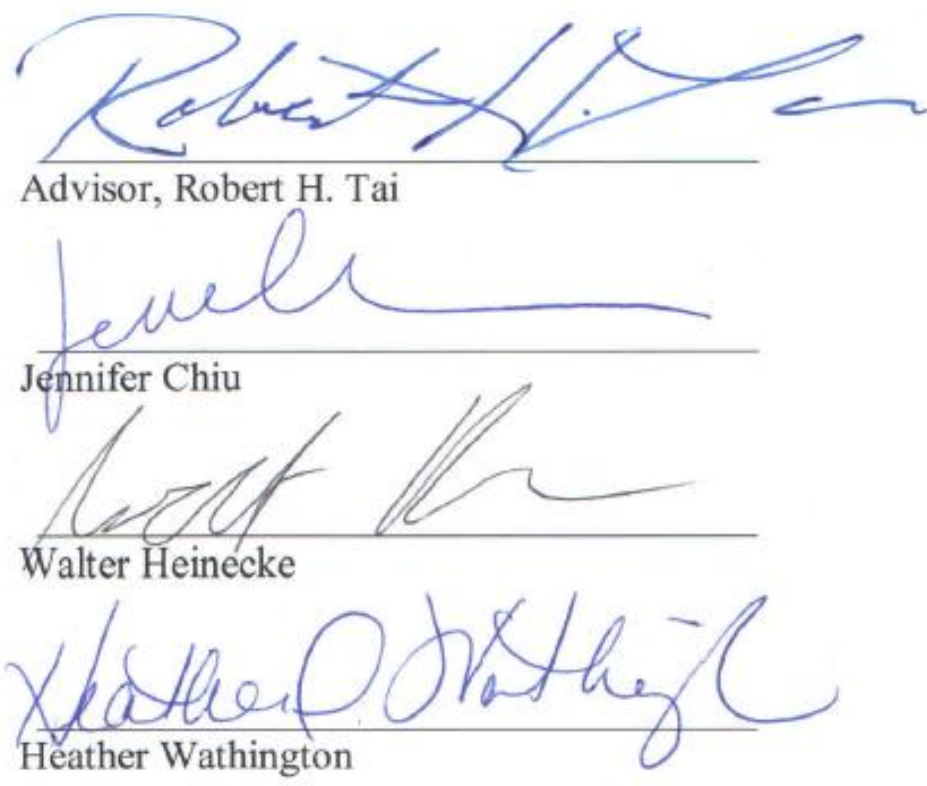




\section{DEDICATION}

For Baba and Ma, who taught me to write my first shaky alphabet, taught me how to count numbers for a life full of calculations and decision making, and introduced me to the beautiful world of learning and the pursuit of knowledge.

For my grandmother, who has inspired me with her energy and enthusiasm in life.

For Professor Tai, who taught me qualities like independence and critical thinking, gave me innumerable opportunities to shine, and inspired me to learn, work hard, and appreciate the world of research.

For Jhumpa Lahiri, who wrote, "You are still young. Free. ... Do yourself a favor. Before it's too late, without thinking too much about it first, pack a pillow and a blanket and see as much of the world as you can. You will not regret it. One day it will be too late." 


\section{ACKNOWLEDGEMENTS}

"It takes a village to raise a child." - African proverb.

My heartfelt gratitude and thank you go to the following people, who have been important parts of my journey as a doctoral student.

Robert H. Tai, my faculty advisor, who has supported me through my training in his research team. Thank you for your constructive criticisms, insights, advice, vision, for teaching me how to "think for a living" and for being my mentor in learning to pursue independent research. My academic experience in your research group was as processoriented as goal-oriented, and finishing on time was possible because of your support. I am thankful that I followed your advice and took multiple methods courses, learned multiple analytic software, traveled all over the country for field work, presented at national conferences early on and was able to finish within three years. Thank you for pushing me to take every statistical course the department offered, and then giving me the academic freedom to pursue qualitative research and defining my niche.

My dissertation committee: Jennifer Chiu, Walt Heinecke, and Heather Wathington for guiding me through my research. Walt, developing an exemplary grounded theory model was a feat in itself, and it would not have been possible without your guidance. Your contribution has been invaluable. Jennie and Heather, you both are my role models. Thanks for helping me crystallize my thoughts whenever I lost the bigger picture, and for giving me that much needed inspirational push.

Donna Jeffe, and Dorothy Andriole, for your invaluable support and advice. I have learned a lot from both of you.

Robert W. Covert, who organized the support dissertation group, and all the participants for sharing their stories and making the dissertation writing a collective experience.

John, Kate, Nathan, Xiaoqing, and Daniel for wonderful memories during my three years in the research group.

Bruce Kelman, who supported and encouraged me all the way from the Pacific Northwest, and was instrumental in getting me situated in one of the best doctoral programs in the country. I hope that you are very proud of my achievements. 
Nivedita, Rupalee, Ella, Kari, Kathan, Deepa, James, and Jay from Curry School and UVA, who supported me through my journey. Shahana, Meenakshi, Bipasha, Sangeeta and Gayathri, for extending your love and support all the way from Seattle.

Mauktik, who wrote to me from distant continents and taught me that a lot of learning happens outside classrooms, amidst traveling, learning new languages, and meeting people from different cultures.

Devshikha, who was not only instrumental in introducing me to the field of education, but also supported me during my doctoral training with her insights, suggestions, pep talk, and invaluable feedback on my manuscript.

Professor Avik Ghosh, for the much needed "Yes, you can do it!" talk and for helping me understand student expectations from a professor's perspective.

Yamini and her family, for nothing in particular, but everything in general.

Deepak, who extended his hospitality in California whenever I needed to get away. Many of the important ideas of this dissertation were conceived while visiting him at his Google office in Mountain View over orange juice and gummy bears.

Nancy Wall, who meticulously edited her longest dissertation very professionally, promptly, and gave me invaluable feedback. It was a pleasure to work with her.

My family: My grandparents, parents, sister, and brother-in-law, who extended their love and unconditional support all the way from Calcutta. Thank you for imbibing the value of hard work and persistence early on. You have been my support system while I was busy creating a life for myself away from home.

Google, Google Scholar, and Youtube, that were wonderful resources for writing and formatting this manuscript. Radio Mirchi, for keeping the music flowing during the long nights of writing. I wonder how dissertations were written during the pre-Google era.

And finally to Shampa Ghosh, my friend who kept me well-nourished through my dissertation writing and made sure that I never went to bed hungry. You have been like my family in a foreign country. 
TABLE OF CONTENTS

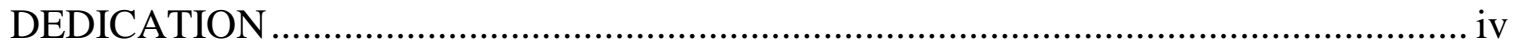

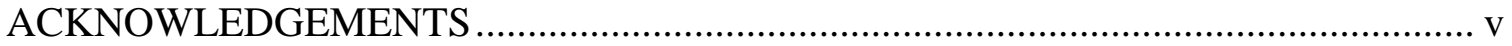

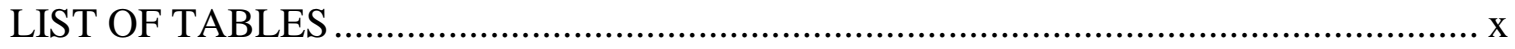

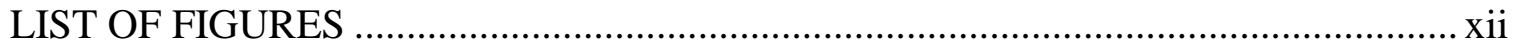

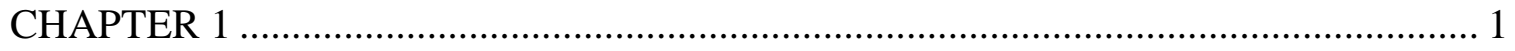

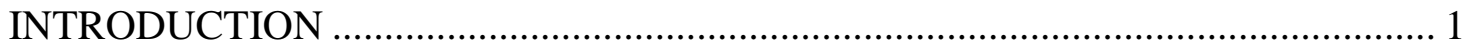

Theoretical Frameworks ...................................................................................... 5

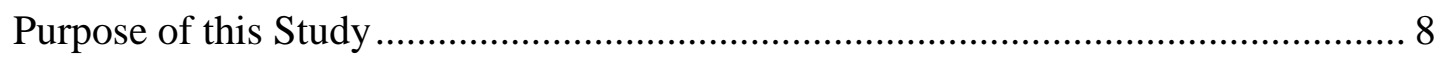

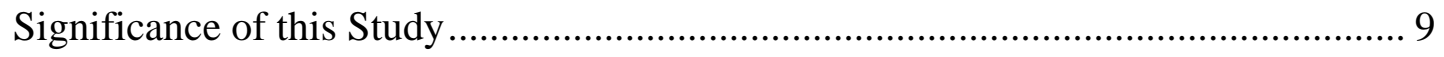

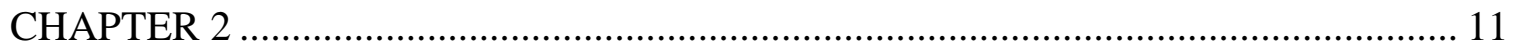

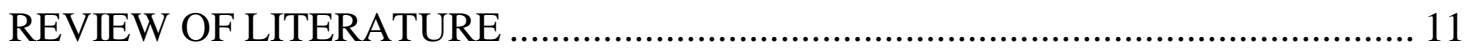

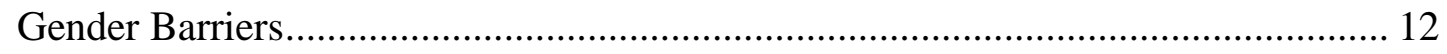

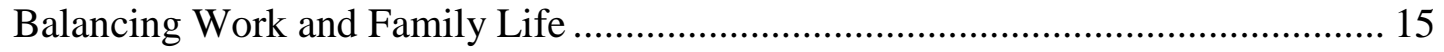

Barriers of Underrepresented Racial and Ethnic Minorities ..................................... 27

Summary of Existing Research .......................................................................... 43

Limitations of Existing Research .......................................................................... 44

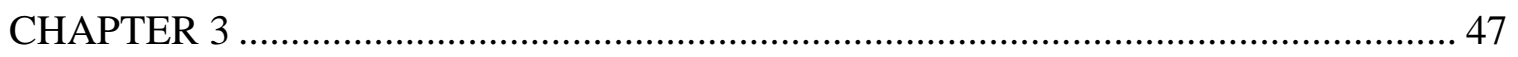

RESEARCH DESIGN AND METHODOLOGY ………............................................ 47

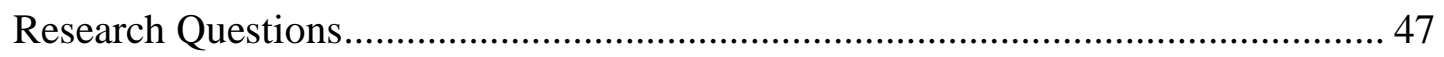




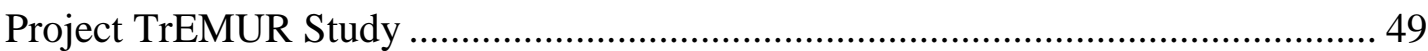

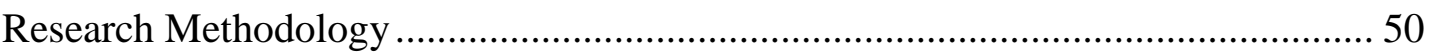

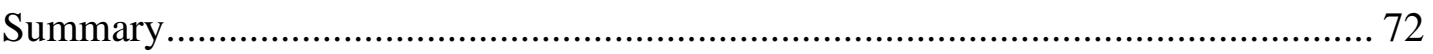

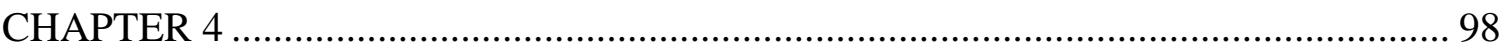

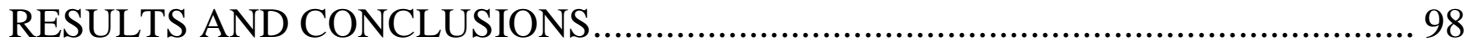

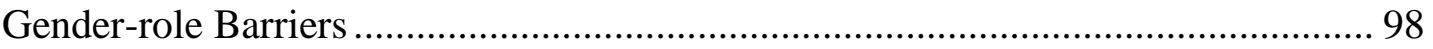

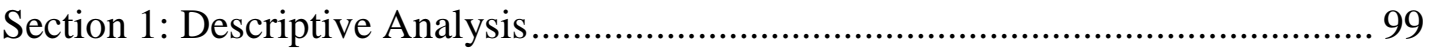

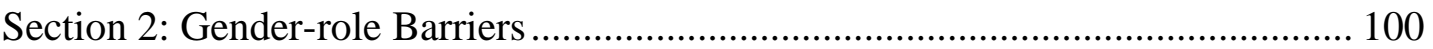

Description of the Condition-Process-Outcome Theoretical Framework ............... 101

Section 3: Strategies to Overcome Gender-role Barriers ................................... 120

Insight on Two-Physician Families ................................................................ 129

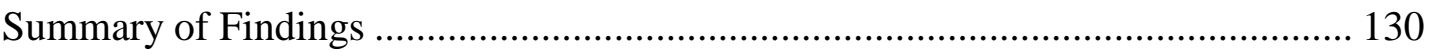

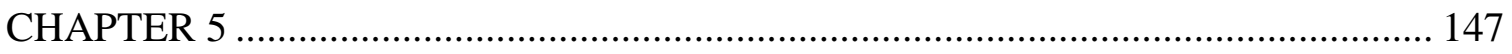

RESULTS AND CONCLUSIONS ................................................................... 147

Barriers of Underrepresented Racial/Ethnic Minorities .................................... 147

Individual-Institutional Theoretical Framework ................................................ 148

Barriers Reported by Black Males............................................................... 150

Barriers Reported by Black Females ......................................................... 163

Barriers Reported by Hispanic Males ............................................................... 192

Barriers Reported by Hispanic Females ........................................................ 202

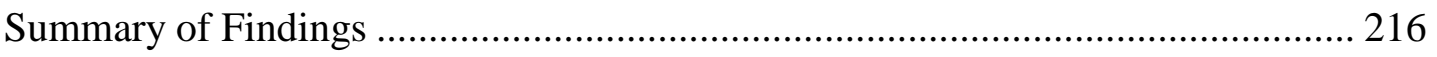

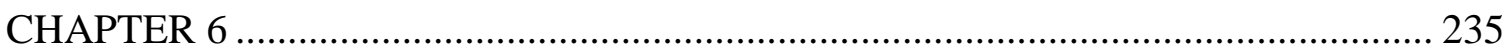


DISCUSSION AND IMPLICATIONS ........................................................... 235

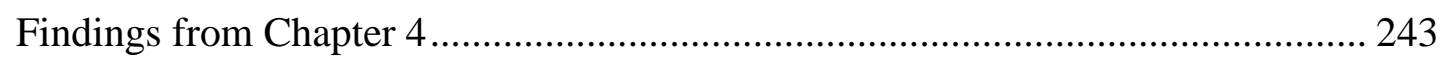

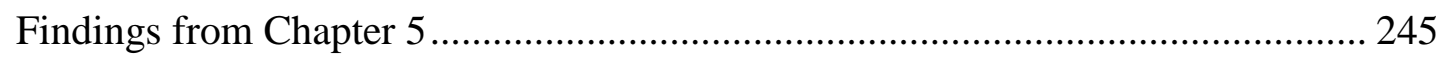

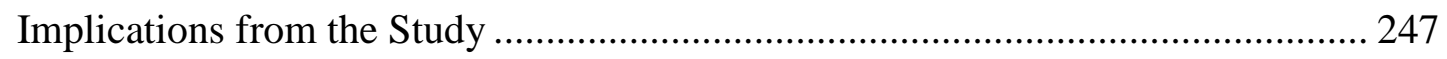

Recommendations from the Study ......................................................... 249

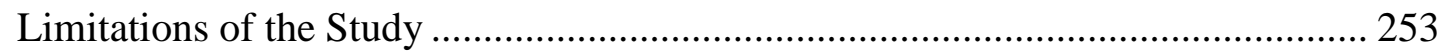

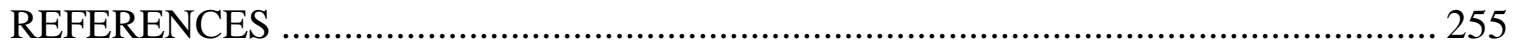

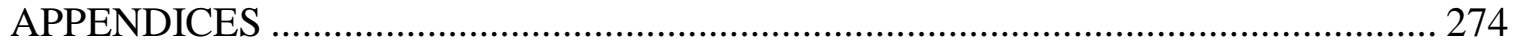

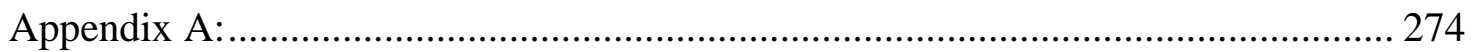

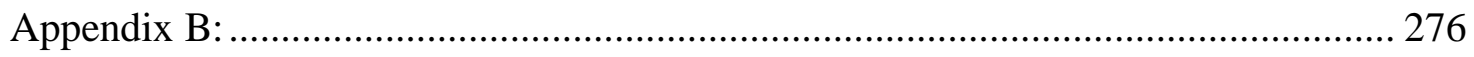




\section{LIST OF TABLES}

TABLE

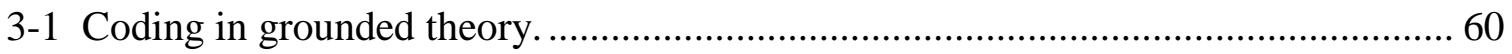

3-2 Racial and Ethnic Distribution of the Overall Study $(\mathrm{N}=214)$................................. 74

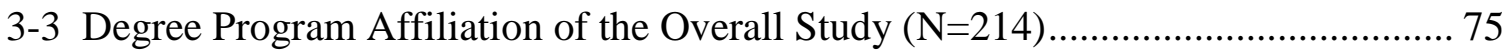

3-4 Overall Distribution Based on Geographic Region in the U.S. $(\mathrm{N}=214)$.................. 76

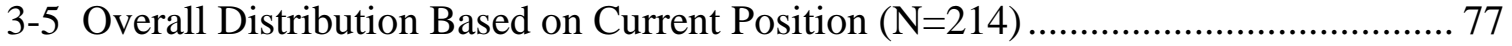

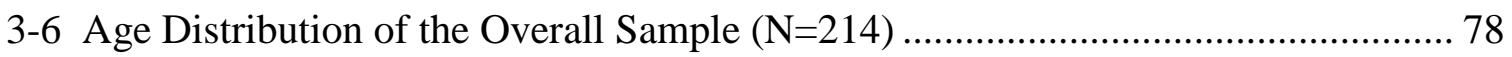

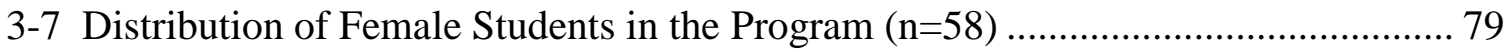

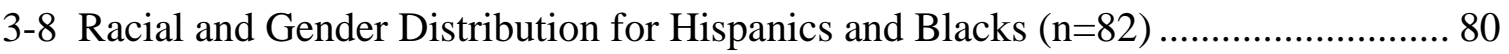

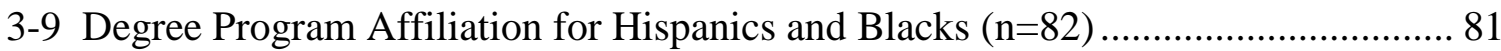

3-10 Distribution of Hispanics and Blacks Based on Geographic Location $(\mathrm{n}=82) \ldots \ldots . . .82$

3-11 Distribution of Hispanics and Blacks Based on Current Position $(\mathrm{n}=82)$............... 83

3-12 Age Distribution of Hispanics and Blacks (n=82) …............................................. 84

3-13 Comparison of Students, Female versus Male, Hispanic versus Black. $(\mathrm{n}=34) \ldots . . .85$

4-1 Demographics of Females Reporting Gender-role Barriers $(\mathrm{n}=40)$........................ 134

4-2 Frequency of Reported Gender-role Barriers ………............................................. 135

4-3 Strategies of Intervention for Gender-role Barriers.............................................. 136

4-4 Strategies of Institutional Intervention for Gender-role Barriers ............................ 137

5-1 Frequency of Reported Barriers for Black Males................................................. 218 
5-2 Frequency of Reported Barriers for Black Females

5-3 Frequency of Reported Barriers for Hispanic Males............................................ 220

5-4 Frequency of Reported Barriers for Hispanic Females .................................... 221

5-5 Frequency of Reported Barriers for Blacks and Hispanics ................................ 222 


\section{LIST OF FIGURES}

FIGURE $\quad$ Page

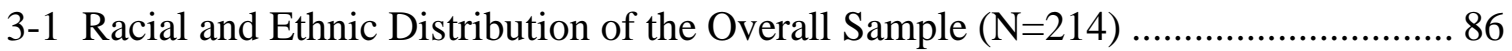

3-2 Degree Program Affiliation of the Overall Sample (N=214) ............................... 87

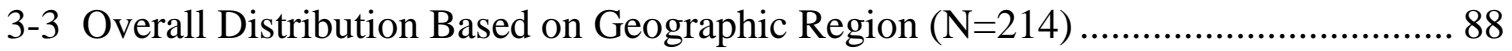

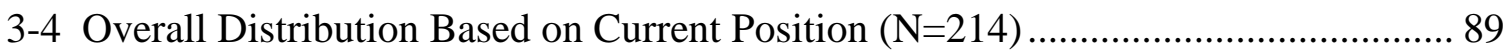

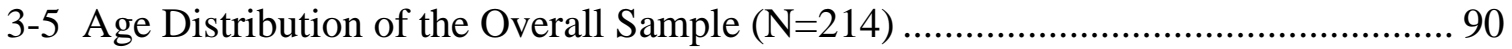

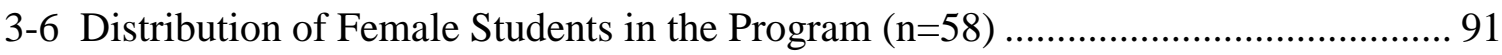

3-7 Racial and Gender Distribution for Hispanics and Blacks $(\mathrm{n}=82)$......................... 92

3-8 Degree Program Affiliation for Hispanics and Blacks $(n=82)$.............................. 93

3-9 Distribution of Hispanics and Blacks Based on Geographic Regions $(n=82) \ldots \ldots \ldots . .94$

3-10 Distribution of Hispanics and Blacks Based on Current Position $(n=82)$.............. 95

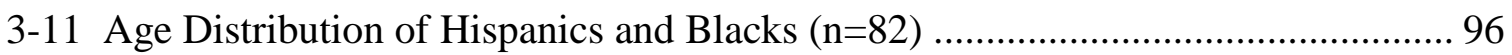

3-12 Comparison of Students, Female versus Male, Hispanic versus Black. $(n=34) \ldots . . .97$

4-1 Degree Program Affiliation of Females $(n=40)$................................................ 138

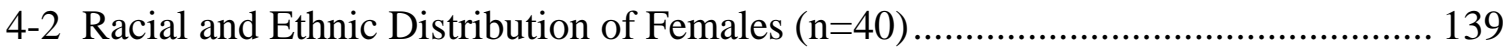

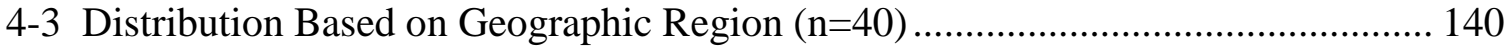

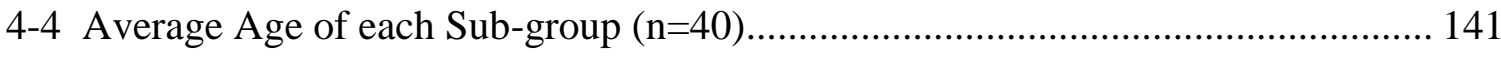

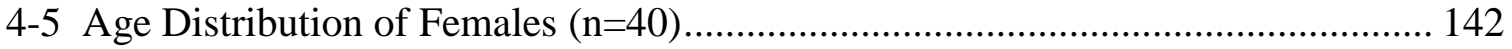

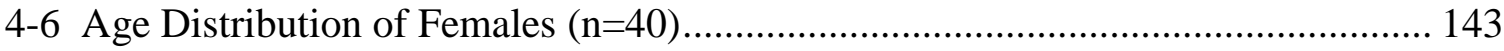


4-7 Reported Gender-role Barriers

4-8 Reported Interventions for Gender-role Barriers.............................................. 145

4-9 Reported Institutional Interventions for Gender-role Barriers .............................. 146

5-1 Frequency of Reported Barriers for Black Males............................................ 223

5-2 Frequency of Reported Barriers for Black Females ........................................... 224

5-3 Frequency of Reported Barriers for Hispanic Males........................................ 225

5-4 Frequency of Reported Barriers for Hispanic Females .................................... 226

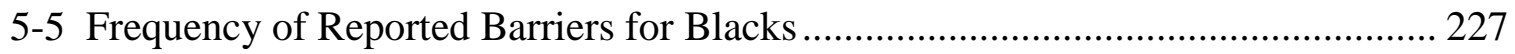

5-6 Frequency of Reported Barriers for Hispanics ............................................... 228

5-7 Frequency of Reported Barriers for Black Males............................................ 229

5-8 Frequency of Reported Barriers for Black Females ........................................ 230

5-9 Frequency of Reported Barriers for Hispanic Males........................................ 231

5-10 Frequency of Reported Barriers for Hispanic Females .................................. 232

5-11 Frequency of Reported Barriers for Black Males and Females.......................... 233

5-12 Frequency of Reported Barriers for Hispanic Males and Females...................... 234 


\section{CHAPTER 1}

\section{INTRODUCTION}

Race and gender are the two important contributing factors to workforce diversity in any field, and the field of medicine and biomedical science research is no exception. Unlike the underrepresentation of women in certain Science, Technology, Engineering, and Mathematics (STEM) fields like physical sciences (National Science Foundation [NSF], 2011), the proportion of women admitted to medical school programs continues to rise (Association of American Medical Colleges [AAMC], 2012; McPhillips et al., 2007). Although recruitment of women entering the pipeline in medicine and biomedical research is not an issue, their retention, promotion, and advancement to leadership positions are issues. Research indicates that women in medicine and biomedical research take longer to advance their careers, and the percentage of successful women decreases up the leadership hierarchy in academic medicine (AAMC, 2012; McPhillips et al., 2007). There is an obvious gender difference in the preparation of women to serve in the workforce.

Additionally, Hispanics and Blacks are the two largest minority groups that are vastly underrepresented in medicine and biomedical research in the United States (U.S.) (AAMC, 2012; NSF, 2011). The Sullivan Commission on Diversity in the Health Workforce (2004) indicates that racial or ethnic diversity in the medical pipeline has not been able to keep pace with the general population of the country. While 
underrepresented minorities (URMs) constitute about $25 \%$ of the population, they represent less than $6 \%$ of physicians in the workforce, their numbers dwindling across the medical school pipeline from applicants to student enrollees, graduates, and faculty (AAMC, 2012; NSF, 2011). This compounds the issues of persistent health disparities and impaired access to healthcare by URMs in the country. The healthcare needs of society are evolving with an increase in demographic diversity of the U.S. However, many workforce challenges are attributed to a lack of acknowledgment of cultural differences, and differential access to healthcare across these demographics. While improving representation of URMs among students and post-degree professionals in the field is the major step toward addressing healthcare disparity issues, the process is arduous and challenged by existing social and professional norms that prevail. Several barriers impede the success of URM students and post-degree professionals in medicine and biomedical research, and while some of these barriers may also be experienced by non-minority groups, the URMs perceived that they needed to work harder in order to overcome them (Bright et al., 1998). Additionally, other barriers may be very specific to a particular group of URMs, with undertones of racism, bias, discrimination, and stereotyping.

This dissertation will now define some of the terms that will be used extensively in the manuscript.

\section{Definition of terms}

- A minority is a racial or ethnic group forming a small proportion of the population in the U.S. This includes Blacks, Hispanics, American Indians or Alaska Natives, Native Hawaiians or other Pacific Islanders, and Asians (NSF, 2011). 
- An underrepresented minority (URM) is one of the three racial or ethnic groups of Blacks, Hispanics, or American Indians, with a representation in the scientific workforce smaller compared to their proportion in the overall U.S. population (NSF, 2011).

- High Hispanic Enrollment (HHE) institutions are the minority-serving academic institutions with a high proportion of Hispanic enrollment (NSF, 2011).

- Historically Black Colleges or Universities (HBCUs) are "any historically black college or university that was established prior to 1964 , whose principal mission was, and is, the education of black Americans, and that is accredited by a nationally recognized accrediting agency or association determined by the Secretary [of Education] to be a reliable authority as to the quality of training offered or is, according to such an agency or association, making reasonable progress toward accreditation." (NSF, 2011).

- $M D$ (Doctor of Medicine) is a physician with a doctoral degree in medicine.

- $\quad P h D$ (Doctor of Philosophy) in this dissertation is a professional with a doctoral degree in any branch of medicine or biomedical sciences, with a focus on research.

- $M D / P h D$ is a combined Doctor of Medicine and Doctor of Philosophy degree granted by medical schools for physician scientists.

- $\quad$ MSTP is a National Institute of Health (NIH) funded Medical Scientist Training Program that is highly competitive $\mathrm{MD} / \mathrm{PhD}$ dual degree programs. They were initially started by the National Institutes of General Medical Sciences (NIGMS) in 1964 (Muslin, Kornfeld, \& Polonsky, 2009; National Institutes of General 
Medical Sciences [NIGMS]; Varki \& Rosenberg, 2002) and support undergraduate students (including minorities) pursuing clinical medicine and biomedical research through economic resources (Varki \& Rosenberg, 2002). About 170 new positions are awarded MSTP grant support every year through their universities and medical schools. It takes 7-8 years to complete the program and each grantee receives a maximum of six years of financial support with no payback obligation (NIGMS). MSTP training grants constitute only a subset of programs offering an $\mathrm{MD} / \mathrm{PhD}$ dual degree in the U.S.; economic support is guided by merit and a research commitment in basic science, as well as clinical research (NIGMS).

- A post-degree professional in this study is someone who has completed an MD, $\mathrm{PhD}$, or $\mathrm{MD} / \mathrm{PhD}$ degree and is currently employed as a faculty, postdoctoral fellow, resident, scientist, or non-scientist. On the other hand, a student in this dissertation is someone who is currently enrolled in an $\mathrm{MD}, \mathrm{PhD}$, or $\mathrm{MD} / \mathrm{PhD}$ program.

- In this dissertation, gender-role barriers are barriers related to succeeding professionally while balancing the gender-roles of childbearing, childrearing, and raising a family. It is a subset within the overall umbrella of gender barriers. In order to understand the issues to successful retention and advancement of women and underrepresented racial and ethnic minorities in the field, it is imperative to study the entire pipeline as students go through the subsequent stages of applying to medical or graduate school, getting accepted into the program, graduating from the program, and integrating into the workforce through their post-degree occupation. 
According to NSF (2011), Blacks and Hispanics respectively constitute roughly $12.2 \%$ and $15.5 \%$ of the resident population in the U.S. However, the percentage of medical school applicants in 2011 consisted of roughly 7.3\% Blacks and 10.6\% Hispanics respectively (AAMC, 2012). On the other hand, the number of female medical school applicants has continued to rise over time, reducing the gender gap (AAMC, 2012). The acceptance rates of women into these programs has also increased over time (AAMC, 2012), indicating that recruitment of women into the pipeline may not be an issue. While the numbers of Black and Hispanic graduates have remained fairly constant over the years (AAMC, 2012), the number of female graduates has risen steadily over time (AAMC, 2012). However, the issue of underrepresentation (for women as well as racial and ethnic minorities) occurs for faculty and leadership ranks in medicine, especially as one goes up in the hierarchy, from being an instructor to being a professor (AAMC, 2012). Blacks and Hispanics constitute roughly $2.9 \%$ and $4 \%$ of full-time faculty positions, while women constitute only $37 \%$ of full-time faculty positions. This indicates that, while recruitment in the pipeline for women and URMs in the field may not be an issue, their retention, promotion, and advancement to higher position are issues. The goal of this dissertation is to study some of the barriers that are issues to the success of women and URMs in the pipeline.

\section{Theoretical Frameworks}

This qualitative research is guided by two existing theoretical frameworks to understand how a marginalized section of the workforce faces certain barriers based on gender and race/ethnicity. The theories are: Socialization Theory, and CulturalEcological Theory. The basic tenets of each theory are described briefly. 


\section{Socialization Theory}

Socialization constitutes the overall process through which individuals acquire or develop certain knowledge, skills, and dispositions that help them integrate into professions, workforces or societies (Brim \& Wheeler, 1966, p.3). The theory of socialization is useful to understanding how professionals socialize and integrate themselves into a particular field or workforce, along with the factors that can determine attrition or retention in the field (Golde, 2005; Lovitts, 2001; Lovitts \& Nelson, 2000). Socialization develops from the belief that individuals can acquire knowledge, skills, the ability to succeed, or the desire to integrate into the workforce by seeking organizational membership (Van Maanan, 1976). The socialization lens has been used in the past to understand how students transform into professionals (Weidman, Twale, \& Stein, 2001), where students entering graduate programs have certain values and beliefs about themselves and the profession, which may or may not change with time, after exposure to outside socializing influences in the program (Stein \& Weidman, 1989). Socialization helps students (including URMs) to integrate and succeed in the fields of research and academic medicine (Jackson, et. al., 2003; Lyons, Scroggins, \& Rule, 1990; Nettles, 1990), and can be used especially to understand the workforce, including factors associated with the persistence or attrition of individuals in the program (Golde, 2000; Seymour \& Hewitt, 1997). This dissertation uses a lens of organizational socialization, gender socialization, and race socialization to examine the research questions proposed.

\section{Cultural-Ecological Theory}

This dissertation also uses the framework for Cultural-Ecological Theory (Ogbu \& Simons, 1998) to understand how the URMs perceive their experiences in academia, as 
well as how the presence or absence of certain opportunities is a barrier to their learning and success in their program. The minority groups of color may belong to voluntary (immigrant) or involuntary (nonimmigrant) communities (Ogbu \& Simons, 1998). Voluntary minorities have willingly relocated to a country, for reasons of better opportunities in life than those in their home country while involuntary minorities have a history of being forcibly conquered, colonized, or enslaved permanently by society against their will. The cultural-ecological theory explaining minority school performance considers ecology as their environment and culture as the way they make sense of the environment and behave in it. Minority school performance is guided by two major factors, the system and the community forces (Ogbu, 1987; Ogbu, 1990). The system includes the different ways in which society and the schools treat minorities. The community forces constitute how minorities perceive and make sense of schooling, based on the treatment they receive. Studying the system includes identifying experiences that affect minorities in a positive or negative way, including the collective barriers that affect minority school performance. Further, the theory indicates that the disparity in school performance between immigrant and non-immigrant minorities, can be partially explained by community forces or by how minorities make sense of their treatment by the school and society (Ogbu, 1999). This study examines some of those academic experiences URMs undergo during their professional training that are a part of the system, and the ways in which URMs make meaning of those experiences that may or may not help them succeed in their career. 


\section{Purpose of this Study}

There are two major and independent components of this dissertation: the gender component and the race/ethnicity component. Each component determines the research questions that are addressed here, as well as the lens used to answer the research questions. The purpose of this study is to examine the medicine and biomedical research workforce, and to understand some of the inequities and barriers reported by students and post-degree professionals in the field. In doing so, this dissertation has adopted two specific strategies:

a. Defining a set of barriers, and examining how a particular sub-population reported their personally-lived experience with that barrier (gender component); and,

b. Defining a sub-population and examining the range of barriers self-reported within that sub-population (race component).

The research questions that will be addressed in this study are:

1. How do women who are either currently enrolled or graduated from biomedical research or medical programs define and make meaning of gender roles as academic barriers?

2. How do underrepresented groups in medical schools and biomedical research institutions define and make meaning of the academic barriers they face and the challenges these barriers pose to their success as individuals in the program?

The first research question defines the lack of professional-personal life balance as a barrier, and uses the gender lens to examine it. Using a female perspective, this 
dissertation examines how females in medicine and biomedical research report their personally lived experiences about the lack of professional and personal life balance as a barrier to their success and persistence in the field, due to reasons of childbearing and childrearing (gender-role).

The second research question examines the barriers reported by the two largest underrepresented racial and ethnic minorities in the U.S. (Blacks and Hispanics) in medicine and biomedical research. Existing research about barriers to success and persistence in the field, within underrepresented racial/ethnic minorities, often tends to examine this group in its entirety, without comparing the barriers of specific races or ethnicities in the same study. Since Blacks and Hispanics are the two most underrepresented groups in the United States (NSF, 2011), this dissertation examines the barriers reported in each group separately and compares them.

The research questions were addressed through qualitative analysis of 146 indepth interviews using a grounded theory approach. This involved creating theory, based on the data, to explain the phenomenon of interest.

\section{Significance of this Study}

The significance of this study lies in the richness and diversity of the data used, as well as the approach of analyses which is uncommon among existing literature. The analysis contributes to the existing knowledge about barriers to success and career progression from the perspective of both race and gender. Quantitative studies usually fail to capture the lived-in experiences of people, despite the strength of their findings. While qualitative studies can capture those lived-in experiences, most qualitative studies have a restrictive sample size, sometimes restricted to one medical institution. The 
strength of this dissertation lies in the robust sample size used ( $n=146$ interviews from more than 60 institutions across the U.S.), as well as the demographic diversity of the interviewees with respect to their gender, race and ethnicity, and degree program affiliation (including students at different stages of their program of study and postdegree professionals like faculty and post-doctoral researchers). While there is an adequate body of literature about barriers of students in the MD program, existing research on barriers to success for students doing a $\mathrm{PhD}$ in the biomedical sciences is rather limited. This dissertation examines barriers of students in the $\mathrm{MD}, \mathrm{PhD}$, and $\mathrm{MD} / \mathrm{PhD}$ dual degree program. While existing studies often tend to aggregate the barriers of the underrepresented racial or ethnic minorities together, or focus on one particular group alone, this dissertation does a comparative analysis between Blacks and Hispanics to investigate if barriers are consistent across groups or specific to a particular group. This dissertation incorporates the experiences of females as well as underrepresented racial and ethnic minorities, and the overall demographic diversity helps in examining the two important components of race and gender that contribute to the diversity in a field. This advances our understanding of how students and professionals experience barriers, as well as make career decisions that help them overcome those barriers and succeed in the field. The focus on barriers provides an understanding of the institutional climate and contributes to the overall workforce development in the field. Developing a better understanding about barriers to success will help in formulating better research-driven policies in the workforce and will help in the improvement of the institutional climate and the learning environment. 


\section{CHAPTER 2}

\section{REVIEW OF LITERATURE}

The research questions proposed in the previous chapter are based on the two broad components of gender and race. The rationale for this research lies in examining some of the barriers faced by students, as well as post-degree professionals in medicine and biomedical research.

The first research question defines the lack of professional-personal life balance as a barrier, and examines it using the lens of gender. Using a female perspective, this dissertation examines how female students and post-degree professionals report their personally lived experiences about the lack of work and personal life balance as a barrier to their success, persistence and advancement in the field.

The second research question examines the barriers reported by underrepresented racial and ethnic minorities (specifically Blacks and Hispanics) in the same field. Existing research about barriers to success and persistence within underrepresented racial/ethnic minorities often tends to examine this group in its entirety, without comparing the barrier of specific races or ethnicities in the same study. Since Blacks and Hispanics are the two most underrepresented groups in the U.S. (NSF, 2011), this research examines the barriers reported in each group separately. 
This review of literature summarizes existing knowledge about each of the two research questions. First, it summarizes existing research about the challenges of balancing work and family life for females in the field. Second, it reviews existing knowledge about barriers reported for persistence of underrepresented minorities in the field. The chapter concludes by stating some of the gaps in the literature and limitations of existing research, which provide a basis for this dissertation.

\section{Gender Barriers}

The recruitment of women into medicine and biomedical science research has improved greatly over the last few decades (AAMC, 2012). Data indicate that the proportion of female applicants who were accepted at accredited U.S. medical schools has risen from about $10 \%$ in the mid-1960s to about $51 \%$ in 2003 (AAMC, 2012). In 2011 , there was a slight decrease in the number of accepted women applicants to $47 \%$, with $47 \%$ matriculants, $47 \%$ first-year enrollments, $46 \%$ women residents, and $48 \%$ women graduates at all Liaison Committee on Medical Education (LCME) accredited U.S. medical schools (AAMC, 2012). Clearly, these enrollment and graduation records indicate that representation of women at earlier career stages in the field is not an issue.

While recruitment and representation are not an issue, the retention, promotion, and advancement to leadership positions of women in the field are important issues (McPhillips et al., 2007). Research shows that women leaders in U.S. LCME-accredited medical schools take longer to advance their careers, tend to serve at less researchintensive institutions and have short tenures compared to their male colleagues (White, McDade, Yamagata, \& Morahan, 2012). The percentage of women further decreases up the hierarchy, from assistant professors (18\%) to associate professors (7\%) and full 
professors $(5 \%)$ indicating that not many women are able to attain tenured positions in their career (AAMC, 2012; Files, Blair, Mayer, \& Ko, 2008; Powell, Scott, Rosenblatt, Roth, \& Pololi, 2010). This is despite the fact that $92 \%$ of the total women faculty was professionally qualified, with an $\mathrm{MD}$, a $\mathrm{PhD}$ or an equivalent health-related doctoral degree (AAMC, 2012). In 2011, women earned only 37\% of the promotions to associate professor, $31 \%$ of the promotions to full professor, $32 \%$ of new tenures, and the number of women faculty departures increased to $40 \%$ (from $37 \%$ in 2009) (AAMC, 2012).

Additionally, there are gender differences in the preparation of faculty appointees for doing research; men who enter academic medicine are better prepared than women, engage in more productive research activities, have accrued greater overall research experiences, and have more research publications during medical school (Andriole \& Jeffe, 2012). It is possible that such differences in the level of preparation between men and women in academic medicine may contribute to gender disparities in their promotion and advancement in the field (Andriole \& Jeffe, 2012). On the other hand, women faculty reported working a greater number of hours weekly and performing more administrative and professional duties, compared to their male colleagues (DesRoches, Zinner, Rao, Lezzoni, \& Campbell, 2010). Despite this, women faculty reported publishing less as well as earning less, in life sciences, compared to men across all ranks (DesRoches et al., 2010). There is, thus, an indication of disparity and a substantial gender gap in compensation and advancement policies for women, despite their long working hours, indicating a differential recognition of the contribution of female researchers in the field (DesRoches et al., 2010).

Women in medicine are susceptible to facing more career-related barriers in 
comparison with men (Carr, et al., 1998; Shollen, Bland, Finstad, \& Taylor, 2009). In studying career progress of women faculty at a reputed U.S. educational institution, we learn that women spend less time in scholarly work and more time in clinical work, progress more slowly in their careers, compared to men, and are less likely to work as a professor or to get tenure (Buckley, Sanders, Shih, Kallar, \& Hampton, 2000).

Additionally, they report having a poorer understanding of promotion and tenure criteria, and value progress indicators like leadership, scholarship and recognition less. This indicates a gender-disparity in career preparation, progress and promotion of women faculty and physicians (Buckley et al., 2000).

Additionally, women are more severely affected by the absence of career flexibility in medicine (Villablanca, Beckett, Nettiksimmons, \& Howell, 2011). Despite indicating greater interest in academic careers in medicine, compared to men, (Nonnemaker, 2000), women have been underrepresented in advanced ranks or leadership positions for decades (AAMC, 2012; Nonnemaker, 2000; Powell et al., 2010; White et al., 2012; Yedidia \& Bickel, 2001). In 2012, women held only 37\% of full-time medical school faculty positions at the LCME accredited U.S. schools (AAMC, 2012). In summary, despite an increasing number of women students, physicians, and faculty in the workforce (Nonnemaker, 2000), as well as skilled and well-trained potential leaders, senior physicians, and research scientists, women are vastly underrepresented in senior academic ranks of professorships (AAMC, 2012), as well as in leadership positions in medical schools and teaching hospitals (Powell et al., 2010). While women represent about half of all medical students and resident populations, their numbers dwindle to about one-third of full-time faculty positions (AAMC, 2012). This trend of women being 
denied tenure or being underrepresented in higher faculty ranks or leadership positions is a matter of concern, indicating that while recruitment is not an issue, retention, advancement and promotion of women are issues (McPhillips et al., 2007).

Women experience more barriers to career success, satisfaction and retention compared to men (Shollen et al., 2009; Carr, et al., 1998). Several contributing factors include family responsibilities, lack of mentors and role models, gender discrimination and stereotyping, lower salaries, more competition for space and resources, less access to resources like administrative staff and graduate student or fellow assignment, and isolation, that impede the academic advancement and trigger underrepresentation of women at higher positions in academic medicine (Burgess, Joseph, van Ryn, \& Carnes, 2012; Colletti, Mulholland, \& Sonnad, 2000; Shollen et al., 2009). Amongst the several individual, institutional, and societal barriers that limit the advancement of women in the field and contribute to a leaking pipeline (Villablanca et al., 2011), this dissertation examines the barrier to establishing a balance between professional and personal lives, while shouldering family and childcare responsibilities, as a barrier that could likely be associated with the existing trend of lack of advancement.

\section{Balancing Work and Family Life}

Women are more significantly affected by life events such as childbirth and childrearing, because of their traditional roles of primary caregivers, which requires significant time contribution regardless of field of career (Bellini, Abbuhl, Grisso, Lavizzo-Mourey, \& Shea, 2001; Colletti et al., 2000; Gander et al., 2010; Mason \& Goulden, 2004; Villablanca et al., 2011; Yedidia \& Bickel, 2001). An important determinant in the premature dropout or slower career progress of women is the 
challenge associated with balancing personal and professional life (Shauman \& Xie, 1996; Shollen et al., 2009; Villablanca et al., 2011), a lack of balance causing burnout (Powell et al., 2010) and fatigue (Gander et al., 2010). This reflects on the broad social values which do not value parenting or the role of women as caregivers for future posterity (Yedidia \& Bickel, 2001). It is estimated that more than $90 \%$ of time devoted to family responsibilities is spent on childcare (Carr, et al., 1998), which often precludes women from focusing on the benchmarks of career progress, such as tenure and promotion, and limits their geographic mobility that might be necessary for career advancement (Yedidia \& Bickel, 2001). Compared to men, women faculty with children face more barriers in establishing themselves in academic careers, receive less institutional support, less institutional research funding, less secretarial support, have fewer peer-reviewed publications, and experience slower career advancement and lower career satisfaction (Carr, et al., 1998). Additionally, women who had children early in their career are more likely not to receive tenure, compared to their male colleagues, a trend specific to the school of medicine alone (Villablanca et al., 2011) and observed in several qualitative, as well as large-scale quantitative studies (Mason \& Goulden, 2004).

In a 20-year longitudinal study of $160,000 \mathrm{PhD}$ candidates across multiple disciplines, women were more likely to remain single or childless, and reported having fewer children than desired due to their career demands (Mason \& Goulden, 2004). While men report a higher tendency to miss family obligations, due to professional demands in academic surgery, women are significantly more likely to miss work obligations due to family (Colletti et al., 2000), often imposing work restrictions or modifying and adapting their work patterns based on family needs (Maume, 2006). 
The number and age of children in a family have an important bearing on women, while no such trends are observed for men (Maume, 2006). For example, women increase their number of job trade-offs by $33.8 \%$ with each additional child (in this article, job trade-off refers to work restrictions or limiting work efforts to meet the needs of the family). Similarly, women with preschool-children make $46.3 \%$ more trade-offs compared to women without children or women with older children (Maume, 2006). Women faculty with children less than five years old, are less likely to get tenure compared to their male contemporaries (Mason \& Goulden, 2004). The number of children is positively associated with job trade-offs women make, indicating that women tailor their work patterns to their family needs more likely than men do, while there is no evidence that men allow family responsibilities to guide their professional life (Maume, 2006). Women with young children or family responsibilities face more hurdles in an academic career, have fewer opportunities to publish in journals (publications being a measure of academic productivity) (Bellini et al., 2001), spend less time in research and writing and more time doing less academically rewarding work, have poorer networking opportunities, are less frequently included in professional networks, and have modestly lower career aspirations compared to men (Villablanca et al., 2011).

Choosing a career in academic medicine is often influenced by factors like the training environment and interaction with faculty, mentors, role models, or family (Borges, Navarro, \& Grover, 2012). Balancing personal and professional lives requires making value-based choices, setting boundaries, making trade-offs, and taking cyclic decisions based on multiple life events, such as completing residency, developing longterm relationships, childbearing and pursuing career options (Brown, Fluit, Lent, \& 
Herbert, 2011). Women surgeons often struggle to achieve this balance with their decision to have children, and fear criticism for their decisions. However, women who value quality family time often set discrete boundaries between work and family and use strategies like hiring outside help for household work and childcare (Brown et al., 2011).

\section{Lack of Institutional Support}

Lack of institutional support contributes significantly to exacerbating the problem of women being unable to balance their family life effectively and attain career benchmarks in medicine. In a study with 75 pediatric departments at medical institutions, only about 25 offered on-site childcare facilities, while childcare was rarely available for mildly ill children or as a backup option for working women (McPhillips et al., 2007). Other institutional barriers like staff shortage compounds the problem when women cannot take leave due to unforeseen circumstances like illness in children (Gander et al, 2010). Despite policies on breastfeeding that stipulate adequate time and facilities in the workplace for breast-pumping, as well as the established importance of having facilities for lactating mothers, to support undisrupted nursing, about $20 \%$ of the departments in this study lacked adequate lactation facilities for their faculty or trainees (McPhillips et al., 2007). However, there is now a renewed interest in establishing more on-site childcare facilities, as well as more family-friendly career flexibility policies amongst both genders (Villablanca et al., 2011).

Women deans at many institutions often strongly recommend establishing institutional supports like childcare facilities on-site or near the workplace, and tenure for salaried part-time faculty (Dannels et al., 2009). Due to gender disparities, men are less affected by the lack of amenities, such as on-site childcare facilities, emergency 
childcare, and part-time positions (Bellini et al., 2001). Existing institutional supports to help women balance career and families are inadequate, and affect women between ages 28-40 more than other age groups, because of their maternal age (Hewlett, 2004). Thus, many acknowledge the wisdom of postponing career during the childbearing and childrearing age, and resuming professional activities more aggressively in their forties and fifties, since the fertility window span is short and is non-negotiable for women (Hewlett, 2004).

Several institutions question a woman's commitment to academic careers and frown upon the decision to have children (Yedidia \& Bickel, 2001). Despite the established need for policies to help women balance their family life and career, only three family-friendly policies of benefits [benefits for part-time faculty (88\%), paid maternity leave (87\%), and paid paternity leave (69\%)] are available in more than $68 \%$ of the medical schools (Dannels et al., 2009). Further, several policies that could increase gender equity amongst women faculty, such as an automatically delayed tenure clock for birth, adoption, or families with special needs were available at fewer than $14 \%$ of the medical institutions (Dannels et al., 2009). Thus, women often face hardships balancing academic and family life, constraints on career choices, and a lack of female role models to guide them in successfully balancing professional and personal lives (Yedidia \& Bickel, 2001).

\section{Work/Life Hours}

Some researchers opine that, since women have different reproductive responsibilities as well as timelines, compared to men, it is unfair to replicate the male competitive model for women in the labor market (Hewlett, 2004). Childbearing affects 
the careers of men and women differently (Carr, et al., 1998; Shauman \& Xie, 1996). The male-to-female ratio in work hours is roughly 1.43 for scientists with preschool children, indicating different time commitments to childcare duties for men and women, and although this disparity in working hours reduces as children get older, the difference remains even for parents with teenage children (Shauman \& Xie, 1996). This trend continues for women in decanal and other leadership positions in the medical workforce, as well (Shauman \& Xie, 1996). In addition, men with children are less affected by afterhour professional commitments like meetings in early mornings, late evenings, or during weekends that tend to compromise their time with family, as compared to women with children (Bellini et al., 2001; Colletti et al., 2000; Carr, et al., 1998). Many women in medicine, who have family responsibilities, find it challenging to pursue social and cultural activities like evening classes, music groups, or sports training, because of difficulties in attaining work/life balance, and thereby view children as a hindrance to their working life (Gander et al., 2010). As a result, women often suffer from fatigue and sleep disorders, and delay their pregnancies, thereby compounding the problem by considerably increasing fertility issues (Gander et al., 2010).

Misinformation about late pregnancies abounds, with market-driven fertility treatment industries vouching that delaying pregnancy may be harmless and most women believing that they can get pregnant in their forties with the aid of fertility treatments, contrary to existing research (Hewlett, 2004). Thus, successful women, especially women of color, run the risk of remaining single or childless and facing fertility issues, while the same is not true for men (Hewlett, 2004). Further, the proportion of childless female professionals in their forties remains high (Hewlett, 2004). 


\section{Role of Part-Time Employment}

Although part-time employment options for faculty and part-time residency options for students are available in some institutions, few offer them for other dependent care and even fewer number of women make use of them due to an increased training time, financial drainage, and the associated guilt of not being involved with work on a daily basis (McPhillips et al., 2007). Further, the effect of part-time employment for faculty on different tracks (for example, research track versus clinical track) is unclear (McPhillips et al., 2007). Work/life balance affects the academic advancement of women faculty irrespective of their part-time or full-time status (Fox, Schwartz, \& Hart, 2006). However, the changing demographics of medicine are increasing the demands for a parttime academic position with time, allowing for more flexibility for women to tailor their

careers based on their family needs (Palda \& Levinson, 2009). Research suggests that this may eventually improve the quality of healthcare, patient satisfaction, resource utilization and productivity, improving recruitment and retention of women in higher ranks in academic medicine (Palda \& Levinson, 2009).

Research indicates that when women choose part-time career options, they do so mostly for reasons of childcare (contrary to men doing so for outside employment) (Fox et al., 2006). However, faculty members who get tenure are most likely to be men working full-time (Fox et al., 2006). There are both advantages and disadvantages to working part-time (Harrison \& Gregg, 2009). Provision for working part-time and flexibility in the timeline of career milestones, can help in achieving better work/life balance, especially for women faculty involved in raising families (Fox et al., 2006; Harrison \& Gregg, 2009). However, some institutions view part-time work unfavorably, 
as a means to work less, which challenges the cultural values associated with working in the field of medicine (Harrison \& Gregg, 2009). It would be important to develop creative models that can integrate successful part-time professionals into academic medicine in the future, and to rethink and remodel work policies based on individual needs (Harrison \& Gregg, 2009).

\section{Pregnancy during Residency}

Since the period of residency, fellowships, and the initial stages of an academic career coincides with the childbearing age, many residents face the dilemma associated with planned or unplanned pregnancy (Gander et al., 2010; McPhillips et al., 2007). There are two kinds of predicaments to this situation: first, the complications arising due to women who delay their pregnancy to be able to fulfill professional demands, and second, the perceived lack of support reported by pregnant female students (Willett et al., 2010).

Since medical training is typically long and coincides with the childbearing age of a woman, pregnancy during residency is often common and planned in advance (Sayres et al., 1986). However, a demanding residency period often makes it difficult for a woman of childbearing age, who is also limited by her age of fertility, to spend adequate time and energy raising a family (Phelan, 1988; Sayres et al., 1986). Motherhood and medicine are two disparate and independent vocations, both requiring commitment, attention and availability (Young-Shumate, Kramer, \& Beresin, 1993, Phelan, 1988). Getting pregnant during residency is sometimes viewed negatively in medicine (Phelan, 1988). More alarmingly, some women residents voluntarily terminate pregnancies (Finch, 2003) or defer having children, compared to their male colleagues, because of the belief 
that pregnancy causes career threats for female residents (Willett et al., 2010). As an adverse outcome of late pregnancy, women tend to risk age-related decreased fertility, unintentional childlessness, and premature labor (Finch, 2003). There is an existing belief among women residents that residency training increases pregnancy complications, despite an established lack of strong association between residency training and pregnancy complications (Finch, 2003).

Pregnant residents face several barriers, due to the unrealistic work demands of residency coupled with extremely long work hours, excessive standing and physical exertion, as well as the implicit expectation that an absent resident's workload will be shared by the other residents (Finch, 2003). In a comprehensive literature review, Finch (2003) summarizes existing barriers for medical residents in terms of a lack of maternity leave policies, lack of awareness of existing maternity leave policies, inconsistencies in such policies throughout the U.S., policies not adhering to legal and professional guidelines and recommendations, pressure to resume work earlier, and lack of flexibility about residency requirements. Existing studies indicate that stress of childbearing is compounded by physical demands of residency, lack of support from fellow residents and their departments, anger and resentment toward the pregnant resident from fellow nonpregnant residents, heightened discrimination, lack of role models who have successfully balanced their personal and professional lives, guilt and vulnerability (Finch, 2003). Thus, pregnancy is an option for residents only when a program is supportive and has flexible elective time (Phelan, 1988). While part-time work options could be effective in reducing the stress at work, during and after pregnancy (Sayres et al., 1986), many believe that pregnant residents are a hiring risk (Finch, 2003), with some male residents 
indicating that pregnancy is disruptive to collegial relationships and a risk to optimal department functioning (Tamburrino et al., 1992).

\section{Parental Leave Policies}

Despite the established legal and professional guidelines about parental leave policies, many residents are not aware of their rights and end up taking shorter leave (Finch, 2003). The Pregnancy Discrimination Act (1978) prohibits workplace discrimination, on the basis of pregnancy, in terms of hiring, promotion, reinstatement, and job termination. According to the maternity leave policy adopted by the American Medical Association in 1991, residents are allowed a minimum 6-week maternity leave. Lack of adequate parental leave (Villablanca et al., 2011), disparity in unstated parental leave policies, cost of unpaid leave, and low levels of subsidized childcare costs are some of the many sources of anxiety for parent residents (McPhillips et al., 2007). Lack of awareness about parental leave during pregnancy is common in younger women faculty as well, who choose not to request family-flexible accommodations (Villablanca et al., 2011). This is an indication of the work-life culture in the field, the demands of patient care and on-call responsibilities, and the perceived biases, stigma and resulting hesitancy in taking time off (Villablanca et al., 2011).

\section{Recommendations for Improving Work and Personal Life Balance}

In order to maintain faculty diversity in academic medicine, one must redefine the indicators of advancement and address the need for work-family balance (Fox et al., 2006). Existing literature recommends strategies to overcome work/life balance barriers, including individual efforts, such as altering career plans to be able to raise children, and institutional interventions, like understanding the organizational culture and 
recommending necessary changes (Powell et al., 2010). Although the origin of such gender-role barriers stems more from social and personal values, such barriers can be overcome by institutional interventions (Shollen et al., 2009; Yedidia \& Bickel, 2001), which may be critical for maintaining productivity (Villablanca et al., 2011).

Suggested familial strategies for addressing these barriers include encouraging women to start a family early, supplementing household help, and renegotiating and reallocating more family responsibilities to men (Yedidia \& Bickel, 2001). Similarly, institutional strategies include flexing tenure and promotion policies, modifying faculty schedules, establishing daycare centers at medical schools, extending pre-tenure probationary periods and establishing short-term part-time tenure-track positions for faculty with family responsibilities (Yedidia \& Bickel, 2001). Other institutional interventions with prolonged impact include eliminating gender bias in promotion, salary, and research allocation for women (Shollen et al., 2009), minimizing nighttime commitments for parents with young children, reallocating faculty with family responsibilities to clinical or other tracks having less demanding requirements for tenure (Yedidia \& Bickel, 2001), providing better access to quality childcare, better facilities for lactating mothers, transparent parental leave policies, flexible work hours for mothers (McPhillips et al., 2007), providing effective mentoring and support groups ( Villablanca et al., 2011), redefining policies, creating a family-friendly culture, and adopting needbased faculty development avenues like part-time tenure tracks, prorated tenure tracks, tenure rollback options, changing career development grant requirements to include parttime faculty, increased mentoring, and more supporting networks (Fox et al., 2006). These would improve the retention of women in academic medicine because career 
choices are primarily governed by the formative training experiences, as well as the institutional interactions with faculty, mentors, and role models (Borges et al., 2012).

Lastly, it is important to advocate for part-time faculty appointments for women with family responsibilities, since the current policy of junior faculty development grants requiring full-time appointments is not conducive for part-time faculty (Fox et al., 2006). Many of the recommendations suggested can be implemented with little monetary cost to academic institutions, with directed effort (Villablanca et al., 2011). 


\section{Barriers of Underrepresented Racial and Ethnic Minorities}

The healthcare system in the U.S. was initially based on an ethnocentric model that valued White economic interests, and human values prescribed by Whites, while excluding the non-White or Black patients or providers (The Sullivan Commission on Diversity in the Health Workforce, 2004). The Civil Rights Era of the 1960s eliminated many obvious racial and ethnic discriminatory barriers of the healthcare system, but could not completely remove certain deeply set patterns of health care inequity and preferential access to healthcare careers. Thus, racism is still existent in several healthcare professions, although usually at a subtle level, negatively impacting the quality of healthcare minorities receive (The Sullivan Commission on Diversity in the Health Workforce, 2004).

Despite the adoption of various diversity initiatives by the government and medical institutions, the representation of URM medical students remains dismal (Agarwal, Vlaicu, \& Carrasquillo, 2005). According to The Sullivan Commission on Diversity in the Health Workforce (2004), the racial or ethnic diversity in the medical pipeline has not kept pace with the general population of the country $(25 \%$ URM population compared to less than $6 \%$ URM physicians in the workforce), thereby compounding the persistent racial and health disparities in the U.S and causing impaired access to healthcare by URMs. With an increase in diversity in the U.S. population, the healthcare needs of its people have changed. However, most of the barriers in the workforce arise due to a lack of acknowledgment of cultural differences, disparate access to healthcare, and language barriers.

Blacks and Hispanics constitute two of the largest minority communities in the 
U.S. (NSF, 2011), with Hispanics including individuals of Mexican, Puerto Rican, Cuban, Central American, as well as South American descent (de los Santos \& de los Santos, 2003; Santiago \& Brown, 2004; Valcarcel, Diaz, \& Santiago-Borrero, 2006). Hispanic students lag behind other non-minority races and ethnicities in terms of their achievement in higher education (Santiago \& Brown, 2004). Since non-white MD-PhD students are more likely to graduate from funded training schools, such as the Medical Scientist Training Programs (MSTPs) funded by the National Institute of Health (NIH), (Jeffe \& Andriole, 2011), it would be important to identify the potential barriers URMs are likely to face during their training in medicine and research, with the eventual goal of uplifting their economic stature and contributing to the long-term economic prosperity of the country (Santiago \& Brown, 2004). Several factors, such as the focus of research programs, gender, mentors and role models, influence the career trajectory of individuals in academic medicine (Borges, Navarro, Grover, \& Hoban, 2010), and factors that become barriers for URM students and cause premature dropout and attrition include, career interest loss during residency, mismatched specialty selection in medicine and research, and increased educational debt (Andriole, Whelan, \& Jeffe, 2008; Borges et al., 2010).

Further, both male and female faculty of color are vastly underrepresented in medicine, especially in the higher ranks (Wong et al., 2001). Research summaries by Betancourt, et al., (2003) indicate that although Blacks, Latinos, and Native Americans constitute about $28 \%$ of the entire U.S. population, their representation as medical school faculty (about 3\%), public health school faculty (less than 16\%), and city and county health officers (17\%) does not match their proportion in the U.S. population. Women of 
color are especially underrepresented in medicine, despite the increase in the number of non-minority women applicants (Wong et al., 2001). Hence, this dissertation aims to identify and study some of the factors that are barriers to the success of URMs in medicine and biomedical science research. Existing research tends to aggregate barriers of various sub-groups of URMs, but seldom compares the between-group URM barriers (for example, Black versus Hispanic). Of the many barriers that impede the success of URM students and minorities in the field, some may also be barriers for the general population, while others would be specific to certain URM groups (for example, racism). This review of literature will summarize research on existing barriers, which may or may not be specific to certain URM groups.

\section{Racism}

Racism in medicine can exist in various forms, some of which are individual racism (discriminatory actions towards individuals based on visible traits), cultural racism (belief that one's cultural heritage is superior to others), and institutional racism (implementing policies intentionally or unintentionally that disadvantage particular groups) (Barbee, 1993). Some of the manifestations of racism are through denial of racism (for example, by not using the term racism), colorblindness (by believing that race is a social construct, an invisible trait not relevant to an individual's behavior), and aversive racism (characterized by ambivalent beliefs about them being egalitarian, nonprejudiced, and non-discriminatory) (Barbee, 1993). In colorblind racism, there is an accepted dogma among Whites in the U.S. where race is no longer considered a delimiting factor in life events (Bonilla-Silva \& Dietrich, 2011). Additionally, symbolic racism alludes to beliefs that Blacks no longer face discrimination, and are no longer 
viewed as underserved groups, creating resentment among symbolic racists toward programs that promote equality between Blacks and Whites (Cox, 2010). Henry \& Sears (2002, p. 254) discuss that symbolic racists believe that Blacks no longer face racial discrimination, and their barriers are as a result of their own unwillingness to take responsibility. This belief promotes the wrong notion that Blacks are benefitted undeservingly, and are not justified in feeling resentment for facing racial discrimination.

In medical school, racism may be institutionalized, personally mediated, or internalized (Jones, 2000). Of these, institutionalized racism means having differential access to resources and opportunities in society, including both material access like quality education, employment, and medical facilities, as well as power access like information, resources, and voice, due to one's race (Jones, 2000). Such forms of racism are believed to create an association between socioeconomic status and race (Jones, 2000). Personally mediated racism constitutes intentional or unintentional biases, prejudices, discrimination, and assumptions about other's abilities based on race (Jones, 2000). Internalized racism is acceptance of negative stereotypes about one's own abilities by people of the stigmatized races (Jones, 2000).

Training URM physicians and improving their representation are important for a demographically diverse country like the U.S., since ethnic diversity among URM physicians will ensure care for the underserved populations (Xu et al., 1997), promote patient satisfaction, cross-cultural care and research diversity, meet the needs of a diverse population (Wong et al., 2001), and ensure improved access and better quality healthcare for minorities (Bright, Duefield, \& Stone, 1998; Mitchell \& Lassiter, 2006; Nivet, et al., 2008; Price et al., 2004). Minority physicians are more likely to care effectively for other 
minorities of the same ethnicity, as well as for the poor and the underserved (Betancourt, et al., 2003). Minority patients have racial preference of doctors to bridge language and cultural barriers, and diversity in the field will help reduce healthcare disparities by fulfilling minority patient needs and bridging cultural gaps (Lakhan, 2003). Training Black and Hispanic physicians and researchers in the workforce would be an important step to caring for both the economically disadvantaged groups and minorities, as well as alleviating issues of trust among patients due to fear of exploitation (Corbie-Smith, Thomas, Williams, \& Moody-Ayers, 1999).

In addition, URMs in the field also face economic barriers, inadequate financial resources (for students and faculty in academic medicine) (Peek, Kim, Johnson, \& Vela, 2013; Wong et al., 2001), inadequate career counseling, high attrition rate, lack of support networks, peer-competition, higher expectations, lack of role models or mentors, and individual and institutional discrimination (Wong et al., 2001). Minority women faculty members face more obstacles to career advancement than minority men or majority women, their barriers having both gender and racial perspectives to them (Wong et al., 2001). URMs who grew up outside the U.S. also report the lack of adequate acculturation experiences, as well as spoken English as a language barrier (Snyder \& Bunkers, 1994). Language barriers often create difficulties with publications and presentations in classes or at conferences (Snyder \& Bunkers, 1994). URMs who are foreign nationals studying and working in the U.S., are sometimes poorly oriented to their academic expectations in graduate school (Snyder \& Bunkers, 1994). Racial discrimination and prejudice increase distress for minority students in medical school, which is manifested as burnout, depression, and isolation (Dyrbye et al., 2007). 


\section{Stereotype Threat Theory}

Of the many social causes for race-based achievement disparity, stereotype threat is an important issue (Nosek et al., 2009). Stereotype threat is defined as the risk of “confirming a negative stereotypic expectation about one's group” (Keller \&

Dauenheimer, 2003). It is a situation of being judged due to set social stereotypes about one's group (Spencer, Steele \& Quinn, 1999; Shih, Pittinsky \& Ambady, 1999), arising when environmental cues trigger physiological and psychological reactions that affect behavior in a negative way (Burgess, Warren, Phelan, Dovidio, \& van Ryn, 2010). Among Blacks it is associated with hypertension, elevated arterial blood pressure during an academic test, and poorer performance on difficult test items (Blascovich, Spencer, Quinn, \& Steele, 2001). Although stereotype threat is mostly studied for gender-based disparities (Eccles, 1987), few studies describe how stereotyping could affect performance in certain races.

Racial stereotyping and discrimination in medical school are barriers to academic success by minority students, aggravated by distraction, self-doubt, depression, lack of institutional support in promoting diversity and cultural awareness, and an environment with pressures to dispel cultural or race-based negative stereotypes (Odom, Roberts, Johnson, \& Cooper, 2007). Existing research on stereotyping in medicine and biomedical science research is sparse, although some studies have examined the influence of negative stereotyping on the academic performance of Blacks and Latinos in other fields (Chang, Eagan, Lin, \& Hurtado, 2011). Most of these studies examine achievement in school and college level science and math courses (Osborne, 2001; Steele \& Aronson, 1995). For example, Steele (1997) explains that negative racial stereotypes can adversely 
affect the academic performance of highly talented Black students, due to anxiety, fear of judgment, and conforming to negative stereotypes associated with their group's intellectual abilities. This is more common in Blacks in predominantly White and Asian institutions, compared to selective HBCUs (Chang, Cerna, Han, Saenz, 2008). Stereotype threat may adversely affect URM's academic performance and diminish their performance on standardized tests and medical entrance examinations like MCAT and USMLE (Burgess et al., 2010). URM trainees also report experiencing stereotyping when they are mistaken for housekeepers and nurses, and feel isolated due to their low numbers of social groups and URM faculty role models (Burgess et al., 2010). Reducing stereotype threat in medical trainees will help in recruiting more URMs into medicine, and will aid in providing culturally sensitive patient care to diverse individuals (Burgess et al., 2010).

\section{Barriers for URM Students in Medicine}

URM students often report experiencing “everyday racism”, marginalization through segregation, and feeling like a misfit in medical school (Beagan, 2003). Most barriers are psychosocial, and hence a reflection of the institution and society. Other individual barriers, such as impostor syndrome are more prevalent in specific genders (and not races) in medicine (Legassie, Zibrowski, \& Goldszmidt, 2008; Oriel, Plane, and Mundt; 2004). Similarly, although tokenism is usually studied in women (Turner, 2002), and associated with social isolation, stereotyping, performance pressure, and inability to seek effective mentoring and peer-networking, racial tokenism in the field has not been adequately documented. Encouragingly, many of these barriers are amenable to intervention (Bright et al., 1998). 
Barriers to recruitment and retention of URMs into the field includes poor selfefficacy, academic under-preparedness, debt and student loans, community and family obligations, lack of critical mass in the field, social and racial barriers, inadequate program support (Butts et al., 2012), poor peer-networks, lack of professional recognition, and poor acceptance (Bright et al., 1998). Although certain barriers are not racial (for example, debt), URMs suffer more due to their underrepresentation, exclusion, and lack of support networks. URM medical students sometimes report feeling the pressure to do better than other students, due to their race (Bright et al., 1998). Race also had a bearing on the career options students were encouraged to pursue in school (Bright et al., 1998). Other barriers to academic achievement include poor mentoring, isolation due to minority status, and lacking a sense of belonging, field knowledge, or opportunities for collaboration (Cora-Bramble, Zhang, \& Castillo-Page, 2010).

\section{Institutional and Individual Barriers for Students}

Institutional and external barriers create a rift between the perception and implementation of diversity initiatives to increase URM faculty diversity (Mahoney, Wilson, Odom, Flowers, \& Adler, 2008). Institutional or workplace barriers include financial burdens, due to insufficient tuition reimbursement programs (Snyder \& Bunkers, 1994). While low-URM schools consider the lack of institutional leadership a barrier to workforce diversity, high-URM schools consider institutional leadership a facilitator for recruiting and retaining URM faculty (Peek et al., 2013). Despite the acknowledged need for URM inclusion and racial diversity, URM medical students in the clinic often experience racial discrimination and feel that the institutional policies and practices for social, academic, and financial support do not reflect a commitment to 
promoting diversity, or recruiting and retaining minorities (Hung et al., 2007). URM medical students also report loneliness, isolation, lack of individuality acknowledgment from institutions, lack of knowledge about cultural differences, lack of teacher support, and discrimination as some of the barriers to their success in the field (Gardner, 2005). Lack of mentors, especially mentors and role models of the same race in the field, is considered a huge barrier (Bright et al., 1998).

Individual barriers for minority women in the field include faculty bias (in grading papers, evaluating clinical performance, and assessing written examinations), expectation of better performance, fear of failure, and lack of a support network through family and friends who understand the needs of the profession and encourage aspiration for education (Snyder \& Bunkers, 1994). Cultural barriers for URMs include taking family responsibilities into priority, thereby compromising on the time and energy left for professional commitments for women (Snyder \& Bunkers, 1994). It also includes lack of critical mass of URM students and professors as role models, time commitment, unpreparedness in writing for graduate students (exacerbated by poor language and writing skills), the stress of establishing work/life balance, and concerns over performance in standardized tests for admission that is disconnected with testing the field's content knowledge (Snyder \& Bunkers, 1994). Adding to the list of minority barriers are a lack of financial and social support, challenges with standardized tests, racial stereotyping, bias and discrimination, and insufficient professional exposure (Odom et al., 2007). Several barriers identified with the retention of non-minority students in nursing include inadequate academic preparation, monetary barriers, social maladjustment, and a lack of support from faculty or institutions (Nugent, Childs, Jones, 
\& Cook, 2004). Financial barriers, especially among first generation college students, force them to work full-time or part-time, especially if they are also the main breadwinners in the family (Nugent et al., 2004). Additionally, social maladjustment amongst URMs is another barrier, especially because the transition from home and high school to college could be their first experience with discrimination that causes difficulty in establishing peer-networks and engaging in social interactions (Nugent et al., 2004). This occurs among URMs in predominantly White institutions.

\section{Barriers to Upward Mobility of URM Faculty}

Minority graduates are vastly underrepresented in faculty positions compared to White graduates (Andriole \& Jeffe, 2012). While institutions invest considerable initiative in recruiting minorities, barriers to achieving diversity in the workforce include lack of adequate representation of URM faculty (Agarwal et al., 2005), discrimination amongst URM faculty who are promoted at a lower rate compared to their White colleagues and face other barriers to advancement (Fang, Moy, Colburn, \& Hurley, 2000), lack of awareness, lack of mentors and role models, lack of a congenial academic environment, lack of diversity, and the perception of bias and discrimination (Nivet, et al., 2008). Despite improvement in URM enrollments in medical schools and graduate research programs, racial and ethnic minorities continue to be underrepresented in faculty positions and leadership roles (Nivet, et al., 2008).

Minority faculty often feel compelled to serve on committees, mentor students, and engage in community services that may typically not be helpful in their professional advancement (these contributions being called the "black tax") (Cohen, 1998). URMs also face discrimination while competing for senior faculty rank positions (Cohen, 1998). 
URM faculty recruitment and retention are also hindered by family circumstances and issues related to spouses (Peek et al., 2013).

Racial and ethnic diversity among National Institutes of Health (NIH)-funded investigators is low, but crucial because of their unique perspectives and understanding of the diversity in healthcare issues based on race (Shavers et al., 2005). Barriers identified to obtaining NIH funding as minority investigators are multiple, and these barriers are mostly due to existing institutional bias. These institutional barriers also include several factors like inadequate institutional support, insufficient research infrastructure and training opportunities, barriers to development of independent researchers, lack of opportunities for being mentored, a lack of understanding or sensitivity toward researchers studying minorities, policies that signify institutional bias, unfair competition, lack of research support for minorities, and several barriers pertaining to society, culture, and overall environment (Shavers et al., 2005). Other structural barriers to postrecruitment success and satisfaction include poor retention efforts and lack of mentoring (Price et al., 2009).

For faculty members in medical schools visible individual traits such as race, ethnicity, citizenship status, and gender often provoke bias in the workplace (Price et al., 2004). Minority faculty often report ethnicity-based recruitment disparities, subtle bias in promotion policies, reduced exposure to career options and training, and lack of minority role models and mentors one can identify and interact with, especially with regard to socio-cultural issues (Price et al., 2004). URM faculty also report racial/ethnic bias and discrimination in their academic environment, especially by a superior or colleague, compared to majority faculty and causing lower career satisfaction (Peterson, Friedman, 
Ash, Franco, \& Carr, 2004). Similar reported barriers include prolonged systematic segregation, discrimination, and elitism in academic medicine that discourage the recruitment and retention of URM faculty (Nivet, et al., 2008).

Bias, discrimination and negative stereotyping, due to individual characteristics like race, ethnicity, and gender, often led to reduced career satisfaction, issues in retention, and barriers to promotion for URM faculty (Nivet, et al., 2008). The most cited reasons for attrition amongst URM faculties in medical school include a lack of professional advancement opportunities, poor financial compensation, and leadership barriers, along with a lack of protected time for teaching and research, lack of communication skills, and discrimination (Cropsey et al., 2008). Other barriers are isolation and loneliness of URM faculty within their specialty, and lack of networking opportunities between URM and non-URM colleagues that prevents the forging of personal and professional relationships (Cohen, 1998; Nivet, et al., 2008). These barriers, however, are not applicable to URM faculty in minority-serving institutions because professionals around them are more aware of the racial and ethnic bias issues and how they impede professional advancement (Nivet, et al., 2008).

URM faculty are often reported to have less inclination in terms of time and energy, than non-URM faculty to pursue responsibilities of teaching, research, and publication that facilitate promotion (Nivet, et al., 2008). Instead, their time is often spent pursuing clinical work, doing community service, and mentoring URM students (Nivet, et al., 2008). The problem is worse for URM faculty within minority-serving institutions where the demands are more and supports are fewer, given their smaller faculties and fewer institutional supports like the lack of availability of data, biostatisticians, and 
technical writers (Nivet, et al., 2008). The barriers to promotion of URMs often exacerbate the financial barriers (for example, inability to repay educational loans) due to which URM faculty members choose private practice over academia, further causing attrition (Nivet, et al., 2008).

Inadequate mentoring and role modeling for URM faculty, especially in

predominantly White institutions is another cited barrier (Nivet, et al., 2008). This causes isolation, and a lack of understanding about the factors that contribute to faculty retention, promotion, and success (Nivet, et al., 2008). This problem is as much a part of the minority-serving institutions as it is a part of predominantly White institutions (Nivet, et al., 2008). As a result, URM faculty often report spending more time on administrative duties and less time on their research agenda, scholarly pursuits, and publications necessary to compete for higher positions of deans and chairs (Nivet, et al., 2008).

These barriers discussed among junior URM faculty often create vicious cycles for the workforce. For example, scarcity of senior faculty members causes a reduced number of available mentors, which decreases the recruitment and retention of junior faculty who could transition to the role of senior faculty with time (Nivet, et al., 2008).

\section{Barriers faced by Hispanics}

The U.S. ranks high among countries with ethnically diverse populations, and minorities currently constitute more than a third of the current population (Valcarcel et al., 2006). The underrepresentation of Hispanic minorities in the medical research workforce is a cause of concern. Although Hispanics constitute about $12.5 \%$ of the U.S. population, according to the 2002 Census, they represent only $3.4 \%$ of medical school enrollees. About $34 \%$ of the Hispanic population is unlikely to have health insurance, 
compounded with a high risk incidence of diabetes, obesity, AIDS, neural tube defects in babies, and cardiovascular diseases (Valcarcel et al., 2006).

Given the prevalence of these conditions, as well as the underrepresentation of Hispanic professionals in the medical field, it is imperative to study the barriers faced by Hispanics in the pipeline in order to improve recruitment and retention, and reduce attrition (Valcarcel et al., 2006). Although minority physicians are more likely to attend to minority patient needs, lower pay, higher educational debt, reduced academic faculty morale, and increased academic faculty dissatisfaction are some of the reasons the workforce is unable to recruit enough Hispanic physicians and researchers into the field. Barriers for Hispanic faculty include competition for limited research funding, lack of research and training support, lack of opportunities for academic employment, and increasing financial debt for medical graduates (Valcarcel et al., 2006).

\section{Language and Communication Barriers}

Effective communication is an important tool that links biomedical professionals inside and outside their professional arena (Harris, Bransford, \& Brophy, 2002). Language barriers are commonly reported among Hispanics patients seeking healthcare who have a limited understanding of English (Cooper \& Powe, 2004). Thus, Hispanic patients proficient in English are likely to receive better healthcare and be more satisfied compared to patients with limited English knowledge (Cooper \& Powe, 2004). While there is substantial research on the communication barriers between healthcare practitioners and patients (Schouten \& Meeuwesen, 2006), more research is needed to study the communication barriers faced by medical trainees in the programs, because such research might uncover areas amenable to intervention. Existing literature indicates 
the dominance of the English language in scientific publication, as a result of which nonnative English writers often do not find enough linguistic support and, hence, struggle with writing and publishing (Cameron, Zhao, \& McHugh, 2012). This interferes with their ability to communicate both professionally and personally (Lonie, 2010).

Linguistic barriers in science could potentially affect the individual researcher, as well as the overall institutional research output (Cameron, Chang, \& Pagel, 2011). Foreign researchers often find themselves caught in a difficult situation when their foreign institutions do not adequately train them for bilingual endeavors and U.S. institutions do not provide supportive resources to those non-native English speaking researchers (Cameron, et al., 2011). Additionally, the rate of publication is used as an indicator of individual, as well as institutional productivity, and is imperative to securing research funding (McGrail, Rickard, \& Jones, 2006). However, many institutions do not actively teach academic writing approaches and students do not start writing until they are about to start their dissertation (Dong, 1998).

Language (Meneghini \& Packer, 2007), verbal communication skills (Lee, Vaishnavi, Lau, Andriole, \& Jeffe, 2009), and the lack of adequate training in writing (Guilford, 2001) have previously been reported as barriers that could impede a wellrounded training in the physician scientist training programs. Different demographics of student race and gender, resulting in varied student communication styles, stress the importance for cultural competency training in the biomedical workforce that will improve professional interactions (Lee, et al., 2009). 


\section{Recommendations for Improved URM Representation}

As challenging as it is to parse out individual barriers from institutional barriers, it would benefit educational institutions to reduce barriers for students. The MD-PhD programs are lengthy, demanding, and highly competitive, where students spend anywhere between seven to eight years training themselves. Attrition of students due to institutional barriers is a loss to the workforce, to the reputation of the school, and to the nation's economy.

Some of the recommendations to improve representation of URMs include, developing key diversity benchmarks, and improving mentoring and faculty development programs (Wong et al., 2001). Departments of medicine with higher proportions of URM faculty employ multiple strategies and programs for recruiting and retaining URMs (Peek et al., 2013). There are strong recommendations made about early interventions to strengthen the minority medical student pipeline, which in turn will improve faculty diversity (Page, Castillo-Page, \& Wright, 2011). Since the low number of URM faculty adversely impacts diversity in academic medicine, investing in faculty development and retention to attract and retain bright and successful faculty in medical schools would be useful (Cropsey et al., 2008). These junior faculty development programs would address issues with career counseling and would help prepare one for academia, familiarizing junior faculty with the institutional culture, conducting workshops on pedagogy and grant writing, and providing mentorship from senior faculty (Daley, Wingard, \& Reznik, 2006). 


\section{Summary of Existing Research}

Existing studies indicate that, while women are not underrepresented in the medicine and biomedical pipeline as students, they certainly face several individual and institutional barriers to their advancement into higher positions of faculty and leadership (AAMC, 2012; Files et al., 2008; Powell et al., 2010). Of the many possible reasons for this, hardships in balancing professional and personal lives (Brown, et al., 2011; Shauman \& Xie, 1996; Shollen et al., 2009; Villablanca et al., 2011) is a possible barrier to retention, success, and advancement. Since the period of career advancement for women also coincides with the childbearing and childrearing age, women find it challenging to succeed in their professional lives and get promotions to higher positions at the same time (Gander et al., 2010; McPhillips et al., 2007). While pregnancy during medical training may be viewed negatively (Phelan, 1988), delaying pregnancy increases the risks associated with health complications, age-related decreased fertility, unintentional childlessness, and premature labor as an adverse outcome of late pregnancy (Finch, 2003).

Further, Blacks and Hispanics experience several barriers to their success and retention in the program, as the two largest underrepresented racial/ethnic minority groups in the U.S. (NSF, 2011). While some of these barriers may not have racial undertones (for example, financial barriers), URMs could be more afflicted by them. There are other barriers, such as colorblindness (Bonilla-Silva \& Dietrich, 2011), aversive racism (Barbee, 1993), symbolic racism (Henry \& Sears, 2002), stereotyping (Odom et al., 2007), impostor syndrome (Oriel, et al., 2004), and tokenism, that are 
offshoots of various forms of intentional or unintentional racism. While most studies tend to aggregate the barriers of underrepresented racial and ethnic minorities together, few studies differentiate between specific barriers of Blacks and Hispanics, and tend to compare the barriers in the same study. While some of the barriers are also barriers for the general population, some barriers are very specific to particular groups.

There is overall consensus for the belief that barriers exist between different genders, races, and ethnicities, and examining these barriers would be a positive step toward retaining and advancing students and faculty in the workforce, as well as increasing the diversity of the workforce. This is important not only for the individuals and institutions, but also for society.

Training physicians from URMs would be important for a culturally diverse country, given that URM physicians are more likely to care for the medically underserved populations (Xu et al., 1997) in a way that promotes patient satisfaction and crosscultural care, meets the needs of a diverse population, and brings diversity in research (Wong et al., 2001). Ethnic diversity among physicians is associated with improved access and quality of healthcare for minorities (Bright et al., 1998; Mitchell \& Lassiter, 2006; Nivet, et al., 2008; Price et al., 2004). Hence, every step must be taken to improve diversity in the workforce and eliminate individual, institutional, and societal barriers for members of the workforce.

\section{Limitations of Existing Research}

Substantial research has been done in medicine studying gender-role barriers for women and barriers for the URMs. These include both qualitative and quantitative studies that use a variety of methods for data collection, including interviews, 
observations, focus-group discussions, and surveys. Quantitative studies usually are unable to capture the lived-in experiences of people adequately and, while qualitative studies tend to do so, most of them have a restrictive sample size, sometimes restricted to one medical school. While there is an adequate body of literature about barriers of students in the MD program, existing research on barriers to success for students in the research programs (for example, $\mathrm{PhD}$ or $\mathrm{MD} / \mathrm{PhD}$ ) in the biomedical sciences is sparse. Existing studies often tend to aggregate the barriers of the underrepresented racial or ethnic minorities together, or focus on one particular group. However, there are no comparative analyses between Blacks and Hispanics in the same study that investigate whether barriers are consistently reported across groups, or if there are barriers specific to a particular group. Further, studies usually incorporate the experiences of either students or faculty in the field, but seldom both. Most of the mentoring barriers in the workforce focus on Blacks but less often on Hispanics, making it difficult to understand if there could be underlying gender or racial/ethnic dynamics associated with mentoring barriers. The line between mentoring in MD and $\mathrm{PhD}$ programs is not well defined, although each program requires specific skills to succeed, and mentoring experiences in one program would not be similar to the other. Also, the aim of effective mentoring is to establish independence rather than fostering overdependence. While students and faculty members indicate how lack of mentoring or lack of professional and personal life balance acts as a barrier to their success and advancement, the literature that studies how successful mentoring helps students transition to independent researchers in medicine, or the strategies used by students and faculty who have been successfully able to balance the responsibilities of childbearing and childrearing, and thus could act as role models and 
mentors, is sparse. While literature on barriers and lacking abound, there is a dearth of research about successful mentoring approaches, or strategies used by professionals who overcome racial barriers or learn to balance the demands of professional and personal lives. In this regard, it is hoped that this dissertation will expand on the current body of knowledge about barriers, including the traditional focus on racial/ethnic and gender barriers. Studying both student barriers and faculty barriers would be imperative, since some in the student pipeline will eventually transform into the future faculty pipeline in academic medicine. 


\section{CHAPTER 3}

\section{RESEARCH DESIGN AND METHODOLOGY}

This chapter discusses the research design and methodology used in this dissertation, with a justification for the methods chosen in the context of the research questions. It also explains the paradigm used to address the research questions. Grounded theory is an appropriate methodology used to examine the phenomenon of barriers in the specified field, and in developing a theory that explains the phenomenon. This chapter details the research questions and the research methods, including a description of the participants, data collection, coding and analysis strategies.

\section{Research Questions}

The purpose of this dissertation is to isolate and study some of the barriers women and underrepresented racial/ethnic minority groups face as they transition in their career in medicine and in biomedical science research. The gender component of the analysis includes females in medicine and biomedical sciences (including females from underrepresented races and ethnicities), who report facing barriers to their success in the $\mathrm{MD}, \mathrm{PhD}$, or $\mathrm{MD} / \mathrm{PhD}$ dual degree program. The racial component of the research question includes Blacks and Hispanics. These barriers may be specific to a particular race, ethnicity, or gender, or may be prevalent across the general population. 
Based on a preliminary data analysis of barriers for men and women across different demographics, several barriers were identified by the participants including, but not limited to, economic barriers, racism, mentoring barriers and language barriers. However, for the first research question, I was interested in specifically looking at how women report gender-role as a barrier to success while balancing professional and personal lives. Hence, I purposefully and specifically focused on only gender-role barriers reported by females, and excluded any other kind of barriers from this analysis. The gender-role barriers reported by men have not been analyzed in this dissertation. Similarly, for the second research question, I was specifically interested in comparing barriers of Blacks and Hispanics, and hence, intentionally did not focus on barriers reported by other races and ethnicities, for example, Whites and Asians. The barriers from non-Blacks and non-Hispanics could potentially be addressed in a future study.

Based on this reasoning, the goal of this dissertation is to address the following research questions using descriptive analysis, and a grounded theory methodology:

1. How do women who are either currently enrolled or graduated from biomedical research or medical programs define and make meaning of gender roles as an academic barrier?

This involves the analysis of gender-roles, for example, childbearing and childrearing experiences that poses a barrier to maintaining the balance between professional and personal lives for women.

2. How do underrepresented groups in medical schools and biomedical research institutions define and make meaning of the academic barriers they face and the challenges these barriers pose to their success as individuals in the program? 
This involves the following multi-level comparative data analysis of barriers:

a. Comparison between barriers of Hispanic males and Hispanic females.

b. Comparison between barriers of Black males and Black females.

c. Comparison between barriers of Blacks and Hispanics.

Examining these barrier, as well as studying how the participants overcome these barriers, could provide a better understanding of the institutional climate, as well as personal life experiences through individual stories. The overall goal of this research is to strengthen the medicine and biomedical research workforce diversity in terms of the enrollment, retention, and advancement of women, as well as racial and ethnic minorities.

\section{Project TrEMUR Study}

The two research questions are analyzed using interview data from Transitions in the Education of Minorities Underrepresented in Research (Project TrEMUR). Project TrEMUR is a mixed-method study designed to examine the career trajectories selected or not selected by individuals in medicine and biomedical research through both qualitative and quantitative data analysis. The overall aim of the project is to examine the following overarching question: "What factors influence the choice of a biomedical research career trajectory for individuals of differing demographic groups, with a specific focus on racial/ethnic and gender difference?" Specifically, the aim of the study is to understand the professional and personal experiences of individuals through four main transition points:

a. Students planning careers in medicine or biomedical research through an $\mathrm{MD}, \mathrm{a} \mathrm{PhD}$, or a combined $\mathrm{MD} / \mathrm{PhD}$ program.

b. Students who entered medical school intending to have substantial career involvement in research, and either did or did not enroll in the $\mathrm{MD} / \mathrm{PhD}$ programs. 
c. Students enrolled in the MD/PhD programs who either did or did not complete the program at graduation, and

d. Contemporary graduates with an $\mathrm{MD}, \mathrm{PhD}$, or $\mathrm{MD} / \mathrm{PhD}$ degree who may or may not be currently involved in primarily research-based careers.

The quantitative component of this study examines national data collected from students and medical school graduates by the Association of American Medical Colleges (AAMC). The quantitative data is not a part of this dissertation analysis.

The data for this dissertation were collected from 214 in-depth interviews conducted by phone and in person with students currently pursuing their $\mathrm{MD}, \mathrm{PhD}$, or $\mathrm{MD} / \mathrm{PhD}$ degree, and post-degree professionals in medicine or biomedical research who have pursued these degrees in the past. Out of 214 interviews, 146 interviews were selected and used for this dissertation based on specific demographics.

\section{Research Methodology}

This dissertation aims to understand barriers to success for women as well as for underrepresented racial and ethnic minorities, in medical schools and biomedical research programs using a qualitative research design. While quantitative research using the positivist paradigm assumes a single, discernible reality and the possibility that the researcher can be separated from the research, qualitative research portrays reality as the sum of multiple perspectives held by the participants and assumes that the researcher is an instrument of data collection and is not separated from the research (Erickson, 1986). The aim of a qualitative researcher is to interpret reality from the perspective of individual participants through their lived experiences. Marshall \& Rossman (2006) state that "Qualitative research is pragmatic, interpretive, and grounded in the lived 
experiences of people" (p. 2).

\section{Data Collection}

The data for this dissertation were collected from interviews that were digitally audio-recorded and transcribed verbatim. Although Schwartz-Shea and Yanow (2012) advocate the use of multiple sources of data collection, for example observations as well as interviews, so that the study design does not suffer from a mono-method error, it is largely the research question that drives the methods. As indicated, given the nature of the research question, it is not possible to observe participants in a setting for personal or professional barriers. Therefore, the strength of the research method lies in the rigorousness of analysis of the in-depth interviews, as well as the large sample size of 146 interviews examined in this dissertation. The methods used are not separated from the researcher; the researcher is an instrument in the study, which accounts for the possibility of potential biases that could surface during data collection and data analysis of this study. During the interview, each participant was specifically asked one open-ended question, "Beyond programmatic rigor, tell me about any specific barriers that you felt you needed to overcome in order to succeed in your program," or "Were there any specific barriers that you felt you needed to overcome in order to succeed in your field?" The research questions in this dissertation are based on the responses to this question. However, interviewees have discussed the barriers to their success in the program as responses to other questions as well, mostly even before they were asked the specific question about barriers. In order to capture the richness of the responses, this dissertation analyzes text and content regarding barriers in the entire interview, and not just the specific response to one particular question about barriers. 


\section{Rationale for Qualitative Research Design}

Qualitative research designs are appropriate for studies where researchers strive to understand the processes the participants experience within a given context (Maxwell, 2005). This dissertation tries to understand the processes by which individuals in the workforce identify and make meaning of certain barriers to success in the program they face, using grounded theory.

\section{Rationale for Grounded Theory Methodology}

Strauss and Corbin (1994) indicate that "theory consists of plausible relationships proposed among concepts and sets of concepts, whose plausibility is strengthened through continued research."

Grounded theory is a methodology of qualitative data analysis that is used to develop a theory, as compared to the logical deduction based on existing theoretical frameworks (Charmaz, 1983). The theory developed is "conceptually dense" or has many conceptual relationships and is essentially grounded in data developed through the course of actual research that has been systematically and simultaneously collected and analyzed in the particular study (Strauss \& Corbin, 1994). Grounded theory reflects temporariness, where theories are developed based on the perspective of researchers, which means that the developing theory is fallible and limited in time, as well as interpretive in nature.

For this dissertation, grounded theory was used to develop two such theories, one based on gender-analysis, and one based on race-analysis, that was grounded in such a systematic and repeated collection and analysis of data based on local knowledge, activities, and interpretations. Using this methodology, this dissertation aimed to identify, analyze, and explain some of the underlying processes that constituted barriers for either 
women, that were related to their gender-roles or barriers for Blacks and Hispanics in the specified field. This chapter explains why grounded theory was chosen as the most appropriate research design, describing in detail the research site and the sample, and how data was collected, analyzed, and verified.

Grounded theory is similar to other methodologies that could have been used in this dissertation (due to its reliance on interviews, memos, and methodological journals as the source of data and interpreting results through perspectives and voices of the subjects whose actions are studied). However, what makes grounded theory the best methodology for this data is its scope for theory generation and development, using initially collected data to make analytic interpretations, create emergent ideas, and continue subsequent cycles of data collection, theoretical analysis and verification throughout the period of the study (Strauss \& Corbin, 1994). Here, verification indicates the strategies used to create and apply certain categories in a study. The researchers assume the responsibility as interpreters of the phenomenon under investigation. This resulted in the evolution of theory based on the "richness of concept development and relationships", also called the “conceptual density" (Strauss \& Corbin, 1994). In grounded theory, it is possible to make constant comparisons, systematically pursuing generative concept-related questions, theoretical sampling, systematic coding, attaining conceptual density, and creating a conditional matrix (Strauss \& Corbin, 1990) that helps in integrating conditions and consequences from the macro level to the micro level into a theory (Strauss \& Corbin, 1994). Here, theory is defined as a relationship between concepts or sets of concepts (Strauss \& Corbin, 1994). 


\section{Steps of Grounded Theory}

The two characteristic features of grounded theory are that it is interpretive in nature and focuses on the development of a new theory based on data (Strauss and Corbin, 1994). The various steps in a study, starting from the generation of research questions to formulating a theory, have been discussed in relation to the data used for this dissertation as follows:

\section{Generating research questions.}

The first step of using grounded theory to develop a theory is developing research questions based on the phenomenon one is interested in studying. The two research questions that guided this dissertation have been described above.

\section{Research site and participant selection.}

Following approval from the Institutional Review Board (IRB), the research team conducted 214 in-depth semi-structured interviews with participants from all over the U.S. for the qualitative component of the project. While the majority of them were conducted by telephone, some of them were also conducted in person. The researchers initiated contact with over 50 schools of medicine with $\mathrm{MD} / \mathrm{PhD}$ programs, as well as with several professional associations and affinity groups, through posting to websites and to listserves.

The team developed recruitment flyers that were mailed to the program coordinators and posted within these schools of medicine, so that interested participants could initiate contact and schedule an interview. The schools were representative of the different geographical locations. The flyers and posters were displayed on the bulletin boards for visibility. Further, the departmental chairs who were contacted then sent out an 
email to the cohorts, urging interested participants to interview with our research team. We sent out the distribution materials to a few schools as a time, to avoid being overwhelmed with the amount of responses we got. Once we had heard from particular schools and had interviewed interested participants, we mailed a new round of flyers and posters to the next batch of schools.

The team also developed a project website where interested participants could learn more about the study. The team maintained a client relations management database to manage participant contact information, interview status for current participants, a list of potential participants, and several data reports based on demographics.

We chose a combination of purposeful and snowball sampling, and interviewees were also asked to identify potential participants from their institutions or networks, based on out interview protocol. When we are interested in a specific phenomenon, purposeful sampling helps increase the validity of the sample and ensures that rich data is collected using interviews (Miles \& Huberman, 1994; Marshall \& Rossman, 2006). Additionally, snowball sampling or chain sampling helps identify potential participants through current participant contact (Miles \& Huberman, 1994; Marshall \& Rossman, 2006). The individuals were initially identified based on referrals from medical school researchers and administrators. A sample of schools was purposefully selected based on accessibility and openness to our research inquiries. The research group contacted the administrators, biomedical researchers, graduate students, and medical students at these institutions and queried them about their willingness to be interviewed about their professional career decisions. The interviewees were specifically asked to refer us to their contemporaries, potential interviewees who might be interested, and they were urged to 
share our contact information (snowball sampling). We have found from past research work, that after having participated in an interview, individuals often have a very positive feeling about the experience and will offer to make contact with their contemporaries and provide our contact information to these individuals, along with a summary of their experience.

\section{Collecting initial data.}

The data collected during this study was solely through semi-structured in-person and telephone interviews. Qualitative research positions itself on the idea and belief in the importance of a participant's perspective (Marshall \& Rossman, 2006). Specifically, phenomenological approaches help in understanding a phenomenon from the perspective of the participants, through their personally lived experiences (Kvale \& Brinkmann, 2009; van Kaam, 1959; Fischer \& Wertz, 1979; Giorgi, 1970; Giorgi \& Giorgi, 2003). Interviewing is an effective tool for understanding a phenomenon through participant perspectives (Kvale \& Brinkmann, 2009), specifically through past experiences, present experiences, and essential experiences regarding the phenomenon (Seidman, 1998; Marshall \& Rossman, 2006). Rich descriptions in an interview help the researchers make meaning of a phenomenon through emerging and recurring themes and ideas (Creswell, 1998, p. 150; Gall, Gall, \& Borg, 2007). Such an approach could be applied to a widerange of phenomenon, garnering thick descriptions of the data through interviews and using the qualitative findings to inform future quantitative studies (Moustakas, 1994; Richardson, 1999).

Prospective interviewees were interviewed in a private setting. They were provided with copies of all consent forms for their review prior to the interview. At the 
beginning of the interview, the team reviewed the consent forms and answered any additional questions or concerns participants raised. Verbal consent was recorded at the beginning of the interview. After the interview, participants were asked if they had any further questions and they were given the opportunity to express their willingness to allow the interviews to be transcribed and have their responses analyzed.

Each interview lasted between 45-60 minutes. During the interview, the participants were asked a series of questions about their personal and professional lives, their motivation behind making certain career choices, the support system received and not received, the barriers they faced, etc. (See appendix B for the complete questionnaires). The interviews were digitally audio-recorded with consent and transcribed verbatim with the help of a transcription service for research purposes. The demographics of the 214 interviewees are displayed in the figures 3-1 to 3-5 and tables 32 to 3-6.

During the interview, each participant was specifically asked one question, "Beyond programmatic rigor, tell me about any specific barriers that you felt you needed to overcome in order to succeed in your program," or "Were there any specific barriers that you felt you needed to overcome in order to succeed in your field?" The research questions in this dissertation are based on the responses given to this question. However, interviewees have discussed the barriers to their success in the program as responses to other questions as well, mostly even before they were asked the specific question about barriers. In order to capture the richness of the responses, this dissertation analyzes text and content regarding barriers in the entire interview, and not just the specific response to one particular question about barriers. 
For research question 1, this dissertation analyzes responses from 118 female interviewees when they reported experiencing their gender-role as caregivers for children as a barrier to success. Since the question about barriers was open-ended, participants discussed a number of other barriers as well. For the purpose of this question, this dissertation analyzed only female interviews that discussed gender-role as a barrier.

For research question 2, this dissertation analyzed responses about barriers to success in the program from 82 interviews with Black and Hispanic males and females. These interviewees are or have been in an $\mathrm{MD}, \mathrm{PhD}$, or $\mathrm{MD} / \mathrm{PhD}$ program. The demographics of the interviewees, for example, their race, gender, age, geographic location, degree program, as well as their current professional affiliation, are provided in the tables and figures at the end of this chapter.

\section{Open coding and in vivo coding.}

In the 1967 publication of "The Discovery of Grounded Theory”, Glaser and Strauss (1967) advocated a systematic process of analytic theory generation where the researcher compares data using a "constant comparative method". Grounded theory "seeks not only to uncover relevant conditions, but also to determine how the actors respond to changing conditions and to the consequences of their actions" (Corbin \& Strauss, 1990, p.5). Thus, in grounded theory, there is a close relationship between coding and data analysis. The first step to analysis is open coding that inductively categorizes, sorts and organizes data for analysis. Using grounded theory allows coding for processes (Charmaz, 1983), as one proceeds from the initial phase of exploratory coding to more complex analytic codes that summarize ideas (Glaser, 1978).

Simultaneous with data collection, I began initial coding for each interview 
transcript. Charmaz (1983, p. 111) notes that "codes range from simple, concrete, and topical categories to more general, abstract conceptual categories”. Further, Glaser and Strauss (1967) noted that the codes transform into categories during data saturation. In open coding, I adopted a strategy of line by line coding (Glaser, 1978), to capture events that initiated actions related to my research question, and to gain a theoretical understanding of the underlying processes in the data using the constant comparative method. I grouped similar data and gave them conceptual labels.

I continued the process of open coding for all the interviews, not attempting to sort or rearrange codes right away without understanding the potential relative relationship between codes and their relevance to the research context. Once done with open coding, I started to consider the relationship between various emergent categories. For example, the operative code "mentoring" alone gave rise to broader categories such as "mentorship barriers", "skill building", and "strategies to overcome barriers". This simultaneous coding and data analysis helped me to reflect on the goodness of fit of the emergent categories and my research context. Some codes like "professional position" helped me organize data, but did not show any distinguishing patterns in the data. Such codes were used mainly for organization and not for analysis. Although some codes started very broadly, I was able to either eliminate them or specify them in more detail with time.

I also included in vivo coding where the conceptual labels used the exact terminology used by the participants. While some of these in vivo codes were eventually eliminated, some remained and contributed to the development of a theory. Some examples of open codes and in vivo codes used are given below. 
Table 3-1

Coding in grounded theory.

\begin{tabular}{|c|c|}
\hline Open Code & Quote \\
\hline Economic & $\begin{array}{l}\text { I guess the one thing that it has made me seriously consider is whether or } \\
\text { not I want to try to stay in academics when I'm done with my postdoc } \\
\text { here or just get a job in industry. The main reason for that is just the } \\
\text { paycheck, because with what you make on a postdoctoral salary } 50 \\
\text { percent of my income is going to go to childcare. If we have a second } \\
\text { child then } 100 \text { percent of my income goes to childcare. }\end{array}$ \\
\hline $\begin{array}{l}\text { Self- } \\
\text { confidence }\end{array}$ & $\begin{array}{l}\text { Well, the confidence was not always there. I did doubt myself on a lot of } \\
\text { things ... When I was a graduate student, it never seemed possible that I } \\
\text { would get a post-doc. When I got the post-doc, I'm like I'm never gonna } \\
\text { get a faculty position. When I got a faculty position it was like I'm not } \\
\text { gonna get tenure. Every step was like a confidence doubting issue type } \\
\text { of thing. }\end{array}$ \\
\hline Mentoring & $\begin{array}{l}\text { Well, a lot of the people that are teaching in medical schools and medical } \\
\text { university environments, they don't really know how to mentor naturally. } \\
\text { They have to learn how to be a mentor, so I would say one of the barriers } \\
\text { is identifying people that know how to be good mentors. }\end{array}$ \\
\hline In vivo Code & Quote \\
\hline $\begin{array}{l}\text { Impostor } \\
\text { syndrome }\end{array}$ & $\begin{array}{l}\text { The only minority, person of color, the only person of color. That was } \\
\text { definitely really difficult for me, just because I hadn't really been in a lot } \\
\text { of environments where that was the case. ... it was just really hard, } \\
\text { because then you start to question your self-worth, you also question your } \\
\text { intelligence, you question whether or not you really belong, because no } \\
\text { one looks like you. You're like, "Do I really belong here?" and they call } \\
\text { it the imposter syndrome. }\end{array}$ \\
\hline Competitive & $\begin{array}{l}\text { The only time I think I really had trouble is as a medical student of } \\
\text { collaborative oncology, it was competitive. }\end{array}$ \\
\hline $\begin{array}{l}\text { Maternity } \\
\text { leave }\end{array}$ & My boss wasn't thrilled by the idea of me taking maternity leave at all. \\
\hline
\end{tabular}

\section{Collecting more data based on open coding, memos, and methodological}

\section{journals.}

214 interviews that were collected in cycles over a two-year period were used in this dissertation. The interviews were transcribed and read, and the emergent codes were 
noted after each round of interviews. Based on these, the questionnaires were modified slightly based on the aims of this study. According to Marshall \& Rossman (1995), "indepth interviewing is a data collection method relied on quite extensively by qualitative researchers" (p. 81). While the interviews were the primary source of data for this study, additional tools like memos and methodological journals were also used to shape the data based on analytic interpretations (Charmaz, 1983, p.110). Thus, the interview questions used in subsequent rounds were increasingly better informed compared to those used during the early stages.

Qualitative data analysis occurs simultaneously with data collection (Creswell, 2012). I have reflected on my process of conducting the interviews by maintaining a methodological journal. This has helped me to keep a record of the various methodological decisions I took during the data collection and analysis and manuscript preparation in order to make the study more rigorous (Erickson, 1986).

\section{Axial coding.}

Open coding was followed by a second stage of coding (axial coding) where I developed codes into categories. According to Strauss and Corbin (1994), “Open coding fractures the data and allows one to identify some categories, their properties and dimensions. Axial coding puts those data back together in new ways by making connections between a category and its sub-categories" (p. 97).

Axial coding is the process of coding by which a category is treated as an axis around which related concepts develop (Charmaz, 2006). It involves refining the categories developed, keeping in mind how categories might be related to each other. Since the conceptual labels alone could not indicate the relationships among conditions 
and processes, I used a coding structure that linked various categories of data. The overall aim of this was to develop hypothetical relationships between phenomena through categories, as well as to verify emerging relationships. Once the concepts and categories were integrated and the linkages were validated against additional data, hypothetical statements regarding a potential theoretical model began to emerge. Once again, writing analytic memos to structure the concepts around barriers helped to crystallize the possible underlying phenomena in this data.

An example of axial coding is described as follows: "Mentoring" was a barrier among many others that emerged as a gender-role barrier for women. Within the broader code of "mentoring", several categories that emerged included "lack of mentoring", “academic barrier", “maternity leave”, "strategies of overcoming”, “lack of networking”, and "institutional". All these sub-categories revolved around the common axis of mentoring.

\section{Constant comparative method.}

Constant comparative method is a primary method by which abstract concepts and theories are generated analytically, through an inductive process of subsequent levels of comparing different data, data with categories, different categories, and categories with concepts (Charmaz, 2006). These steps were followed periodically by comparing data within an interview or between interviews. This method is used to compare and determine relationships between categories at the conceptual level. For example, I used this method to reflect on whether a certain category (work/life balance) was causally related to another category (gender barriers). In order to understand this, I scanned the data for questions like, "When did "gender barriers" occur? Did "work/life balance" have 
a role in causing such barriers?"

\section{Theoretical sampling.}

Theoretical sampling is a process of sampling to develop emergent theories, and was conducted to substantiate established relationships between related categories and to look for an emerging theory after the categories were formulated to a certain extent. This was an inductive technique of data analysis done using a process of verification, after sufficient data was collected, coded and analyzed. For example, if the data supported the established relationship between categories, I tried to identify variations in these relationships through theoretical sampling in order to guide the emergent models. This was paralleled by the additional collection of data through interviews. Theoretical sampling was done at a point where the inductively emerging conceptual categories were sufficiently developed to construct specific questions around them (Charmaz, 1983, p. 125). Through theoretical sampling, I was able to ensure that data analysis and theory development were a progressive process that helped in understanding relationships among categories and concepts. This helped to refine and elaborate on conceptual categories.

\section{Selective coding among core categories.}

After open and axial coding, selective coding was used as the final stage of coding. While axial coding resulted in the formulation of categories, their properties, and relationships among various categories, selective coding was done in order to identify a core category, as a systematic tool for integrating these categories. This core category accounted for the majority of events and processes related to the research topic of barriers. Choosing a core category happened over time, as I gained a better understanding 
of the data and my perception of the research phenomena evolved.

\section{Sorting and integrating memos.}

Analytic memos were narrative documents used as tools during coding and analysis to guide the emerging theory. These memos helped understand the data at the conceptual level and establish linkages between the various categories of data. In this dissertation, documenting progress of ideas regularly through memos helped me understand the evolution of codes, create the analytic framework, and select a core category around which other categories were based. Memo writing took place during the entire duration of data collection and analysis. It was important in documenting how my personal biases might influence the study. It was also crucial for the development of the theories that are discussed in subsequent chapters. During the process of writing memos, sometimes new patterns and ideas emerged that were originally not a part of the codes or categories. For example, the discussion on two-physician families in chapter 4 emerged out of writing memos to document barriers and support frameworks for females, which was not a part of the initial analysis.

Writing memos was followed by sorting and integrating them. During sorting, memos with the same categories were grouped together. For example, all memos related to the category of "economics" were put together. Sorting was followed by integration, during which the relationships between categories were revealed.

\section{Developing a theory.}

This was the last step of analysis using grounded theory that led to the emergence of a theoretical framework based on the data, in contrast to the verification of an existing theory. The theories developed for each research question have been discussed separately 
in chapters 4 and 5 .

\section{Researcher as an Instrument}

Grounded theory is a methodology of qualitative research that embraces a postpositivist orientation. This theory ontologically assumes that reality is probabilistic and imperfectly perceivable. Epistemologically, validity of knowledge is interpretive and empirical. The researcher acts as an instrument for data collection and analysis (Guba \& Lincoln, 1994), and thus it is important that the researcher possess "theoretical sensitivity ... the attribute of having insight, the ability to give meaning to the data, and capability to separate the pertinent from that which isn't”' (Strauss and Corbin, 1990, p.42). The researcher attains theoretical sensitivity through familiarity with the topic, familiarity with existing literature, and with prior training and experience in the field. The researcher plays a vital role in interpreting the meaning making and interpretation of the participants by adding their own meaning making and interpretations using their research questions and conceptual framework (Schwartz-Shea \& Yanow, 2012). A well-documented research report includes the full disclosure about the researcher, their relationship to the study, and how the process of data collection and data analysis has evolved (SchwartzShea \& Yanow, 2012). This adds to the credibility of the study (Rossman \& Rallis, 2012). In this section, I have described my background and qualifications as a researcher who has participated in the collection and analysis of data.

As a qualitative researcher, it is difficult to parse out my own beliefs and assumptions from influencing the data collection and the data analysis of the study. Thus, I have brought my own experiences, interpretations, biases, and world view (SchwartzShea \& Yanow, 2012). A sub-focus of the overall Project TrEMUR is to address the 
barriers that currently enrolled students or graduates in the $\mathrm{MD}, \mathrm{PhD}$, or $\mathrm{MD} / \mathrm{PhD}$ programs face within and outside the program, which is the primary goal of this dissertation. Prior to joining the PhD program in Science Education at the University of Virginia, I have spent eleven years studying and doing research in the field of Biology. Some of the research areas discussed by the participants are closely related to my own research focus in the past. I have a Master of Public Health in Toxicology, a degree that many of the biomedical professionals in this study have earned during their education. Some of the barriers I personally faced in the field of Toxicology are related to the barriers participants have discussed. When the participants explained their research focus and the barriers they faced within or outside their programs, I could very well relate to them. I have sometimes added my responses during the interviews stating the same, for example, "I can understand the issues you have shared with me. I have been a bench scientist myself and have worked on closely related topics". This sometimes made my interviewees establish renewed connection with me (for example, sometimes they asked, "I am curious, why did you shift to a different field?"), but most of the time I presume they were unaffected, as they did not ask me questions.

Further, some of the barriers discussed by the individuals were due to the fact that they were underrepresented minorities in the field, or because they were women. Being a woman, as well as a foreign student, it is possible that the lens I used to analyze my data was influenced by my identity. Thus, I was never removed from the topic of the study, or from the methods I used for data collection and data analysis. In fact, I was particularly interested in studying the way women and underrepresented racial and ethnic minorities made sense of the barriers they faced in academia. However, I have been aware of the 
potentially biased decisions I might have made during the phases of the studies, based on who I am, as an instrument. I have attempted to portray the similarity in my educational background to the reader.

In order to ensure that my background or identity did not influence my interest, data collection, or analysis of the study, I have examined my own assumptions about barriers in the field, and have strived to ensure that my assumptions were not imposed on the study. Additionally, writing memos has been a useful exercise to voice my biases to see if my field background or interest in studying barriers, as a female, has interfered with my data analysis. I have also engaged in a careful systematic reflection on data collection using a methodological journal (Rossman \& Rallis, 2012). I agree that I was never removed from the topic, process of data collection, or my meaning making of the data. However, my participation was minimal, and at a conscious, unobtrusive level (Rossman \& Rallis, 2012).

\section{Data Management and Analysis}

Data for this study were collected in the form of audio tape recordings. The recorded interviews were transcribed verbatim and researcher comments were added in the later analysis. For confidentiality, no individually identifiable information was released. Each interviewee was assigned a code that was used in all data materials in which they were mentioned. Each interviewee was de-identified for any personal or identifying information like their name. The audio tapes and the transcribed data were stored in a password protected locked file, and only members of the research team had access to that information. The copy of the codes was maintained in a secured location in the private secure office of the principal investigator. In instances where the demographic 
identification of individuals might lead to their identification, the report included aggregated information that would preclude identification. For example, if only one Hispanic female biomedical researcher was interviewed among all schools in the Western U.S., no data about Hispanic female biomedical researchers identified the geographic region of Hispanic female biomedical researchers.

Creswell (2012) states that data collection and data analysis is a simultaneous process. Thus, data collection was followed by writing journals and analytic memos to reflect on emerging codes and categories. The study includes field notes, audio-tape recordings, and interview transcripts that were read multiple times over time to generate emerging codes. The data were analyzed using a computer aided qualitative analysis program ATLAS.ti.6.2.27 (ATLAS.ti, 1999). The generation of codes, as well as the

process of writing memos, led to categories, concepts, and the development of a theory supported by vignettes, quotations, and tables (In this dissertation, the quotations were slightly modified when required to correct for grammar or were suitably abbreviated to avoid repetition and redundancy. However, the quotes were not modified for content).

\section{Research Strategy}

To understand how women, as well as underrepresented racial and ethnic minorities, make meaning of the barriers to success they face in their field, this dissertation analyzes interview data from 146 participants (out of 214 interviews originally collected for the study), modeled on a grounded theory approach. Qualitative research is a way of learning about a phenomenon in which the researcher is the instrument of the research (Rossman \& Rallis, 2012). Qualitative research is inductive and interpretative, using multiple methods of learning about the phenomenon, which 
include observations, interviews, and document collection. As discussed above, the nature of the phenomenon under study meant that it was not possible to observe participants in a setting for personal or professional barriers. Therefore, this dissertation depends solely on the analysis of in-depth interviews. In this dissertation, the phenomenon under study is barriers to success in a program. The context is the various institutions, and the participants in this study are the interviewees who belong to those institutions. The focus of this dissertation is on the interviewees' interpretation and meaning making of barriers to success in the program. Using a grounded theory methodology allows the understanding of the phenomenon of self-reporting of various barriers and obstacles to success in the $\mathrm{MD}, \mathrm{PhD}$, or $\mathrm{MD} / \mathrm{PhD}$ dual degree programs. The strength of the method used lies in the context-specific meaning making (Schwartz-Shea \& Yanow, 2012).

\section{Validity and Credibility}

Glaser and Strauss (1967; Strauss and Corbin 1990) also identify four criteria for judging the validity of the resulting theory: fit, understanding, generality, and control. Fit requires that the "theory be closely related to the daily realities (what is actually going on) of substantive areas, and so be highly applicable to dealing with them" (1967, p. 239). Understanding requires that the theory "be understandable to people working in the substantive areas ... Their understanding tends to engender a readiness to use it, for it sharpens their sensitivity to the problems they face" (p. 240). Generally requires that the theory is "flexible enough to make a wide variety of changing situations understandable, and also flexible enough to be readily reformulated, virtually on the spot, when it does not work in application." (p. 242). "Control requires that the substantive theory must 
enable the person who uses it to have enough control in everyday situations to make its application worth trying” (p. 245).

It is important to note that grounded theory was developed in "defense against doctrinaire approaches to verification" (Glaser and Strauss, 1967, p. 7). Glaser and Strauss objected to the role of qualitative research functioning as an exploratory effort to initiate surveys verified in a quantifiable manner. They considered the generation of theory to be of equal importance to the verification of theory. Testing the theory in new situations to account for new variations of phenomena can appropriately increase the theory's reproducibility and generalizability rather than seeking exact correspondence among social situations. Although theory generation occurs via abstraction, a grounded theory methodology ensures that the resulting theory is empirically generalizable.

According to Erickson (1986) the results of a research study are prone to suffer from several threats to validity. Some of them are inadequate amount of evidence, a lack of variety in the kinds of evidence used, and a poor account of disconfirming evidence. Further, Erickson (1992) indicates that a core assumption of qualitative studies is that the participants do not act in isolation, but are part of a larger context, indicating that qualitative findings should not be generalized and should be interpreted with caution. Credibility and trustworthiness can be achieved in a qualitative study using several strategies, including a rigorous process of data collection, triangulation of data from multiple sources, a description of the researcher as an instrument and their role in the study, and peer-debriefing to ensure that the findings align with the data (Rossman \& Rallis, 2012). 
I have used several strategies to address these issues and to ensure the plausibility of the results, including:

- Spending extensive time in the field, personally collecting 27 of the 214 interviews for the study, and coordinating many of the other interviews, corresponding with the interviewees to set up a time, and allocating interviews to other members of the research team.

- I have used field notes and analytical memos to support my data collection and analysis. Analytic memos document the researcher's thought process during the study, provide evidence of the link between the data and the emerging theory, and are an important source of validity in a study using grounded theory.

- Using a computer-based qualitative data analysis tool ATLAS.ti.6.2.27

(ATLAS.ti, 1999) to organize the data. Further, I have used excerpts, quotes, and vignettes to present my findings. Only those findings that were supported by data multiple times were used.

- Requesting a peer researcher in the team to check my findings and its evidence in the collected data (Rossman \& Rallis, 2012).

- Being transparent about my role as a researcher in the project and how my professional experience might potentially have influenced the phenomenon I have examined (Rossman \& Rallis, 2012).

The findings of this study cannot be generalized, but are meant to describe the meaning- making perspective, and inform a quantitative component of this study for future research. Erickson (1986, p.130) discussed that "One discovers universals as manifested concretely and specifically, not in abstraction and generality". Thus, my 
findings could be both unique and generic. A thick description of the data for meaningmaking has ensured validity in the study, and will help the reader in their own meaningmaking and interpretations, to establish credibility through their own beliefs about this phenomenon, through prior knowledge or through individually lived experiences.

\section{Ethical Considerations}

The research team obtained approval from the Institutional Review Board (IRB) prior to starting data collection. The participants were provided a copy of the IRB approved consent form for their perusal, and the consent form was reviewed in person or over the telephone. Verbal or written consent was obtained from every participant before starting the interview. Based on Erickson (1986), I informed the participants about the nature of the study and the potential risks it might involve, however minimal. A copy of the consent form has been attached (Appendix A). The interviews were performed in a private setting and the interviewees could skip any question that made them uncomfortable. Every participant was assured confidentiality, and their interview transcripts were stripped of any identifying information. No identifying information would be used in preparation of the research report for the dissertation manuscript.

\section{Summary}

Building a demographically diverse workforce in medicine and biomedical science research is imperative, not only for equity of the URMs, but also for meeting the healthcare needs of an increasingly diverse population and reducing healthcare disparities and issues of access to healthcare. This dissertation aims to study why highly qualified students make certain career decisions to pursue or not pursue their field. Using a qualitative-grounded theory research framework, as described herein, has guided me 
through this process of examining my research questions. As a researcher, I was the observer and my analysis and methodological decisions were documented in a journal. The theories that emerged from the analyses are strong and defensible, based on a diverse database of interviews with thick descriptions. Chapter 4 and Chapter 5 consisted of data analyses and conclusions. Chapter 6 consisted of discussion and implications based on the results, the findings adding to the preexisting body of literature. Future recommendations for individuals, institutions, and policy were made. 
Table 3-2

Racial and Ethnic Distribution of the Overall Study $(N=214)$

\begin{tabular}{ccccccccc}
\hline Race/Ethnicity & Asian & Black & Hispanic & Mixed & $\begin{array}{c}\text { Native } \\
\text { American }\end{array}$ & $\begin{array}{c}\text { Pacific } \\
\text { Islander }\end{array}$ & White & Total \\
\hline Male & 6 & 18 & 9 & 3 & 1 & 1 & 58 & 96 \\
Female & 14 & 37 & 15 & 5 & 0 & 0 & 47 & 118 \\
\hline Total & 20 & 55 & 24 & 8 & 1 & 1 & 105 & 214 \\
\hline
\end{tabular}


Table 3-3

Degree Program Affiliation of the Overall Study $(N=214)$

\begin{tabular}{cccccc}
\hline Degree & MD & PhD & MD/PhD & $\begin{array}{c}\text { Left the } \\
\text { program }\end{array}$ & Total \\
\hline Male & 15 & 28 & 52 & 1 & 96 \\
Female & 26 & 48 & 44 & 0 & 118 \\
\hline Total & 41 & 76 & 96 & 1 & 214 \\
\hline
\end{tabular}


Table 3-4

Overall Distribution Based on Geographic Region in the U.S. $(N=214)$

\begin{tabular}{ccccccc}
\hline $\begin{array}{c}\text { Geographic } \\
\text { Region }\end{array}$ & $\begin{array}{c}\text { Central } \\
\text { U.S. }\end{array}$ & $\begin{array}{c}\text { Northeast } \\
\text { U.S. }\end{array}$ & $\begin{array}{c}\text { Southern } \\
\text { U.S. }\end{array}$ & $\begin{array}{c}\text { West } \\
\text { U.S. }\end{array}$ & $\begin{array}{c}\text { Outside } \\
\text { U.S. }\end{array}$ & Total \\
\hline Male & 27 & 19 & 35 & 12 & 3 & 96 \\
Female & 23 & 30 & 44 & 18 & 3 & 118 \\
\hline Total & 50 & 49 & 79 & 30 & 6 & 214 \\
\hline
\end{tabular}

Central U.S. - Illinois, Indiana, Kansas, Michigan, Minnesota, Missouri, Ohio, Oklahoma, Nebraska, North Dakota, South Dakota, Wisconsin.

Northeastern U.S.- Connecticut, Maryland, Massachusetts, New Hampshire, New Jersey, New York, Pennsylvania, Rhode Island, Vermont, Washington, DC

Southern U.S.- Alabama, Arkansas, Florida, Georgia, Kentucky, Louisiana, Mississippi, North Carolina, South Carolina, Tennessee, Texas, Virginia, West Virginia

Western U.S.- Arizona, California, Colorado, Hawaii, Nevada, Oregon, Utah, Washington 
Table 3-5

Overall Distribution Based on Current Position (N=214)

\begin{tabular}{cccccccc}
\hline Category & $\begin{array}{c}\text { Faculty/ } \\
\text { Researcher }\end{array}$ & $\begin{array}{c}\text { Former } \\
\text { Student }\end{array}$ & Graduated & $\begin{array}{c}\text { Non- } \\
\text { scientist }\end{array}$ & Scientist & Student & Total \\
\hline Male & 25 & 1 & 8 & 5 & 2 & 55 & 96 \\
Female & 31 & 0 & 17 & 9 & 2 & 59 & 118 \\
\hline Total & 56 & 1 & 25 & 14 & 4 & 114 & 214 \\
\hline
\end{tabular}


Table 3-6

Age Distribution of the Overall Sample $(N=214)$

\begin{tabular}{cccccccc}
\hline $\begin{array}{c}\text { Age } \\
\text { (years) }\end{array}$ & $22-29$ & $30-39$ & $40-49$ & $50-59$ & $60-69$ & $\begin{array}{c}\text { No } \\
\text { answer }\end{array}$ & Total \\
\hline $\begin{array}{c}\text { Male } \\
\text { Female }\end{array}$ & 40 & 30 & 15 & 6 & 4 & 1 & 96 \\
\hline Total & 91 & 41 & 15 & 9 & 2 & 0 & 118 \\
\hline
\end{tabular}


Table 3-7

Distribution of Female Students in the Program $(n=58)$

\begin{tabular}{ccccc}
\hline $\begin{array}{c}\text { Program } \\
\text { Year }\end{array}$ & MD & PhD & MD/PhD & Total \\
\hline Year 0 & 1 & 0 & 0 & 1 \\
Year 1 & 3 & 1 & 6 & 10 \\
Year 2 & 2 & 8 & 2 & 12 \\
Year 3 & 2 & 1 & 3 & 6 \\
Year 4 & 3 & 2 & 5 & 10 \\
Year 5 & 0 & 1 & 2 & 3 \\
Year 6 & 0 & 2 & 1 & 3 \\
Year 7 & 0 & 0 & 7 & 7 \\
Year 8 & 0 & 0 & 3 & 3 \\
Year 9 & 0 & 0 & 2 & 2 \\
Year 10 & 0 & 0 & 1 & 1 \\
\hline Total & 11 & 15 & 32 & 58 \\
\hline
\end{tabular}


Table 3-8

Racial and Gender Distribution for Hispanics and Blacks ( $n=82)$

\begin{tabular}{cccc}
\hline Race/Ethnicity & Hispanic & Black & Total \\
\hline Male & 10 & 18 & 28 \\
Female & 16 & 38 & 54 \\
\hline Total & 26 & 56 & 82 \\
\hline
\end{tabular}


Table 3-9

Degree Program Affiliation for Hispanics and Blacks $(n=82)$

\begin{tabular}{ccccc}
\hline Degree & MD & PhD & MD/PhD & Total \\
\hline Hispanic Male & 2 & 1 & 7 & 10 \\
Hispanic Female & 8 & 6 & 2 & 16 \\
Black Male & 5 & 9 & 4 & 18 \\
Black Female & 8 & 22 & 8 & 38 \\
\hline Total & 23 & 38 & 21 & 82 \\
\hline
\end{tabular}


Table 3-10

Distribution of Hispanics and Blacks Based on Geographic Location (n=82)

\begin{tabular}{ccccccc}
\hline Geographic Location & Central & Northeast & South & West & Outside U.S. & Total \\
\hline Hispanic Male & 1 & 0 & 4 & 3 & 2 & 10 \\
Hispanic Female & 0 & 7 & 7 & 1 & 1 & 16 \\
Black Male & 4 & 4 & 7 & 2 & 1 & 18 \\
Black Female & 3 & 13 & 15 & 6 & 1 & 38 \\
\hline Total & 8 & 24 & 33 & 12 & 5 & 82 \\
\hline
\end{tabular}


Table 3-11

Distribution of Hispanics and Blacks Based on Current Position ( $n=82$ )

\begin{tabular}{ccccccc}
\hline Category & $\begin{array}{c}\text { Faculty/ } \\
\text { Researcher }\end{array}$ & Graduated & Non-scientist & Scientist & Student & Total \\
\hline Hispanic Male & 2 & 1 & 0 & 0 & 7 & 10 \\
Hispanic Female & 3 & 3 & 0 & 1 & 9 & 16 \\
Black Male & 8 & 1 & 1 & 0 & 8 & 18 \\
Black Female & 17 & 9 & 1 & 1 & 10 & 38 \\
\hline Total & 30 & 14 & 2 & 2 & 34 & 82 \\
\hline
\end{tabular}


Table 3-12

Age Distribution of Hispanics and Blacks $(n=82)$

\begin{tabular}{cccccc}
\hline Age (years) & $22-29$ & $30-39$ & $40-49$ & $50-59$ & Total \\
\hline Hispanic Male & 6 & 2 & 1 & 1 & 10 \\
Hispanic Female & 7 & 7 & 1 & 1 & 16 \\
Black Male & 6 & 2 & 8 & 2 & 18 \\
Black Female & 11 & 15 & 5 & 7 & 38 \\
\hline Total & 30 & 26 & 15 & 11 & 82 \\
\hline
\end{tabular}


Table 3-13

Comparison of Students, Female versus Male, Hispanic versus Black. $(n=34)$

\begin{tabular}{cccccc}
\hline $\begin{array}{c}\text { Program } \\
\text { Year }\end{array}$ & $\begin{array}{c}\text { Hispanic } \\
\text { Male }\end{array}$ & $\begin{array}{c}\text { Hispanic } \\
\text { Female }\end{array}$ & $\begin{array}{c}\text { Black } \\
\text { Male }\end{array}$ & $\begin{array}{c}\text { Black } \\
\text { Female }\end{array}$ & Total \\
\hline Year 1 & 3 & 0 & 1 & 1 & 5 \\
Year 2 & 1 & 3 & 1 & 1 & 6 \\
Year 3 & 0 & 0 & 1 & 2 & 3 \\
Year 4 & 2 & 3 & 2 & 1 & 8 \\
Year 5 & 0 & 1 & 1 & 2 & 4 \\
Year 6 & 0 & 1 & 1 & 0 & 2 \\
Year 7 & 1 & 0 & 0 & 2 & 3 \\
Year 8 & 0 & 1 & 1 & 0 & 2 \\
Year 9 & 0 & 0 & 0 & 0 & 0 \\
Year 10 & 0 & 0 & 0 & 1 & 1 \\
\hline Total & 7 & 9 & 8 & 10 & 34 \\
\hline
\end{tabular}


Figure 3-1

Racial and Ethnic Distribution of the Overall Sample $(N=214)$

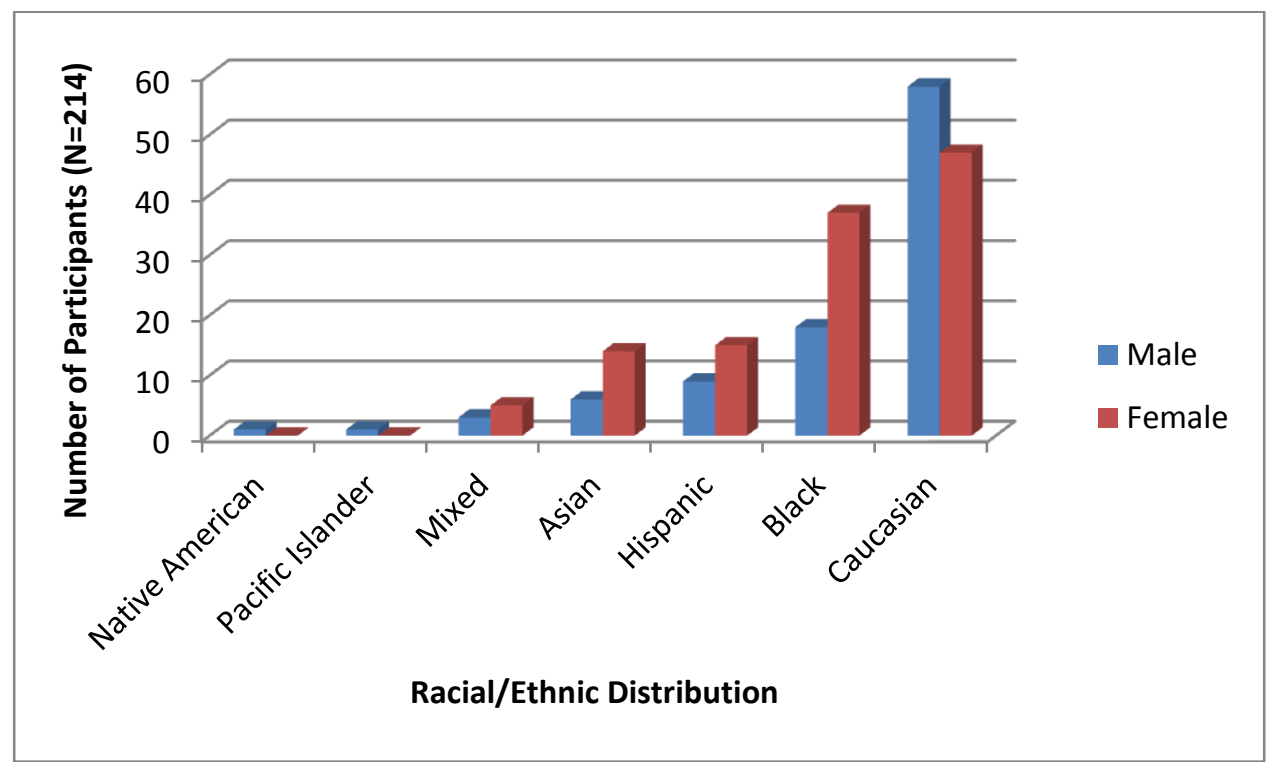


Figure 3-2

Degree Program Affiliation of the Overall Sample $(N=214)$

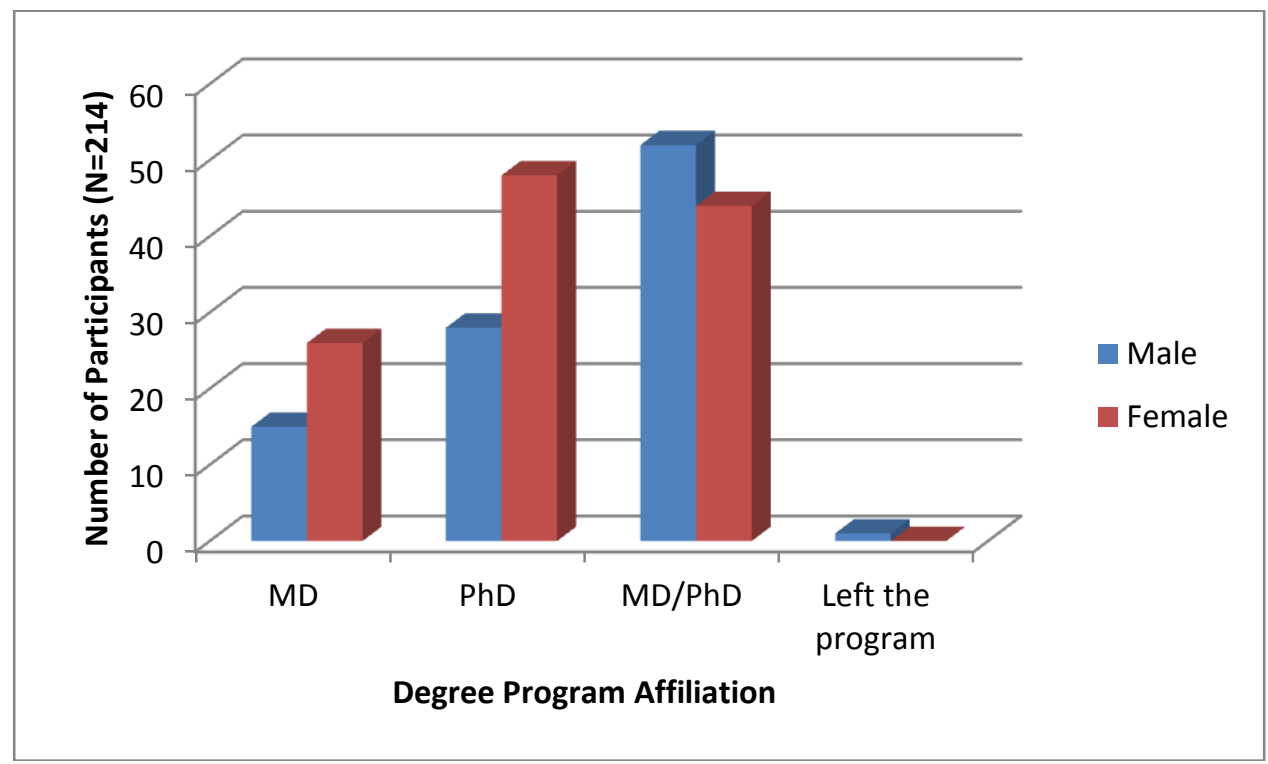


Figure 3-3

Overall Distribution Based on Geographic Region (N=214)

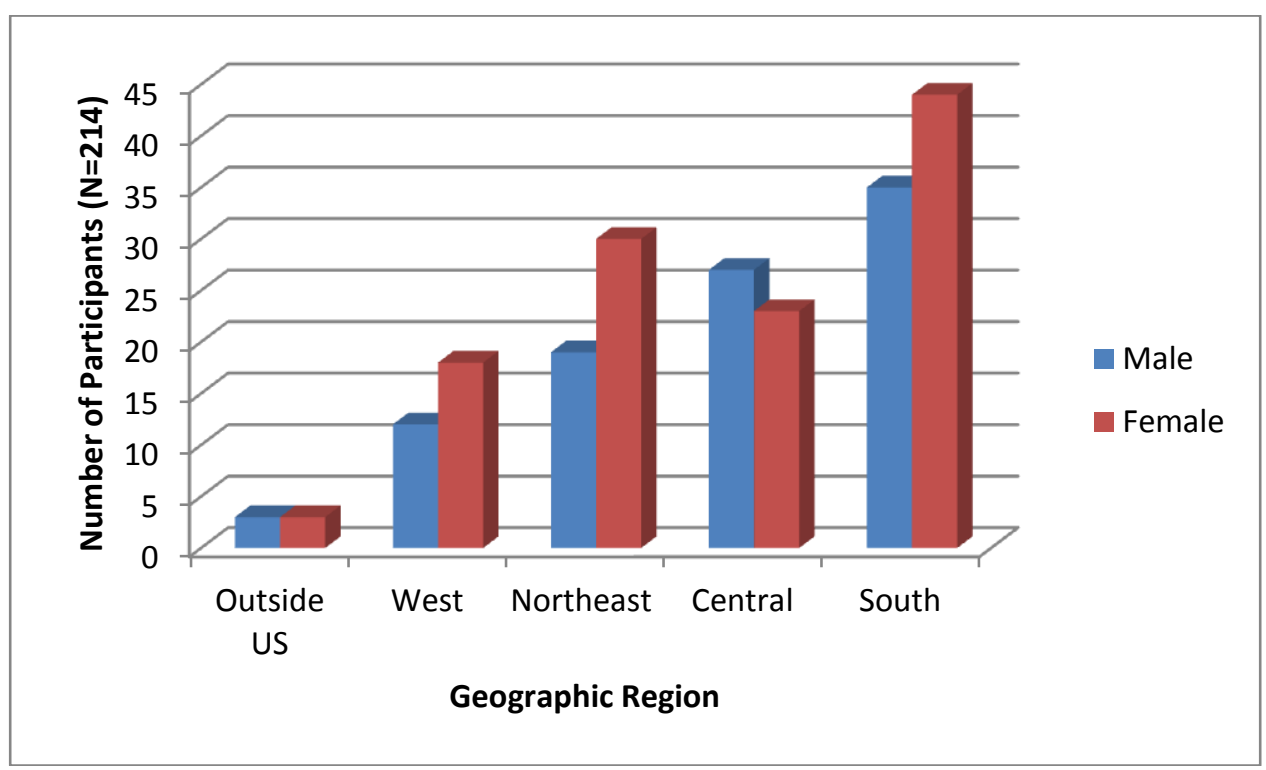


Figure 3-4

Overall Distribution Based on Current Position $(N=214)$

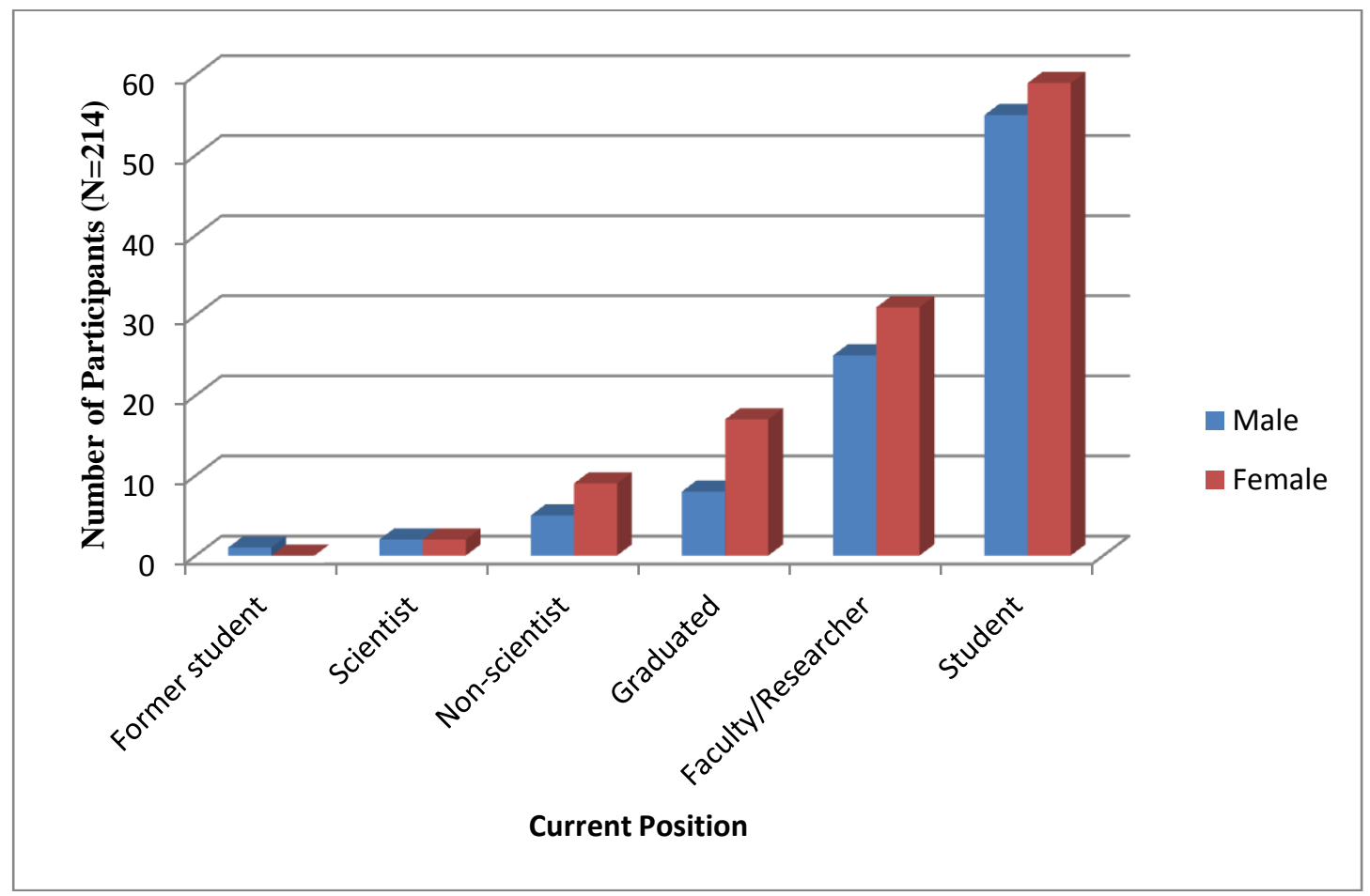


Figure 3-5

Age Distribution of the Overall Sample $(N=214)$

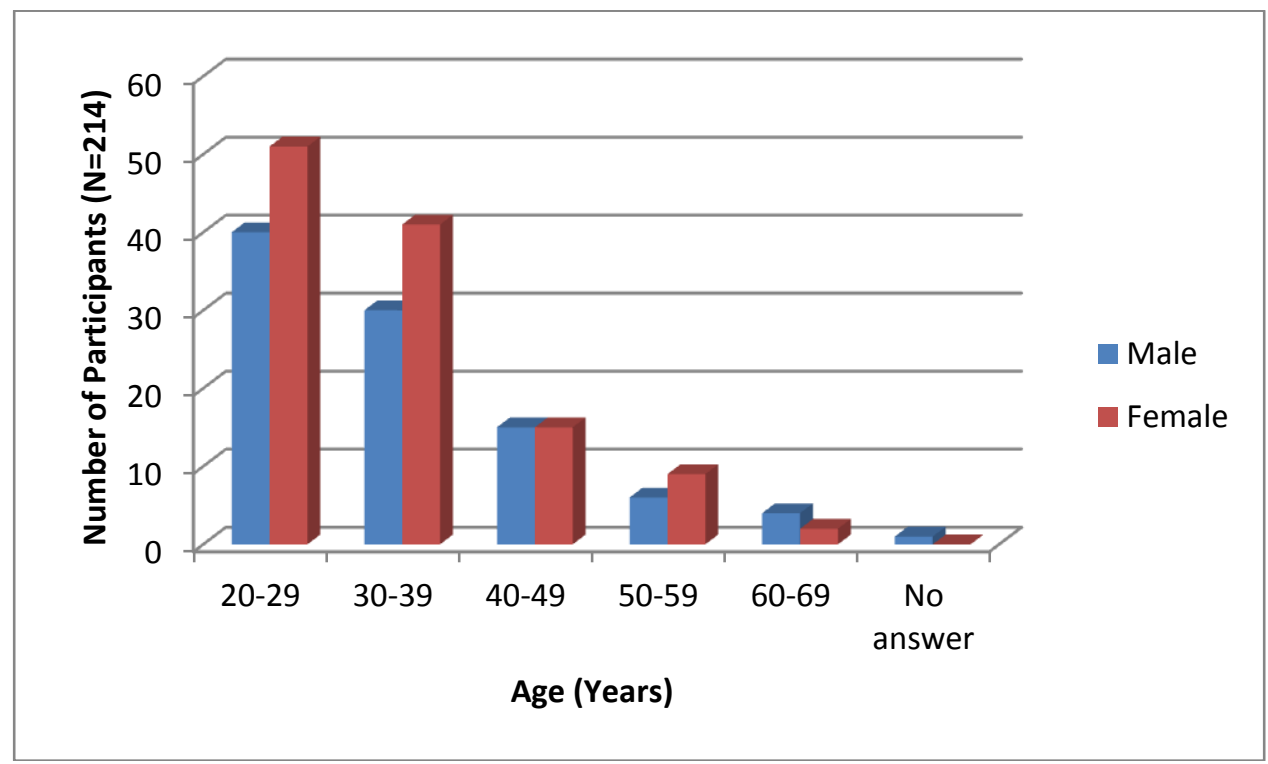


Figure 3-6

Distribution of Female Students in the Program $(n=58)$

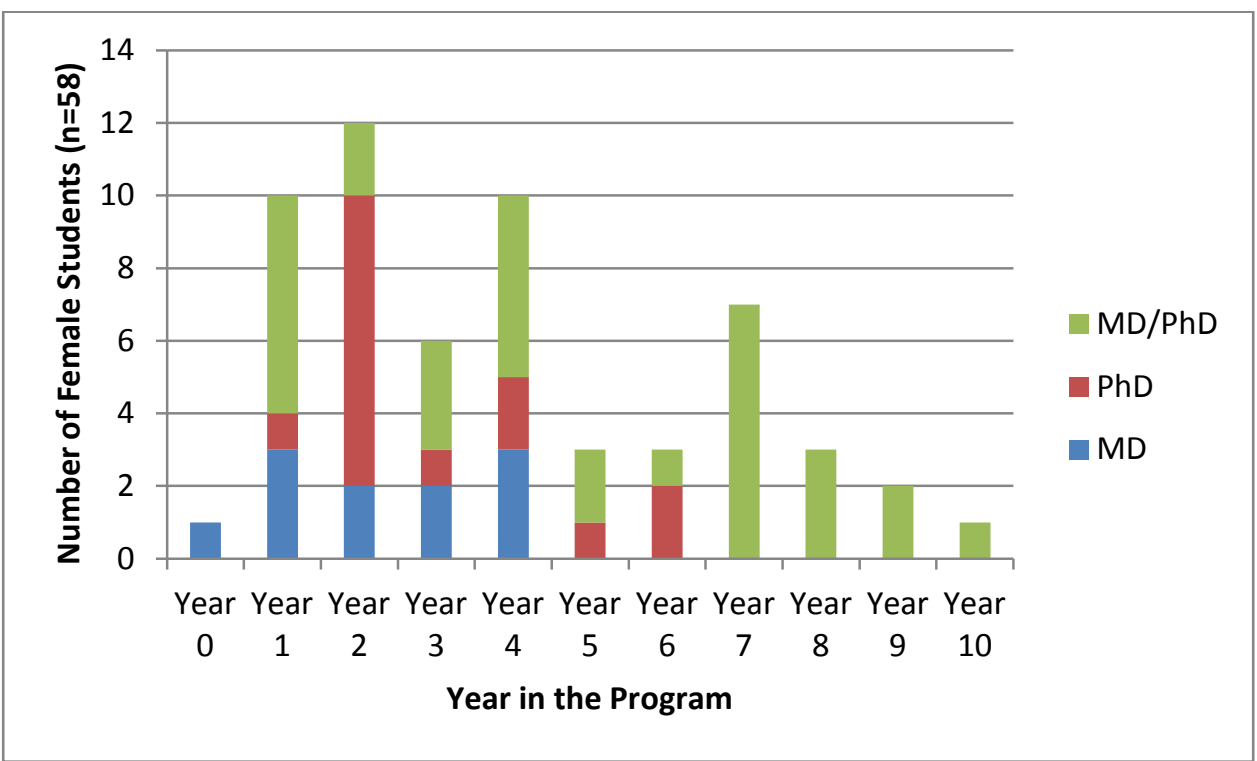


Figure 3-7

Racial and Gender Distribution for Hispanics and Blacks ( $n=82$ )

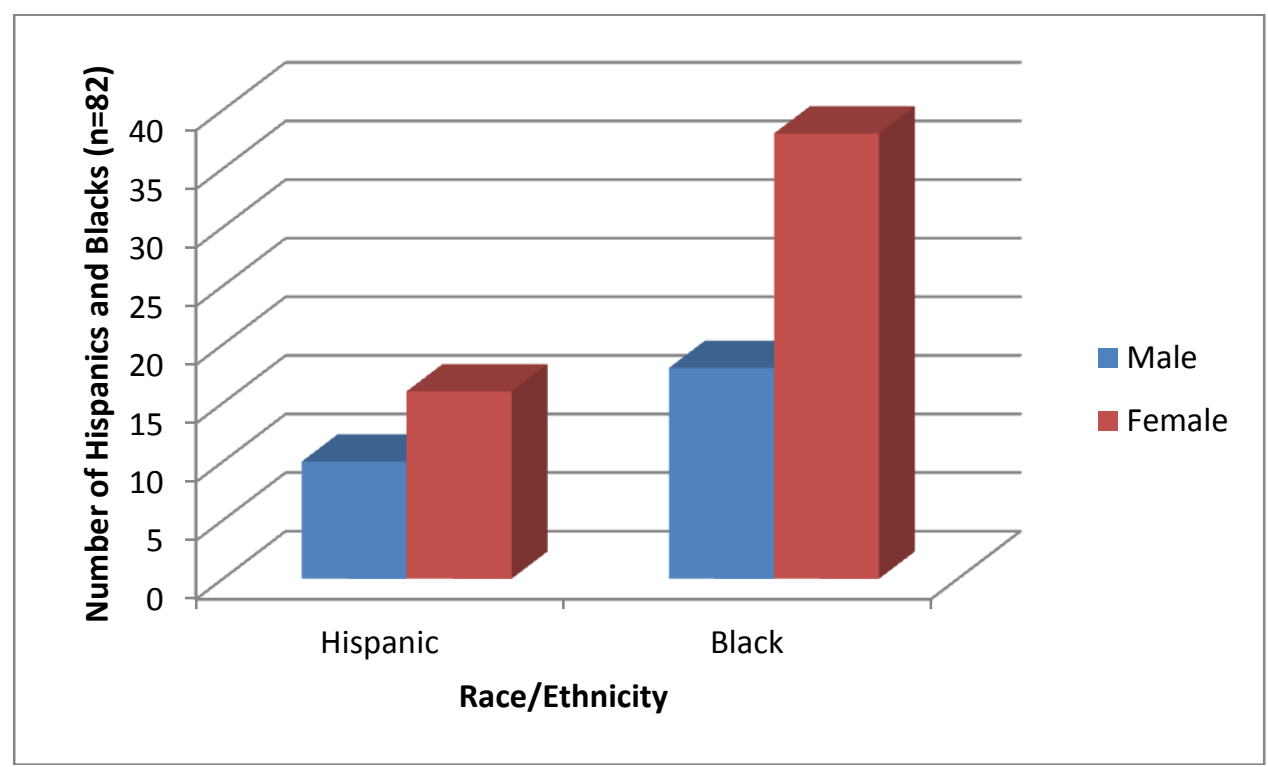


Figure 3-8

Degree Program Affiliation for Hispanics and Blacks $(n=82)$

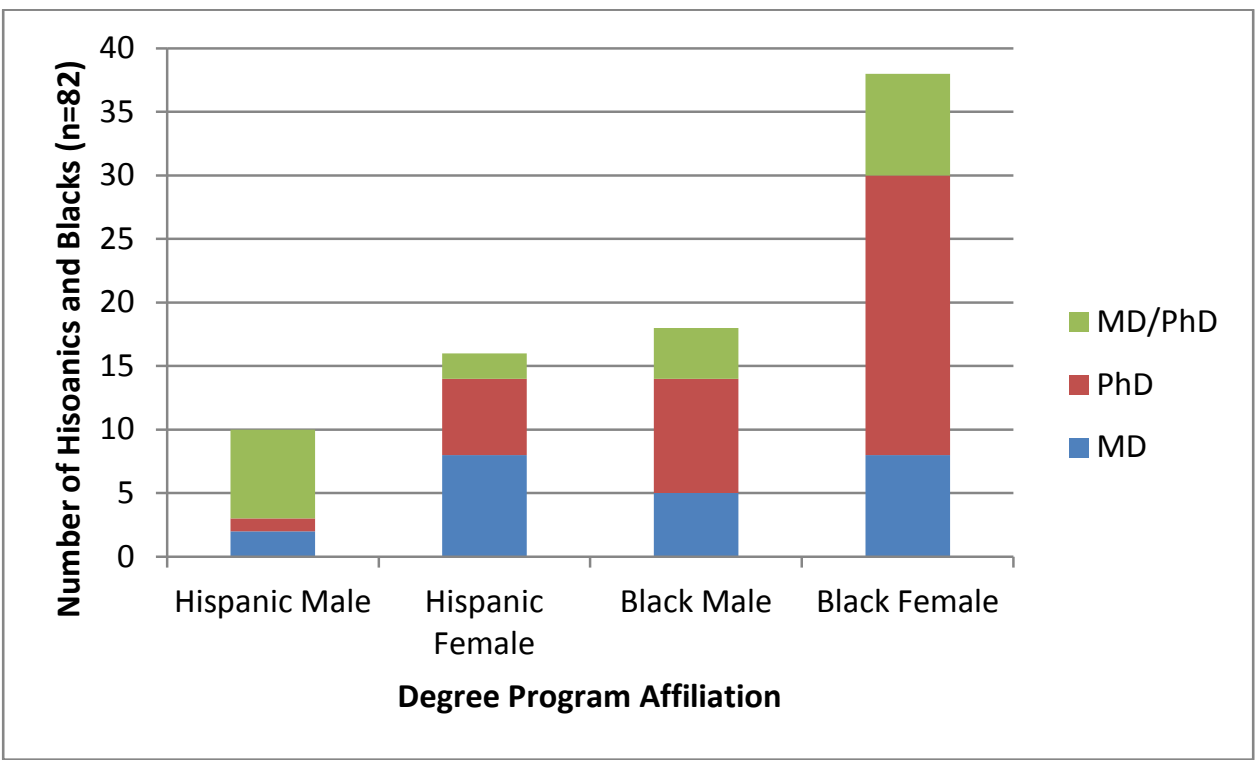


Figure 3-9

Distribution of Hispanics and Blacks Based on Geographic Regions ( $n=82$ )

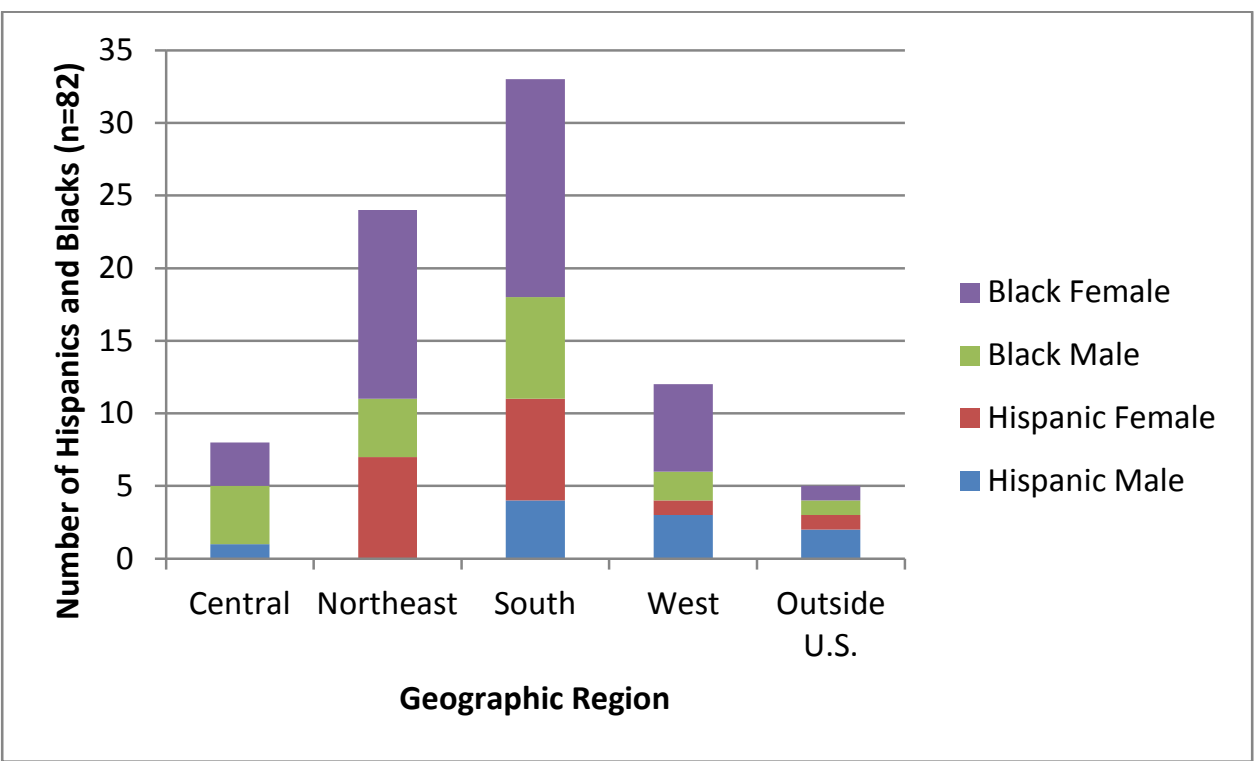


Figure 3-10

Distribution of Hispanics and Blacks Based on Current Position (n=82)

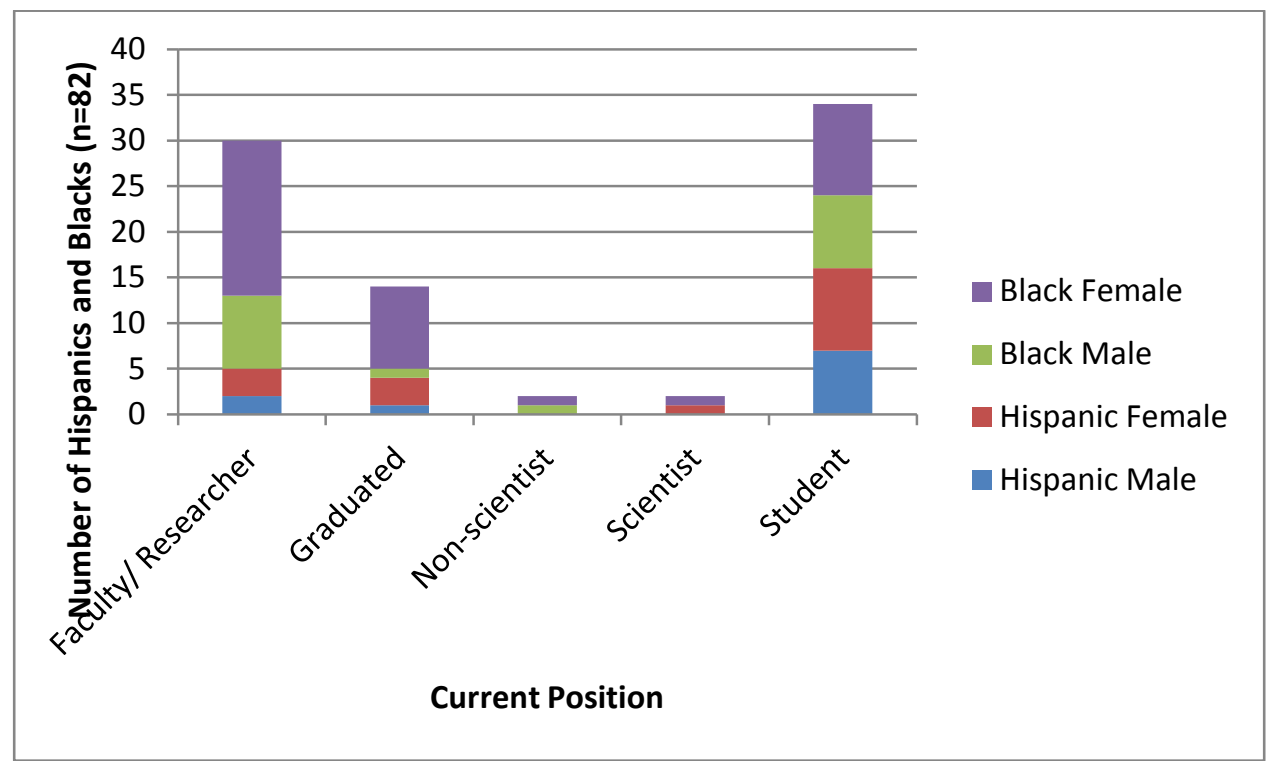


Figure 3-11

Age Distribution of Hispanics and Blacks $(n=82)$

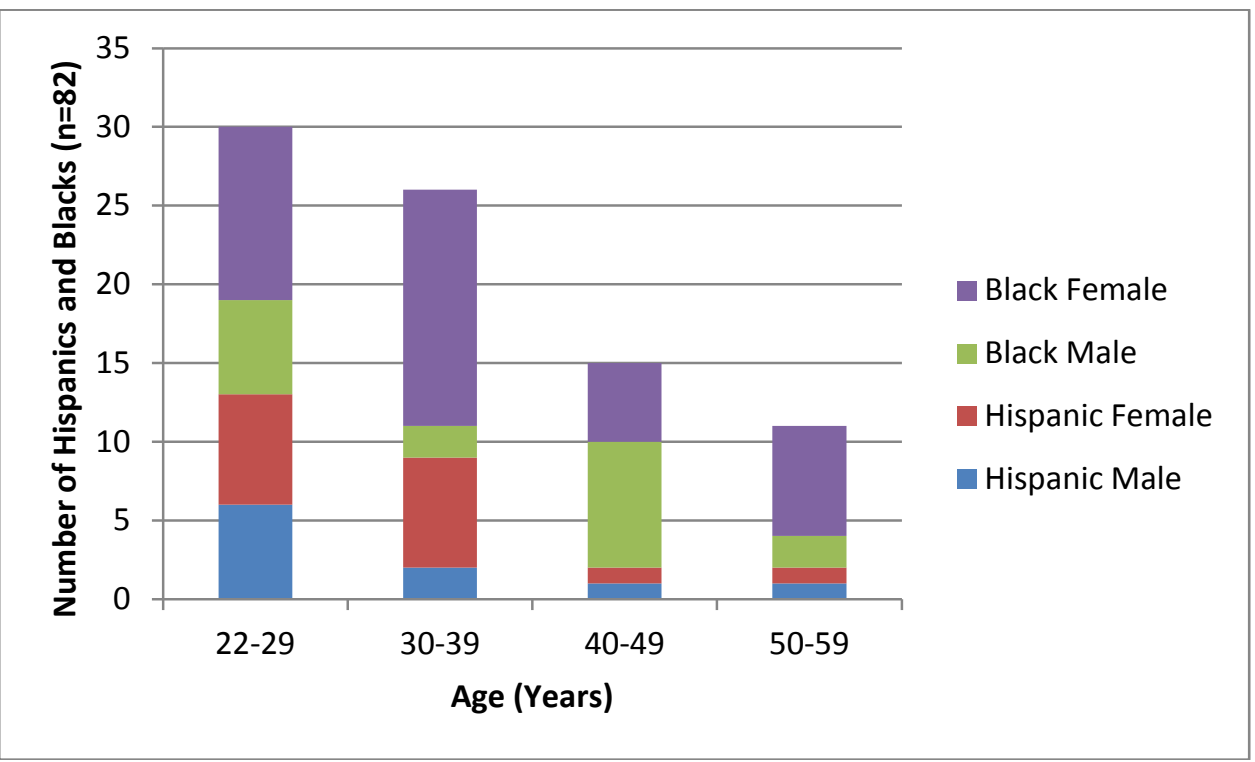


Figure 3-12

Comparison of Students, Female versus Male, Hispanic versus Black. $(n=34)$

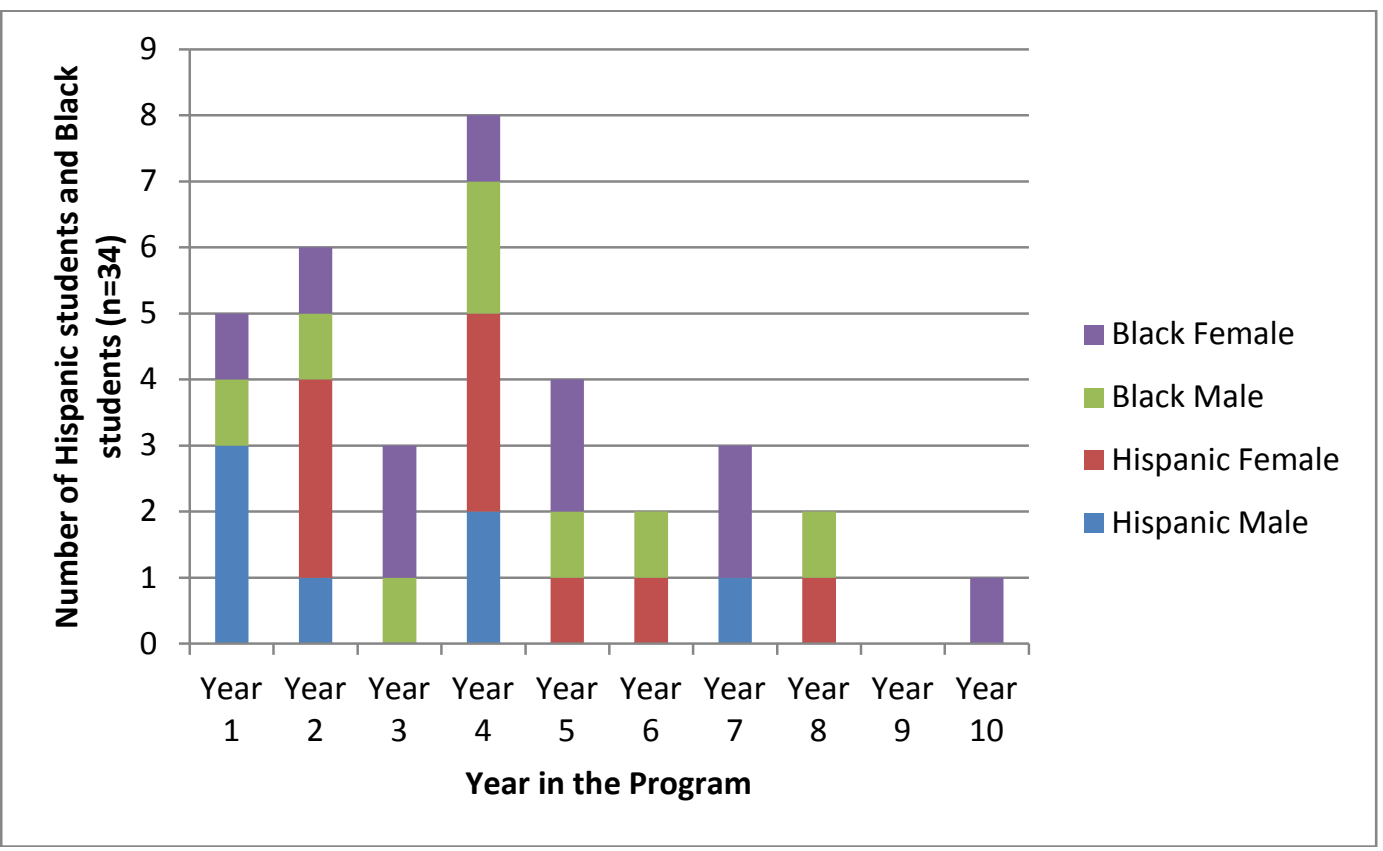




\section{CHAPTER 4}

\section{RESULTS AND CONCLUSIONS}

\section{Gender-role Barriers}

The qualitative analysis is divided into two broad components of gender and race. This chapter will detail the findings of gender-role barriers in women, using a grounded theory approach. As stated earlier, the purpose of studying gender-role for women, in medicine and biomedical research, was to isolate factors contributing to their barriers to success in the program. A participant in this study aptly summarized the purpose of this analysis, questioning if medical school was the right place for her.

"As a PhD, you have nothing to fall back on in a medical school. They'll have the MDs do the teaching of the class, or MDs can go do clinical time to make up for that difference. PhDs cannot, so they'll be very quick to let you go, let alone tenure takes forever to get in a medical school, too. If you go and you have a baby, that's just taking more time away from you that you're not writing grants, and that you're not writing papers. I already feel guilty, from time to time, if I take a breath and just enjoy a Saturday. I don't know that medical school would have been the place for me."(Faculty, Black, PhD, 35 years)

To answer this question and similar ones related to gender-roles as barriers for women in medicine and biomedical research programs, this dissertation analyzed 118 interviews from women in the abovementioned field, who were either currently enrolled in a program, or were post-degree professionals working as faculty, residents, postdoctoral fellows, non-scientists, or scientists. The rationale for choosing to study the gender-role barriers of women was somewhat influenced by the classical expectations of 
roles of women as caregivers within the family. Anecdotal evidence of women shouldering the major responsibilities of caring for children abound, reflected by the response of an interviewee in this study:

"I grew up in a family where my mother has worked all my life, but we still, as many families did a couple decades ago, three, four decades ago, we ate at home as a family around the table. Mom cooked the meals. Mom did the shopping. Mom made sure we had clothes on our back, and I still feel that responsibility. My husband helps, but it's still primarily my responsibility because I take it." (Faculty, Hispanic, MD, 42 years)

Of the 118 women interviewed, 40 women from all groups of students and postdegree professionals (one-third of the total number of women) reported personally facing some form of gender-role barrier during their career that impacted the decision making at various steps in their professional life. This dissertation focused only on personally-lived barriers, and not on the responses from females who closely observed another colleague, classmate, or friend grapple with such barriers in their career. In addition to describing those barriers, some of the interviewees also discussed strategies for working around those barriers. This chapter is divided into three sections. Section one provides a descriptive analysis of the sample of females who reported barriers associated with their gender-role of childbearing and childrearing. Section two describes the emergent theoretical framework based on the reported barriers. Section three describes the various strategies reported by females that helped them overcome gender-role barriers.

\section{Section 1: Descriptive Analysis}

As stated earlier, 40 out of 118 female participants (27 graduates and 13 students) reported facing some form of gender-role barrier in the program. The breakdown of their program affiliation, race and ethnicity, as well as geographic location, is provided at the end of this chapter (Table 4-1, Figure 4-1 - Figure 4-4). In this dissertation, there is 
representation of females across all the degrees, most of the minority races and nonminority groups, as well as across geographic locations within the U.S. The average age of the female participants who reported gender-role barriers is 38 years. Within this group, the average age of post-degree professionals is 43.2 years and the average age of students is 27.2 years.

\section{Section 2: Gender-role Barriers}

This section discussed the emergent theoretical framework under the umbrella of gender-role barriers for females associated with childbearing and childrearing, using a grounded theory approach.
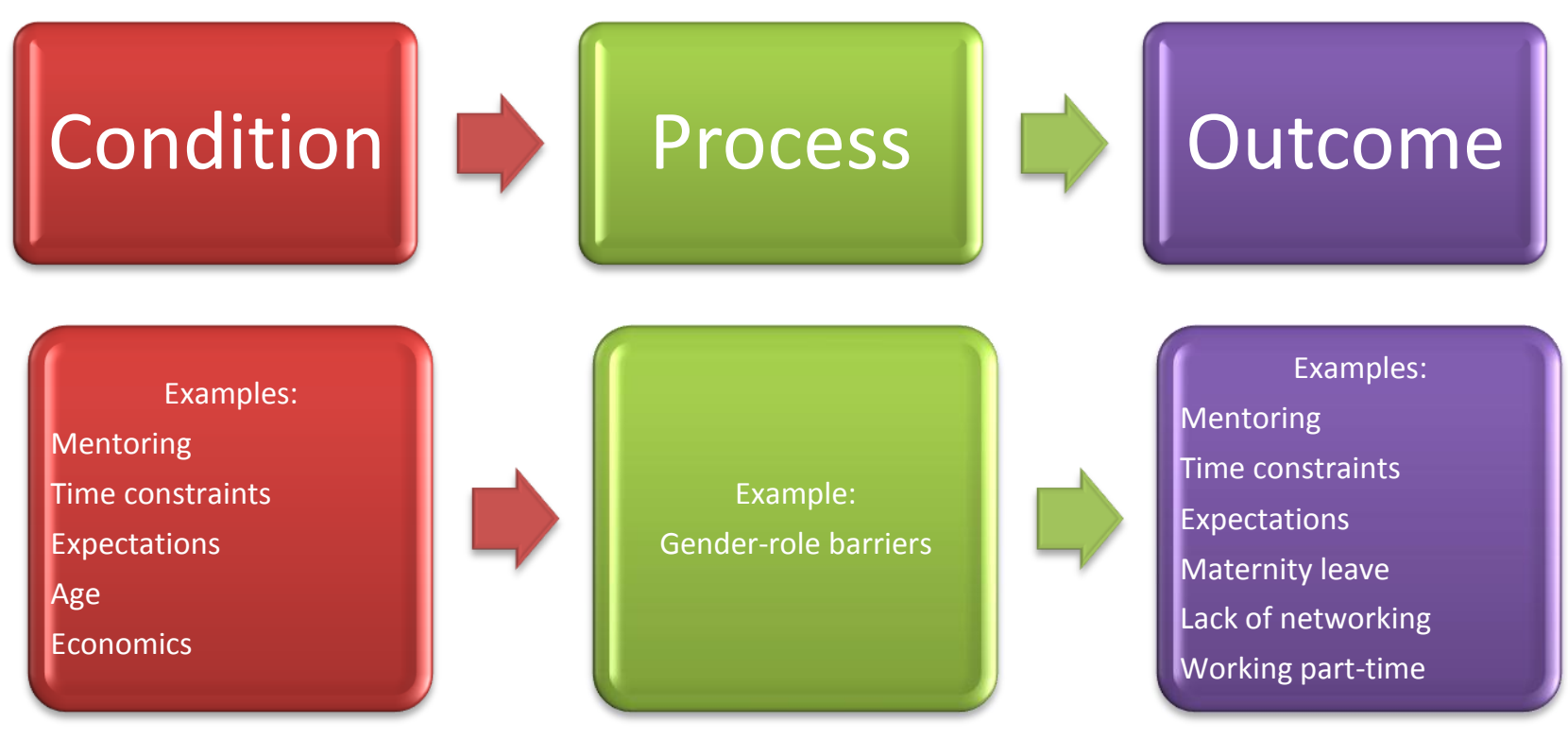

This discussion starts with a description of the various categories that developed from the data, and the causal linkages associated with each category. The emergence of each category (shown as rectangular boxes), as well as the causal linkages (shown as arrows) are supported by representative quotes based on the same theme. 
In this chapter, the essence of this discussion is driven by the fundamental finding that there are certain factors that act as "conditions" that cause gender-role barriers for women. Additionally, there are other factors that are "outcomes" of the gender-role barriers women face in the field. In this dissertation, the "process" refers to the genderrole barriers faced by women in the study. Both the "conditions" and "outcomes" have several themes that are self-reported as such gender-role barriers for women.

\section{Description of the Condition-Process-Outcome Theoretical Framework}

The following discussion explains each component of this theoretical framework.

Condition. In discussing gender-role barriers, there are several conditions that are instrumental in facilitating such barriers. These factors have been described based on data from this study, and have been supported by quotations.

Mentoring barriers. This is the most widely reported barrier, where female participants discussed various situations where their mentors, advisors, or departmental chairs were not supportive of their decision to start a family. The examples are discussed below.

The first example relates to lack of support. A female participant describes the culture of the institution where the principal investigator was not very supportive of students having children. There was an underlying perception that women with children will no longer take their research seriously, because of additional family responsibilities. Being a result-driven field, most mentors (including some women mentors) primarily focused on research, data collection, and paper publishing. This often created a conflict of interest between advisors and female students who have or have considered having children. Age compounds the problem somewhat, because by the time women have 
completed graduate studies and postdoctoral training and become professors, they are at the advanced maternal age, facing the prospect of high-risk pregnancies. For the same reason, some female PIs choose not to have kids, and expect the same from their students, according to the interviewee.

"There's still an underlying pressure I see as a female, to not have children or to postpone it ... I've heard PIs say some things, like, "Can't you just come to the lab and you can leave the kid in the conference room?" ... inherent in the profession is that it's not very female friendly. Even though the incoming classes of this institution are a majority female, it still is something that is an issue, even for the female PIs. They're not always supportive, because they're as just on their missions as anyone else." (Postdoctoral fellow, Black, $\mathrm{PhD}, 37$ years)

The second example is related to seeking women mentors. There is a gender gap in the profession, compounded by the fact that there are not many women in leadership positions. As a result, it is very hard to find women mentors. Most women are too busy juggling work and family life and, as a result, there is no time to mentor young female mentees. The interviewee attributes this as one of the possible causes of female attrition in the program.

"All of my best mentors except for one person have all been men, which I think really speaks to the gender gap. We don't have enough women in academic medicine and in positions of leadership. I definitely didn't find many who were mentors, and the women who are, many of them are either too busy, too overloaded, or just trying so hard to balance family and work that it's very hard for them to also mentor young women. I think that may be part of why so many of my female classmates dropped out." (Student, Asian, $9^{\text {th }}$ year MSTP, 30 years)

The third example is related to seeking advice from female mentors and role models in the field. The interviewee discussed the dearth of women mentors in the field. Further, there is a dearth of good advice about how females can prepare themselves to have children, as well as balance it with their scientific lives. Female professors in career panels often discussed the issues of balancing work and family life, and said that they 
chose not to raise a family because of work. This was often deemed very discouraging and bad advice by the female students.

“There weren't many female role models. Just because I think that, by nature, like most academic professors, the majority are men. Then we would have these career panels. They'd purposely bring in female professors, so, you know, the females in the audience could get some kind of sense of how to balance family. They would say things like they actually chose not to have a family because of science. That it's just not possible to have children and be a scientist. ... it scared all the rest of us that we started doubting everything. They just, they want people, I felt, that had balanced family and work well enough. Then they would give us awful advice. ... I don't think there's any good preparation for females on when to have children and how to balance it with your scientific life." (Non-scientist, White, $\mathrm{PhD}, 34$ years)

The fourth example is related to a male advisor's attitude. The female interviewee discussed her advisor's views as a barrier. When she got married in the second year of her graduate school, her advisor gave her unsolicited advice not to get pregnant. She did not feel open to discussing anything other than science with her advisor.

"I got married when I was two years into graduate school, and my advisor called me into his office to say to me, "I understand that you're getting married," ... "Well, now would not be a good time to get pregnant," ... What I missed, the difference is that I did not feel open to discuss anything other than science with my advisor." (Faculty, Black, $\mathrm{PhD}, 59$ years)

Time constraints. Next to mentorship barriers for females striving to balance work and family life, time constraints are the next most reported barrier. In this example, a female participant reported such time constraints, as she struggled to maintain a work/life balance. This example is related to the length of the program, and the participant described how the program spanning several years was a barrier to her desire to start a family.

"I guess the biggest barrier is just the time it takes to complete this program. I'm taking a year longer than the average MSTP students to compete the program. ... I've spent an extra year in lab, so I'll finish in nine (years). Having been married since college, the main barrier for me now is trying to figure out when to start a 
family. Since there are no natural breaks in the training process, that's basically been the biggest problem that I face is to figure out when to have kids. ... it's difficult to remain in the program full-time when you have small children. ... it's still in our society most of the childcare burdens do fall on women." (Student, Mixed race, $7^{\text {th }}$ year MSTP, 29 years)

Expectations. The next most frequently reported gender-role barrier was dealing with expectations, where females reported struggling due to set expectations. This example relates to societal expectations for women to have children.

"The only thing I've faced as a barrier is, I think, as a woman going into this program, people do question you. ... When you're a woman trying to go into that field and I am an investment. People are paying money for me to come here. They wonder about their investment in women. There's a societal pressure for women to have babies and stay at home. Even if you don't have babies and you don't stay at home, you still have to have the babies. I don't think it is socially acceptable to say I don't want babies. ...

I told one of my friends that I wanted to have kids but I didn't want to stay home with them, and I wanted a husband who did, they just looked at me, right, they're like, no, you don't. I think that the gender roles thing definitely, I don't know if they use it to admit people, but I think it can definitely be a barrier in the way that people treat you." (Student, White, $1^{\text {st }}$ year MD, 24 years)

Institutional barriers. Dealing with institutional as well as departmental barriers is another very frequently reported gender-role barrier treated as a condition. The first example relates to the institutional climate. In this example, the female participant described how her institutional climate that focused equally on research and clinical training, was a barrier to her working part-time.

"Yeah, there's not a lot of us (working part-time). There's a few. [Name of school] is very a research oriented institution and yet it's one of the biggest hospitals in the country and they need people to do the clinical work. ... The pressure to do research is huge and yet all the clinical work has to happen." (Faculty, White, MD/PhD, 39 years)

The second example relates to departmental barriers. In this example, the female participant described her departmental culture, where it was explicitly stated to female students that having a baby would affect one's career. This often caused anxiety and 
intimidation.

"But there was definitely the women faculty at that time, almost none of them had families and we were actively told that that would be a detriment to our careers. I think that was a hurdle to overcome. ... I think everybody was hearing that message (about having a family), but I think it affected me and the other women scientists a lot more." (Scientist, White, PhD, 33 years)

The third example relates to being discouraged from pursuing a particular

specialty. In this example, the female participant described how the work culture in the

field of surgery is so intense that it discourages women who want to raise a family.

"I thoroughly think that the current generation has a greater family life expectation and I think the compromise in that was more obvious say 20 years ago than now. I think females in surgery expect to have a balanced life and I think some of them are more likely gearing away from surgery because they want to have a life. They want to have family, they want to have children and if that choice of career is going to decrease the opportunity for that there is it seems to be a little bit more of a back away." (Scientist, Black, MD, 56 years)

Age. Age is viewed as another barrier for females striving to balance work and

family life. The first example relates to delayed pregnancy.

"You always know that gender's a barrier in surgery, being pregnant is a barrier. I have to say that I actually delayed my pregnancy. I'm 45 and I'm having my first child. It may be a barrier that occurred, but definitely something that I was thoughtful of where did I want to be in my career when I had my first child." (Faculty, Black, MD, 45 years)

The second example relates to delaying pregnancy until finishing school.

"I think it's more of a barrier for women than it is for men, because if you postpone having kids until you're done with residency, which I don't think is a way to go, personally, then you are 35 by the time you technically finish school. If you want to do that and have kids, that really is a time crunch. There's already a time crunch for women doctors as it is." (Student, White, $4^{\text {th }}$ year MD in $\mathrm{MD} / \mathrm{PhD}, 25$ years)

Work and family life balance. Balancing work and family life is a barrier reported by female participants. The following example illustrates this:

"It is a difficult balance, to balance career and family. That is challenging, and 
the barriers of how you actually make yourself happy with that balance and not feel guilty all the time. Between, you know, the time you spend at work, inevitably conflicts with the time that you want to spend with your family. And the time you wanted to spend with your family can conflict with stuff that you need to get done at work. I always associate balance as a myth. I don't know how you achieve balance. I mean, that is a barrier or a difficulty." (Faculty, Black, $\mathrm{MD}, 51$ years)

Economic barriers. Two female participants discussed some form of economic consideration that was a barrier for their gender-role as caregivers for children. Their responses are documented below.

"I guess the one thing that it has made me seriously consider is whether or not I want to try to stay in academics when I'm done with my postdoc here or just get a job in industry. The main reason for that is just the paycheck, because with what you make on a postdoctoral salary, 50 percent of my income is going to go to childcare. If we have a second child, then 100 percent of my income goes to childcare and then it becomes a question of is it worth it for me to be working and putting all of my paycheck into daycare for two children or would we better off with me not working and me being the caretaker? There's some financial reasons for that ..." (Postdoctoral fellow, Asian, $\mathrm{PhD}, 31$ years)

"I know that at some point, what's gonna happen most likely is that I'm gonna have a child in the middle of my training. Then I'm gonna find real financial strain. I'm married, and it's okay for us to be okay like with the salary right now. That's not a salary to support a family for sure. Although, right now I'm not experiencing the real strain, I know that if I decide to have a family, I would definitely feel it. The decision of having a family, I think, is something that really, really affects the woman." (Student, Hispanic, $5^{\text {th }}$ year MSTP, 32 years)

Timing. A female participant discussed her experiences with going through a

dilemma about when to time a child during her $\mathrm{MD} / \mathrm{PhD} /$ residency cycle.

"That's a big issue for women I think, going through $\mathrm{MD} / \mathrm{PhD}$ programs, is when do you take the time out? Do you take it during your $\mathrm{PhD}$ and then you prolong your PhD while the clock is ticking? You can't really do it when you're in the MD program cuz that's so short anyway, and things tend to run on a very regimented cycle there. Then you're into residency, which is, I believe, three years, and then you're well into your 30s and trying to establish yourself in practice, and when do you do it? ... I think that's what the system has built for folks to go straight through without taking that kind of break. If you take that kind of break you very much run the risk of being punished for it." (Non-scientist, White, MD, 45 years) 
Promotion barriers. In discussing gender-role barriers, women in academic medicine reported struggling with promotion and seeking leadership positions, facing discrimination despite having the same abilities and reaching the same professional milestones as their male colleagues. This is mirrored by a female graduate in this study who reported the following.

"I think for women in academia the issue is always level of promotion. ... I think for barriers it was more or less acceptance by colleagues in terms of level of ability. It just seemed like no matter how good you were, you didn't get that recognition as your male counterpart would get. ... I think most women in surgery at that time struggled with equal levels of being promoted through academia as our male counterparts seemed to excel. That became quite a visible issue across the board, too, in terms of looking at women who were at the level of associate professor - our professorship was very minimal while your colleagues who entered and trained with you and at the same (time) and did the same amount of work seemed to move ahead in their promotion level. I think that's still trying to break that glass ceiling. It was a barrier for me, yes." (Scientist, Black, MD, 56 years)

In vocalizing worries about career issues, one female participant discussed the

following:

"I didn't see how you could do that (have kids) and maintain a tenure track position. The women who are in the department I was in, I would never wanna be them. ... going home when the kids are sick or dealing with that is very different from taking as much as three months out of your career. ... For someone who's constantly planning for her career like I am, the prospect of having kids is worrisome in terms of how that's gonna affect my ability to continue earning at the level I should be earning at. I think it's really difficult for women in all fields. I just don't think there's the support. I don't think it's because there aren't enough female graduate students. ... These are conversations that graduate school would have panels of female professors talk about work/life balance, talk about how they did it. It all just seemed miserable the way they did it. Nannies are raising your kids all the time, coming into lab meetings two days after giving birth, all sorts of crazy situations, which there's no expectation to do that, but they believed that if they didn't they would suffer career wise." (Non-scientist, Black, PhD, 32 years)

Barriers related to pursuing a family. In discussions about nurturing personal 
relationships, a female faculty member describes her experiences living through divorce,

remarriage, childlessness, not being able to spend time with extended family, and

sacrificing personal relationships, because her work kept her too busy to be able to pursue these relationships.

"I do feel like I've had to sacrifice a lot on the personal level. I was married when I entered the $\mathrm{MD} / \mathrm{PhD}$ program and it didn't last. My husband wanted a wife and I was too busy to be a wife. He actually gave me the choice that either I had to quit the MSTP or he couldn't stay married to me. I'm divorced and I do worry that one day I'm gonna look back on all these years. I'm almost 40. I do not have kids. I am recently remarried but my new husband is also struggling, which is causing a lot of stress in our relationship. Just because I'm not home and when I'm home I have to work. Cuz I don't have enough time really in the day to get my work done at the hospital. ... it's been difficult for me because I'm getting further and further behind because I have to also nurture my personal relationships. As far as with my extended family I almost never get to see them or even talk on the phone to them. Because I'm working. I think in order to at least continue to pursue it, you really do have to give up a lot on a personal level." (Faculty, White, MSTP, 38 years)

Process. In this dissertation, process refers to the phenomena under study, which is gender-role barriers faced by women in the specific field. The category of "process" lies at the center of this theoretical framework, flanked by conditions and outcomes on each side. While "conditions" refer to the set of factors that influence "process", "outcomes" refers to the set of factors that are influenced by "process".

Outcomes. In this theoretical framework, the category on the right most corner is known as "outcomes", which refers to the set of factors that are influenced by "process". These factors are discussed as follows:

Mentoring barriers. As indicated previously, barriers faced as a result of poor mentoring from mentors, advisors, and departmental chairs, were most frequently reported. In relation to the "outcome" component of gender-related barriers, these participants recounted events where they had to personally face mentoring barriers as a 
result of their childbearing and childrearing decisions.

The first example of outcomes is related to mentoring and seeking maternity

leave. The interviewee talks about the prevalent perception of maternity leave as a part of vacation time.

"I have a two and a half year old. If I think about gender being a barrier, I think definitely one is having children during the program. It's being specifically female. When I originally approached my boss about taking maternity leave, he asked me, "Oh, how long do you want?" Then it's like, "Oh, well then you're not going to take vacation, I guess." It was assumed that maternity leave was part of vacation. I think that was definitely a barrier. I took an extra year in the $\mathrm{PhD}$ because I had a baby ...." (Student, Hispanic, $8^{\text {th }}$ year MSTP, 32 years)

The second example is related to a lack of support from the department

chair. A female interviewee reported that she got a lot of attitude from males in the department. The chair of her department told her that he did not think women belonged in science, and that women with children should not work.

"Having children can slow you down. They're part of life. I was so glad when I was remarried and had a chance to adopt three kids. ... Attitude in the situation I was in, which was a very typical attitude for men at that time, was not so good. Also, the chair of the department that I did my graduate training told me he didn't think women belonged in science. He also wanted to know what kind of birth control I was using, and women with children shouldn't be working." (Faculty, White, $\mathrm{PhD}, 64$ years)

Time constraints. After mentoring barriers, time constraints for women striving to balance work and family life were most widely reported. The first example relates to time constraints for family. With the changing landscape of social, family and work life for women, women struggle to spend more time with children. In this example of a twophysician family, the interviewee reported sharing the primary responsibilities at home, while balancing her work.

"It gets harder and harder just to kind of maintain what I consider to be the traditional family structured evenings and days. ... I feel like in some ways I'm 
little, tiny failures to my children, those games that I can't go to because I'm working or the evenings where I have a deadline and I don't spend quite as much time with them as I'd like to." (Faculty, Hispanic, MD, 42 years)

The next example relates to tenure clock. The interviewee described how running on the tenure clock is a major barrier for young parents. There is some discussion about the potential supports that could be provided (like on-site childcare services), but she does not indicate if her institution provided it.

"In my experience, the biggest barriers are just trying to figure out how to succeed academically while raising a family. Trying to have a successful scientific or academic career, it's hard to do that part-time. There's a tenure clock ... It's still very challenging. Some people just have to decide that they're either not going to be on the tenure-track or they may have to choose something else. I think that that is a huge barrier in trying to help young parents succeed. There's been eternal discussion about how to help, from providing on-site childcare, to getting concierge services to buy your groceries and get your car fixed for you while you're working." (Faculty, Asian, MSTP, 45 years)

There was another discussion related to external responsibilities. One faculty

member discussed how accumulating external responsibilities was a major barrier to not spending enough time with her children.

"I think that's the key is, that once you start accumulating external responsibilities such as family, children, then suddenly your time is not limitless like it had been before. Quite frankly, now as a faculty member every weekend is, "Well, I could get some work done or I'm going to miss my son's soccer game again." (Faculty, Hispanic, MD, 42 years)

Additionally, one interviewee related not being able to spend enough time with her children. In this example of a two-physician family with a busy spouse, the female participant discusses her time barriers because she has to shoulder most of the family responsibilities while trying to juggle work.

"I think for most people if you're a woman and you have kids, you generally have more responsibility to getting the kids cared for and take them where they need to go and run the house. ... Not that I wanted to give it up, you know? I value my time with my kids ... but I know that I cannot be as quote unquote productive, if you will, as somebody who's single or somebody who has no kids. There's only 
the same amount of hours in a day for me as for them and I have other things to do when I come home at night. It is a barrier. I have three kids. I also have a husband who's an interventional cardiologist, so he is really busy. He does call and when he's on-call for the weekend he's gone." (Faculty, White, MD, 47 years)

Expectations. Dealing with set expectations from workplace, family and society was another frequently reported gender-role barrier. The first example relates to set expectations of females caring for children despite having a husband. The female participant described how, at her workplace, she saw that the males had to shoulder lesser responsibilities at home, and could focus more on work. However, she feels that it is expected of her to balance her work with family responsibilities, and that is why she works part-time.

"The only barrier I feel now, as I get older is just being a female. I think it even actually is much harder than being a male scientist. ... A lot of it had to do with having children because I want to take care of them. ... I work from home part of the time, just so I can be around to pick up the kids from pre-school, and drop everybody off, and make sure everybody's okay. I feel like that's my job. Even though my husband is wonderful, I still feel like that's my job because that's my female role in the family. ... no one expects them (her male colleagues) to stay home or take care of the kids, to drop them off, or take them to the doctor. Like that's not expected of them, but that's expected of me. It makes it much harder." (Non-scientist, White, $\mathrm{PhD}, 34$ years)

The next example relates to family expectations being tied to cultural values and poverty. In describing cultural values from a different country and economic strata, this female participant describes her barriers because her family did not understand much about her profession. There was an underlying expectation of diverting focus from career and raising a family eventually. This she attributes to the fact that the cultural values are different, and she hailed from a background that was not affluent. Her family did not have exposure to the professional culture in her field.

"They (my family) understand very little. In my country, it is not a career that is 
an option for people. ... They don't understand why I would give up a potential financial reward over doing research. Why give up surgery to do research and why it is that I cannot be with them more often or why I have to work on the weekends and why I am not having babies. In my culture, the family values, doing a lot of things for your family is valued a lot. It's hard to be career-minded in a situation like that. I try to explain to them how it works, but I don't think it connects to them. I think in my case it's a little different, because I don't come from a privileged background. My family is very poor, and we've never had like a lot of means. There's not a lot of professionals. There's no doctors." (Student, Hispanic, $5^{\text {th }}$ year MSTP, 32 years)

Additionally, a participant recounted her experience with the classical

expectations of roles within the family. In this example of a two-physician family, this

female participant shoulders the majority of family responsibilities, because her husband has more patient care duties while she focuses more on research.

"One of the issues that comes up in terms of barriers for women is the classical expectation of roles within the family, and how do we deal with that. Part of it is the career. Although my husband and I are both physicians, I do primarily research, which means my schedule is often a little bit more flexible than his. Much of what I can do I can do at home in the evenings, on the weekends from the road. He has more patient care, so he has clinic three times a week and patients he needs to see in the hospital. If there is a sick child it's usually me that stays home. If there's a doctor's appointment it's usually me that takes them. If somebody has to leave early to take a child to soccer practice or basketball it's usually me, that kind of thing." (Faculty, Hispanic, MD, 42 years)

Institutional and departmental barriers. The next frequently reported barrier is

facing institutional and departmental barriers. Particularly, this example relates to institutional perception, where the participant described the disparity in institutional perception of childcare responsibilities between genders as a barrier.

"If you already have children, heaven forbid your kid gets sick and good luck getting a sympathetic ear. I was in residency, and one of the guys was taking off out of the midday of call. He asked someone to come in and cover for him for four hours because his kid had a Little League championship. Everybody was talking about what a great dad he was for doing that. I'm thinking, yeah, he's a great dad. You realize if it were a mom taking off - (Right, then it just would not be viewed the same way, by any stretch.) No, she doesn't value her career. She's not taking her obligations seriously. Yeah, that's a barrier." (Non-scientist, White, 
$\mathrm{MD}, 45$ years)

Age. Age is another barrier for females striving to balance work and family life.

This example relates to age and geographic mobility.

"The other barrier that I had is, since I was older and I had family, those were factors that determined where I could go and what kind of work I could do as well." (Faculty, Black, $\mathrm{PhD}, 58$ years)

Work and family life balance. Balancing work and family life is a barrier faced

as an outcome to gender-role barriers. Responses from participants are provided.

"For me, having a family was an obstacle ... I wanted a family young and so figuring out how to have a family and be part of the program has been challenging and at times frustrating, when I have to stay home with a sick kid or I can't stay the extra hours and work in the lab 12 hours a day. Things take a little bit longer or I have to get help from somebody in the lab to finish something for me, so balance has, I guess, been something that's been a little bit challenging for me." (Student, White, $7^{\text {th }}$ year $\mathrm{MD} / \mathrm{PhD}, 29$ years)

"I really felt like I could do well as a clinician in pathology yet still have time to do a research career. One of the things that did also occur to me was I knew that I wanted to have a family and I wanted to be able to do that and do the other things also. ... Without having family in the area to back me up on childcare and things like that. I would think that if you're the primary caregiver there would be potentially some barriers and there probably still are that some people feel like if you have to leave and go get your sick kid from school or something like that, you're not being as committed as someone who doesn't have to do that." (Faculty, White, MSTP, 49 years)

Maternity leave. Not being able to seek or utilize maternity leave, and the

perception of the institution around maternity leave, are some of the barriers three female participants reported struggling with. Their responses are described below.

The first example relates to women shortening their time for medical leave.

"There is a strong paternalistic streak in my department and it drives me crazy ... We're also at the age where women are having their families and I think because we're shorthanded on the clinical side, the women minimize the time that they take for medical leave, which is not necessarily in their best interest. I mean we're not a big group but we're about half women but if you have to look at the age distribution, the women are the younger ones in the department. We're more of 
the junior faculty." (Faculty, White, MSTP, 44 years)

The second example relates to unrecognized maternity leave.

"That's always going be a problem when you've got the clock ticking and there's an $\mathrm{MD} / \mathrm{PhD}$ timeline that's got to be met. ... barrier for me in residency. My residency director says, well, you're pregnant. Congratulations. You know you get two weeks of vacation a year, right? ... I was only the second woman to really push that with the residency director." (Non-scientist, White, MD, 45 years)

The third example relates to maternity leave.

"I guess if I think about gender being a barrier, I think definitely one is having children during the program. It's being specifically female. When I originally approached my boss about taking maternity leave, he asked me, "Oh how long do you want?" Then it's like, "Oh, well then you're not gonna take vacation, I guess." I mean it was assumed that maternity leave was part of vacation. I think that was definitely a barrier. ... my boss wasn't thrilled by the idea of me taking maternity leave at all. ... he wanted me to confirm with the director of the graduate school how many weeks I actually did get. I sat down with him and discussed it. It was a very awkward formal meeting about it. I felt that it shouldn't be." (Student, Hispanic, $8^{\text {th }}$ year MSTP, 32 years)

Losing work productivity. Two female faculty members reported losing work

productivity as a barrier, as they struggled to achieve the work/life balance and take care

of children at home. Although there is a working spouse in the same profession, one of

the female participants reported shouldering a majority of the responsibilities at home.

"I know that I cannot be as quote unquote productive, if you will, as somebody who's single or somebody who has no kids or, you know? There's only the same amount of hours in a day for me as for them and I have other things to do when I come home at night. It is a barrier. I have three kids." (Faculty, White, MD, 47 years)

"Many people lose productivity with a pregnancy and an infant. I think that, you know, it's very competitive. People need to be highly productive ... I just very much encourage people to not overly focus on achievement, their professional achievement and to look more at the balance of their lives." (Faculty, Hispanic, $\mathrm{MD}, 50$ years)

Support from spouse. Two female faculty participants indicated that they faced barriers to balancing their professional and family lives due to their gender-roles. In both 
cases, although they had support from their spouses, they were expected to shoulder the majority of family responsibilities. Further, in the second example, her spouse (despite being a stay at home father) did not provide her with much flexibility to pursue her professional interests beyond work hours, for example, evening seminars, conferences, and weekend engagements.

"I still think that among my peers the women still take care of far more of the child-related issues than their spouses do. Even though my spouse does a lot, definitely during a lot of the crucial, earlier years when I was young faculty, I was still taking on the brunt of figuring out the whole home front situation. I still had to be on top of everything." (Faculty, White, MSTP, 46 years)

"My husband is a stay at home dad - there are some definite times where, for example if there's a seminar in the evening. He questions do you really have to do that because you're there ten hours a day. Why do you have to stay there until 7:00 tonight, I'm like because it's important to be seen at these things because people are there or I want to get to know other faculty across campus because I only see science faculty. Whatever reason, but I definitely feel like I have to ask permission and God forbid something is on the weekend. It's like, oh, yeah, big time permission for that or going to a conference is so much harder now. ... Last summer I went to two conferences and every day for a while my husband's like do you really have to go to those?" (Faculty, Black, PhD, 34 years)

Lack of networking opportunities. Two female graduates discussed barriers

associated with not being able to network adequately in the field. These barriers arose

when women tried balancing their family responsibilities with work.

"For instance, it's on a weekend, the biology department retreat. It is much easier for a guy to leave his kids and his wife for the weekend and go ... It is much harder for a woman to do that. ... Having talks at 4 p.m. when day care ends sometimes at 4 p.m. makes it hard for women to be there. It's not like they have to be there for their work, but they do have to be there for the networking and the schmoozing and the jokes and the drinking. ... This makes life harder for women specifically. ... There is so much political networking involved, going out for drinks with the guys, playing soccer, playing golf, things that as a woman it's harder to network. ... The networking is so much part of making your career here." (Postdoctoral researcher, White, $\mathrm{PhD}, 35$ years)

"For a lot of females in surgery I think it would have been helpful to be able to know about organizations or opportunities to link with other females so that you 
don't feel like you are going through the challenges alone and it wasn't until you speak to someone else who is facing the same issue that you realize that well, it's not just me, I'm not crazy. I think that having those alliances would have been helpful." (Scientist, Black, MD, 56 years)

Timing. Two female participants discussed their experiences with having a child in school and not knowing when to time having a child. In one example, the participant described how she dealt with the barrier of having a child when in school.

"Now that I'm in school I have dealt with the barrier of having a child while in school. It was. Running to code blues while I was eight months pregnant was super-awesome! I think that it was an experience that truly made me stronger for having done, to know how much I can truly do." (Student, Mixed race, $4^{\text {th }}$ year $\mathrm{MD}, 25$ years)

Seeking promotion. One female faculty reported issues with seeking leadership positions, as well as getting promotion, as a barrier as she struggled to achieve the work/life balance and take care of children at home. This female participant discussed her perceptions of why so few women compete for decanal positions and other leadership positions in medical institutions. In most institutions, one needs to be a full professor to assume deanships. Additionally, the number of female full professors is low in most of these institutions. This is an example of a long-term impact of gender-role barriers in women.

"In many of the institutions you really do need to be at the full professor level to assume the deanships. If you look at the percentage of women that are at full professor level, it's low. ... the ability to lead has nothing to do with whether you're a full professor or not. ... if that's the ticket that you have to have, it automatically knocks out a number of women. ... If you have kids, or you have parents, or other duties that take you off that upward trajectory, sometimes it's hard to get back on that." (Faculty, Black, MD, 51 years)

Specialty selection. In discussing the issues of raising a child irrespective of specialty, one female participant discussed the following.

"I don't think it's any different in emergency medicine than it is in medicine in 
general. I've kind of mentioned how there's always an issue of deciding when you're going to have children, and being concerned about balancing your family's life with everything that you need to do academically. I don't think that's any worse in emergency medicine; in some ways, it might be slightly better, because it's a lot of shift work, so you're not on call a lot. Although shift work is kind of hard because it disrupts sleep schedules, even in your family, so there's that. I don't think it's a lot different than other areas of medicine, though." (Faculty, White, MSTP, 34 years)

Academic stress. In discussing academic stress of balancing work and family life,

one female participant discussed the following.

"I think an academic career is extremely stressful. I think that it is a very difficult way to balance family and work. I think that there are many ways in which the academic world is very petty and sort of status-seeking and non-collaborative and self-defeating and I don't like any of those things." (Faculty, Hispanic, MD, 50 years)

Missed opportunities. In discussing missed opportunities, one female participant discussed the following.

"I think the big barrier at some point that really became when I got pregnant that ... when I met with this faculty who was doing mosquito research and he was an MD and had lots of clinical work in the field, it would've involved me being in Egypt a couple months out of the year and I was like, "Oh, yeah, by the way, I'm pregnant," (Faculty, White, MD/PhD, 39 years)

Working part-time. In discussing working part-time, one female participant

discussed the following.

"Being part-time is a huge barrier to get any access to research time... I was part-time as a fellow and I had the time to do research and I was given the opportunity to do more research and I couldn't balance that in the clinical responsibilities that were given to me. Because when you're part-time, my funding is for the clinical work I do, not research. I had to do clinical work, but that left no time to do research, no time to get additional training that I was told I needed to do research. Then ultimately financially it would've been an incredible hit to try and do more and research, 'cause it basically would not have been compensated time. I think my family obligations and my desire to work parttime put me in that situation. Certainly being part-time didn't give me a lot of support to span out." (Faculty, White, MD/PhD, 39 years)

Program culture. In discussing the difference in the MD program culture, one 
female participant perceived the program as being less flexible, with less peer support and long work hours.

"It's also really hard to be so much older than your classmates. So many of them are in their early 20s. They go out and get drunk every weekend, whereas I spend my spare time giving my kid baths and putting him to bed.... I'm older than they are, and this is not uncommon. I think of my classmates in the MD-PhD program, a third of us had children during training; ... We're just in a different place in our lives, and you don't really feel like a part of your peer group, so that was hard. You feel more like a peer with the residents and the attending, but they don't view you as a peer, so it's like you just don't have any place. I think all of that made it hard. Then the work hours just were brutal. I started on OB/GYN. There's also a culture shock where medicine is very hierarchical, especially here ... you have to ask permission to do things like go to the bathroom, whereas in $\mathrm{PhD}$ land, your faculty encourage you to call them by first name. I'm just saying it's indicative of the culture." (Student, Asian, $9^{\text {th }}$ year MSTP, 30 years)

\section{Concluding Remarks}

There are several factors contributing to processes and outcomes in the proposed theoretical framework. Interestingly, there are far more factors in the outcome component than there are in the condition component. Additionally, there are certain contributing factors that are categorized both as a condition and as an outcome, depending on how they are reported in this study. Some examples include mentor barriers, time barriers, expectations, institutional barriers, age, work/life balance, timing and promotion. For example, lack of mentoring or poor mentoring can contribute to women delaying pursuing their gender-role responsibilities of childbearing and raising a family (condition). Additionally, raising a family can prevent someone from seeking out mentoring resources (outcome). This distinction is especially important for designing institutional interventions and policies, where we tend to focus more on the symptoms and not on the sources. The findings of this study indicate that addressing sources of barriers is as important as the symptoms of barriers, and while they might sometimes be 
the same factors, they may become a condition or an outcome depending on when women face these barriers in their careers.

This further sheds light on the importance of temporal intervention. The findings indicate that administering interventions for gender-role support (process) after facing the barrier is important, but that what is equally important is designing interventions for gender-role support before the barrier arises. Since there are many overlapping components of barriers, it would be useful to study the same barrier from a temporal perspective (that is, whether it contributes to gender-role barrier, or whether it is a result of a gender-role barrier). 


\section{Section 3: Strategies to Overcome Gender-role Barriers}

Based on the data collected from this study, 24 participants discussed strategies to work around gender-role barriers, which are categorized into three levels of interventions: individual level, family level, and institutional level.

\section{Individual Level Interventions}

Hiring outside help. Hiring sitters to share some of the responsibilities of child care is an effective way to balance work with parental responsibilities. Existing research literature, as well as data from this dissertation, supports this.

"We've tried really hard to build up a nice group of sitters, people that we trust to pick up our kids and haul them around town.” (Faculty, Hispanic, MD, 42 years)

Timing a late PhD. As opposed to timing children late in life, one female participant started her PhD at the advanced age of 44 years, to ensure that the children had grown up.

"I came (to a new area) by myself. Both my daughters graduated from college, and they're on their own now. The timing was very important for me. When I did come here my youngest daughter she was a senior in college, but her dad is still there. All my family's there so she had support. ... I couldn't (start graduate school early) because my kids were young." (Postdoctoral fellow, Mixed race, PhD, 52 years)

\section{Not delaying having children.}

"I do think that there is never a good time to have a child and women should go ahead and have a child if they feel that it's important for them to be biological mothers ... Do it as soon as they possibly can. As soon as they're out of residency despite the fact that it will undoubtedly hurt their careers and that there really is no good time. Many people lose productivity with a pregnancy and an infant. ... but I think that that's okay. ... I just very much encourage people to not overly focus on their professional achievement and look more at the balance of their lives." (Faculty, Hispanic, MD, 50 years) 


\section{Forming a support system.}

"You know, sometimes we want to do it all and not accept help, but you've got to have a really good support system around you, particularly personally." (Faculty, Black, MD, 51 years)

\section{Family Level Interventions}

Help from spouse. One female participant described that it is very helpful when a spouse can work from home and is able to take care of children. In this study, while we see that while females from two-physician families shoulder the majority of responsibilities of family, sometimes spouses working in different fields have more flexibility in terms of work hours.

"I'm also lucky that my husband has been able to be reasonably flexible; he does not travel a lot. In the last two years he's been working from home, which has just been amazingly useful for me. I stopped having to coordinate where everybody had to be when he started doing it. ... We've had plenty of challenges in terms of after-school care." (Faculty, White, MSTP, 46 years)

\section{Institutional Level Interventions}

Support from mentors, advisors, and role models. Of all the strategies of balancing work and family life discussed in this dissertation, seeking support from mentors, advisors, and role models was the most widely recommended strategy to overcome gender-role barriers. Ten females discussed several examples of how seeking support from mentors and advisors, both male and female, helped them in succeeding in their professional life while caring for a family. There are several examples of how having effective women advisors, mentors, and role models is beneficial to success in the field. 
"Having women advisers and mentors has been very helpful because you're able to see how they're able to balance what they do with their family. I wish they would give some seminars on that." (Student, Black, $7^{\text {th }}$ year $\mathrm{MD} / \mathrm{PhD}, 27$ years)

"I still have relatively young children, early 20's. ... When I was a post-doc there was a senior woman scientist doing a senior fellowship, she had influence on me. She was a good mentor in the beginning of my career and along the way.

Mentoring in the sense that she was a senior woman talking to me about steps she had taken. She had a family. I really viewed her positively as a role model."

(Faculty, White, $\mathrm{PhD}, 64$ years)

"I think that it's been important to have someone that recognizes that there are obstacles ... she's been helpful in terms of saying like these are the obstacles that I see and that you may need to think about ahead of time. Also, she's an excellent model of someone who has a life outside of work, which she has managed to kind of balance. It has allowed her to be a mother and a wife and a scientist, so you believe that it's possible." (Student, White, $4^{\text {th }}$ year MSTP, 29 years)

There is an example of how being matched with female mentors who have successfully balanced families is deemed beneficial.

"One of the people I'm thinking about working here with, we were talking about science and I was like, you know, I know you have kids ... we do need mentors. You do need to find a way to do it all. The other woman I've been matched with, she also has kids. Her husband stays home. He's a writer. The other woman, her husband's an MD-PhD. I think it is relevant that we at least have mentorship of women who do it all. I think the better way to approach the system is to say would you feel good about if we could provide some sort of service where you could have mentorship on how to do these kinds of things?" (Student, White, $1^{\text {st }}$ year MSTP, 22 years)

Further, there is a discussion on emulating a mentor as an example of a twophysician family. In this example, the interviewee describes that having a mentor who, himself, is balancing work and family life, makes one more empathetic to their students' struggles. The interviewee has received immense support from her mentor, who also belongs to a two-physician family and juggles family responsibilities with work. The interviewee feels supported, and believes that her adviser has advocated for her and has helped her further her career. 
“He's a good life mentor. Although he's a good 15 years ahead of me in many ways our lives are somewhat parallel. He's a two physician family just as my husband and I are. He has actually a son who's only a couple of years older than my kids are, so we often deal with the same life issues. ... I appreciate the fact that he's still in the game enough to realize that the meetings at 6:00 p.m. don't always work if I have to get the kids. He's very accommodating in that regard because he's still in the thick of having to pick up the kids from school ... He's a good life coach as far as how to maintain work/life balance and things like that. He's always advocated for my career advancement, always kind of fashioned opportunities for me to collaborate with other research groups, ... It's been a very, very good mentoring relationship." (Faculty, Hispanic, MD, 42 years)

Next, there is a discussion on the importance of an understanding adviser, who

does not micromanage and allows for flexibility of time for this particular interviewee,

who witnessed that her peers did not always have understanding advisers and the

expectation was to stay in the lab around the clock.

"I was very fortunate in my advisor's lab because what he would do is, "This is what I expect you to do. How you get it done is up to you." I tended to get in early. I would leave at a certain period of time because I had to get my children home. Then I would schedule my work so that I would have a good stopping point and get there early the next day. Family considerations did play a part. My advisor is very supportive in that respect because he had young children. I think that made a difference." (Faculty, Black, $\mathrm{PhD}, 58$ years)

Next, there is a discussion based on advice in finding good mentors.

"Find good mentors. Identify good mentors, and figure out what you need to succeed, and to go out there and find it. ... As a busy mom, spouse, administrator, physician, it's hard to put myself on the calendar. To even think about what I want and where I want to go with my career. I think that a mentor can really provide that for you, that direction, accountability, and questions, and thinking about what it is that you want." (Faculty, Asian, MSTP, 45 years)

Further, there is a lot of value in talking to and seeking advice from female mentors who have successfully balanced work and family. According to this interviewee, despite the advancement of women with time, they are restricted career-wise by family considerations and responsibilities. Talking to other women mentors about their experiences is very valuable in that respect. 
"In general surgery there aren't as many women practicing. Within the $\mathrm{MD} / \mathrm{PhD}$ population there are definitely even fewer women, and the training is really long. By the time I finish my training I'll probably be 38 or 39 , like when I get my first real job. It's important to talk to other people about how they approached, if they had to take time off for maternity leave and also how to sort of balance the career. Women are kind of known in research to sort of peak later in their careers because often early in their careers they're sort of establishing their families if they need to. I've talked to a lot of women about that, and that's been really helpful to have mentors who have been successful in the areas that I'm attracted to academically, but would be more difficult to approach logistically." (Student, White, $6^{\text {th }}$ year MSTP, 28 years)

Next, there is a discussion on the importance of pairing female mentors and mentees.

"I've also had several advising appointments with a female MSTP professor, who's given me advice about family planning and what not. Some of the MSTP programs pair female mentors with female students, you'd talk about the challenges of just women in science and trying to balance family life with research life. I believe that I was paired with one based on scheduling conflicts and what not because there was two or three lunch meetings that we ended up having as a small group with the female advisor." (Student, Mixed race, $7^{\text {th }}$ year MSTP, 29 years)

The discussion continues on to having an advisor as a model for emulating work-

life balance.

"I was lucky enough to have a graduate advisor who really did have a very balanced work-life relationship, and would leave work at a normal hour and would go home and spend time with his kids, and would be home on the weekends. ... As a man, he was putting his family first, and he set boundaries. ... he was right to do that, and he's still successful. But I do feel that the other women scientists who were associate professors or assistant professors were not given that same, picture. ... To be honest, they weren't very friendly women. But I definitely think it affected me and my fellow women scientists in training colleagues a lot because that's a time in your life where you're looking ahead and you're saying what should my life look like. Do I want to have children?" (Scientist, White, $\mathrm{PhD}, 33$ years)

Choosing a specialty based on family responsibilities. This strategy of choosing a specific branch of practice that allows one to spend more time with family is not uncommon. In this dissertation, four females indicated that their choice of specialty in 
medicine was based on their desire to prioritize their time with children, as well as strike

a better balance between professional and personal lives.

\section{Dermatology.}

"Once I had a family then of course I'm thinking about flexibility, and the schedule, and the time commitment, and all those things. Now my actual goal is to do dermatology, and trying to apply in a research track, dermatology program. ... It became a matter of finding an area in medicine that was gonna give me time with my family as well as giving me flexibility and stuff." (Student, Hispanic, $8^{\text {th }}$ year MSTP, 32 years)

\section{Clinical pathology.}

"One of the reasons I actually decided against doing pediatrics was that at that time they did every third night call. I was thinking about having a family and I knew that there would be no way I would be able to do that until after I was out of residency if I chose a residency like that. In the end I actually, by choosing pathology, I actually had both of my children ... I was able to balance the three of them because with pathology, there are things that you control your time just a little bit more than you do in some of the other specialties. ... I do think that I purposely chose a specialty where I felt like I could juggle everything." (Faculty, White, MSTP, 49 years)

\section{Pediatric hospital medicine.}

"Straight out of residency, you could have this job and do lots of different things in the hospital (without doing a fellowship). At the time, it was actually a great job as a mom of young children because there you can work a couple 16 hour shifts during the week, and then have time to be at home with your kids. You could work all night or you could work weekends. The way that it would balance out the rest of my life was interesting to me." (Faculty, Asian, MSTP, 45 years)

\section{Administration.}

"I never planned to go into the administrative part of things. I just picked my specialty because I knew I wanted to have a family. I didn't want a clinical specialty where I'd be up all night, a lot of call, where it would be difficult to balance a family and work." (Faculty, Black, MD, 51 years)

Choosing academia over medicine. The strategy of choosing to stay in academia versus choosing medical school is a strategy that allowed one to spend more time with family. In this dissertation, three females indicated that choosing academia over medicine 
was based on their decision to prioritize their time with children, as well as strike a better

balance between professional and personal lives.

\section{Flexibility to have a family.}

"One of the things I knew I wanted out of medicine is flexibility, and what I saw in academia would give me flexibility as well, because I knew I wanted, to ultimately have a family, ultimately have time to do other things. From what I saw, my friends in academia who were physicians had more balanced lives." (Faculty, White, MSTP, 34 years)

\section{Academia versus medical school.}

"Family is just the most important thing for me. Honestly, it's one decision against me going to a medical school versus a non-medical school, academia, is because I felt that if I wanted to have a family, that they would not be accepting of it." (Faculty, Black, $\mathrm{PhD}, 35$ years)

\section{Culture of medical school.}

"I interviewed at a medical school, and I could just really tell that was their attitude. Here, you ask them how many years to tenure, it's five or six is the common thing; medical school, it's like eight, and they really didn't define what tenure was. Eight years to tenure means you're not getting it at all. They really wanted me to produce a lot of stuff, all of these papers. I knew that I wanted to have a family. I'm 35, I can't wait any longer. I knew I wanted to have a family, so they'd be pretty pissed if I came here pregnant." (Faculty, Black, PhD, 35 years)

\section{Flexibility of staying longer in a PhD program with a child.}

"I had data and was going to graduate or finish my PhD and go back to medical school, but I got pregnant and just had a child 11 weeks ago. I have a year left on my funding, and after talking to my PhD mentor he encouraged me that it would probably be a better idea to stay in a lab with an infant. ... I talked to the head of our program and he agreed that it would probably be a better idea with an infant to do one more year of $\mathrm{PhD}$ and have a stronger $\mathrm{PhD}$ and then go back to medical school and not try to juggle my third year with an infant." (Student, White, $7^{\text {th }}$ year $\mathrm{MD} / \mathrm{PhD}, 29$ years)

\section{Choosing to work for people who value work/life balance. Choosing to work}

for an institution that has a reputation of supporting women in balancing work and family

life is an effective strategy to overcome gender-role barriers. In this dissertation, two 
interviewees discussed their choice of an institution based on how well they would be supported in raising a family.

\section{Choosing to work for people who valued work/life balance.}

"I am married and I have a family and there are definitely times when some of my peers were working much closer to $24 / 7$ than I was. I think I've been very lucky, mostly, to work for people, and some of that is intentional, to choose people to work for who believe that having a life outside of work is important. Because certainly some of my peers have sacrificed family ... I had my older child when I was a first-year pathology resident and my younger child during my first three months of my post-doc." (Faculty, White, MSTP, 46 years)

\section{Choosing a family-oriented place where having a baby was not a barrier.}

"After being hired, before I came to work here, I had to warn them, I'm four-anda-half months pregnant. It's such a family oriented place, that it made me feel really comfortable. It made me want to work harder, because everybody appreciates family, everybody appreciates hard work, but then also going to your family at the end of the day. These people made it a really good group." (Faculty, Black, PhD, 35 years)

Networking with other women groups. The data indicates that there is value in

seeking support from a network of women's groups and organizations that provide advice on strategies to balance work and family life. Two females in this dissertation talk about such groups, and how being a part of them, as well as networking with other working women in the field with families, was beneficial.

"There're just a bunch of different student organizations, one is Women in Medicine, another is people interested in pediatrics and oncology. They set up talks either at lunchtime or in the evenings throughout the year. In the Women in Medicine panel, six or seven of the faculty at [name of school] will come and talk about how they became doctors in their field, what path they took to get there, how it is balancing family life and their profession and things like that. I find that really helpful for considering the different specialties." (Student, Hispanic, $2^{\text {nd }}$ year MD, 23 years)

"We have sort of a speaker series throughout the year of different women, successful physicians, and they sort of talk about their careers and things. Then their big event is a panel each semester with a bunch of different people, and they each talk about their career paths. You can ask questions ranging from clinical 
questions, to about how they balance their home life and work and professional questions about moving up in the ranks. I think they've done a pretty good job sorta explaining where they face barriers and where they think there have been less barriers now ..." (Student, Hispanic, $2^{\text {nd }}$ year MD, 23 years)

"We're forming a group now of women in the $\mathrm{MD} / \mathrm{PhD}$ program to try to talk more about those issues, because a lot of people make the decision of not becoming an $\mathrm{MD} / \mathrm{PhD}$ student based on the fact that by the time we finish we have run out of our biological clock. The length of the training is so long. I struggle with decisions myself, because I'm 32 in the middle of my training. I have three more years before I'm considered advanced maternal age. ... The decision of having a family, I think, is something that really, really affects the woman." (Student, Hispanic, $5^{\text {th }}$ year MSTP, 32 years)

Establishing work rules. One female participant discussed how she had established her own rules in order to spend more time with her family. Thus, despite her mentor expecting her to work over the weekends, she would not comply.

"I know my post-doc mentor was chagrined that I refused to come in on the weekend. Because I was like I have a baby and I'm not coming in on the weekend. She was there every weekend and so I think she often was like well if you could just work one weekend day it'd be great. I was like I don't want to and I'm not going to." (Faculty, Black, PhD, 34 years)

Institutional choice. By choosing an institution with more women who have children, the female participant became a part of an environment that was conducive to her success.

"I came to [name of school] where 40 percent of their residents were female. ... It was wonderful because it was in an environment that was high achieving, that it had a wonderful environment for women. ... It was a lot of diversity and at least half of the residents who were female in the program, either had children, or were pregnant while they're in the residency. ... I probably interviewed at 10 to 15 programs. At [name of another school] of course, if a male resident had a child, that wasn't an issue. If a female resident was pregnant, a major issue. It was not an issue at [name of school], so I've sort of chosen for that." (Faculty, White, MSTP, 34 years)

Working part-time (as a clinician). One female participant advocated working part-time in order to balance work and caring for the family. Although working part-time 
is sometimes frowned upon, it gave her enough flexibility to pursue a career and earn, while still spending a lot of time with the children. Once her children are grown up, she would consider going back to working full-time.

"I worked full-time for the first year and I was done. ... I had my second son not too long ago and so I think that cemented my choice as a part-time clinician ... The choices and the position that I'm working in work really well for us. ... certainly once you're part-time people don't think of you as often and when they do, it's kind of a shock ... I'm in the process of thinking about what I want my career to be like in three to four years ... What I do now is very attractive to me. Financially we're doing really well. I have a lot of spare time ... so it's hard for me to think of giving some of that up." (Faculty, White, $\mathrm{MD} / \mathrm{PhD}, 39$ years)

\section{Insight on Two-Physician Families}

In this dissertation, two female participants describe some of the characteristics of two-physician families. One of the disadvantages of a two-physician family is that both partners are very busy juggling work and personal lives. In both cases, the female participants indicated shouldering primary (and more) family responsibilities because their husbands are busy traveling or on-call.

"My husband travels a lot as part of what he does for work. It gets harder and harder just to kind of maintain what I consider to be the traditional family structured evenings and days. ... I feel like in some ways I'm little, tiny failures to my children, those games that I can't go to because I'm working or the evenings where I have a deadline and I don't spend quite as much time with them as I'd like to." (Faculty, Hispanic, MD, 42 years)

"I think for most people if you're a woman and you have kids, you generally have more responsibility to getting the kids cared for and take them where they need to go and run the house. ... I also have a husband who's an interventional cardiologist, so he is really busy. He does call and when he's on-call for the weekend he's gone." (Faculty, White, MD, 47 years)

Based on this dissertation, we see that one strategy to deal with the business associated with two-physician families is to have an understanding mentor who is aware of the difficulties of balancing work and family life. In this example, having a mentor 
who also belongs to a two-physician family, and is balancing work and family life makes one more empathetic to their students' struggles.

“He's a good life mentor. Although he's a good 15 years ahead of me in many ways our lives are somewhat parallel. He's a two physician family just as my husband and I are. ... we often deal with the same life issues. ... He's very accommodating in that regard because he's still in the thick of having to pick up the kids from school ... He's a good life coach as far as how to maintain work/life balance and things like that ... It's been a very, very good mentoring relationship." (Faculty, Hispanic, MD, 42 years)

\section{Summary of Findings}

The findings discussed above do not indicate inferential, associative, or causal relationships. Instead, the qualitative analyses provide emergent themes or patterns of gender-role barriers reported by specific demographics of women in this study. These themes contribute to the overview of the "barrier-landscape" in the field, studying in detail a specific contributing barrier. The findings of this chapter are summarized as follows:

1. Program distribution: While the post-degree group of females (faculty, residents, postdoctoral fellows, scientists and non-scientists) belong to the $\mathrm{MD}, \mathrm{PhD}$, or $\mathrm{MD} / \mathrm{PhD}$ program, none of the female students who reported gender-role barriers belonged to the PhD group (Table 4-1; Figure 4-1).

2. Racial/Ethnic distribution: The majority of the females who reported gender-role barriers were either White or Black. In addition, among these two groups, as well as Asians, there were more female post-degree females who reported such barriers compared to female students. However, for Hispanics and mixed races, the number of students reporting gender-role barriers was marginally more than postdegree females (Table 4-1; Figure 4-2). 
3. Age distribution: The average age of the female participants who reported genderrole barriers was 38 years. Within this group, the average age of post-degree females was 43.2 years and the average age of students was 27.2 years. This corresponds to the maternal age span for females when they are more likely to experience and report these barriers (Figure 4-4).

When the age distribution of females reporting gender-role barriers was examined (Table 4-1; Figure 4-6), it was seen that females in their thirties reported gender-role barriers most frequently, followed by females in their twenties. In fact, evidence from this study indicates that some females in their thirties reported concerns about reaching advanced maternal age and struggling to balance a family while continuing to contribute to the workforce. However, such evidence is suggestive of participant experiences in this study, and should be interpreted with caution without making generalizations.

Lastly, looking more closely into the age distribution of those females (Table 4-1; Figure 4-6), it was found that the age groups from which the maximum number of gender-role barriers was reported, were the early thirties followed by the late twenties. In addition, the next age group most frequently reporting these barriers was in their late forties. Thus, looking at the graph, we saw a bimodal distribution with two peaks, one in the twenties-thirties, and the other in the late forties. Data from existing literature indicated that women in medicine and biomedical research take longer to advance their careers, and the percentage of successful women decreases up the leadership hierarchy in academic medicine (AAMC, 2012; McPhillips et al., 2007). This might indicate a 
gender difference in the preparation of females to serve in the workforce, and many factors could contribute to it. The findings of this dissertation indicate that gender-role could be one of those factors. While the first peak in the graph (late twenties and early thirties) could be indicative of females struggling to persist in the field, the second lower peak (late forties) could be indicative of females trying to get promotions to higher leadership positions in the field.

4. The gender-role barriers for women were used to develop a "Condition-ProcessOutcome" model in this study. Based on the data, we see that while some factors act as "conditions" contributing to gender-role barriers, other factors are as a result of gender-role barriers, also known as "outcomes", with significant overlap between the two categories.

5. Within gender-role barriers in females, mentoring barriers, time constraints, and expectations, as well as institutional barriers, are some of the most frequently reported barriers (Table 4-2; Figure 4-7). For example, while discussing mentoring barriers affecting their balance of work and personal lives, interviewees often discussed how their mentor's lack of understanding or lack of support and training resulted in interviewees facing gender-role barriers.

6. Of the 40 female interviewees who reported gender-role barriers, 24 of them also discussed several strategies used to overcome those barriers that included individual-level, family-level, and institutional-level interventions (Table 4-3; Figure 4-8). Of these three interventions, the institutional-level interventions were most frequently reported.

7. Of the institutional interventions reported in this study to overcome barriers, 
mentor support was the most frequently reported strategy, followed by choosing the right specialty and choosing academia over medicine (Table 4-4; Figure 4-9). These findings not only strengthen and validate existing literature about the scarcity of women in professional leadership positions at medical and research institutions, but they do more. These findings go a step further than existing literature and specifically look at some of the contributing factors that could be related to gender-role barriers (for example, lack of mentoring), as well as some resulting consequences of gender-role barriers (for example, decreased work productivity or decreased networking opportunities, as a result of gender-role barriers). In addition, these findings also address the question of "what can be done?" by proposing certain institutional interventions that could reduce such barriers. Furthering this line of findings, future research could examine the specific kinds of gender-role barriers and institutional strategies to reduce those barriers, based on quantitative studies. Future research could also look into what factors other than gender-role barriers could be preventing women from persisting, advancing themselves and being promoted in the field at the same rate as men are. This would help in addressing an important question, "Are women facing barriers in the field because of their gender? If so, then to what extent do gender-role barriers contribute to gender barrier?" 
Table 4-1

Demographics of Females Reporting Gender-role Barriers ( $n=40)$

\begin{tabular}{|c|c|c|c|c|}
\hline Demographics & & Graduate & Student & Total \\
\hline \multirow{4}{*}{ Degree } & $\mathrm{MD}$ & 7 & 3 & 10 \\
\hline & $\mathrm{PhD}$ & 13 & 0 & 13 \\
\hline & $\mathrm{MD} / \mathrm{PhD}$ & 7 & 10 & 17 \\
\hline & Total & 27 & 13 & 40 \\
\hline \multirow{6}{*}{ Race/Ethnicity } & Asian & 2 & 1 & 3 \\
\hline & Black & 10 & 1 & 11 \\
\hline & Hispanic & 2 & 3 & 5 \\
\hline & Mixed & 1 & 2 & 3 \\
\hline & White & 12 & 6 & 18 \\
\hline & Total & 27 & 13 & 40 \\
\hline \multirow{7}{*}{$\begin{array}{c}\text { Geographic } \\
\text { Region }\end{array}$} & Central US & 9 & 4 & 13 \\
\hline & Northeast & 9 & 4 & 13 \\
\hline & US & & & \\
\hline & $\begin{array}{c}\text { Southern } \\
\text { US }\end{array}$ & 6 & 2 & 8 \\
\hline & West US & 2 & 3 & 5 \\
\hline & Outside US & 1 & 0 & 1 \\
\hline & Total & 27 & 13 & 40 \\
\hline \multirow{10}{*}{ Age (years) } & $20-24$ & & & 3 \\
\hline & $25-29$ & & & 7 \\
\hline & $30-34$ & & & 10 \\
\hline & $35-39$ & & & 5 \\
\hline & $40-44$ & & & 2 \\
\hline & $45-49$ & & & 6 \\
\hline & $50-54$ & & & 3 \\
\hline & $55-59$ & & & 3 \\
\hline & $60-64$ & & & 1 \\
\hline & Total & & & 40 \\
\hline
\end{tabular}


Table 4-2

Frequency of Reported Gender-role Barriers

\begin{tabular}{lc}
\hline \multicolumn{1}{c}{ Gender-role Barrier } & Frequency \\
\hline Mentoring & 6 \\
Time & 5 \\
Expectations & 4 \\
Institutional & 4 \\
Age & 3 \\
Work/life balance & 3 \\
Maternity leave & 3 \\
Work productivity & 2 \\
Support from spouse & 2 \\
Networking & 2 \\
Economics & 2 \\
Timing & 2 \\
Leadership and promotion & 1 \\
Others & 8 \\
\hline
\end{tabular}


Table 4-3

Strategies of Intervention for Gender-role Barriers

\begin{tabular}{lc}
\hline \multicolumn{1}{c}{ Intervention } & Frequency \\
\hline Individual level & 4 \\
Family level & 1 \\
Institutional level & 24 \\
\hline
\end{tabular}


Table 4-4

Strategies of Institutional Intervention for Gender-role Barriers

\begin{tabular}{lc}
\hline \multicolumn{1}{c}{ Institutional Intervention } & Frequency \\
\hline Mentor support & 10 \\
Choosing the right specialty & 4 \\
Choosing academia & 3 \\
Working for people who value work/life balance & 2 \\
Networking & 2 \\
Establishing work rules & 1 \\
Institutional choice & 1 \\
Working part-time & 1 \\
\hline
\end{tabular}


Figure 4-1

Degree Program Affiliation of Females $(n=40)$

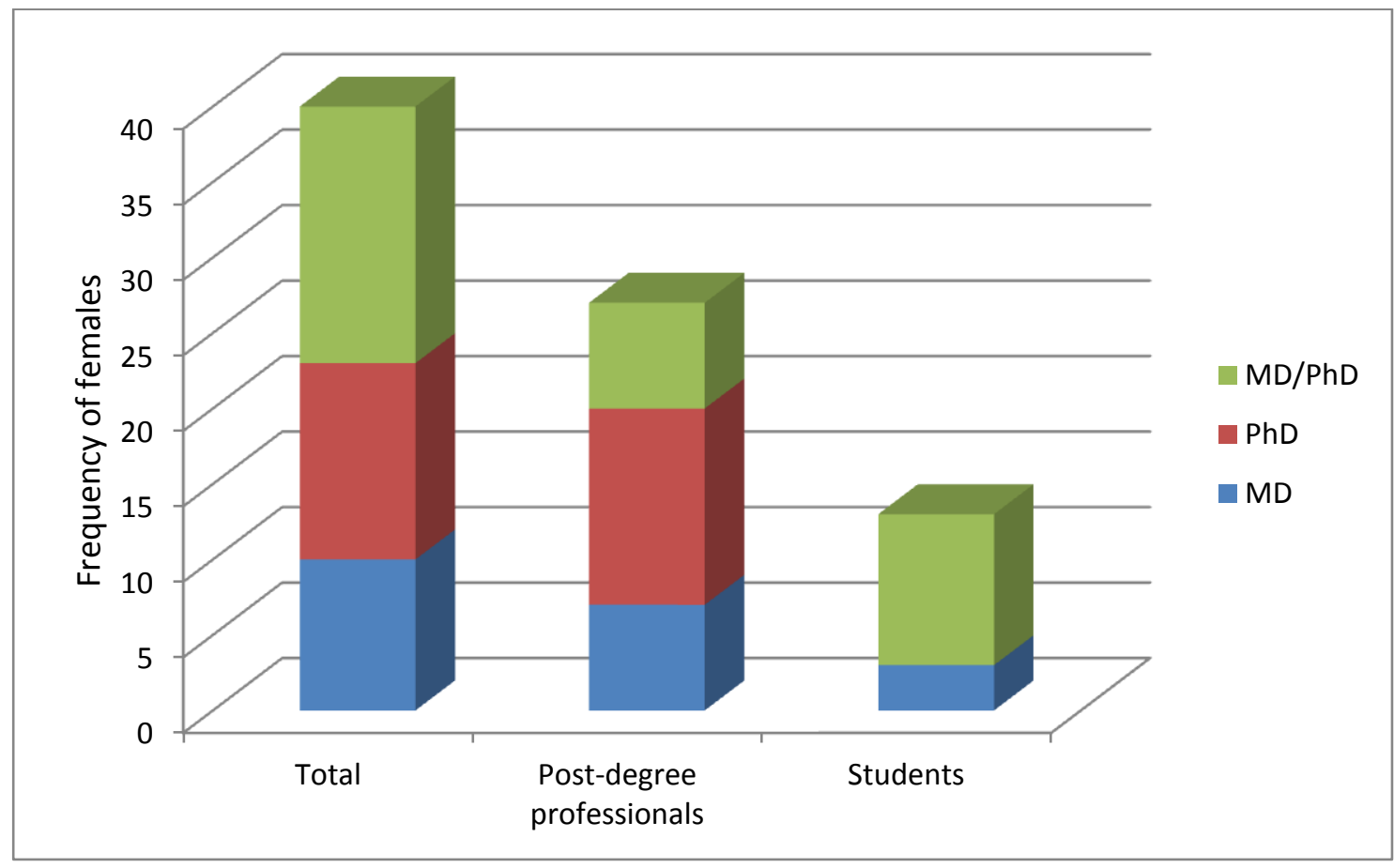


Figure 4-2

Racial and Ethnic Distribution of Females $(n=40)$

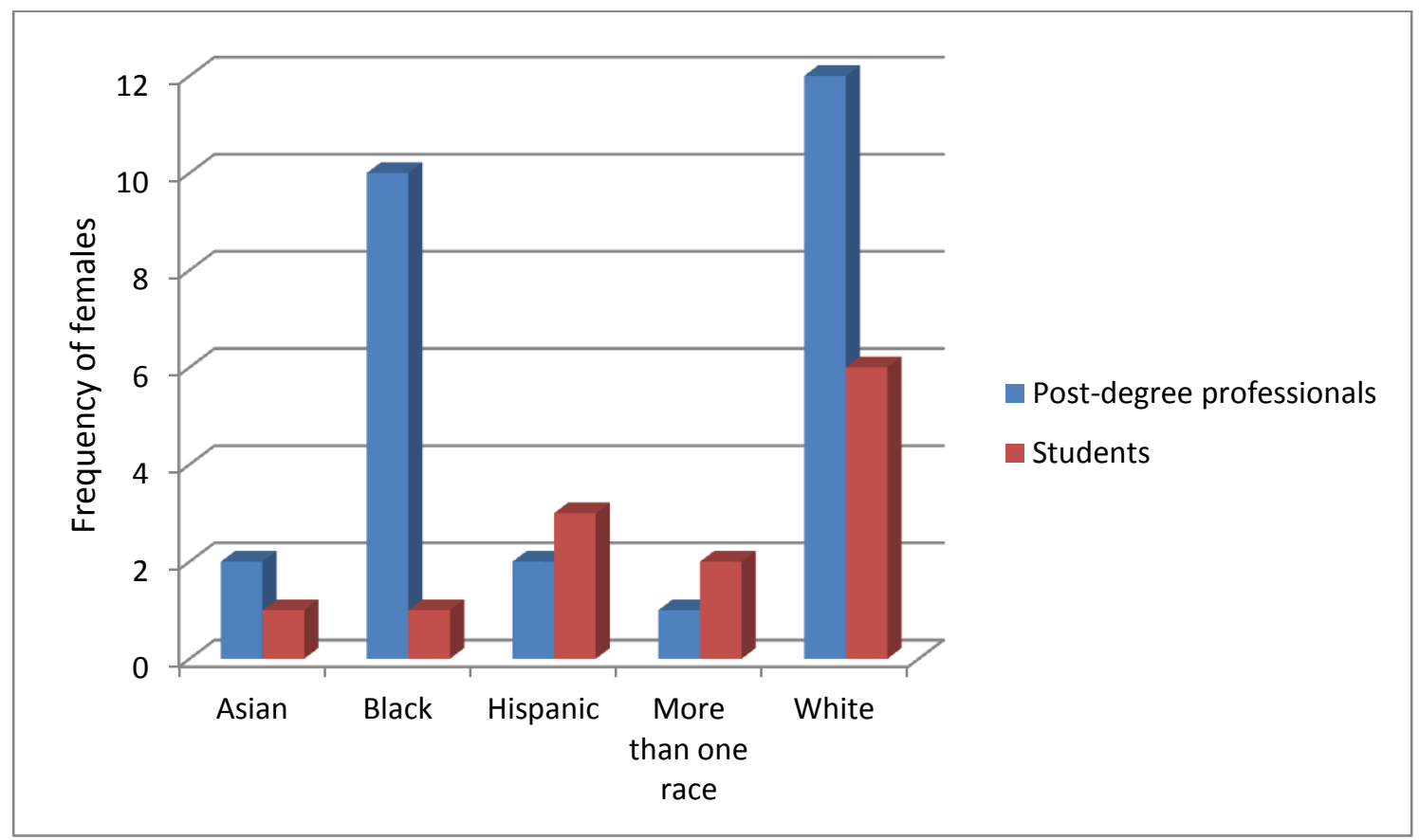


Figure 4-3

Distribution Based on Geographic Region ( $n=40)$

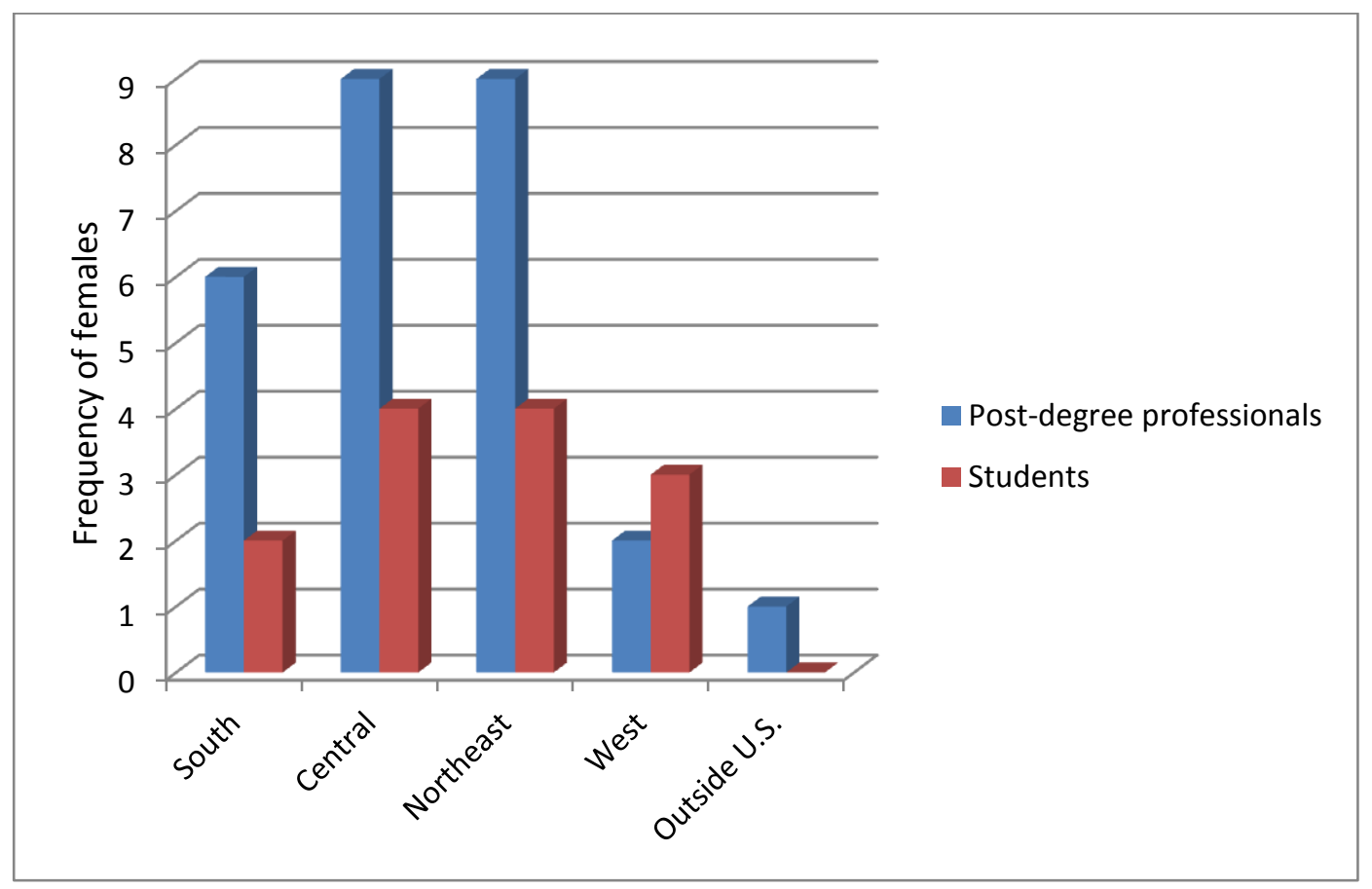


Figure 4-4

Average Age of each Sub-group $(n=40)$

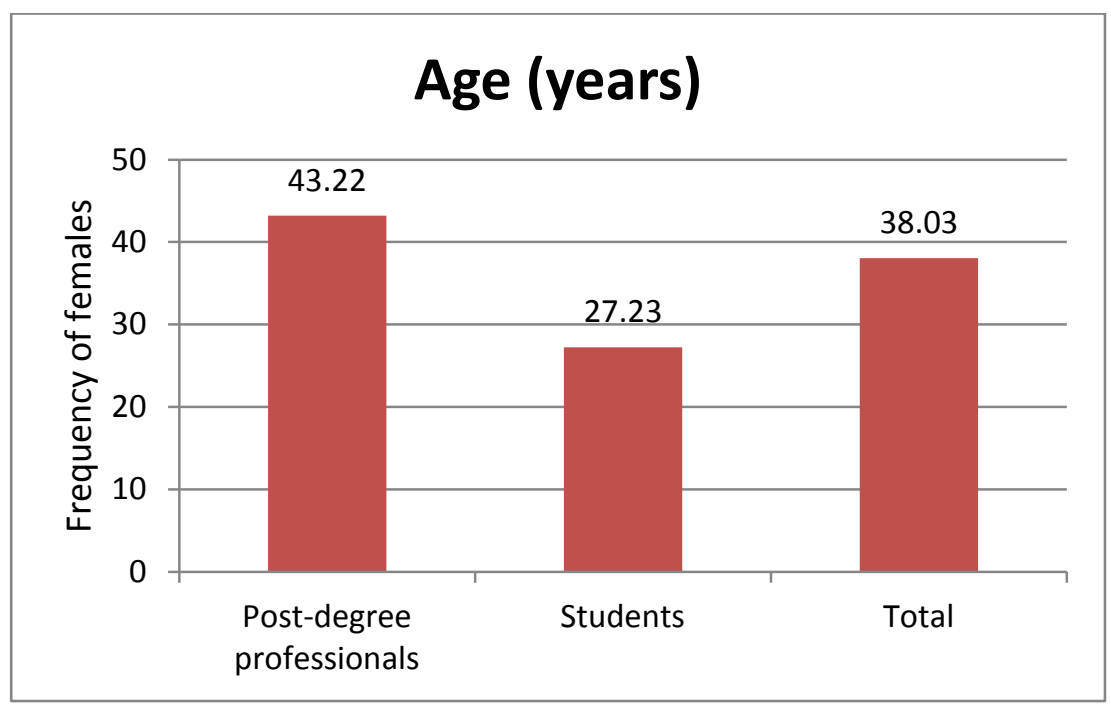


Figure 4-5

Age Distribution of Females $(n=40)$

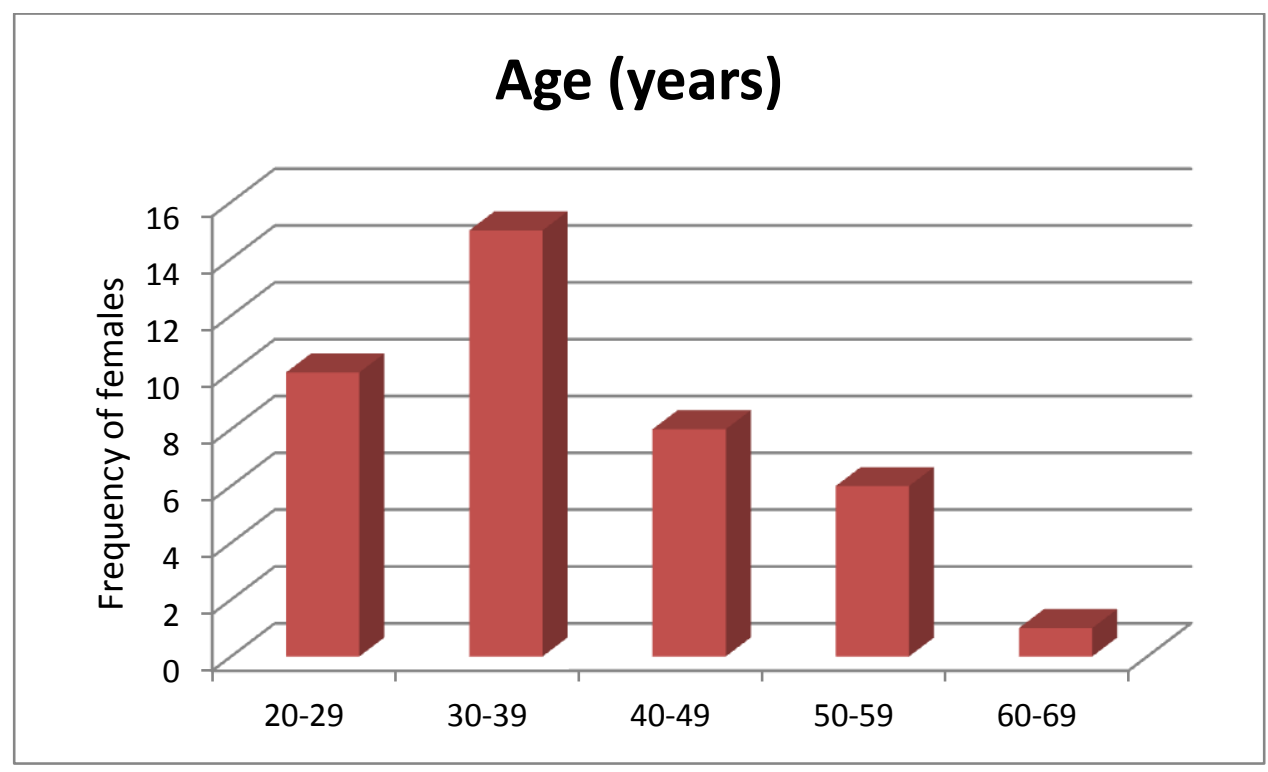


Figure 4-6

Age Distribution of Females $(n=40)$

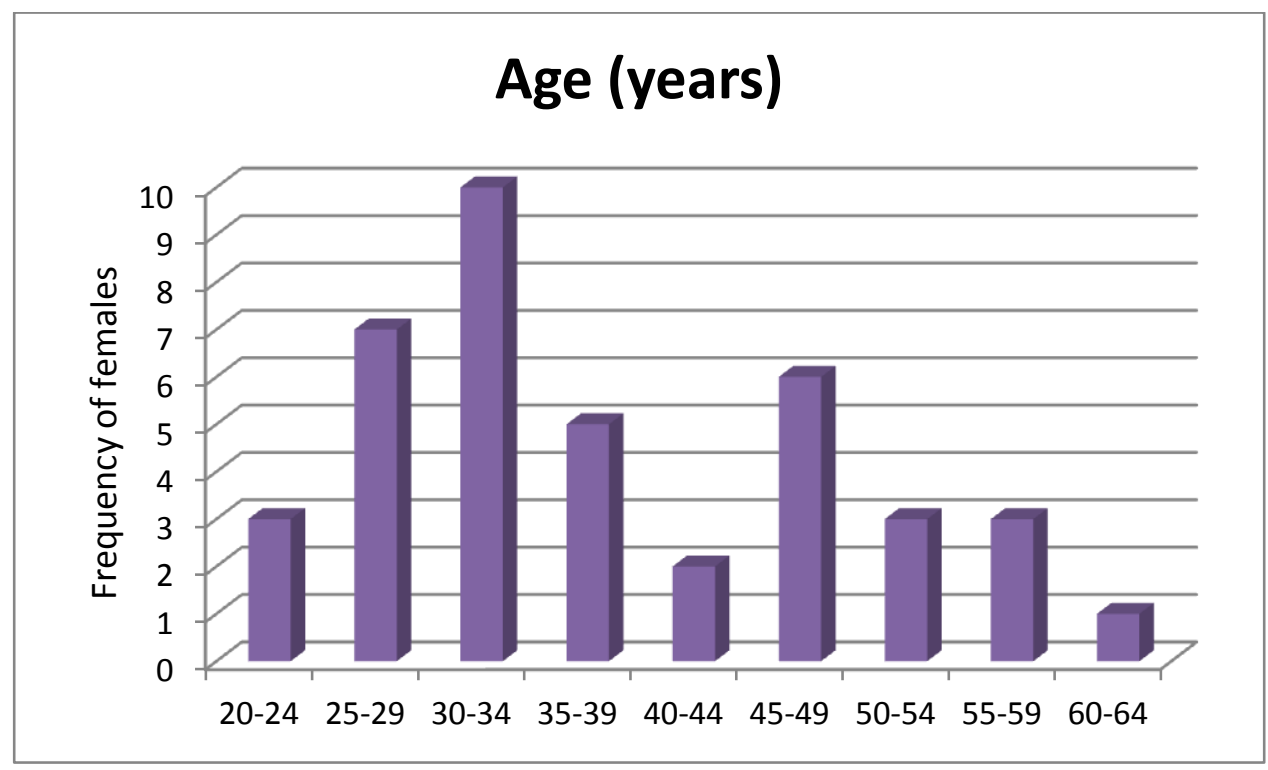


Figure 4-7

Reported Gender-role Barriers

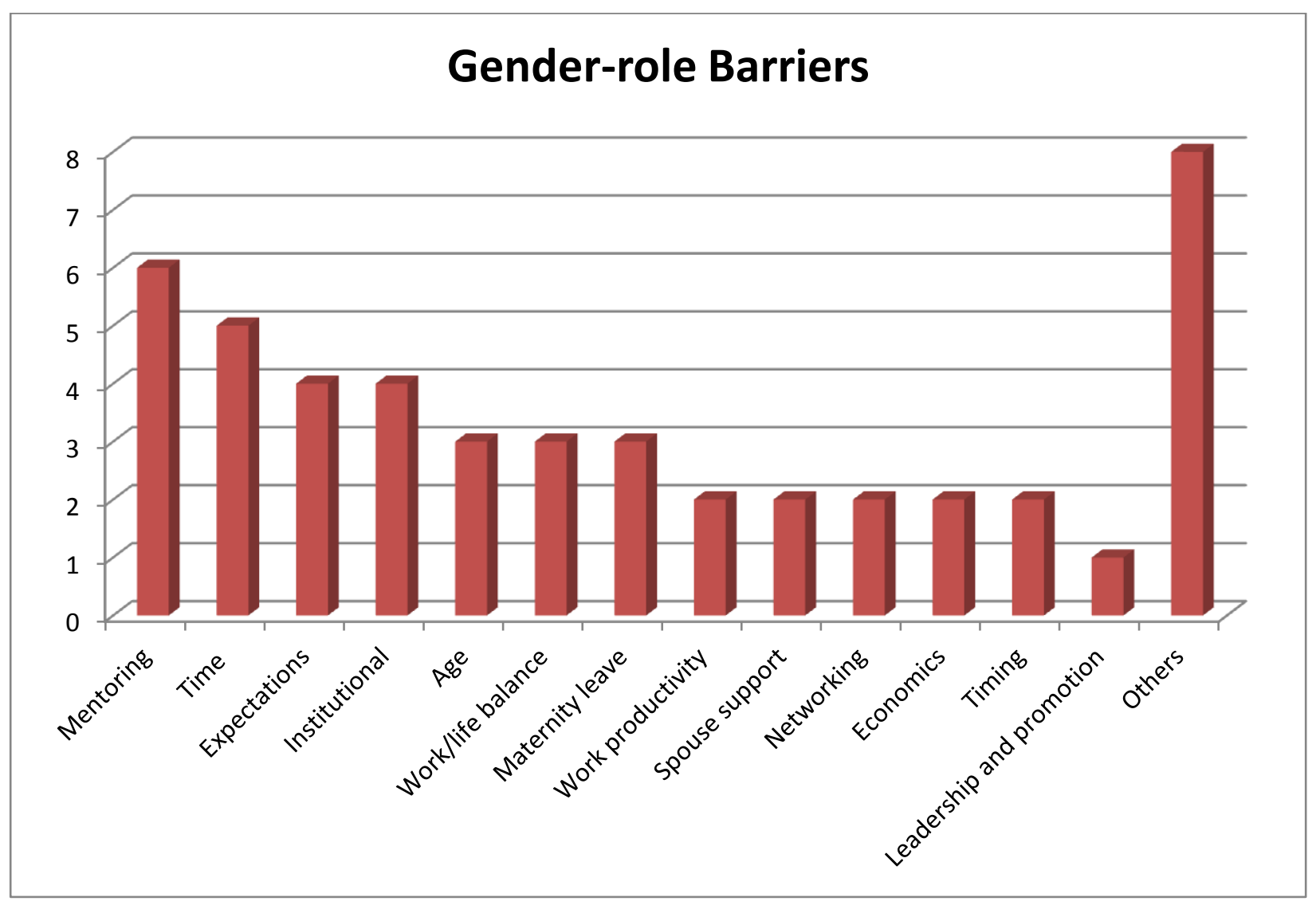


Figure 4-8

Reported Interventions for Gender-role Barriers

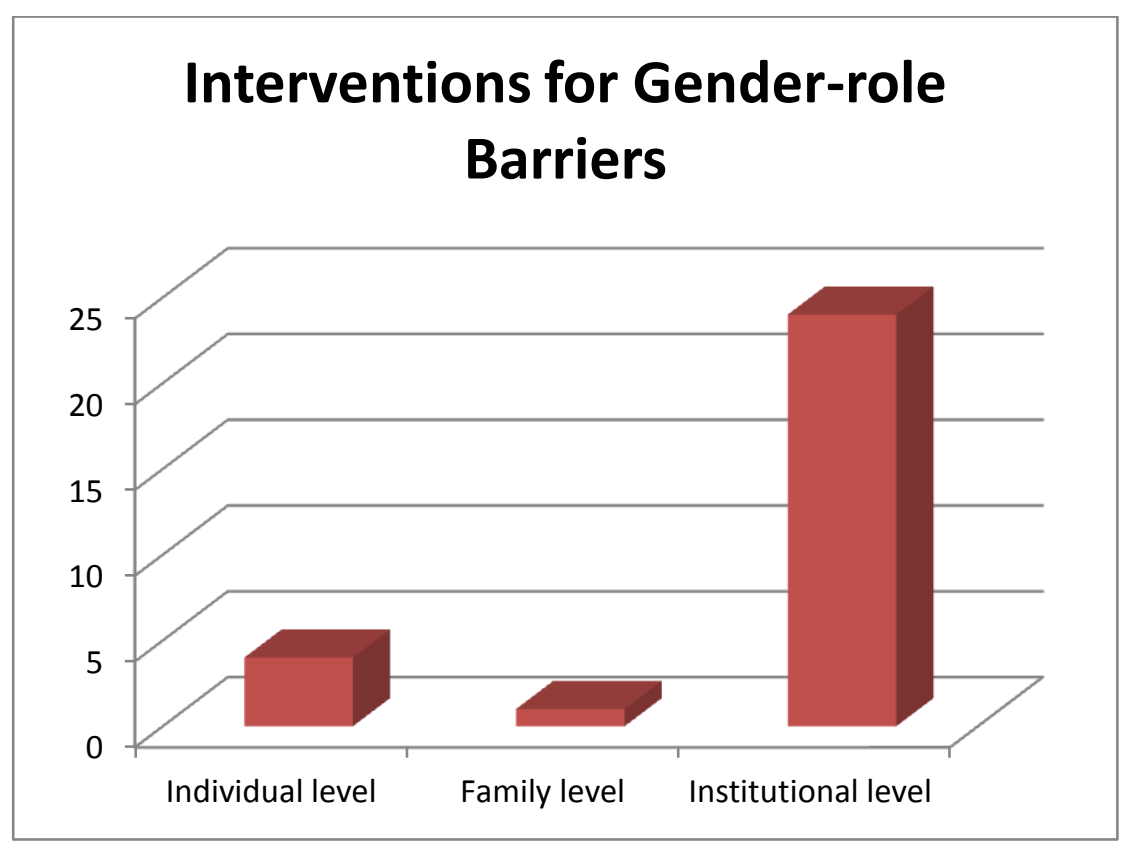


Figure 4-9

Reported Institutional Interventions for Gender-role Barriers

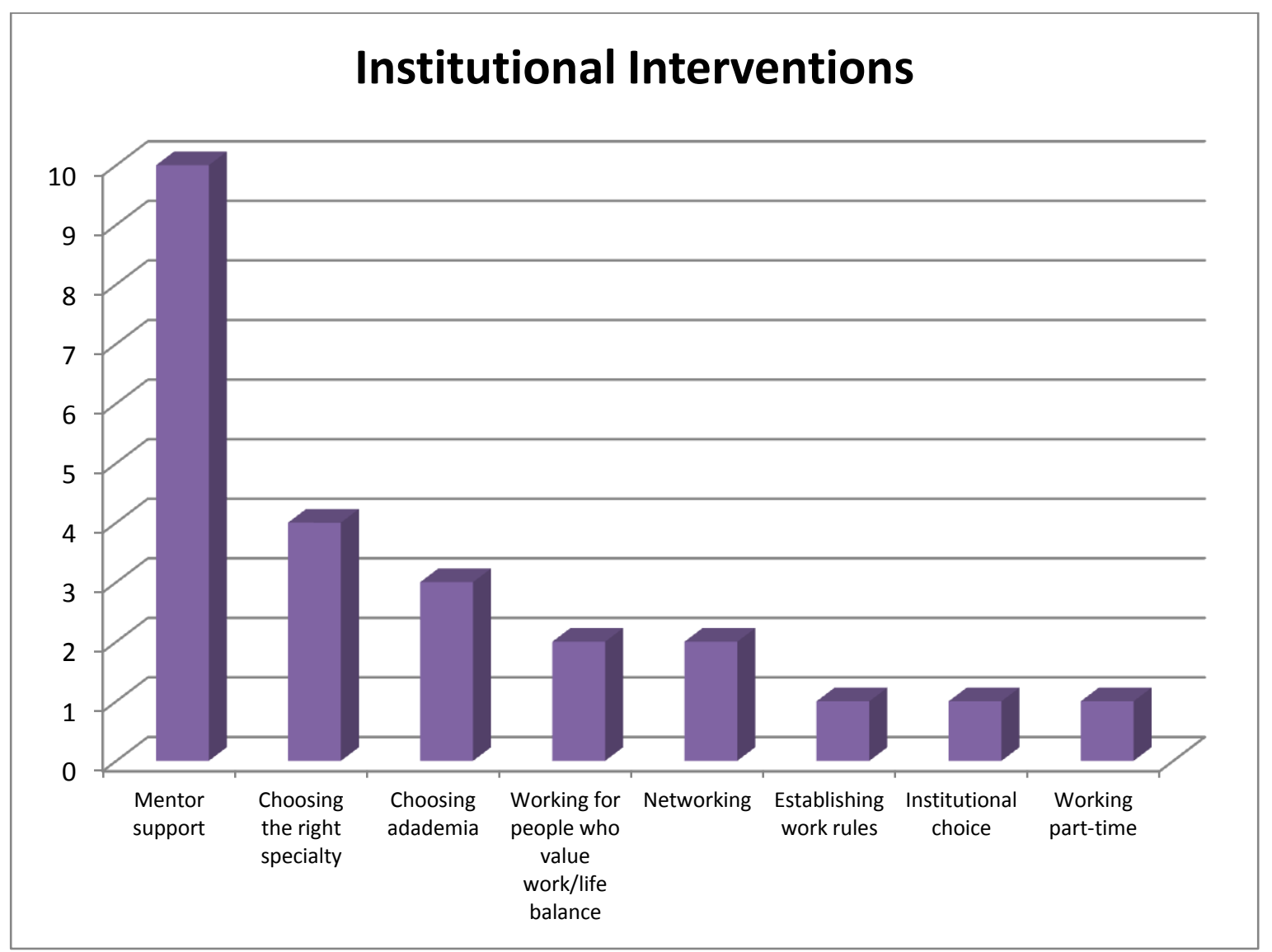




\section{CHAPTER 5}

\section{RESULTS AND CONCLUSIONS}

\section{Barriers of Underrepresented Racial/Ethnic Minorities}

Chapter 4 of this dissertation examined gender-role barriers for female students and graduates in biomedical research and medical programs. This chapter qualitatively examines barriers of the two largest underrepresented racial/ethnic minority groups in the field: Blacks and Hispanics.

This dissertation describes and qualitatively compares the four sub-populations, drawing out the evident similarities and differences in emergent themes:

- Barriers reported by Black males,

- Barriers reported by Black females,

- Barriers reported by Hispanic males, and

- Barriers reported by Hispanic females.

Finally, this analysis created a model summarizing the findings, which were supported by quotes and vignettes. In this dissertation, the quotations were slightly modified when required, to correct for grammar, or were suitably abbreviated to avoid repetition and redundancy. However, the quotes were not modified for content. Further, this study used a web-based software tool for word cloud or weighted list design called Wordle (Feinberg, 2013) to visually represent the themes of barriers based on how frequently they were reported in the study (Figure 5-7 to 5-12). The size of the words in 
these figures is proportional to the frequency with which they were reported by the participants (bigger the size of the word, the more times it was reported). This is a form of data display based on visual designs.

\section{Individual-Institutional Theoretical Framework}

The overarching theoretical framework based on data from this study (also called the Individual-Institutional theoretical framework) classifies most reported barriers as individual barriers or institutional barriers. Individual barriers are those that individuals face as a result of their identity and their beliefs. These are barriers intrinsic to the self and which arise with minimal influence of the academic institutions they are affiliated with. Thus, individuals are likely to face those barriers irrespective of their choice of institution. Some examples include gender, race, immigration status, family influences, or being a first generation academician. On the other hand, institutional barriers are those that individuals face in their current academic program that are either due to lack of adequate training prior to entering the program, or to the structure and design of the current academic program itself. They could also be due to their academic experiences from their previous academic institution. These include both challenges arising due to human interaction, as well as challenges due to the way a particular program is designed. These barriers are intrinsic to the program. Some examples include poor mentoring and lack of career guidance.

However, we see that the individual and individual influences do not occur in isolation, but act on and influence one another. Thus arises a third category of barriers, called overlapping barriers, that arise due to a combination of the structure of a particular program, as well as the way individuals made sense of the program based on their 
identity. These are barriers intrinsic to the individual as well as intrinsic to the program, and indicate the interaction between the self and the institution. This category of barriers is a representation of the "fit" of an individual in the program. The discussion of barriers in this study will be based on this framework, which is represented diagrammatically.

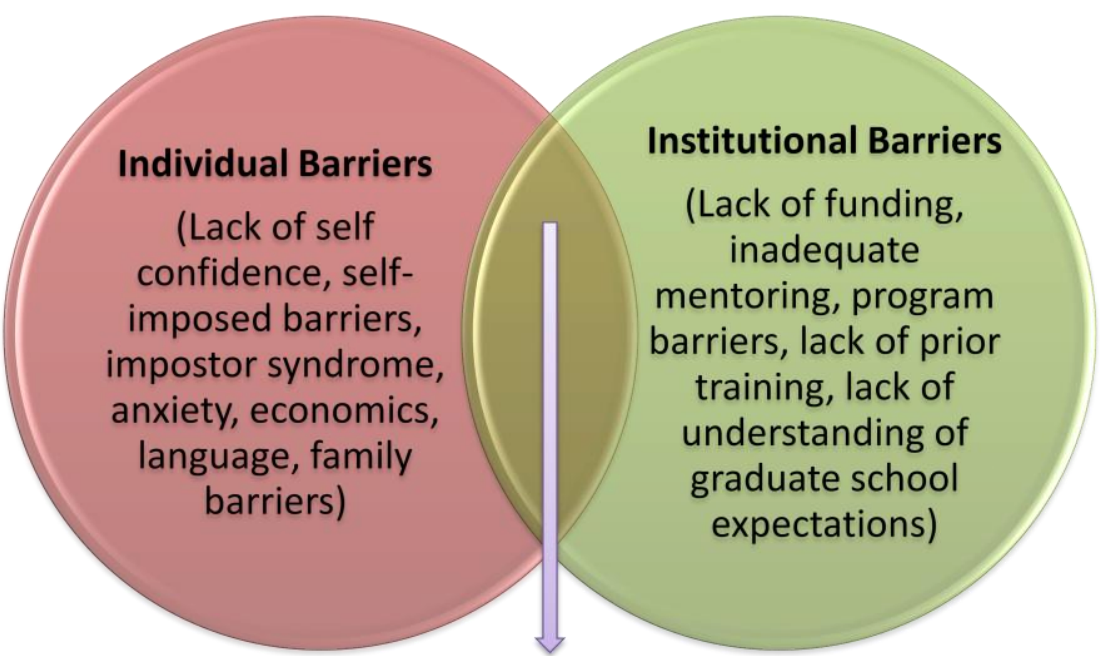

\section{Overlapping Barriers:}

Racism and performance pressure

Economic barriers and specialty selection

Gender and glass-ceiling effect

Maternity leave issues

Promotion issues for women

Race and stereotyping

Language barriers causing barriers in communication or test taking

Foreign status

Cultural identity and academic environment

Lack of understanding of academia due to lack of family exposure 


\section{Barriers Reported by Black Males}

In this analysis, the responses of 18 male Black participants were analyzed and categorized into several themes of barriers, as discussed below.

\section{Racism}

Seven Black male participants who indicated facing some kind of barrier related to one of the several themes of racism. The several emergent themes are discussed below.

The first example is based on minority perception. Here, the participant indicated encountering several occasions of mistaken identity, which he perceives as unintentional, but stereotypical nevertheless.

"I experience barriers every day. ... My office has pictures of my three kids. I'm African American, my kids are African American. They'll be someone sitting in my office ... they have a chance to look at the walls, ... and I walk in, and they say, "Are you Doctor [name]?" Now, who else could I possibly be walking into my office? ...

Those are some barriers because there are expectations. I tend to go to a lot of schools to talk to students about what I do. ... I'm in eighth grade at a local public school ... I had a girl raises her hand just before the teacher introduces me, and says, "Um, where's Dr. [name]? I don't see any doctor in the room." ... I said, "Well, because, what do you expect?" She says, "An old white guy." ... They questioned, how am I going to fit in because it's a bunch of old white guys." (Faculty, MD, 45 years)

The next example is based on preconceived notions. Here, the participant

indicated facing assumptions from his colleagues, based on his race.

"I actually had an internal medicine chair tell me, without looking at my CV, without reviewing my grades as a medical student, that I would never match to radiation oncology because it was so competitive. ... That's the only person who made an assumption based upon my race." (Faculty, MD, 48 years)

He further discussed that, as faculty, he was able to get underrepresented racial and ethnic minorities into the same specialization by overcoming such perceived notions 
or set stereotypes. He did it by encouraging students to strategize and be competitive, do their background research of specialty, as well as develop writing skills.

"Radiation oncology is a fairly competitive residency. I think the only reason I've been able to get a number of African-American, Hispanic students in the residency is because I told them you can do this.... There's a strategy around this. You gotta do a little research. You gotta make sure your writings are good enough." (Faculty, MD, 48 years)

The next example discusses how racism is overcome by collaboration. Here, the participant indicated facing racism in the U.S.. He further discussed that such notions of racism could be overcome by collaboration.

"Barriers in America, not in the field. ... It's all over the US. ... especially African- Americans do express that, constantly in this field." (Faculty, $\mathrm{PhD}, 46$ years)

"I wish that people of African descent should be more like ... get together and form like one set of collaboration and help each other ... That would make a difference. More collaboration between underrepresented individuals. ... In America everyone should be together, and more network and help out each other." (Faculty, $\mathrm{PhD}, 46$ years)

The next example discusses exclusion from certain institutions because of being Black. Here, the participant indicated facing institutional racism because certain institutions or programs did not enroll Black students at all. Further, there were White professionals within those institutions who did not train Black people back in the nineties by design.

"There were some limitations in terms of just where I was coming from. ... there were programs that I was applying to who didn't take black folks at all. ... Even in the nineties, there were residents who had never trained black people, and it was by design ... the head of neurosurgery had never trained a minority and was not bashful about telling you he wasn't interested in that." (Faculty, MD, 48 years)

Next, the participant discusses facing harsh scrutiny for mistakes because of his 
race.

"You'll be overly scrutinized and it'll be a terrible thing for you to put yourself through because they'll be looking for every mistake you make and so forth ...particularly if you're a minority you wind up not doing a lot of things. ... I feel more pressure than I would if this were an institution that was very diverse or the upper leadership was very diverse.” (Faculty, MD, 52 years)

Next, the participant discussed facing institutional racism, and describes his differential experiences in racism with two institutions. He faced more barriers and instances of being looked down upon in one historically Black institution than at another university, which was not historically Black.

"I went to [name] University, which is a historically black university. Some of the biggest obstacles I ever had was there. ... a lot of my peers there looked down on me, to be quite frank, and a lot of my professors." (Faculty, PhD, 40 years)

Next, the participant describes facing racism and performance pressure. Here, the participant indicated facing racial barriers because of the low number of Blacks in this institution, as well as in the field of science in general. As a result, he felt like his performance was always judged by others and held up as an example upon which other Blacks would be recruited in the field.

"I think there's some racial barriers here. ... there's very few African Americans and Africans here and I think that's true of most science practice. It makes it a bit difficult. It is a barrier ... I felt like just maybe every presentation was sort of speaking ... like I have to really do well to sort of set the tone for other black people so that they'll pick up another black person or something. ... it's more of a structural problem than anything sort of deliberate." (Student, $6^{\text {th }}$ year MD/PhD, 28 years)

Next, a participant describes experiencing racism in the field and overcoming it with hard work. Here, the participant indicated suffering barriers because people did not associate a Black man with a professor and engineer. As a result, he was denied opportunities in the field. However, he indicated that one can overcome the racial 
perceptions of others through hard work. He discussed that when people realized your

worth, they moved past the racial perceptions.

"It's just initially people don't look at black men as being professors or being engineers, that's not the perception ... I think I was denied opportunities because of that. ... On the job students didn't believe I was the engineering professor initially. I had to prove myself and my teaching. ... I think off the street people look at you, they make judgments on you but when they find out about you they look at you differently. ... Once people see that you come in with all of this and how it's going to help their program, it builds them. ... I have experienced that along my entire career. Not just here but in industry as well. ... That made me even work harder. This is one of the barriers I needed to overcome to succeed in the program. Whenever I step in a meeting I realize I'm the only black male there. ... it is a barrier and I've heard the same thing from a lot of other minorities as well." (Student, $2^{\text {nd }}$ year $\mathrm{PhD}, 45$ years)

\section{Personal Barriers}

Seven Black male participants discussed various personal barriers they faced in order to succeed in the program. The barriers are discussed individually.

Isolation and exclusion. Three participants shared their experiences with feeling isolation and exclusion from their groups, either because of their looks or because of the way in which they spoke. These are exemplified below.

"Where I am now there's not many people who look like me or have say similar life experience. ... you sort of feel like you're on this island alone. You don't really know who to trust or to really put faith in. I think that's been another thing I've been trying to navigate." (Faculty, $\mathrm{MD} / \mathrm{PhD}, 41$ years)

"You get to a point there're very few African-Americans who are right in your spot that can be your mentor, so you find mentorship from other people and other disciplines. ... A lot of that I think might be self-imposed because you feel that extra pressure.... one situation I actually overheard a conversation, them saying, "This guy's really smart. If he just wasn't black he'd probably get this position," and I felt compelled to go back and talk to the colleague about it, and I did." (Faculty, MD, 52 years)

"When I was coming out of high school, I didn't speak very well. I didn't carry myself the way a lot of the other students did, but I still did well. ... I definitely had no shortage of situations where peers and professors told me that I didn't have what it takes. They would assume that I couldn't perform because I guess the 
way I spoke and the way I dressed. ... I had various obstacles. Part of the problems I had with my undergraduate advisor were I think, resulted from some of that. In undergraduate, frequently during the beginning of the semester I would kind of be ostracized in my math classes. I still deal with some of those issues." (Faculty, PhD, 40 years)

Lack of confidence. In this example, the participant indicated how self-doubt or a lack of confidence was perceived as a barrier to success. However, the reasons for such lack of confidence are not clear.

"Well, the confidence was not always there. I did doubt myself on a lot of things ... When I was a graduate student, it never seemed possible that I would get a post-doc. When I got the post-doc, I'm like I'm never gonna get a faculty position. When I got a facility position it was like I'm not gonna get tenure. Every step was like a confidence doubting issue type of thing." (Faculty, PhD, 40 years)

Self-created barrier. In this example, the participant indicated how he was the barrier to his own success. He discussed some of the reasons for such a barrier perception being a lifestyle change in graduate school, as well as not having prior research or laboratory experience. This was overcome by dedicating a lot of time to learning and adjusting to the new environment.

"To me, the only barrier was myself. ... Many, many times when I first started, it was extremely difficult. Even though I felt like I had some preparation coming out of undergrad, as far as questions-wise, it was a whole new mindset, a different way of learning, a different way of thinking. ... a lot of students came in here already having the research background and kind of understanding a lot of the techniques here. When I came in, I had very, very limited, as far as techniques, so I really had to learn everything kind of on the fly." (Student, $4^{\text {th }}$ year $\mathrm{PhD}, 27$ years)

Impostor syndrome. In this example, one participant discussed how he and his fellow students experienced impostor syndrome. He lived with the constant fear and selfdoubt that he did not deserve to be in the program, and people would soon find out about his lack of fit in the program. Although he regularly received positive feedback from his 
advisor, he still doubted his abilities to be in the program. Impostor syndrome was not specific to a race or group. He was also aware that the barrier could be overcome by discussing it and counseling with others. However, people rarely talked about it. In addition, he mentions that their school provided workshops that worked with students and helped them to ameliorate their fears of feeling like an impostor.

"You feel like you will be exposed very soon for the fraud you are. ... I'm like 'Oh my God, someone's gonna find out very soon,' Then it's all gonna be over, my game will be over, that really I'm actually very stupid. ... I'm aware that this is happening to me. ... you did something wrong and it kinda seems like 'Oh my God, they think I'm dumb!' So the challenge there for me has been just to be aware of it and not let it get to me and just realize that actually you are doing fine, just keep doing what you're doing, right, and people are noticing that you are actually good. ... I realize that that's just not specific to me, a lot of people have this feeling." (Student, $4^{\text {th }}$ year $\mathrm{PhD}, 26$ years)

"They have workshops on this (impostor syndrome), they bring in people ... The one thing they talk about is that it's efficiency ... One thing that I think this workshop talks about is impostor syndrome. ... People do not talk about this, but I think if we did talk about it, it would go away." (Student, $4^{\text {th }}$ year $\mathrm{PhD}, 26$ years)

Fear of failing. In this example, the participant shared his fear of failing as a barrier, which is associated with his perception of race, and his geographical location. $\mathrm{He}$ indicated feeling the fear in his current workplace, but not in a prior city, which was a melting pot of several cultures.

"Just basically sometimes fear, even at my age, I'm scared I will fail, I won't make it. ... it's almost like when I'm before committee or before a group of people I'm being judged twice. ... You can just feel the tension sometimes. This is the first place I've lived, so it's very different than [name of city]. There is racial tension here, unlike [name of city] which is a melting pot, you know?" (Student, $2^{\text {nd }}$ year $\mathrm{PhD}, 45$ years)

\section{Institutional Characteristics}

Four Black male participants reported certain institutional characteristics that were deemed as barriers. These institutional characteristics included the lack of resources 
or support to pass benchmark examinations during the initial years of $\mathrm{PhD}$, barriers in performing research, exclusion from campus, as well as the competitive environment of the program as barriers to succeeding in school (without explaining further).

\section{Not having enough support to get through the oral exams.}

"Once you're in that Ph.D. program and you passed that oral exam, then there are more opportunities for supporting you, but not so much once you just got into graduate school, so that students that get in for first and second year, they don't have a lot of support. By support I'm talking about not just financial support, but mechanisms in place to kind of help get them through that oral exam process that I think is a big, a barrier, right there. A lot of students are not able to make it through the Ph.D. program because of that." (Non-scientist, PhD, 30 years)

\section{Research barrier and exclusion from campus.}

"Not only is there just kind of the research barrier, there's also like a 15-minute drive in between where all the other medical students are and where I am.”

(Student, $5^{\text {th }}$ year MSTP, 27 years)

\section{Exclusion from campus.}

"It is quite challenging in a number of ways. We are located on the opposite side of town where a diverse group - the folks that could enrich the study from a racial and ethnic background do not live." (Faculty, MD, 52 years)

\section{Competition.}

"The only time I think I really had trouble is as a medical student of collaborative oncology, it was competitive." (Faculty, MD, 48 years)

\section{Economics Barriers}

Three participants discussed how economic barriers stood in the way of succeeding in the program, as well as their desire to continue with a research career in academia. The themes identified within economic barriers reported from Black men in this dissertation analyses included the disparity in the salary between specialties, the 
disparity in the salary between academia and the private sector, as well as seeking

funding in the program. The participants did not identify any means to overcome these barriers in the interviews.

\section{Specialty selection based on earning ability.}

"I think there is a lot of specialty selection based upon I gotta get out and I gotta make some money cuz I owe so much. ... It's the number one deterrent to engaging in a research career with these financial pressures. Academic jobs don't pay like private jobs. You've got a $\$ 200,000$ something loan debt, sitting on you 'til you walk out the door. The difference in salary is significant in my profession. It's a big deal. It's not unique to anybody. It's for everybody." (Faculty, MD, 48 years)

\section{Discrepancy in salary in academia versus private sector.}

"In essence I think that sometimes where I get really frustrated is why am I doing this when I could be making like four times as much doing something else. I think sometimes the discrepancy between salaries and academia versus the private sector, when people are struggling becomes sort of a big barrier." (Faculty, $\mathrm{MD} / \mathrm{PhD}, 41$ years)

\section{Seeking funding.}

"Funding was probably second-largest barrier and since I haven't gotten any kind of support." (Student, $\mathrm{PhD}, 43$ years)

\section{Prior Academic Background}

Three participants discussed how their previous academic background lacked certain attributes that acted as barriers from doing well in their graduate training. They came from average schools and also lacked adequate undergraduate research experience, which made the learning time longer and the learning curve steeper at their graduate institutions. The smaller schools lacked the research-intensive environment that gave students experience working in the laboratory or acquiring research skills. In one case, the participant volitionally gravitated toward doing research during his undergraduate 
studies, to make him more competitive in graduate school. This, according to him, was an effort to compensate for belonging to an average undergraduate institution and having average grades in school. The interviewee responses to barriers have been categorized as follows:

\section{Average undergraduate school and average grades.}

"I was a pretty good medical student, but I was not coming from a medical school that's Harvard. It's [name of school]. Nobody's really heard of it. I was a B student at a very average medical school, and that's the reason I did the research in medical school. Someone said to me, "You gotta do something that's gonna differentiate you, because right now there's nothing special about you at all. You're a good medical student from an average medical school." I did get some publications when I was an undergraduate." (Faculty, MD, 48 years)

\section{Lack of undergraduate research experience.}

"In my undergraduate, it would have made a difference for me because they didn't have research. But if I went to [name of school], for example, as an honor graduate, and they have 30-40,000 students, we got to find a way to get that student into the labs early." (Non-scientist, $\mathrm{PhD}, 30$ years)

\section{Small undergraduate school with no research background.}

"I came straight from undergrad into the program, and coming from a small ASBCU school, the focus on science wasn't as stringent as maybe for a student coming out of Harvard. Coming here, they already had the advantage because they'd already been through the rigors of how to prepare yourself to become a scientist, where me, it was like a year and a half for me really to decide, 'Okay, I'm going for a $\mathrm{PhD}$. .' (Student, $4^{\text {th }}$ year $\mathrm{PhD}, 27$ years)

\section{Professional Characteristics}

Three participants discussed how not having certain professional characteristics, for example, lacking the leadership skills, not being able to think like a scientist, and getting used to hard work, were perceived as barriers. In discussing leadership skills, the participant discussed how he sought institutional help in order to overcome the barrier, and realized the importance of practicing leadership skills every day. In discussing 
barriers related to thinking like a scientist, the participant discussed how he had to work hard to acquire specific skills like critical thinking, academic writing, and developing the ability to run a lab and do research. In discussing barriers related to hard work in academia, the participant discussed how he had to develop commitment and the yearning to learn, despite the uncertainties of seeking results or funding in research. However, he discussed that the process became less arduous and more enjoyable as one identified a group of like-minded people pursuing research and undergoing similar experiences. He also discussed the difficulties associated with a lack of time frame in completing a $\mathrm{PhD}$, which meant one had to push oneself and stay on track through self-motivation. Doing a $\mathrm{PhD}$ also meant spending long hours in the laboratory, reduced socializing experiences, and long and unstructured work hours that required building a specific mindset to work around those issues.

\section{Inadequate leadership skills.}

"I guess one thing I think I need to work on is just sort of my leadership skills, ... I don't think you really know that you know how to do until you have to do it. ... there's various sort of programs they have on campus for those types of things. I'm starting to participate in those things, which I didn't do previously." (Faculty, $\mathrm{MD} / \mathrm{PhD}, 41$ years)

\section{Thinking like a scientist.}

"For me, the major barrier was just forming my brain into that of a scientist. Scientists require a specific type of skill. It requires a specific way to think about things. It requires an ability to write very differently. When I first started writing and sort of thinking, or at least trying to think as a scientist, meaning critically, I wasn't very good at it. I saw what my professor was doing on a daily basis to keep the lab running in terms of writing grants, bringing money into the lab, making sure things were organized and run smoothly, I always kinda thought to myself that could never be me. It was just more of an ability issue, can I really do this?" (Faculty, $\mathrm{PhD}, 40$ years) 


\section{Getting used to hard work.}

"I think in this field, if you get into a graduate program, you just have to work. You just have to be committed and there's nothing guaranteed. ... Once you find people that are like-minded, you'll realize that it's actually kind of enjoyable ... Getting a Ph.D., there's no timeline. ... You have to push hard because you could take ten years ... it's long hours, it's tough ... Being a graduate student in a lab is tough work, and there is not a lot of opportunity for social ...You're in there at all hours of the night ... I think, really, it's a mindset. ... what I wanted to do is get a $\mathrm{PhD}$ so that I could make up my own experiments and get funding to do it." (Nonscientist, $\mathrm{PhD}, 30$ years)

\section{Mentoring}

Two participants discussed how lack of proper mentoring is a barrier. One of them recommended measures to ensure that students are paired up with a mentor that benefits them, based on prior feedback.

"Well, a lot of the people that are teaching in medical schools and medical university environments, they don't really know how to mentor naturally. They have to learn how to be a mentor, so I would say one of the barriers is identifying people that know how to be good mentors." (Faculty, MD, 54 years)

"I've seen some of that where students have been allowed to partner with mentors who consistently just don't mentor at all. I think that's unforgivable for a program. They're sort of working on that. Creating a database and matching up a student, like if a student takes a mentor who's mentored a student before, they make sure that that student gets in contact with the student who's moved on and gets an accurate assessment." (Student, $6^{\text {th }}$ year $\mathrm{MD} / \mathrm{PhD}, 28$ years)

\section{Juggling Family Responsibilities}

One Black male participant reported juggling family responsibilities with career

as a barrier, as a result of which, he deferred joining medical school for a year.

"When I got accepted into medical school, I had two children and one was on the way, so I actually deferred a year. I went through medical school with my wife and three children, so I juggled all of that. It wasn't the best time to move to a different part of the country and have a baby born the same month you start medical school, so I decided to defer a year." (Resident, MD, 32 years) 


\section{Individual-Institutional Theoretical Framework for Black Males}

Based on data from this study, it is evident that the reported barriers fit into one of the three categories of the theoretical framework.

Some of the individual barriers include lack of confidence, self-created barriers, and impostor syndrome. They are not influenced by the institutional characteristics, but have been barriers for the participants nevertheless. The following two examples illustrate this.

"To me, the only barrier was myself. ... Many, many times when I first started, it was extremely difficult." (Student, $4^{\text {th }}$ year $\mathrm{PhD}, 27$ years)

"Well, the confidence was not always there. I did doubt myself on a lot of things." (Faculty, $\mathrm{PhD}, 40$ years)

Some of the institutional barriers include funding issues, lack of prior academic background, institutional characteristics, and poor mentoring. They are not influenced by individual characteristics of the participants. The following examples illustrate this.

"Well, a lot of the people that are teaching in medical schools and medical university environments, they don't really know how to mentor naturally. They have to learn how to be a mentor, so I would say one of the barriers is identifying people that know how to be good mentors." (Faculty, MD, 54 years)

"Once you're in that Ph.D. program and you passed that oral exam, then there are more opportunities for supporting you, but not so much once you just got into graduate school, so that students that get in for first and second year, they don't have a lot of support. By support I'm talking about not just financial support, but mechanisms in place to kind of help get them through that oral exam process that I think is a big, a barrier, right there. A lot of students are not able to make it through the Ph.D. program because of that." (Non-scientist, $\mathrm{PhD}, 30$ years)

However, based on this study, the majority of barriers for Black males are due to an overlap between individual and institutional attributes. Some of these include racism and minority perception, racism and preconceived notions, racism and institutional 
exclusion, racism and performance pressure, personal barriers and people's perception of them, economic barriers and specialty selection, professional characteristics, and family responsibilities. Some examples from the aforementioned categories will illustrate this.

"There were some limitations in terms of just where I was coming from. ... there were programs that I was applying to who didn't take black folks at all. ... Even in the nineties, there were residents who had never trained black people, and it was by design ... the head of neurosurgery had never trained a minority and was not bashful about telling you he wasn't interested in that." (Faculty, MD, 48 years)

"When I was coming out of high school I didn't speak very well. I didn't carry myself the way a lot of the other students did, but I still did well. ... I definitely had no shortage of situations where peers and professors told me that I didn't have what it takes. They would assume that I couldn't perform because I guess the way I spoke and the way I dressed. ... I had various obstacles. Part of the problems I had with my undergraduate advisor were I think, resulted from some of that. In undergraduate, frequently during the beginning of the semester I would kind of be ostracized in my math classes. I still deal with some of those issues." (Faculty, $\mathrm{PhD}, 40$ years) 


\section{Barriers Reported by Black Females}

In this analysis, the responses of 38 Black female participants were analyzed and categorized into several themes of barriers, as discussed below.

\section{Gender}

Gender issues were the most widely reported barrier for Black females. Eleven participants, including eight faculty members and three non-faculty graduates, reported some form of a barrier that has been categorized into the following themes. None of the students reported facing gender-role barriers.

Glass ceiling effect for gender and race. One Black female participant reported that the combined effect of being a woman and being Black creates a ceiling effect in research and administration, also in part because certain female leadership skills and styles are different than those for men. There is some level of agreement between women across institutions about this issue, according to the participant. These gender biases in leadership areas are mostly because of the lack of overpowering physical appearance for women, or because they are usually soft-spoken, and do not raise their voices like men do.

"I felt the gender and race are a ceiling. This was overall, in the research arena, and in the administrative arena. I think one of the things that is tough as a woman on the administrative level, I think men - we do lead differently. Men, I think, still — for example, they can raise their voice in a meeting. ... women don't have the overpowering physical presence perhaps as men do. I think there's still something on the leadership level that has certain gender biases." (Faculty, $\mathrm{PhD}$, 50 years)

Gender and career opportunities. Several Black females discussed the lack of certain career opportunities that was deemed as a barrier to their success in the program. They are discussed below. 
In discussing promotion or career advancement issues, one female Black participant indicated the culture of a specific branch of medicine. According to her, most women feel disconnected and face issues in promotion. Men get promoted more than women in that specialty, and it is harder for women to adjust in the culture of the program that is thriving with men.

"I think that they have been (gender and minority issues in surgery have been barriers to progress) because I find that some of the men - I don't want to say are taken more seriously, but they're promoted more, or there's more of an interest in them. ... you're welcome to join the club if you can find your place at the table, but nobody's gonna save you a spot." (Faculty, MD, 35 years)

Another female participant (who is not currently pregnant but is considering having a family in future) discussed her concerns about taking a short-term break from career because of family responsibilities, and jeopardizing her future career advancement options in the process.

"Maternity leave ... taking as much as three months out of your career. I do worry about that in my current career. For someone who's constantly planning for her career like I am, the prospect of having kids is worrisome in terms of how that's gonna affect my ability to continue earning at the level I should be earning at. I think it's really difficult for women in all fields. I just don't think there's the support. ... There's a perception that if you're not there, then you're forgotten. And if you do, you're expected to still do well at whatever else you thought you were gonna be doing with your career. I don't know how this is sustainable, all of these crazy expectations." (Non-scientist, $\mathrm{PhD}, 32$ years)

Another Black female described how she saw males in the field progress and get promoted easily compared to women, despite doing the same amount of work. That, according to her, was a barrier to her success. She further discussed what is found in existing literature, which is the hardships women face in getting promoted to higher ranks of professorship in academia.

"I think for women in academia the issue is always level of promotion. That was a big issue in my fellowship and my early years as an attendant. I think most 
women in surgery at that time struggled with equal levels of being promoted through academia as our male counterparts seemed to excel. That became quite a visible issue across board to in terms of looking at women who were at the level of associate professor -our professorship was very minimal, while your colleagues who entered and trained with you and at the same and did the same amount of work seemed to move ahead in their promotion level. I think that's still (an issue)- trying to break that glass ceiling." (Scientist, MD, 56 years)

In discussing salary for women, one Black female participant reported that, in certain situations, women in the field make less money than men do, which was deemed as a barrier. She did not report what those specialties are, or what might be the cause for it.

"For women it's that the pay scale is still lower for women than it is for men. ... that's still a struggle for women." (Scientist, MD, 56 years)

Gender and raising a family. The female Black participant further indicated that she considered starting a family in graduate school a barrier, because of the rigor of the program. She further added that the situations have changed with time, and as faculty, she sees female students being able to plan a family around graduate school.

"Very few of us were married. Nobody had any children, family didn't come into play as much as it does now. Things are definitely different now ... graduate students really have planned their family life a little bit more so in trying to integrate it with what they do, more so than I did. I got married, but I didn't even think about having a family until I could see that okay, maybe then. ... I wasn't gonna add that to all the other things that I was working on." (Faculty, PhD, 59 years)

In addition, another participant (not currently pregnant) discussed in detail her concerns for starting a family, given the perception of women as caregivers in her field, and the lack of support even from other women. She discussed the implicit pressure from the field for women not to have children, or start a family at an advanced age. She discussed having seen principal investigators solely focus on data collection and paper 
publication, and has even heard them ask women to come to work and leave their children in the conference rooms.

"There's still an underlying pressure I see as a female, to not have children or to postpone it ... I don't have any kids. That's in the back of my mind ... At some point, if you have a child, you have a responsibility for taking care of that child, and they look at you like now you can't be taken seriously and that your research isn't important.

As a woman, that's definitely an issue. ... if you wait until you have done the post-doc, you're an instructor, and now you're an assistant professor, well, now you're 40. Now you have to have a high-risk pregnancy, because it was never a good time to have a child. ... Still inherent in the profession , is that it's not very female friendly. ... female PIs are not always supportive, cuz they're just on their missions as anyone else ... or they decide not to have kids, so they think you shouldn't as well." (Postdoctoral fellow, PhD, 37 years)

In discussing gender, delay in pregnancy, and racial barriers, one female Black participant indicated that the professional environment is not very conducive for women, minorities, and especially pregnant women. The number of women in certain programs is dismally low (two out of 40 residents in this case), which is perceived as a barrier.

Additionally, the number of Blacks is also dismally low in the same program (1 out of 40 residents in this case), which is not perceived as an environment conducive to learning. This made the participant extra careful about choosing an institution that had a better representation of women and minorities. According to her, being a surgeon was challenging enough, and being in an institution not representative of women or minorities would have compounded her barriers to success. Thus diversity in the program was viewed as an important asset. Additionally, while choosing the institution, she was careful about making sure that the program had enough pregnant women or women with children, so that she could be supported in the program. Her previous program lacked those attributes. So she had to delay her first pregnancy until age 45 years to ensure she 
was first at an institution that would support her through her pregnancy.

"I have intentionally planned the environments that I spent time in because I know that there are environments that are not friendly to gender, not friendly to race, not friendly to health issues like being pregnant. ... it's hard enough as it is becoming a surgeon, I don't wanna be in an environment that I still have to prove myself as a woman, still have to prove myself as being black. ... At [name of school], if a male resident had a child, that wasn't an issue. If a female resident was pregnant, a major issue. It was not an issue at [name of another school], so in each environment, I've sort of chosen for that. ... You would always know that race, gender, and pregnancy are a barrier in surgery. I actually delayed my pregnancy. I'm 45 and I'm having my first child. It may be a barrier that occurred, but definitely something that I was thoughtful of where did I want to be in my career when I had my first child." (Faculty, MD, 45 years)

Gender and the struggle in maintaining work/life balance. One female Black

participant indicated that balancing career and family is a personal barrier because of time constraints it imposes both for time with family, and for juggling work responsibilities. The participant strongly advocated developing a personal support system and seeking outside help to overcome this barrier.

"Personally, it's always a difficult balance, to balance career and family. That is, that is challenging, and the barriers of how you actually make yourself happy with that balance and not feel guilty all the time. Between, you know, the time you spend at work, inevitably conflicts with the time that you wanna spend with your family. ... sometimes we want to do it all and not accept help, but you've got to have a really good support system around you, particularly personally." (Faculty, $\mathrm{MD}, 51$ years)

One participant expressed an increased concern about maintaining a healthy work/life balance once they decide to have a family. They not only exemplify and try to emulate the lifestyle of colleagues who have successfully balanced their personal and professional lives, but are also very aware of their female colleagues who do not support them in their struggles.

"I don't have kids now, so I guess that's still a future thought, but I didn't see how you could do that and maintain a tenure track position. The women who are in the department I was in, I would never wanna be them." (Non-scientist, PhD, 32 
years)

The same participant described an example where her male boss had the freedom to spend time with children as and when required.

"I'd wanna be the P.I. I worked for. He had a very balanced life. He could go home if his kids were sick cuz his wife worked in a pharmaceutical company so she didn't have that sort of flexibility. He had the flexibility to take care of the kids." (Non-scientist, PhD, 32 years).

One female Black participant indicated that working as faculty and balancing family responsibilities was a major barrier. Although she received a lot of support from her spouse, who is a stay at home dad, she needed to negotiate her time with him if she wanted to work late, work on the weekends, attend seminars or conferences, or socialize with her colleagues after work.

"My husband is a stay at home dad ... there are some definite times where for example if there's a seminar in the evening. He questions do you really have to do that because you're there ten hours a day. Why do you have to stay there until 7:00 tonight, I'm like because it's important to be seen at these things because people are there or I want to get to know other faculty across campus because I only see science faculty. ... I definitely feel like I have to ask permission and God forbid something is on the weekend. It's like oh yeah big time permission for that or going to a conference is so much harder know. Those things are really hard." (Faculty, $\mathrm{PhD}, 34$ years)

Gender and communication skills. One female Black participant indicated that her gender and her young age were barriers in the program, because she had to learn how to talk and act, so that people in the program took her more seriously. She talked about taking a course in communication that taught skills to communicate with colleagues, which she said was helpful.

"I think it was the fact that I was female and the fact that I was young. ... It was challenging. ... to learn how to speak so that they would hear me. ... I remember taking a communication course. They talked about the pyramid versus inverted pyramid style of speaking of women versus men. ... it was learning how to play the politics, learning when to be quiet versus when to talk. Learning how to get 
what you wanna say across and not be seen as "being bitchy," which we all get accused of when we're forceful. Learning not to really, actually, care after awhile. ... as you actually get older or more experienced, those barriers, I think, they may not completely go away, but you kinda care less about them." (Faculty, MD, 51 years)

Gender and role modeling. One female Black participant indicated that the lack of female faculty role models in her graduate program was deemed a barrier, as it reflected an academic environment not conducive for women.

"I think it had to do more with probably being a woman, because actually, in my graduate department there really weren't many women faculty. I didn't have any women role models ... people never got tenure.” (Faculty, $\mathrm{PhD}, 59$ years)

Interaction with people in the field. Three Black females discussed several examples of the way they were treated or perceived by the people in the field.

Student perception of gender and race. One Black female participant indicated that being a woman and being Black made her students perceive her to be soft and friendly, to the extent that they would make unreasonable requests (like extending deadlines or giving extra credits) they would normally not make for their male professors.

"That comes up in classes where I get different questions and different requests than my male colleagues who are teaching the same class. Students will want me to extend things or give them extra credit, that they would never ask my male colleagues. I get more appeals on grades and things like that than my male colleagues do.... I think student perception sometimes dealing with a woman, especially dealing with a black woman. ... (they perceive) that you're gonna be soft because I'm nice and friendly and outgoing. ... then being a black woman I'm sure there are students who might have issues with that. Having an authority figure that's a minority because I'm at a primarily white institution and we're talking kids that have a fair amount of money." (Faculty, PhD, 34 years)

Treatment from faculty. One Black female participant shared her experiences

with a faculty member who did not encourage women to ask questions in class, but had no issues with men doing so, according to her. 
"One of our instructors for one of the biochemistry sections, a really prominent guy, ... He hated when women asked questions in class. A guy could turn around and ask the same question he had torn a woman apart about and he would just answer it." (Faculty, PhD, 44 years)

Acceptance by colleagues in terms of level of ability. One Black female

participant discussed that it was a barrier to be accepted by her colleagues for her abilities because of gender. The recognition for women is not the same as for men. It could be either attributed to women's hesitation to be more vocal about their requirements, their unease in the field and low self-esteem, their inability to fit in, or the lack of recognition, independent of their sub-field.

"I think for barriers it was more or less acceptance by colleagues in terms of level of ability. It just seemed like, no matter how good you were, you didn't get that recognition as your male counterpart would get. ... whether it was an uneasiness and coming to terms with it or about just not being verbal enough to want to say anything ... or lower self-esteem ... I think it was independent of specialty." (Scientist, MD, 56 years)

\section{Racism}

Racial barriers at the social, institutional, and personal level are a big cause of concern. An interviewee in this study summarized the following about the issues associated with racism:

"I would say it's more psychological than it is institutionalized because when you look around and there's no one else like you it makes you just feel isolated. Then because you feel isolated, you isolate yourself which is kind of ironic. I hear complaints that people make here specifically about feeling like they're not respected. They're not taken seriously as scientists. Because of that it makes them not want to be here and then of course if you don't want to be somewhere you're not going to put your best effort forward and then the cycle is worsened." (Postdoctoral fellow, PhD, 30 years)

Nine Black females reported facing some kind of a racial barrier that they had to overcome in order to be successful in their field. The different themes within race as a barrier are discussed as follows: 
Assumptions for being a minority and a woman. In this example, the

interviewee discussed that her barrier was being treated differentially based on her race and gender. She felt that there were a lot of implicit assumptions made based on those. Further, many non-minority males in the program did not know how to relate to her or communicate with her.

"I think I had to overcome the barrier of being treated differently because I was a member of a minority group. I think because I was a woman ... I was on teams of men who were all Caucasian and there was a difference. I think that they didn't know how to relate to me. Everywhere I ever went, I had been exposed to people who were not of color, so it wasn't an unusual thing to me, but is a very unusual thing for a lot of people who are not of color to ever know a person who is of color. They might have a janitor or a maid or something, but they don't just have regular relationships with people of color. As a result, I had to overcome the barrier of them assuming things about me.” (Faculty, MD, 47 years)

Bias. Is there a bias that highly achieving students could not be minority? An interviewee shared a personal example that illustrated this barrier.

"I remembered in one of my exit interviews from [name of school], one of the senior people said we're really, really upset that you're leaving because you're not really a minority because you're good. I don't think people realize that the bias that is there really makes it difficult for people of color to succeed because you're already facing a lot of other challenges." (Faculty, $\mathrm{PhD}, 50$ years)

Being an outsider. This interviewee shared her insights about racial barriers tied to her gender, as well as immigration status. Growing up in a country where the majority of population is of African descent, she never felt like one's color determined one's educational status or stature in the society. However, in the U.S., the color of one's skin is associated with their interest or performance in science, and constantly fighting such negative stereotypes was a barrier. The implicit assumption was that one cannot love science as a Black person. She further described that, moving to the US as a child, she had difficulty adjusting with other Black kids, who would not see her as one of their own, 
because she had White friends and loved pursuing science.

"This is as a black person. I do think one, that I wasn't born in the US and two, that I actually went abroad for part of my training because when I came to the US, it was that I was a black girl that liked science. I was always the person outside meaning I was always different. There's a lot of stress with that. No one expected me to like science. They're always expecting you to fail and do poorly, and it's really difficult." (Faculty, PhD, 50 years)

"Remembering when I was young and I came to the US, the black kids were also oh, you don't sound like us, and you have white friends. ... If you like science, then you're not black or it was from their perspective. I think not fitting into either group ..." (Faculty, PhD, 50 years)

\section{Ethnic barrier.}

“I don't think we're equal. Actually, observing throughout my training (in surgery) and now I'm on the other side of it, with respect to socioeconomic and gender and ethnicity, there's the ethnic barrier." (Faculty, MD, 42 years)

\section{Racial Bias.}

"I am always very thoughtful of how people have perceived me as a clinician or as a researcher. But when people said things or did things that I felt were because of their bias, I really never felt it was about me. But I think that those barriers, you always have to work at a higher level to try to alleviate people's worries and those things that people often times make their first impression a lasting impression." (Faculty, MD, 45 years)

\section{Overcompensation with hard work.}

"As a black person, sometimes you do feel that people look at you in ways ... but there has been a time in life where I think, Okay, if I work 150 percent? ... You sometimes think you have to be excessive in order for someone to give you the credit that you think you might be warranted." (Faculty, $\mathrm{PhD}, 59$ years)

\section{Race, cultural barriers, funding, and duplicity of the academic environment.}

“The external barriers I faced, I mean people's attitudes towards under represented people and sources of funding for underrepresented people that was a big factor for me in graduate school. Also, cultural differences in how people interact. There's really big challenges to overcome with regards to ones, the readiness to speak one's mind. Nobody in my family had ever done a PhD, so I was completely unprepared for the duplicity of the academic environment in 
which people don't always say exactly what they mean.” (Faculty, $\mathrm{PhD}, 32$ years)

\section{Fear of racism.}

"My biggest fear about teaching is that people will see me as somehow less qualified. I need a T-shirt that says, "I'm here because I went to [name of school] and produced two high impact papers, not because I'm black." Yeah it's very easy to look at someone and conclude, "Oh, they're here as a token," and assume they're not qualified to do their job. That is not indeed the case." (Faculty, $\mathrm{PhD}, 32$ years)

In this case, her chair/mentor supported her and advised her not to let people

recruit her for committees beyond a certain limit.

"Well, my chair is very protective of me. He actually said to me, 'You know people are gonna try to recruit you for committees, and if you feel overwhelmed,' that I should route them through him, and he'll tell them that I can't. He's been enormously supportive." (Faculty, PhD, 32 years)

\section{Overcompensation and gender-role barriers.}

"I think there's always a stigma with an African-American, that anything you're doing, you have to do it three times better than a Caucasian does. ... just to show that we can belong, that we should be here. Even as far as getting grants these days with African-Americans, we're not getting the grants for some odd reason. I interviewed at a medical school, and I could just really tell that was their attitude. Here, you ask them how many years to tenure, it's five or six is the common thing; medical school, it's like eight, and they really didn't define what tenure was. Eight years to tenure means you're not getting it at all. They really wanted me to produce a lot of stuff - all of these papers. I knew that I wanted to have a family. I'm 35, I can't wait any longer, so they'd be pretty pissed if I came here pregnant." (Faculty, PhD, 35 years)

\section{Anxiety issues at large gatherings.}

"I think for me, the biggest thing that I had to overcome when I went to conferences was I grew up in an all black area. ... My first fish out of water experience was graduate school. When we went to conferences there would be like 50,000 people and there would be only two black people, that was such an anxiety-invoking experience for me. I think a lot of people in academics, who have grown up in these all black or all Hispanic or all whatever, when you go somewhere and you are just so far out of your element, that can really make you uncomfortable and really make you not even want to stay." (Faculty, PhD, 36 years) 


\section{Self-inflicted racism.}

"I was raised in a very pro-black household and my mom has some scars from discrimination that occurred to her as a graduate student. Because of it she made me very, very skeptical about trusting people at graduate school and something that I think would have helped me a lot would have been to work with others in my classes. Because I was this paranoid as a graduate student I just stayed to myself. I didn't ask questions in class. I would just go home and try to learn all the information on my own.

Even though I never failed anything, I think I would have done much better had I worked in groups and made friends, asked questions, but I was afraid that people would think "Oh, she's a dumb black girl." Being the only black female there I think also kind of hindered my comfort levels." (Postdoctoral fellow, PhD, 30 years)

\section{Barriers in Mentoring}

Six Black females reported facing some form of a mentoring barrier that they had to overcome in order to be successful in their field. The different themes within mentoring as a barrier are discussed as follows:

Mentoring and gender barriers. The interviewee reported not receiving structured mentoring as a barrier, and as a result, she did not receive enough guidance through the process of writing grants, managing budgets, and acquiring skills beyond the realms of learning science and math. This happened in the past, when the faculty was a student. She described the gender-barriers where mentors were mostly senior males who could not relate to younger female mentees, and were unable to train them well through the programs.

"I can't say that I've had necessarily the best mentors along my career. I've been lucky to have met one or two people here and there who have given me some guidance, but I think for the most part, that has been one of the weaknesses of my career is mentoring." (Faculty, PhD, 50 years)

"Again it comes back to gender. Most of the senior people were men. They didn't really relate to women that well. Even though they might respect that the women were hard workers and intelligent, but in the sense of who do you give the tips 
to, I don't think it's purposeful.” (Faculty, $\mathrm{PhD}, 50$ years)

\section{Lacking a good mentor.}

"For me, some of the biggest barriers were things that were external, like having a good mentor, having additional classes and skills. For me, it was just trying to get more of the infrastructure in place to sort of help me be successful." (Faculty, $\mathrm{MD}, 42$ years)

Lack of mentoring tied to minority needs. The interviewee specifically

discussed lack of mentoring as a barrier, especially because minority student needs were different compared to the needs of non-minority students. She described that, although her school made efforts to recruit minorities for enhanced diversity, there was seldom any support system for the minorities. The number of minority students in the school was still dismally low, and for those who were there, the support groups were lacking. This was a challenge to maintaining diversity in the schools.

"I felt like outside the program there's a barrier for my own self, not having the proper information I needed to seek out a mentor early. The university lacked the understanding of minority (needs) ... not even having an understanding of how to help that particular student navigate through. ... those things that were not designed to help a student in my particular situation make it through with the type of support that we need to make it. ... you can celebrate the idea of having a diverse population, but if when you get that one minority that joined the program it's rare to have a minority ... it was kind of like the celebration stops very quickly. ... they didn't know what to do. I quickly learned that celebrating diversity and actually being able to maintain is probably quite different." (Resident, MSTP, 35 years)

Bad mentoring. In this case, the interviewee indicated her mentoring barriers,

which were related to her mentor lacking the confidence in her. He was not supportive of her search for a postdoctoral position.

"My mentor in graduate school I don't think he had confidence in me that I could do the work. One time I was in his office, and he told me that what I would be good at would be basically being like a technician. That was I would say towards the last year of my training. He didn't help me at all (during my search for a postdoctoral position)." (Postdoctoral fellow, $\mathrm{PhD}, 52$ years) 
In another example, the interviewee discussed several aspects of bad mentoring that included the mentor not being invested in the mentee's success, disparity in management styles, conflicts, and a work environment not conducive to learning, based on mentor-mentee interaction.

"I think bad mentors are a huge barrier. I mean if you have bad mentorship-I think mentors that don't really have your interests at heart, I think it's a huge barrier for a student. For me personally, I had an old mentor whose management style did not fit my style, and so there was always a huge amount of conflict there. I found him to be unprofessional, so that also created more conflict, and it basically resulted in a dynamic where you really want to do the work in the lab and you're excited about the research, but you don't like coming to lab, and sobecause of the environment, based on the interaction and dynamic that's between the student and the mentor. I think some mentors don't allow the student to have enough freedom to make mistakes and learn from them because it's a conflict of interest a lot of times." (Student, $5^{\text {th }}$ year MSTP, 26 years)

\section{Mentoring.}

"Not having proper mentorship early on, not being exposed to the hard sciences more than biological science." (Student, $4^{\text {th }}$ year $\mathrm{PhD}, 32$ years)

\section{Personality Barrier}

Several themes that were identified as personality barriers to success included being shy, lacking leadership and time management skills, as well as internal conflicts.

Five Black female participants reported such barriers that are discussed below.

Shyness. Shyness was associated with a hesitance to speak up, which was deemed as a challenge in graduate school. The participant overcame this barrier by forcing herself to participate in discussion classes, despite her discomfort.

"I think one of the things that happens a lot with any novice is that you're hesitant to speak up, and so I remember it was a challenge for me early on in graduate school. This actually changed because ... you'd have discussion classes and I would speak up in class. I forced myself to do that and I forced myself to do it actually because it was the expectation. I wasn't necessarily comfortable with 
that." (Faculty, $\mathrm{PhD}, 59$ years)

Not knowing how to be a leader. A participant discussed how she started to

learn leadership skills at an advanced age and stage of her faculty career.

"The thing standing in my way has been me. I had to really learn what it means to be a leader and what it means to be - to manage people and how to kind of remove yourself from that equation and kind of get out of their way and your way and get the work done. Focus more on the task and less on relationships or build those relationships, but don't make them the issue. Those are basic, really basic management concepts, and those things I had to learn." (Faculty, PhD, 56 years)

Internal conflict. A participant discussed how her internal conflicts became

barriers to her success.

"I think right now, there is this question within me, I think, of whether or not I can really be successful at what I'm doing. That might just be the environment that I'm in right now. I think that's a major barrier that I need to get over." (Postdoctoral fellow, PhD, 29 years)

Time management. A participant discussed how her lack of time management

skills was an issue to her success in graduate school.

"I think one of the things I need to overcome is how to be more efficient in a shorter period of time because the main issue with graduate school is that there's always something else that you can do in a day and kind of knowing where you need to cut it off is something that a lot of us don't really get. We'll stay and we'll keep doing things even though that could be put off for a couple more hours ... we try to get as much done in a full day that you can and it doesn't always work out that you did that specific thing that day." (Student, $5^{\text {th }}$ year $\mathrm{PhD}, 29$ years)

Lack of confidence. A participant shared her experiences with lack of confidence

based on her gender, race, and being from a different geographic location.

"I think a lot of the anxiety that I felt was I am a woman, I am black and I am Southern. ... A lot of it is internal, and then if someone looks at you differently, you're like, oh, is it because they think I'm stupid. I just had a lot of personal issues that I had to get over that were holding me back. It was mostly confidence (Faculty, PhD, 36 years)

What helped her overcome this barrier was choosing a school that had diversity, 
which gave her a chance to interact with people from different backgrounds.

I think that that was one of the benefits that my graduate program, had for us, is because that was the first time that I was staying close quarters with people that didn't look like me, that came from different SES, social economic status. That kind of helped prepare me, in a sense, for my post doctoral life, where there were no minorities." (Faculty, PhD, 36 years)

\section{Program Barrier}

Several themes related to program barriers were identified in this data analysis from responses of four Black female participants. They are individually discussed below.

Rigidity of the program and set expectations in academia. One participant discussed the rigid nature of the program, and of academia in general, that is a barrier. The program focuses on students achieving set milestones and it is the same with academia, which focuses on seeking funding and publication as a measure of productivity. That according to the interviewee is a barrier to creativity and imagination.

"Yes, boards, that was my major barrier. ... my whole life up until like last summer was just everything was for boards and that and just passing in my classes 'cause you know it's like you said it's a rigorous program ...my ultimate goal for the past two years was getting over boards and so now it's about setting a new goal which would be finishing my dissertation, and getting back to medical school in a timely manner. I noticed that with the research I think the culture is kind of more into a business ... now it's more about getting published and getting funded and I think it creates a barrier 'cause you know a lot of publications that are saying a lot but you're not seeing answers. And so I think it's created a barrier for just pure imagination." (Student, $3^{\text {rd }}$ year $\mathrm{MD} / \mathrm{PhD}, 24$ years)

Program milestones. A participant described how certain milestone examinations, as well as the transition from the second year to the third year of the program, were barriers.

"I would say the transition ... The most difficult part academically would be preparing for Step 1. That was very stressful, ... and then the transition from second year to third year was an adjustment ... if you don't do well on this test, there's certain things you won't be able to go on to." (Student, $3^{\text {rd }}$ year MD, 26 years) 


\section{Academic barrier.}

"Aside from academic. I don't think there were any other than academic."

(Student, $2^{\text {nd }}$ year $\mathrm{PhD}, 21$ years)

\section{Steep learning curve as a barrier.}

"I guess one of the things was it was a very steep learning curve for me, because I'm coming from chemistry, biochemistry, going into physiology, which I had never even had a physiology course before I joined this department. It was definitely a steep learning curve for me going into the field that I chose to go into." (Research fellow, $\mathrm{PhD}, 32$ years)

However, she also discussed an interesting point about selecting the right mentor who could help her with the barrier. She reported that she chose her PhD specialty based on her mentor and not based on the department. She felt that it was important that one develop a good professional relationship with the mentor, because learning barriers are inherent in the program, and every student would be facing them.

"I picked my PhD topic not based on the department. I chose it based on the mentor. If you do not have a mentor who's supportive and who is looking out for your best interest, that is something that could really hold you back. ... I thought it was much more important for me to have somebody who was supportive of me than my particular topic. All of us who come in, we have the same barriers, the fact that we have never taught before, and for us to learn how to teach things that we know, on the level we need to be able to teach them to high school students. My mentor was very supportive. My department was a really good department. All the people who were on my committee were really, really supportive, and they really helped me through that." (Research fellow, $\mathrm{PhD}, 32$ years)

\section{Lack of Guidance}

Three Black female participants reported that a lack of guidance was a barrier to their success in the program. Their responses are individually discussed below.

\section{Lack of guidance before starting clinical and research work. A female}

participant indicated that she did not receive adequate guidance from the program, and 
whatever little guidance she received was through other students. She reported receiving hardly any support from the administration, being treated rudely and lacking clinical support. There was a lack of encouragement for students to gain experiences outside medical school that were still relevant to her success in the field. During clinical rotations, there was a lack of guidance about how to treat patients, and instances where she was not given due credit for her work. At the administrative level, there was a lack of support regarding opportunities to travel to different countries, to enroll in other programs, or to pursue professional interests outside the set medical curriculum. This she felt was true, especially for minority groups, and students had to seek opportunities on their own.

"I think that I really lacked any true guidance. ... I don't think that we were supported by the administration enough ... I think I lacked the clinical support as I was coming through. I think if you came in and you weren't a top student right away, if you were just kind of the middle of the road, they just left you there. There wasn't a lot of encouragement for all students to strive for new things. ... Guidance goes all the way back just, in the clinical rotation, I don't think I got a lot of help from the residents on how to think about patients, how to approach the physical exam if I miss something. That was at the clinical level. Then in the administrative level, when there were things that came up, opportunities to go abroad or opportunities to do extra programs or to do something other than just the straight medical curriculum, those opportunities were not typically brought to the members of minority groups." (Faculty, MD, 47 years)

Lack of career guidance from advisor. A female participant reported lack of career guidance from her $\mathrm{PhD}$ advisor as a barrier, because the advisor had other professional interests.

"My PhD advisor was missing a lot. He was trying to set up a company on the side, and so I became his last direct student because he realized he gave no time to his students. Because I was successful in the lab, it worked out. I don't think my direct supervisor ever mentored me in any shape or form. There was no career guidance, opening doors or things like that. He did it to no one." (Faculty, PhD, 50 years) 
Lack of training. A female participant reported lack of adequate training as a barrier, because she came back to graduate school after a substantial time gap, and had difficulty relearning the content knowledge in the field.

"I needed more training. I had my MPH in 1995 - that was like ten years. I love math but who's going to remember those details? I had to go back and get another degree." (Faculty, MD, 42 years)

\section{Family Barriers}

Previously, this dissertation examined several barriers associated with starting and raising a family as a woman. However, this dissertation also examined other familyrelated barriers that were not necessarily related to gender. For example, three participants discussed how being geographically located in a school away from family was a barrier. This not only added to the emotional stress, but also caused monetary considerations when one would have to travel during emergency situations in family despite not earning a lot. The various themes identified are discussed below.

\section{Geographic proximity tied to finances and emotional stress.}

"Only issues I have with family_my mom was sick throughout my training and schooling, so living in a different part of the country, that-actually, that's a barrier I think that people have.

I don't think it was really mentioned to me-you should really consider where is your family, and not necessarily be next door to them, but it's tough to fly across the country to deal with a sick family member. I think those are barriers that I did have later in my training." (Faculty, MD, 42 years)

\section{Family considerations and geographic location.}

"The other barrier, the other problem that I had is, since I was older and I had family, those were factors that determined where I could go and what kind of work I could do as well. My advisor was very supportive in that respect because he had young children. Family considerations were an issue." (Faculty, PhD, 58 years) 


\section{Minority Status}

Three Black females discussed some kind of barriers they faced which they associated with their minority status. In each case, they either felt that there were unequal opportunities for minorities in medical science, or they felt that they were recruited to fill a minority quota. One participant mentioned feeling like an imposter in the program. The various themes have been discussed below.

\section{Unequal opportunities for minorities.}

"I'm trying to be politically correct here. The opportunities are not the same. I mean, I know we've come a long way, but we are not equal in the medical professional." (Faculty, MD, 42 years)

Filling a minority quota. The participant discussed her doubts about her worthiness of being accepted into the program, despite her lack of preparation in terms of research experience or coursework. She felt that she was recruited to help fill a minority quota and contribute to the diversity in the program. She struggled with overcoming the feeling of alienation, and she felt that was a barrier.

"I must be here for meeting a quota, I must be the minority guinea pig. Because there weren't other minority students in my program and everyone else around me had the research experience, had better grades ... I felt like in some ways how can I really do this because I'm not prepared like other people are. I hadn't had some of even the coursework. ... I have to sort of overcome that feeling." (Faculty, $\mathrm{PhD}, 34$ years)

\section{Being singled out as a minority and feeling like an impostor. The participant}

indicated that, although she had a group of minorities in her undergraduate and graduate class, that was not the case for graduate school. Hence, she would feel the isolating environment as a barrier to success. That made her question her self-worth and intelligence, having doubts about whether she really belonged there. She even had 
thoughts of leaving the program at one point. She wondered if she had been recruited to the program to fill a quota, and indicated that the lack of diversity, as well as being singled out in the program, was a barrier.

"When I first started, just sitting in class and realizing that you now are the only one, whereas when I was in undergrad it wasn't the case, even in the graduatelevel courses that I took, there were always four or five of us ... But, that was not the case when I got to graduate school. ... The only minority, person of color, the only person of color. That was definitely really difficult for me, just because I hadn't really been in a lot of environments where that was the case. ... it was just really hard, because then you start to question your self-worth, you also question your intelligence, you question whether or not you really belong, because no one looks like you. You're like, "Do I really belong here?" and they call it the imposter syndrome." (Postdoctoral fellow, $\mathrm{PhD}, 30$ years)

\section{Economic Barriers}

Overall, three participants reported economic barriers. Of them, two faculty members reflected back on their medical student experiences and reported that financial barriers were significant, often tied to taking care of a family. Graduate assistantships were low, and financial barrier is tied with performance issues. For example, some students worked on the side to take care of expenses, but that meant they had less time to devote to academia. If this impacted their grades negatively, the residency programs were not considerate enough to admit students with relatively lower grades, because they were working in addition to going to school. In this analysis, financial barriers were either associated with grades and academic performance, or were associated with the challenges of simultaneously raising a family. However, double-earning members in the family offered some respite from this barrier.

\section{Finances affecting GPA.}

"I don't know too many people that go to med school and work at the same time, and I think without a doubt, that affects your GPA. Now, you can go on these interviews for residency programs, but some places won't even interview you 
without even looking - if you don't meet the numbers, so if you don't meet the numbers, you're not even gonna get an interview to some of these popular programs. Then even if you do get an interview, how many people are sitting back there going, "You know what? Wait a minute. I know the numbers are weaker for this applicant, but that applicant worked two jobs whereas this one did nothing." Not too many people do that. I think that the financial barriers are significant." (Faculty, MD, 42 years)

\section{Financial barriers and the challenges of raising a family.}

"Even though you get a graduate assistantship, depending upon where you live and whether or not you have any other kind of family support, it's difficult to live on a graduate assistantship. Fortunately, I was married at the time, so I did have another source of income. I would not have been able to do that if I had not been, because I had a mortgage, I had children. The graduate assistantships are much better now, but at that time and living in [name of city] it would have been very difficult to live on a graduate assistantship." (Faculty, PhD, 58 years)

Low income. In addition, a third student indicated low income as a barrier to making a decent living for people in the field of biosciences. This will discourage her from pursuing a fellowship in future, especially without the financial support from family. Her perception is people pursue biomedical research for the love of it, and not because of the financial gains.

"Financially I think it's just difficult, when you're pursuing a $\mathrm{Ph} . \mathrm{D}$. in one of the biological sciences or something of that nature. It takes you awhile before you can get to a point where you can make a decent living. I think that the finances definitely have a huge role because I can't really see myself doing a fellowship after finishing a Ph.D. and maybe trying to live off of $\$ 50,000$ or $\$ 45,000$ a year. I think that would have been extremely difficult. I think somewhere else that may have been easier, or if I had financial support from my family." (Student, $4^{\text {th }}$ year $\mathrm{PhD}, 32$ years)

\section{Lack of Preparation}

Three Black female participants reported that a lack of preparation was a barrier to their success in the program. They individually discussed lack of research experience, lack of skills like critical thinking and science writing, as well as choice of undergraduate institution as barriers. Their responses are individually discussed as follows: 


\section{Lack of research experience.}

"I applied to a research based graduate program with no research experience."

(Faculty, $\mathrm{PhD}, 34$ years)

\section{Lack of specific skills.}

"Not so much beyond just working through not having some of the skills that I wish I would've been exposed to earlier like critical thinking and science writing. Those are more so barriers I had to really work through and am still working through to this day." (Postdoctoral fellow, PhD, 29 years)

\section{Choice of undergraduate institution.}

"There were certain deficiencies that I was unaware of academic wise because of the way that I had been trained as an undergraduate. I went to [name of school] which is a four year college and while I was at the top of the class, the teaching methods were not conducive to my success as a graduate student so I had to relearn how to think and how to learn properly for that environment so that caused me a deeper learning curve than some of my classmates who had gone to different types of institutions." (Postdoctoral fellow, $\mathrm{PhD}, 30$ years)

\section{Stereotyping}

Two Black female participants reported feeling like they were stereotyped in the program. In the second example, stereotyping is viewed as an internal barrier. The participant indicated that the internal barriers she faced were because of stereotype threat. This was when she moved from an underrepresented minority institution to a well renowned university. For her, the transformation was very isolating and she felt constantly evaluated for her performance based on her race. She felt that she was not good enough to belong to that particular institution. She believed that stereotyping was based on neuroscientific arguments that certain people have or lack certain genes based on their race. Both responses are included below.

"I think for me it's in both academia, science, and in the administrative realm ... (I have felt stereotype threat)" (Faculty, $\mathrm{PhD}, 50$ years) 
"The internal barriers that I faced had to do with stereotype threat and the usual feeling like you're not good enough to be where you are. That was kind of a big deal for me, especially going from [name of school], which is a majority underrepresented minority institution, to [name of another school], which is not. It was very isolating. I really had some troubles with, you know, feeling like I wasn't good enough to make the cut. I would always be afraid to give props and things because I felt like I was representing my ethnicity or my race, and then if I screwed up on one little thing it would just make everybody say, 'Well they're no good." (Faculty, $\mathrm{PhD}, 32$ years)

\section{Lack of Publication}

Two individuals reported that the lack of publication was deemed as a barrier to their professional success. In the first example, the individual felt that her lack of publication during her $\mathrm{PhD}$ program meant she faced more pressure to publish during her fellowship. She thus extended her 2-year fellowship by another year to get publications, and admits that this gave her a lot of confidence during her job search later on, as the experience of publishing gave her the skills of conceiving the idea, collecting data, coding, and data analysis from scratch.

"I think the biggest barrier was this issue of publication. Having not published during my PhD years I think in fellowship I felt a little more pressure ... That's why I ended up actually taking an extra year of fellowship." (Faculty, MSTP, 37 years)

In the second example, the respondent reported currently facing barriers because of her lack of publishing experience. This is because her principal investigator has lost the motivation to move forward with the papers, because of personal life crises, and the respondent has been unable to work with her principal investigator to get those papers published. The respondent deemed it a barrier, because she has been stuck in a postdoctoral position due to lack of publication.

"One of the things that I'm struggling with is my - the cases from undergraduate, the fact that they're not published. I've been trying to be patient with my previous PI because she lost her husband. ... It's been two years, and I don't 
know how to move that forward ... I feel like, if I had those two other publications, then maybe I would have been in a better position right now to maybe just move farther in my career, and not be stuck in postdoc la-la land." (Postdoctoral fellow, $\mathrm{PhD}, 29$ years)

\section{Institutional Barriers}

Two faculty members reflected back on their professional experiences and reported some institutional barriers that were a hindrance for them. These included lack of support and help with administrative work, learning to navigate the departmental and school level politics, as well as barriers to doing research like funding, ancillary work, and lack of protected time. Faculty responses have been documented under the following broad themes.

Lack of support with administrative work. Setting up a lung cancer database seemed like an arduous task, because the faculty member was unable to secure help with administrative work and running the database.

"Even in my attempts to say start up a prospective database so that we can start tracking all our lung cancer patients because there's very few operative candidates ... I was going to have to pretty much set it up; administer it; enter the data myself because I went to my chairman, I went to the head of the cancer center; I went to the School of Public Health. I could not get someone who would be dedicated to saying, 'Okay, I'm going to be the assistant to run the lung cancer database."” (Faculty, MD, 35 years)

\section{Learning to navigate the politics.}

"I think one of the hard things that I've seen is really having an appreciation for the politics of it all and knowing how to navigate that. Not that anybody ever really does, but I think it's one of those things that you don't realize when you're young, unless you're paying really close attention to what's going on around you, how divisive situations can be. Departmental, school level, yeah." (Faculty, PhD, 44 years)

\section{Barriers to doing research.}

"I'm expected to do research, but there have been some barriers there. Funding, 
ancillary support, and protected time." (Faculty, MD, 35 years)

\section{Communication Barriers}

Communicating content to school children in a simplistic way was deemed a barrier by a participant. She indicated that it was a challenge to simplify the content and present it in an understandable way. She also discussed ways of overcoming that barrier.

"I'd never been in a classroom. I never taught before. It's definitely different being used to being around kids and being in that environment ... I think just learning how to make sure I can bring things down to their level so that they can understand, that's been a big barrier, because sometimes you do things or you make a Power Point and you're like, oh yeah, this is easy. Then you get in there and the kids really don't get it ... I had to realize that some things that I think may be easy is not easy for someone their age." (Research fellow, $\mathrm{PhD}, 32$ years) "There's definitely a lot of on the job training. ... right now, that's why I'm going back and revamping some of the lessons that we originally gave to the students, because you do realize on some of them, okay, they need it more here. Then in the classroom, we just have to talk through it. You have a schedule, but you have to realize that you need to be fluid and flexible, and sometimes things aren't going to go the way you expect it. Sometimes you have to spend more time on a particular topic ..." (Research fellow, $\mathrm{PhD}, 32$ years)

\section{Miscellaneous Barriers}

Three participants reported barriers that are categorized as miscellaneous.

Mistaken identities. One female Black participant reported that she felt like mistaken identities from patients, based on her gender or race, were a barrier. She recounted an incident when the patient refused to acknowledge her as the doctor.

"I certainly think as you try to say color may be a barrier, being a female can sometimes be a barrier not only from your colleagues but sometimes from patients. Even after you've operated on a patient sometimes they fail to recognize that you were actually the surgeon. Those things can be a little daunting after a while. I think there are still some male counterparts that are still not as accepting of abilities of females. I'd probably still have to say that sometimes gender and ethnicity can play a role." (Scientist, MD, 56 years)

\section{Getting used to the environment.}

"Getting used to the environment of where I was - probably the thing that could 
be considered a barrier." (Postdoctoral research scholar, $\mathrm{PhD}, 25$ years)

Citizenship. Citizenship was a barrier for training opportunities, because the respondent did not qualify for some of the extramural funding opportunities. Due to her visa status that limited her stay in the country, she was not able to pursue many research and training opportunities or pursue job opportunities after her training.

"Leaving medical school I went into residency. I did not go into the lab because ... I'm not a citizen. ... I did not qualify for a lot of the extramural funding outside ... I went straight through general surgery, so I did not take time out to pursue research.

The citizenship issues came up for those training opportunities. It was huge because I would have liked to have done time in the lab and I think that would have helped me sort of from a research and mentoring standpoint. ... I just didn't have that opportunity. ... I remember at one point looking for the little branch for funding and couldn't find any that I qualified for because you have to either be a citizen or permanent resident. It's been an impediment.

Then I had very specific criteria that I had to follow then in terms of finding a job and an opportunity came up shortly after I had gotten here ... I did three months in another institution. I really got along well with everyone there. They weren't hiring at the time, but when one of their surgeons left, they called me and said, "Hey, we'd really like to have you." I couldn't do it because it just wouldn't meet my visa criteria." (Faculty, MD, 35 years)

Time to graduate. One non-scientist reported that her length of stay in graduate

school was a contributing factor to her leaving academia. She reported that her faculty

member lost sight of the purpose of graduate training, which she deemed as a barrier.

"I wonder if I was in a different lab, if my project had turned out differently, if I would have done a post doc. I mean, I think I probably would have. I think I would have continued the academic track if my graduate school experience went differently. I think that's where things really went wrong. I think my faculty member lost sight of what the purpose of graduate training is. I just spent too much time in graduate school and just got disillusioned and decided it wasn't worth it anymore. If I had finished in five years or even six years, I probably would have done a post doc." (Non-scientist, $\mathrm{PhD}, 32$ years) 


\section{Individual-Institutional Theoretical Framework for Black Females}

Based on data from this study, it is evident that the reported barriers fit into one of the three categories of the theoretical framework.

Some of the individual barriers include self-inflicted barriers, racial barriers, anxiety, personality barriers, family, and economic barriers. They are not influenced by the institutional characteristics, but have been barriers for the participants nevertheless. The following examples illustrate this.

"I think one of the things that happens a lot with any novice is that you're hesitant to speak up, and so I remember it was a challenge for me early on in graduate school. This actually changed because ... you'd have discussion classes and I would speak up in class. I forced myself to do that and I forced myself to do it actually because it was the expectation. I wasn't necessarily comfortable with that." (Faculty, $\mathrm{PhD}, 59$ years)

"The other barrier, the other problem that I had is since I was older and I had family, those were factors that determined where I could go and what kind of work I could do as well. My advisor was very supportive in that respect because he had young children. Family considerations were an issue." (Faculty, PhD, 58 years)

Some of the institutional barriers include communication barriers, institutional barriers, lack of publishing experience, mentoring barriers, program barriers, and lack of preparation. They are not influenced by individual characteristics of the participants. The following examples illustrate this.

"Even in my attempts to say start up a prospective database so that we can start tracking all our lung cancer patients because there's very few operative candidates ... I was going to have to pretty much set it up; administer it; enter the data myself because I went to my chairman, I went to the head of the cancer center; I went to the School of Public Health. I could not get someone who would be dedicated to saying, 'Okay, I'm going to be the assistant to run the lung cancer database." (Faculty, MD, 35 years)

"Not so much beyond just working through not having some of the skills that I wish I would've been exposed to earlier like critical thinking and science writing. Those are more so barriers I had to really work through and am still working 
through to this day." (Postdoctoral fellow, PhD, 29 years)

However, based on this study, the majority of barriers for Black females are due to overlap between individual and institutional attributes. Some of these have a gender component to them, while some have a racial component. For example, the various barriers that overlap with gender are race are gender interaction and glass-ceiling barriers, specialty selection, maternity leave issues, promotion issues, earning potential, raising a family, attaining work/life balance, communication skills, seeking role models, and interaction with people in the field. Similarly, the various barriers that overlap with race are facing differential treatment, bias, exclusion, funding issues, mentoring barriers, and stereotyping. Other overlapping barriers arise due to time management issues, institutional treatment, and economic barriers in combination with academic performance. Some examples from the aforementioned categories will illustrate this.

"I think that they have been (gender and minority issues in surgery have been barriers to progress) because I find that some of the men - I don't want to say are taken more seriously, but they're promoted more, or there's more of an interest in them. ... you're welcome to join the club if you can find your place at the table, but nobody's going to save you a spot." (Faculty, MD, 35 years)

"I remembered in one of my exit interviews from [name of school], one of the senior people said we're really, really upset that you're leaving because you're not really a minority because you're good. I don't think people realize that the bias that is there really makes it difficult for people of color to succeed because you're already facing a lot of other challenges." (Faculty, $\mathrm{PhD}, 50$ years) 


\section{Barriers Reported by Hispanic Males}

In this analysis, the responses of 10 Hispanic male participants were analyzed and categorized into several themes of barriers, as discussed below.

\section{Economic Barrier}

In this study, economic barrier was the most widely reported barrier among Hispanic males. Four out of 10 participants interviewed reported facing some form of economic barrier at different stages of the program, right from the start of a degree to the career decisions of a faculty. This dissertation analyzed responses from three of those participants, classified into four different themes.

Application to medical school. Application to medical school is the first step of beginning a career in the field of medicine. One male Hispanic student reported that the process of application was too expensive for his parents to bear, especially since it involved significant costs in being able to afford preparation materials, or apply to schools.

"My family, we don't have a lot of money, especially my parents. ... I mean just talking about interviews, getting from place to place ... it requires gas money. It requires me buying a suit. The MCAT, the Kaplan course ... I would say even just to apply to medical school is a big expense. And so I would say money ... that's the biggest one for me." (Student, $1^{\text {st }}$ year MD, 26 years)

Lack of opportunities. A male Hispanic participant discussed how the lack of finances in the family constrained him from pursuing an $\mathrm{MD} / \mathrm{PhD}$ degree away from home. Instead, he first pursued an MD degree closer to home, and then, instead of starting a medical residency, he joined the $\mathrm{PhD}$ program.

Interviewer: "Why did you enter an MD program as opposed to a combined $\mathrm{MD} / \mathrm{PhD}$ program?"

Interviewee: "In my case it was lack of opportunities ... Scientific research 
opportunities. There were no available programs in the area where I was available. My parents didn't have sufficient money to send me to study abroad, which was really what I wanted. ... It was a lack of opportunities that pushed my career. ... My parents didn't have the funds to push me over the edge to study ..." (Faculty, MD and $\mathrm{PhD}, 48$ years)

Low earning. The economics of raising a family centered around the means to raise children and send them to college for one male Hispanic participant. It also revolved around the choice between private practice, for greater monetary compensation, or working as faculty at an academic institution.

"Wanting to leave is very simple. It has to do with the economics. As you get older and you are not well compensated ... If you have been offered triple my salary in private practice ... circumstances and the economics of what I do when you have kids that are now older and in college and in private colleges, it just very difficult. A lot of the challenges have to do with economics. ... particularly those who are in public institutions, we have incredible challenges in terms of paying for a location of our children." (Faculty, MD and $\mathrm{PhD}, 48$ years)

Seeking funding to pursue research. A male Hispanic participant from an $\mathrm{MD} / \mathrm{PhD}$ program discussed facing economic barriers for six years while training in the $\mathrm{PhD}$ phase, augmenting thoughts of leaving research and focusing on the clinical aspect of the training. This was attributed to the uphill battle of seeking funding for research and running experiments. Additionally, he identified a dearth of successful mentors with the same $\mathrm{MD} / \mathrm{PhD}$ career pathway who could mentor him to seek funding. This was a barrier to a career consideration in academic medicine. While a clinical career was more defined and offered a guaranteed job or salary, a research career was not clearly defined, and involved competing for grants every few years, which discouraged students from pursuing a research career.

"I think my biggest barrier was training in the $\mathrm{PhD}$ program. ... for a long time $\mathrm{I}$ thought about giving up on the practical part of it and just dedicating to the clinical. A lot of it was because it felt like it was such an uphill battle to get support to do the research. ... the financial support to be able to run the 
experiments. ... we don't have funded mentors. ... We felt like there was only the verbal support, but not the financial support to get our research done ... We saw how, as compared to a clinical career where you kinda have a guaranteed job or salary, you're fighting for your job every couple of years, depending on the grants you bring." (Fellow, MD/PhD, 32 years)

"We didn't have any what we would consider successful mentors there that had the combined career pathway like as working both clinical and research-oriented. It seemed like we had either one or the other, and so it became hard to see a combined career making it work being a sufficient scientist. It kind of for a while there really drew us away from considering a career in academic medicine." (Fellow, MD/PhD, 32 years)

\section{Language Barrier}

Language barrier was more frequently reported by male Hispanic participants who were either not born in the U.S., or spent a significant time of their life outside the U.S. The following themes were identified based on the responses of four participants.

Language as a barrier in Biology classes. One male Hispanic participant discussed the lack of fluency in English as a barrier to succeeding in Biology classes, where there was an expectation to understand the language, in contrast to subjects like Math and Physics where (according to the participant), one could perform well without mastering the English language.

"The number one (barrier) was language because when I came to the States I actually did not speak very much English. It was okay in my classes because I was only taking math and physics. You don't need to know much English to do well in math and physics. Later on it was a struggle when I started taking things more related to biology." (Faculty, MD and PhD, 59 years)

Language as a barrier to test-taking. One male Hispanic participant reported experiencing language barrier in English. Although the participant had learned English in his native country, and has been living in the U.S. for nine years, lack of fluency in English was viewed as a barrier in reading, vocabulary, test-taking, and in general the speed at which one would solve problems. It was viewed more as an issue of slowness 
than the lack of understanding of the language.

"I know that I need to practice more in test-taking skills and stuff like that, just because sometimes I'll be too slow while reading a problem. It's not necessarily understanding, it's the language sometimes ties me up or something like that.... I went to a bilingual school. My English is appropriate, it's just that sometimes we have a verbal section, it's just not necessarily the understanding, it's just the speed to which you have to read. Sometimes I don't pace myself well ... It's just more like the time issue." (Student, $4^{\text {th }}$ year MSTP, 28 years)

Spoken language as a communication barrier. One non-native English speaker reported a barrier in verbal communication.

"Language barriers as far as communicating because I grew up a Spanish speaker so I learned English as a child. ... I realize that language is a big barrier as far as you're kind of analyzed as far as how you speak. And so being a Spanish speaker, I don't have that strong English foundation.” (Student, $1^{\text {st }}$ year MD, 26 years)

\section{Cultural Barriers}

Three male Hispanic participants discussed some aspect of a culture that was perceived as a barrier. The first participant discussed ethnic barrier, where people from the Hispanic student community were not expected to go to graduate school, and the participant had to overcome that.

"Then there's a little bit of the ethnic barrier. ... I went to a primarily Hispanic college in Texas. I think it was an unspoken expectation that people who go to college they are not Hispanic, they don't need to go to grad school. I think that was the biggest hurdle for me." (Student, $4^{\text {th }}$ year MSTP, 28 years)

The second participant discussed how parental, societal and cultural expectations create certain conditions perceived as barriers for a cultural lack of understanding. For example, pursuing certain professions was not viewed favorably, and there was a disconnect in perception between medicine and research. So while pursuing a medical career was recognized, people did not identify with the science component of an $\mathrm{MD} / \mathrm{PhD}$ career. 
"Somebody goes and says to a Mexican-American family, I wanna become a scientist. If you're becoming a scientist, when are you gonna become a doctor, a real doctor? For first and second generation Hispanic students in MSTP programs, the family ... don't appreciate the science component. They appreciate the medical component only. That is culturally something that is another barrier for minority students to get in. That's a barrier within our own minority's group." (Faculty, MD and PhD, 48 years)

The third participant discussed the cultural differences between families who attended professional programs and families who did not. It was easier for someone with prior family background to pursue a career in medicine due to cultural exposure at home through parental profession.

"It would be a cultural component to that that it might be easy for someone to get to med school because they have the money or they have parents that went to a professional program whereas myself, like my parents they didn't even graduate high school. So maybe there's a cultural divide there or a cultural barrier." (Student, $1^{\text {st }}$ year MD, 26 years)

\section{Institutional Barriers}

Three Hispanic males reported the following institutional barriers discussed below.

Stress in graduate school. One male Hispanic participant identified stress in graduate school as a barrier to success, for him as well as for his classmates. This usually led to depression, and disconnect between the self and social life, family, and relationships.

"Stress... It can get you ... if people don't find ways to de-stress. So that's a big hurdle in grad school. There's a lot of depression so you see a lot of people having a very hard time including myself into how stress takes you to get down on it, don't have time for yourself, no time for social life, no time for family or for the relationships. It brings you down to depression and all that kind of stuff." (Student, $1^{\text {st }}$ year $\mathrm{PhD}, 26$ years)

Structure and rigidity of the program. One male Hispanic participant discussed that the rigid structure of his program was discouraging and made it difficult to find an 
alternate physician in training. Ironically, it is due to the structure of the $\mathrm{PhD}$ program

that one is hemmed into completing the path, at least until one obtains a medical license

and is able to support oneself. It discourages people from a research career, mostly

because students feel a lack of mentorship support during the $\mathrm{PhD}$ phase.

"I was most discouraged, I think also because the way the program was structured, it would have been a little difficult to find an alternate physician in training. It kind of felt like we were locked into the program, at least until I could get my medical license and be able to support myself on the side until I was able to join another program. ... For a while, yes, I think that kind of discouraged me from a research career. I think the people that were in that program felt like we lacked the mentorship support during those six years." (Fellow, MD/PhD, 32 years)

Lack of protected time for a professor. One male Hispanic participant reported

the lack of protected time as a research professor as a barrier. This indicates a mismatch in expectations between the individual and the program.

"My opportunities into having protected time were not great, but primarily because my chair had recruited me for a clinical position. ... The lack of protected time is probably one huge barrier. If you don't have protected time, it's incredibly difficult to do research." (Faculty, MD and PhD, 48 years)

\section{Mentoring Barriers}

Two Hispanic male participants discussed various aspects of mentoring barriers that are described below.

Unforeseen circumstances in mentoring. One participant reported the death of a mentor as a barrier that compelled him to change schools.

"The other barrier as I indicated is that my mentor had a climbing accident before he passed away. I just took that as an opportunity to again look elsewhere and I came to [name of school] where I am." (Faculty, MD and PhD, 48 years)

Poor mentoring. One male Hispanic participant indicated poor mentoring as a 
barrier to succeeding in the $\mathrm{MD} / \mathrm{PhD}$ program.

Lacking physician-scientist mentors in the program. Mentoring for $\mathrm{PhD}$ requires different skills compared to mentoring for MD. One male Hispanic participant discussed the barriers in finding mentors who were physician-scientists and had experience with mentoring in both the clinical and research aspects of the program. This was associated with little understanding of the $\mathrm{MD} / \mathrm{PhD}$ experiences, and hence, little guidance in learning and navigating the program. The participant mentioned disconnects between the expectations of the mentors from both phases of the program, leading to a great deal of uncertainty.

"We had mentors that had a leg in both fields ... They're such different worlds that each side doesn't really understand the point of view of the other side. It just didn't seem like we had enough mentors that were both physicians and scientists." (Fellow, MD/PhD, 32 years)

\section{Lack of Prior Background or Training}

Two male Hispanic participants discussed the lack of prior background in science, math, or biochemistry specifically that was viewed as a barrier to success in the program. In addition, the lack of prior training with laboratory techniques was also viewed as a barrier, and learning and mastering laboratory skills took a significant number of years. The participant discusses how he overcame some of this barrier through tutoring and by attending seminars on study techniques that improved his grasp in the subject, even without having prior background in research.

"I never had any experience with laboratory techniques. I was a history major so I really lacked those skills. I had to start from scratch. It was difficult. It took a while not only to learn to do the experiments; to use the techniques, but to learn to master the techniques.... to feel comfortable enough. ... Because I came from a humanities background my biochemistry, my math was really weak. I think that was a really big barrier for me personally. 
At least in biochemistry I got tutoring and I went to a seminar on study techniques that would help me better grasp biochemistry - even if I didn't have the background in it. Just study techniques; ways to learn better. That was very helpful." (Student, $4^{\text {th }}$ year MSTP, 28 years)

\section{Foreign Status}

One male Hispanic participant discussed barriers attributed to his foreign status in the country. He perceived that this sometimes created difficulty in seeking professional opportunities. He saw this trend prevalent in other foreign students as well.

"I did have barriers mostly because of being a foreign medical graduate. For example, a professor at [an institution] invited me, but I was not interviewed there because I was a foreign medical graduate.” (Faculty, $\mathrm{MD}$ and $\mathrm{PhD}, 48$ years)

\section{Interaction with People in Science}

One male Hispanic participant indicated that scientific setting is a very unique environment and the lack of experience in interacting with people in science was a barrier. Mastering it required time, experience, and acquiring social skills. The participant indicated that it could be addressed and overcome by honing one's social skills, and through teamwork and cooperation.

"Another barrier is in terms of interactions with people when you're working with a select group of people ... the interaction with people in science seems to be to me a little bit more intricate than other social interactions. Learning about it and dealing with it, it can hinder your project. People act differently in social circumstances than they do in the lab. So learning that is tough." (Student, $1^{\text {st }}$ year PhD, 26 years) 


\section{Individual-Institutional Theoretical Framework for Hispanic Males}

Based on data from this study, it is evident that the reported barriers fit into one of the three categories of the theoretical framework.

Individual barriers were very few for Hispanic males and mostly included language barriers. They were not influenced by the institutional characteristics. The following example illustrates this.

"Language barriers as far as communicating because I grew up a Spanish speaker so I learned English as a child. ... I realize that language is a big barrier as far as you're kind of analyzed as far as how you speak. And so being a Spanish speaker, I don't have that strong English foundation." (Student, $1^{\text {st }}$ year MD, 26 years)

Some of the institutional barriers include economic barriers like funding, institutional barriers, mentoring barriers, lack of prior training in the program, and interactions of people in the field. They are not influenced by individual characteristics of the participants. The following examples illustrate this.

"Stress.... It can get you ... if people don't find ways to de-stress. So that's a big hurdle in grad school. There's a lot of depression so you see a lot of people having a very hard time including myself into how stress takes you to get down on it, don't have time for yourself, no time for social life, no time for family or for the relationships. It brings you down to depression and all that kind of stuff." (Student, $1^{\text {st }}$ year $\mathrm{PhD}, 26$ years)

"I was most discouraged, I think also because the way the program was structured, it would have been a little difficult to find an alternate physician in training. It kind of felt like we were locked into the program, at least until I could get my medical license and be able to support myself on the side until I was able to join another program. ... For a while, yes, I think that kind of discouraged me from a research career. I think the people that were in that program felt like we lacked the mentorship support during those six years." (Fellow, MD/PhD, 32 years)

Some of the overlapping barriers for Hispanic males included economic barriers

due to family background, language barriers in biology classes, language barriers causing barriers in communication or test taking, ethnic barriers, and foreign status of an 
individual. Some examples of these are as follows.

"Then there's a little bit of the ethnic barrier. ... I went to a primarily Hispanic college in Texas. I think it was an unspoken expectation that people who go to college they are not Hispanic, they don't need to go to grad school. I think that was the biggest hurdle for me." (Student, $4^{\text {th }}$ year MSTP, 28 years)

"I did have barriers mostly because of being a foreign medical graduate. For example, a professor at [an institution] invited me, but I was not interviewed there because I was a foreign medical graduate." (Faculty, $\mathrm{MD}$ and $\mathrm{PhD}, 48$ years) 


\section{Barriers Reported by Hispanic Females}

In this analysis, the responses of 16 female Hispanic participants were analyzed and categorized into several themes of barriers, as discussed below.

\section{Economic Barriers}

Consistent with Hispanic male barriers, economic barriers were most widely reported by six female Hispanic participants. They are described as follows.

Loan and debt. Two female participants reported debt incurred during medical school as a barrier.

"The financial aspect has been a burden. I had to take out an extra loan." (Resident, MD, 28 years)

However, the financial burden incurred by student loans and debts was significantly reduced in future through the dual income of household members, through having a second job during residency (moonlighting), and through NIH's loan repayment program. Debt relief was reported to be helpful in retaining more people in academia and in overcoming economic barriers.

"My husband and I were very fortunate in the sense that from our dual salaries we were able to pay down my debt much more quickly because, basically, he supported both of us. ... My entire income, including my rather extensive moonlighting income from when I was a resident, we dedicated that to paying down some bills. I had over $\$ 100,000$ of debt. ... The one thing that did help me a lot is the NIH's loan repayment program. ... I think debt relief would be probably helpful in retaining more people in academia." (Faculty, MD, 42 years)

Although medical school or graduate school expenses were a big factor for consideration, and the lack of money to pay them was often deemed as a barrier, this study indicated that some universities and programs were designed to help students through this, mostly through scholarships and contributions from donors to help students 
with their tuitions and educational expenses.

"I think the financial aspect of it is, for me, was the barrier. Deciding to go to medical school-I could have never attended undergraduate school were it not for the kindness and generosity of scholarship donors, through [name] University, because if I had taken out loans then medical school would not have even been an option. ... thankfully I applied for a few scholarships and a little bit of that burden is taken off for me. We have some donors here at our school. They made a trust fund for our program..." (Student, $4^{\text {th }}$ year MD, 25 years)

Lab funding. One female Hispanic participant indicated that sparse funding in

the lab makes it hard to afford resources to conduct research.

"The only barrier I do feel now is in a lab situation where there's no, very sparse funding. That makes it incredibly hard because I don't have the tools of my trade which are things like antibodies or animals." (Student, $6^{\text {th }}$ year PhD, 32 years)

Expenses of applying to school tied to immigration status. One female

Hispanic participant reported how a combination of the lack of finances and the lack of citizenship restricted her to a specific location, which was deemed as a barrier.

"Probably just financial (barrier) ... when I was applying to colleges I didn't want to go to a state school. I wanted to go someplace bigger, but I actually didn't have a green card at that point. I wasn't eligible for any scholarships. You have to be a citizen, a permanent resident to have. That's the only time where I felt very much like I want to do certain things, but I'm being prevented from doing them by some outside force." (Student, $2^{\text {nd }}$ year MD, 24 years)

Low salary. Low salary was deemed a barrier to living costs of cities. The participant discussed the advantages of choosing a school in a city with a low cost of living, indicating that affordability could have long-term implications in school selection.

"Yes, finances. We don't get paid a lot. Luckily, though, I think in Baltimore City, it feels like a lot more. I think living in New York or in Boston or in San Francisco, I think if you talked to those that are in those areas, they have a much more difficult time than I do in Baltimore City." (Student, $5^{\text {th }}$ year MSTP, 32 years)

Economic barriers in starting a family. One female participant anticipated 
financial strain as a future barrier in her decision to start a family in the middle of her training, despite being of advanced maternal age. This is an example of how two or more barriers influenced each other and contributed to the decision making of individuals. The participant found herself in a dilemma about her age, the length of the $\mathrm{MD} / \mathrm{PhD}$ training, and her economic constraints in terms of salary. While deferring having children until one completes professional training gives rise to complications associated with advanced maternal age, starting a family with the low salary of trainees constitutes a barrier.

"In terms of family, absolutely. ... The length of the training is so long. I struggle with decisions myself, because I'm 32 in the middle of my training. I have three more years before I'm considered advanced maternal age. At some point, what's gonna happen most likely is that I'm gonna have a child in the middle of my training. Then I'm gonna find real financial strain. ... That's not a salary to support a family for sure. ... The decision of having a family, I think, is something that really, really affects the woman." (Student, $5^{\text {th }}$ year MSTP, 32 years)

\section{Gender-role Barriers}

Five female Hispanic participants described how they perceive balancing work and family life a barrier.

\section{Classical expectations of roles within the family and the role of a double}

physician family. The participant faculty described the difficulties with juggling work and family responsibilities. She also indicated ways of overcoming such a barrier and balancing work and family life, for example, by hiring outside help, and by allocating responsibilities between domestic partners. She further explained that a double physician family is a unique and advantageous combination, because partners understand professional pressures.

"One of the issues that comes up in terms of barriers for women, is the classical expectation of roles within the family and how do we deal with that, and part of it is the career. ... Once you start accumulating external responsibilities such as 
family, children, then suddenly your time is not limitless like it had been before." (Faculty, MD, 42 years)

She further explained that, although being in a double physician family, she was a researcher while her husband was a clinician. Due to the differing expectations of work for researchers and clinicians, her schedule was somewhat more flexible and she could work from home.

"Although my husband and I are both physicians, I do primarily research, which means my schedule is often a little bit more flexible than his. Much of what I can do I can do at home in the evenings, on the weekends from the road. He has more patient care." (Faculty, MD, 42 years)

Another participant described how another way to balance work and family was

by developing a support network of women undergoing similar experiences.

"We're forming a group of the women in the $\mathrm{MD} / \mathrm{PhD}$ program to try to talk more about those issues, because a lot of people make the decision of not becoming an $\mathrm{MD} / \mathrm{PhD}$ student based on the fact that by the time we finish we have run out of our biological clock. The length of the training is so long." (Student, $5^{\text {th }}$ year MSTP, 32 years)

Concerns about decreased work productivity. One female participant voiced her concerns about her decreased work productivity because of family responsibilities. She also described institutional support initiatives and resources like on-site daycare facilities that would help in overcoming such barriers.

"I think that the biggest problem with the gender is still maternity. It's this concern that, as soon as you have a kid, your productivity's gonna go low, and there are ways for the universities to actually help mothers, like have a daycare on-site, for example, kind of things that could help a lot." (Faculty, PhD, 35 years)

Lack of institutional support. One female participant discussed how the lack of institutional support caused barriers for women expecting children and seeking maternity leave. She discussed the lack of awareness among her colleagues that maternity leave is 
not vacation. She also discussed how she had to take extra time to complete her training, since she had a child in the middle of her training.

"If I think about gender being a barrier, I think definitely one is having children during the program. It's being specifically female. When I originally approached my boss about taking maternity leave, he asked me, 'Oh, how long do you want?' Then it's like, 'Oh, well then you're not gonna take vacation, I guess.' I mean it was assumed that maternity leave was part of vacation. I think that was definitely a barrier. I took an extra year in the PhD because I had a baby." (Student, $8^{\text {th }}$ year MSTP, 32 years)

Support from school, daycare, and family. Based on this study, schools and family can act as resources to overcome the barriers women face with respect to childbearing. For example, a participant indicated that with her family living nearby, she had a support network team of her mother, aunts, and cousins to take care of her child while she finished training.

"Now that I'm in school, I have dealt with the barrier of having a child while in school. I have a very supportive school. They really worked with me. ... It is a lot easier on everyone for the baby to be in one place ... With family it's a lot more doable." (Student, $4^{\text {th }}$ year MD, 25 years)

\section{Personal/Internal Attributes}

Four female Hispanic participants discussed some kind of personal barrier that they overcame to succeed in the program. These personal barriers were frustration, lacking social skills, not knowing how to organize, and lacking self-confidence (associated with gender, minority status, and a mismatch in personality)

\section{Dealing with frustration.}

"My biggest problem is to deal with frustration. This is very, very personal.

When I get frustrated, and this is the hardest thing about becoming a PI, is that you can't fire everybody all the time." (Faculty, $\mathrm{PhD}, 35$ years) 


\section{Lack of social skills.}

"I don't think I have the world's best social skills and I think that that maybe has

been a bit of a barrier to me.” (Faculty, MD, 50 years)

\section{Learning to organize.}

"Just learning how to organize material from many different sources. Because I think I was used to having one textbook or one set of notes and a lot of times you're sorta bombarded with many different sources. I think the first step for me first year was just learning how to organize myself." (Student, $2^{\text {nd }}$ year MD, 23 years)

\section{Lack of self-confidence (associated with gender and minority status). One}

participant discussed how being a woman and being a minority could have an important bearing on self-confidence. She further discussed that the way to overcome it was to build an effective professional network of mentors, professors, and role models for support and confidence. Confidence in public-speaking was another attribute discussed, and according to the participant, it could be improved by participating in public speaking seminars.

"I think the biggest barrier, especially for a woman in this area, is to see if they have what it takes to be a physician-scientist. Although my pre-med office did not support me very much, my mentors did. I had a few female professors that supported me all the way. If you're a woman and you don't have someone to look up to, it's much, much harder for you to think that you can do it." (Student, $5^{\text {th }}$ year MSTP, 32 years)

"Confidence, being able to speak up in public. It is important to be very confident and take public speaking seminars if possible. Especially when you're a minority student, you don't have a lot of role-models around you, people have a certain pre-conceived notion of what you're capable of and who you are." (Student, $5^{\text {th }}$ year MSTP, 32 years)

Mismatch in personality. A participant viewed science as a male-dominated, aggressive field where one needed to be assertive in order to be successful. This was viewed as a barrier that the participant overcame by working on boosting her confidence. 
Being of an introverted nature, she reported that she had to better her written and oral communication skills in order to succeed in the field.

"I think in science, it's a very aggressive, very masculine field. If you're an extrovert that is loud, you'll get your voice heard. If you are more on the quiet side, you might not get your voice heard, depending on the environment and depending on the lab you're in." (Student, $5^{\text {th }}$ year MSTP, 32 years)

\section{Race/Ethnicity}

Three female Hispanic students discussed race and their minority status as a barrier. One of them perceived that being from a particular minority class made many people assume that one did not have to work hard in order to be successful in the program. This added to the pressure of performing and achieving.

"I was a minority, because I'm a female and a Hispanic. So yes, sometimes there were barriers to overcome." (Non-scientist, $\mathrm{PhD}, 31$ years)

"Even in this post-racial society, you still have to be better than the average in order to be considered good. If you are of color, you better bring it. You can hear, ... 'Oh, you're gonna have an easier time. You don't have to worry about studying for that test, because you're Hispanic. You're gonna find a job....' I think the people that like the challenge are the ones that make it and don't think about it. The people that caught up and say, 'Oh, this is unfair', are the ones that give up." (Student, $5^{\text {th }}$ year MSTP, 32 years)

Additionally, one participant extensively discussed the role of stereotyping and

Latino cultural identity or perception as a barrier. In discussing stereotyping, she

described how she did not conform to the stereotype of being a Latino, because she strove to be successful in school. She needed to build her confidence and be more aggressive in order to move past the stereotypical barriers.

"I had peers who were of similar racial background who basically felt like I was not being treated to sort of the stereotype of what a Latino was supposed to be. Being successful is not in contra indication to being Latino. Moving past those things, I think sometimes confidence and feeling comfortable, and maybe even being more aggressive and moving forward in the academic environment. Those are things I think I have struggled with.” (Resident, MD, 30 years) 
In discussing her cultural identity as a Latino, she described how being academically driven was not a part of her cultural identity, and being a minority was viewed as a cultural barrier.

"Being really academic and driven and moving forward was not part of the cultural identity. I grew up in an environment where being Latino was not just a cultural thing, but also this identity of where you were supposed to be in society, what kind of student you were supposed to be, where you were headed. ... Right now, I'm in a program where I'm one of two females, and I'm the only Hispanic person there. Being in those environments; or being in an environment when I was younger and I had Latino kids basically saying, you're a nerd or you're not being real Latino because you're going to the lab with the white kids, kind of thing." (Resident, MD, 30 years)

\section{Workplace Environment}

Three participants discussed the lack of a supportive work environment that posed a barrier to their success. The barriers are specifically discussed below.

Lack of a supportive work culture. One participant detailed the culture of a specific branch of medical science that was deemed not supportive. She discussed the general culture of the field, and the mindset of her colleagues in the field that were deemed as barriers to success.

"In surgery, just the culture in surgery. It's not a very supportive culture. I feel like people aren't very encouraging at times. It's the kind of program where you get yelled at a lot. I didn't always feel like someone was on my side. I didn't always get the sense that people wanted me to succeed, so I feel like that was definitely a barrier that I was dealing with.” (Resident, MD, 28 years)

Long work hours. The same participant discussed how work hours lengthier than the stipulated limit of 80 hours/week led to fatigue. This also meant there was less time to study and learn. This was again reflective of the culture and environment of a specific branch of medicine.

"In my surgery residency, just the work hours. We're supposed to be limited in 
having an 80-hour work week, but oftentimes, because there aren't enough students, people end up working much more than that. You're chronically fatigued and also you don't have as much time to study, because you're always working, so this I think is a barrier to the learning, because of the work hours." (Resident, MD, 28 years)

Competition in academia. Two participants specifically talked about the competitiveness of the research environment as a barrier, where one was constantly expected to push oneself, network, develop contacts, collaborate, and publish.

"I think that sometimes academic can be very competitive, very aggressive. ... I have been in situations where I felt like, gosh, this person has gone ahead-I'm working on one project, and they've gone ahead and talked to someone about doing something else; just sort of that you've got to throw yourself out there.... trying to make those contacts, move ahead, try to push this project forward, that kind of stuff." (Resident, MD, 30 years)

"Then being a researcher, I had to, a lot of times kind of compete with other students to be able to do my work and to be successful and get published." (Nonscientist, $\mathrm{PhD}, 31$ years)

\section{Family Influences}

Three female Hispanic participants discussed some sort of lacking in family culture that were perceived as barriers. These were lack of family exposure and lack of family support.

\section{Lack of family exposure.}

"I don't come from a family of academics or a family that knows you know, that would come from a very working class family and have been sort of clueless like I was saying you know, not even accepting things that people were trying to give me. I think that all those things make it difficult. It has been a source of weakness in my advancement." (Faculty, MD, 50 years)

\section{Lack of family support and emotional support.}

"Because I moved away from my country and my family is there, that is really hard. ... it's long-distance, so I think that it would be helpful if I had more 
emotional backup here.” (Faculty, $\mathrm{PhD}, 35$ years)

"My family wasn't very supportive about me going to graduate school, because they don't know anyone with a $\mathrm{PhD}$. They just wanted me to get my bachelor's and make money. It's been kind of a struggle to do this without really that much support.... they don't see the purpose. They're not really encouraging me very much, so that's tough. Being Hispanic and a female, I find I just feel outta place sometimes." (Student, $2^{\text {nd }}$ year $\mathrm{PhD}, 22$ years)

\section{Mentoring}

Two female Hispanic participants discussed how the total or partial absence of effective mentoring has been a barrier to their success in the program, and a barrier to their achieving independence as researchers.

Barrier in achieving independence. In this example, attaining independence was associated with the ability to secure grants. This required time, training, and effective mentoring. Although the participant received general career mentoring, she reported not having received adequate mentoring in research, which has negatively impacted her research career. Further, she did not get along with her research mentor.

"It took me a very long time to develop independence. I don't feel that I was particularly well-mentored in research and it's been a difficult path. But only in the last few years did I feel that I have achieved some independence, that I have more control over my research destiny." (Faculty, MD, 50 years)

In another example, a student discussed how not finding good mentoring in the specialty lab of her choice was initially a barrier to her success.

"The hardest thing for me was to find a mentor. I went to labs all in the bladder at first, because I really was interested in the bladder. It just turned out that these just were the really worst people to pick as far as working for them. ... that was my major hurdle, finding the right person and the right lab to join." (Student, $2^{\text {nd }}$ year $\mathrm{PhD}, 22$ years) 


\section{Language Barrier}

Two female Hispanic participants reported how English being their second language was perceived as a barrier. In the first example, the participant was discouraged from applying to a lab based on her lack of communication skills in English. In the second example, the participant viewed her lack of English proficiency as a barrier to writing and oral presentations that took more time to master.

"My first language is Spanish. It's not English. I was interested in working in the (undergrad) lab of this person ... The e-mail basically said that someone with my English skill level was destined to be a laboratory technician, a bench person 'cause I can clearly not communicate." (Post-doctoral associate, $\mathrm{PhD}, 33$ years).

"When I joined as a graduate student, I had to rethink more carefully because of the language barrier. I think having the English as a second language, it was at the beginning a barrier for me. ... There's a lot of writing and oral presentations that you have to do and it took me double or triple the time, so I had to work extra hours to be able to overcome that barrier." (Non-scientist, PhD, 31 years).

The participant discussed the importance of improving English skills for nonnative speakers, especially during writing and making oral presentations. For this, the NIH program has a public speaking resource that provides feedback and improvement opportunities in English speaking, and was viewed as an important tool in overcoming the language barrier.

"Having English as my second language ... I learned English here in the US. I'm quite good at writing, but I take my time. That is something that I have to work on, because scientists write and they give talks all the time.... I was incredibly fortunate, because the NIH program had a component of public speaking that I think has made a big difference. It would have been a lot worse without that, because they would record us talking about science and they would give us feedback. They would teach us how to give a talk." (Student, $5^{\text {th }}$ year MSTP, 32 years) 


\section{Lack of Program Understanding}

A lack of understanding about how academia worked has been reported as a barrier by two female Hispanic participants. Interestingly, this lack of understanding was reported both as a faculty member, and as a graduate student.

Lack of faculty understanding of academia. This reported lack of understanding about academia was associated with a lack of adequate mentoring, as well as a lack of prior family exposure in the field. For example, the faculty member did not have an understanding of the importance of writing grants or publishing papers during the initial stages of her career.

"I think I never had a good sense of how academics worked. ... It happened through conversations with colleagues more than anything. ... I think that I was very under-mentored as a junior faculty member. It's closely tied to the mentoring ... I think it's because I don't come from a family that knows anything about academics and I didn't know it. I think that's the issue that I didn't understand it." (Faculty, MD, 50 years)

\section{Lack of student understanding of graduate school expectations. A female}

Hispanic participant indicated how not knowing the expectations of graduate school was a barrier to passing research milestones, for example, qualifying exams and thesis. She did not feel adequately prepared to pursue these milestones, and had to find out how to achieve these milestones on her own.

"I think not knowing the expectation of graduate school initially was a barrier, because I actually didn't pass my qualifying exam the first. I didn't really have a clear idea of what they expected me to know and be prepared for. The other thing is also not knowing exactly was expected for the thesis. I felt like I had to really seek out my own examples of what a thesis should look like, and how to do it. I feel like all those things weren't really discussed in detail with me either." (Student, $8^{\text {th }}$ year MSTP, 32 years) 


\section{Individual-Institutional Theoretical Framework for Hispanic Females}

Based on data from this study, it is evident that the reported barriers fit into one of the three categories of the theoretical framework.

Individual barriers for Hispanic females included family responsibilities, family

influences, and personal barriers. These barriers were independent of institutional characteristics. The following example illustrates this.

"I don't think I have the world's best social skills and I think that that maybe has been a bit of a barrier to me." ... "I don't come from a family of academics or a family that knows you know, that would come from a very working class family and have been sort of clueless like I was saying you know, not even accepting things that people were trying to give me. I think that all those things make it difficult. It has been a source of weakness in my advancement." (Faculty, MD, 50 years)

Some of the institutional barriers include economic barriers (loan, debt, laboratory

funding, and low salary), workplace environment, mentoring barriers, and lack of understanding of graduate school expectations. They were not influenced by individual characteristics of the participants. The following examples illustrate this.

"The only barrier I do feel now is in a lab situation where there's very sparse funding. That makes it incredibly hard because I don't have the tools of my trade which are things like antibodies or animals." (Student, $6^{\text {th }}$ year $\mathrm{PhD}, 32$ years)

"In surgery, just the culture in surgery. It's not a very supportive culture. I feel like people aren't very encouraging at times. It's the kind of program where you get yelled at a lot. I didn't always feel like someone was on my side. I didn't always get the sense that people wanted me to succeed, so I feel like that was definitely a barrier that I was dealing with.” (Resident, MD, 28 years)

Some of the overlapping barriers for Hispanic females included economic barriers (due to immigration status or gender-role), gender-role barriers (related to a decrease of work productivity and a lack of institutional support), racial barriers (related to institutional attitude, academic environment, and stereotyping), cultural identity and 
academic environment, language barriers, and lack of understanding of academics, due to lack of family exposure. Some examples of these are as follows.

"Probably just financial (barrier) ... when I was applying to colleges I didn't want to go to a state school. I wanted to go someplace bigger, but I actually didn't have a green card at that point. I wasn't eligible for any scholarships. You have to be a citizen, a permanent resident to have. That's the only time where I felt very much like I want to do certain things, but I'm being prevented from doing them by some outside force." (Student, $2^{\text {nd }}$ year MD, 24 years)

"If I think about gender being a barrier, I think definitely one is having children during the program. It's being specifically female. When I originally approached my boss about taking maternity leave, he asked me, 'Oh, how long do you want?' Then it's like, 'Oh, well then you're not gonna take vacation, I guess.' I mean it was assumed that maternity leave was part of vacation. I think that was definitely a barrier. I took an extra year in the PhD because I had a baby." (Student, $8^{\text {th }}$ year MSTP, 32 years) 


\section{Summary of Findings}

Based on the data from this study, some of the most frequently reported barriers for Black males included racism, personal barriers, and institutional barriers (Table 5-1; Figure 5-1; Figure 5-7). Additionally, the most frequently reported barriers for Black females included gender, racism, mentoring, and personality barriers (Table 5-2; Figure 5-2; Figure 5-8).

For Hispanic males, some of the most frequently reported barriers included economic barriers, language barriers, cultural barriers, and institutional barriers (Table 53; Figure 5-3; Figure 5-9). Additionally, the most frequently reported barriers for Hispanic females included economic barriers, gender-role barriers, personal and internal attributes, race and ethnicity, workplace environment, and family considerations (Table 5-4; Figure 5-4; Figure 5-10).

On combining the barriers for Black males and females, this dissertation reported the most frequently identified barriers for Blacks being racism, gender barriers, mentoring, and personal barriers (Table 5-5; Figure 5-5; Figure 5-11). Similarly, on combining the barriers for Hispanic males and females, the most frequently reported barriers for Hispanics in this study were economic barriers, language barriers, institutional and workplace environment barriers, and gender-role barriers (Table 5-6; Figure 5-6; Figure 5-12).

From this study, it is evident that the barriers for Blacks are qualitatively different from the barriers for Hispanics in the pipeline. While Blacks report facing racism issues, gender barriers (for women) and mentoring issues, Hispanics report facing economic barriers and language barriers. Thus the "one size fits all" strategy might not be effective 
to strategize interventions at institutions. Interventions should be exercised with caution, considering the demographics of the students or professionals an institution enrolls every year. For example, based on this study it seems that institutions enrolling a large number of Hispanic students could benefit from developing English communication skills through mentored participation in research presentations and manuscript preparation. Similarly, Black students could be better supported in institutions sensitive to the needs of people from different racial/ethnic backgrounds and cultures to avoid isolation and exclusion.

As argued earlier, one of the setbacks of existing literature is that, while most studies tend to aggregate the barriers of underrepresented racial and ethnic minorities together, few studies differentiate between specific barriers of Blacks and Hispanics, and tend to compare the barriers in the same study. While some of the barriers of these minorities are also barriers for the general population, some barriers may be specific to particular groups. We know that Blacks and Hispanics are the two largest minority groups that are vastly underrepresented in medicine and biomedical research in the U.S. (AAMC, 2012; NSF, 2011). This necessitated studying barriers of these sub-groups individually, and comparing them. The findings from this chapter, based on this study, establish that barriers within different groups of minorities could be different. This is true not only for students, but for post-degree professionals as well. Future research in this direction should focus on examining the differences within minority groups based on quantitative study designs. From examining differences "within" different minority groups, future research should also focus on the differences "between" minority and nonminority groups, to examine if the barriers reported are different. 
Table 5-1

Frequency of Reported Barriers for Black Males

\begin{tabular}{lc}
\hline \multicolumn{1}{c}{ Barrier } & Frequency \\
\hline Racism & 7 \\
Personal & 7 \\
Institutional & 4 \\
Economic & 3 \\
Prior academic background & 3 \\
Professional characteristics & 3 \\
Mentoring & 2 \\
Family responsibilities & 1 \\
\hline
\end{tabular}


Table 5-2

Frequency of Reported Barriers for Black Females

\begin{tabular}{lc}
\hline \multicolumn{1}{c}{ Barrier } & Frequency \\
\hline Gender & 11 \\
Racism & 9 \\
Mentoring & 6 \\
Personality & 5 \\
Program & 4 \\
Lack of guidance & 3 \\
Family & 3 \\
Minority status & 3 \\
Economic & 3 \\
Lack of preparation & 2 \\
Stereotyping & 2 \\
Lack of publication & 2 \\
Institutional & 2 \\
Communication & 1 \\
Miscellaneous & 3 \\
\hline
\end{tabular}


Table 5-3

Frequency of Reported Barriers for Hispanic Males

\begin{tabular}{lc}
\hline \multicolumn{1}{c}{ Barrier } & Frequency \\
\hline Economic & 4 \\
Language & 4 \\
Cultural & 3 \\
Institutional & 3 \\
Mentoring & 2 \\
Lack of prior training or background & 2 \\
Foreign status & 1 \\
Interaction of people in science & 1 \\
\hline
\end{tabular}


Table 5-4

Frequency of Reported Barriers for Hispanic Females

\begin{tabular}{lc}
\hline \multicolumn{1}{c}{ Barrier } & Frequency \\
\hline Economic & 6 \\
Gender-role & 5 \\
Personal/Internal attributes & 4 \\
Race/Ethnicity & 3 \\
Workplace environment & 3 \\
Family & 3 \\
Mentoring & 2 \\
Language & 2 \\
Lack of program understanding & 2 \\
\hline
\end{tabular}


Table 5-5

Frequency of Reported Barriers for Blacks and Hispanics

\begin{tabular}{lc|lc}
\hline \multicolumn{1}{c}{ Barriers for Blacks } & Frequency & \multicolumn{1}{c}{ Barriers for Hispanics } & Frequency \\
\hline Racism & 16 & Economic & 10 \\
Gender & 11 & Language & 6 \\
Mentoring & 8 & Institution/Workplace environment & 6 \\
Personal & 7 & Gender-role & 5 \\
Institutional & 6 & Personal/Internal attributes & 4 \\
Economic & 6 & Mentoring & 4 \\
Personality & 5 & Race/Ethnicity & 3 \\
Program & 4 & Family & 3 \\
Family & 4 & Cultural & 3 \\
Minority status & 3 & Lack of program understanding & 2 \\
Lack of guidance & 3 & Lack of prior training/background & 2 \\
Miscellaneous & 3 & Foreign status & 1 \\
Prior academic & 3 & Interaction of people in science & 1 \\
background & & & \\
Professional & 3 & & \\
characteristics & & & \\
Lack of preparation & 2 & & \\
Stereotyping & 2 & & \\
Lack of publication & 2 & & \\
Communication & 1 & & \\
\hline
\end{tabular}


Figure 5-1

Frequency of Reported Barriers for Black Males

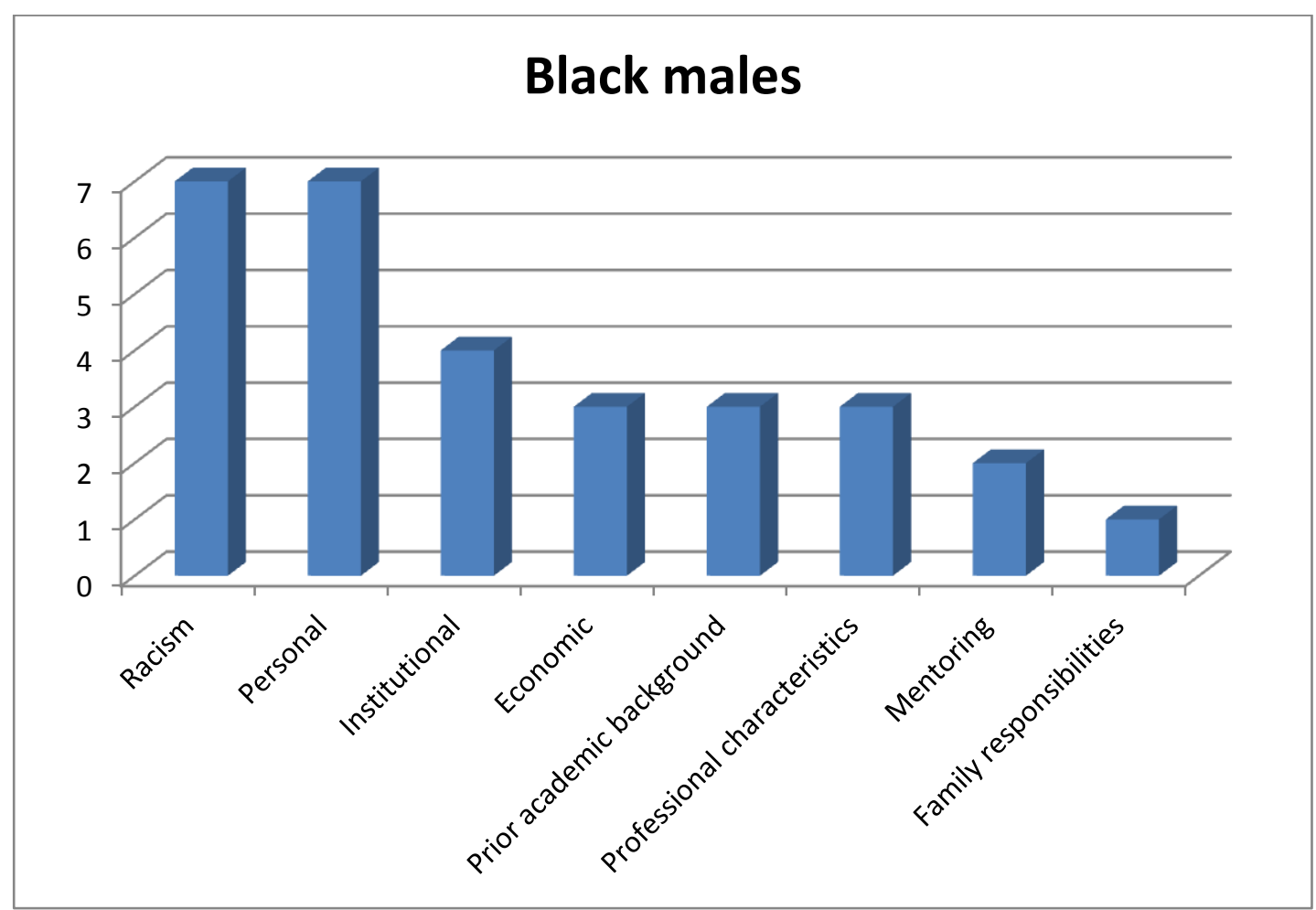


Figure 5-2

Frequency of Reported Barriers for Black Females

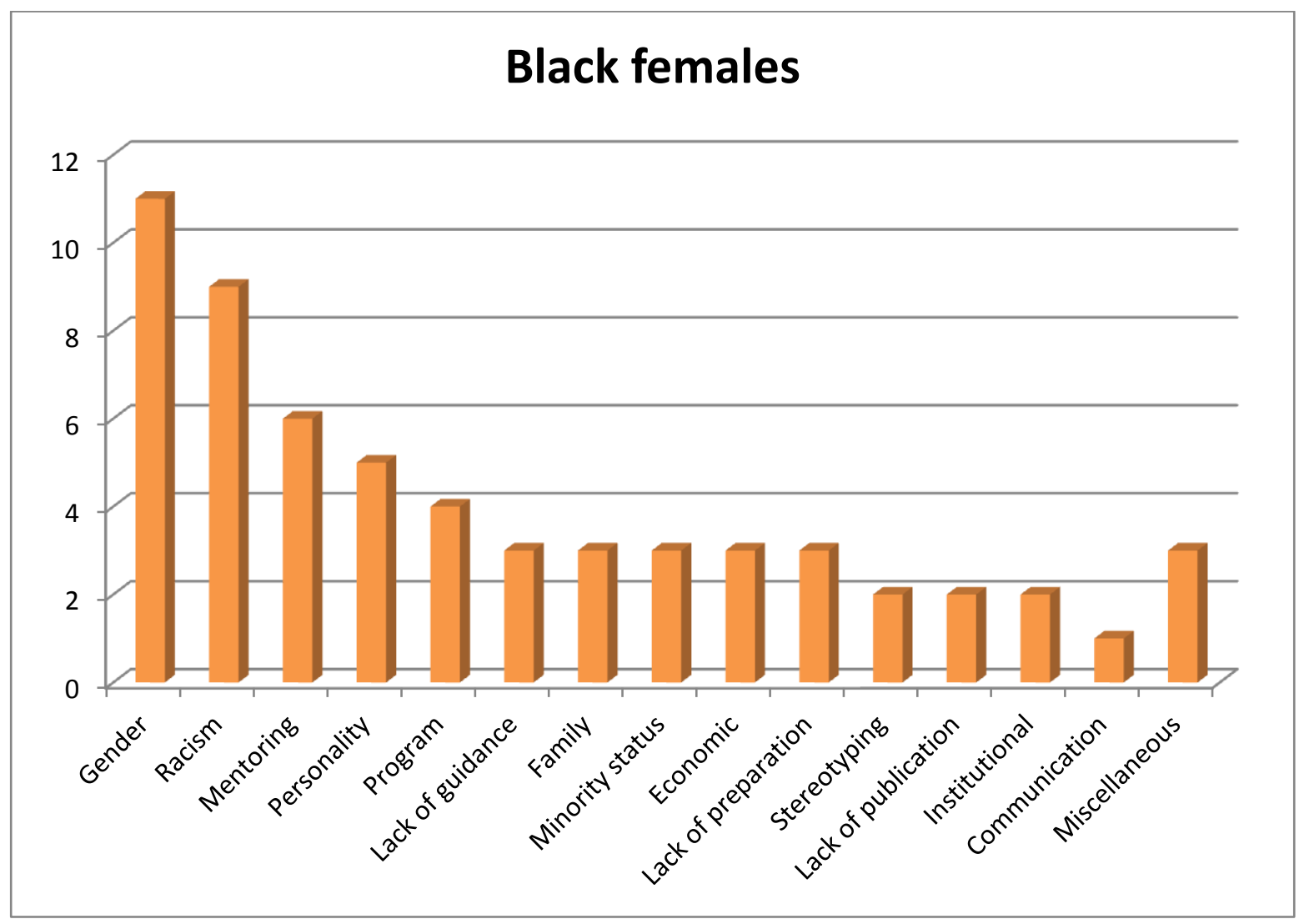


Figure 5-3

Frequency of Reported Barriers for Hispanic Males

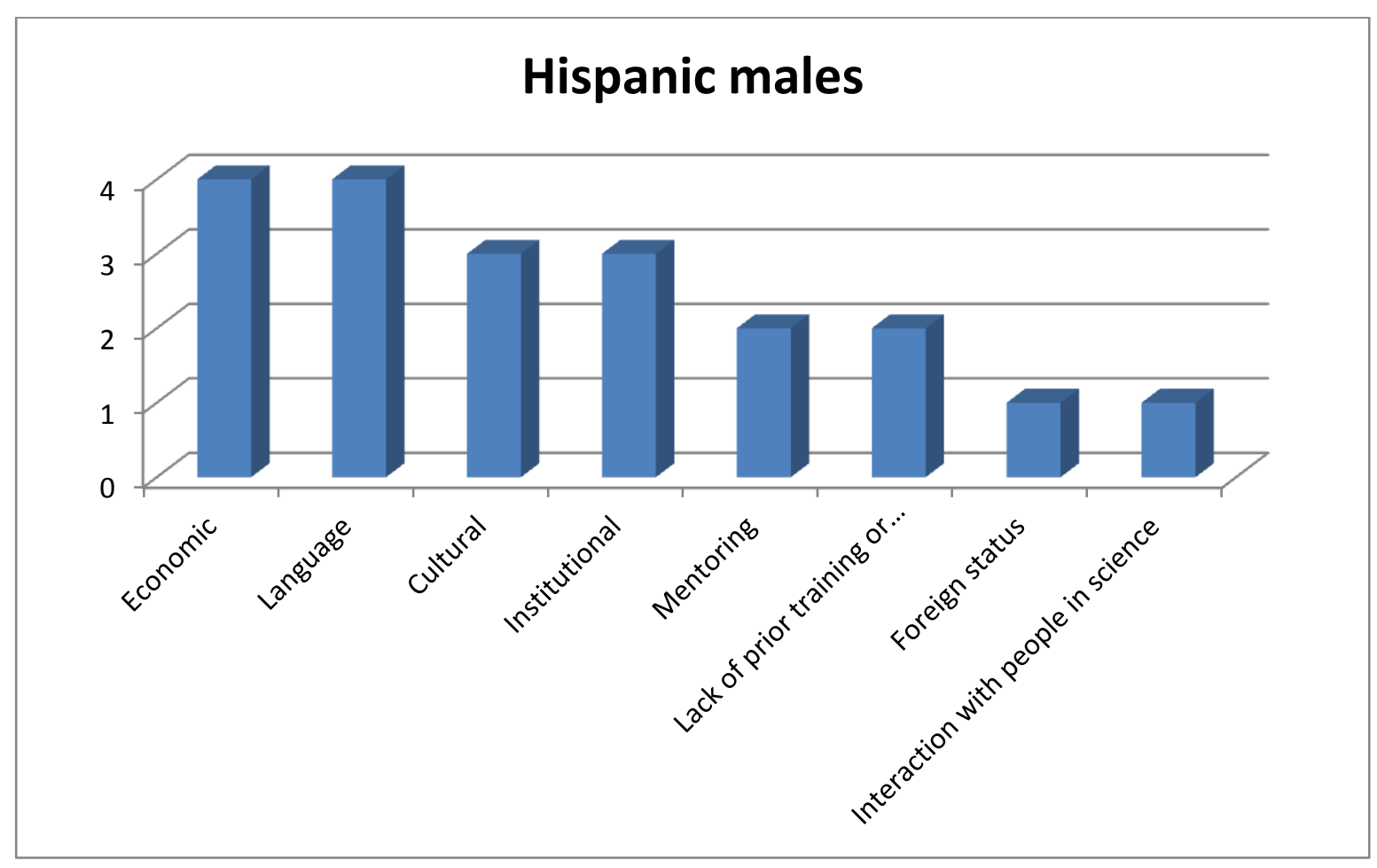


Figure 5-4

Frequency of Reported Barriers for Hispanic Females

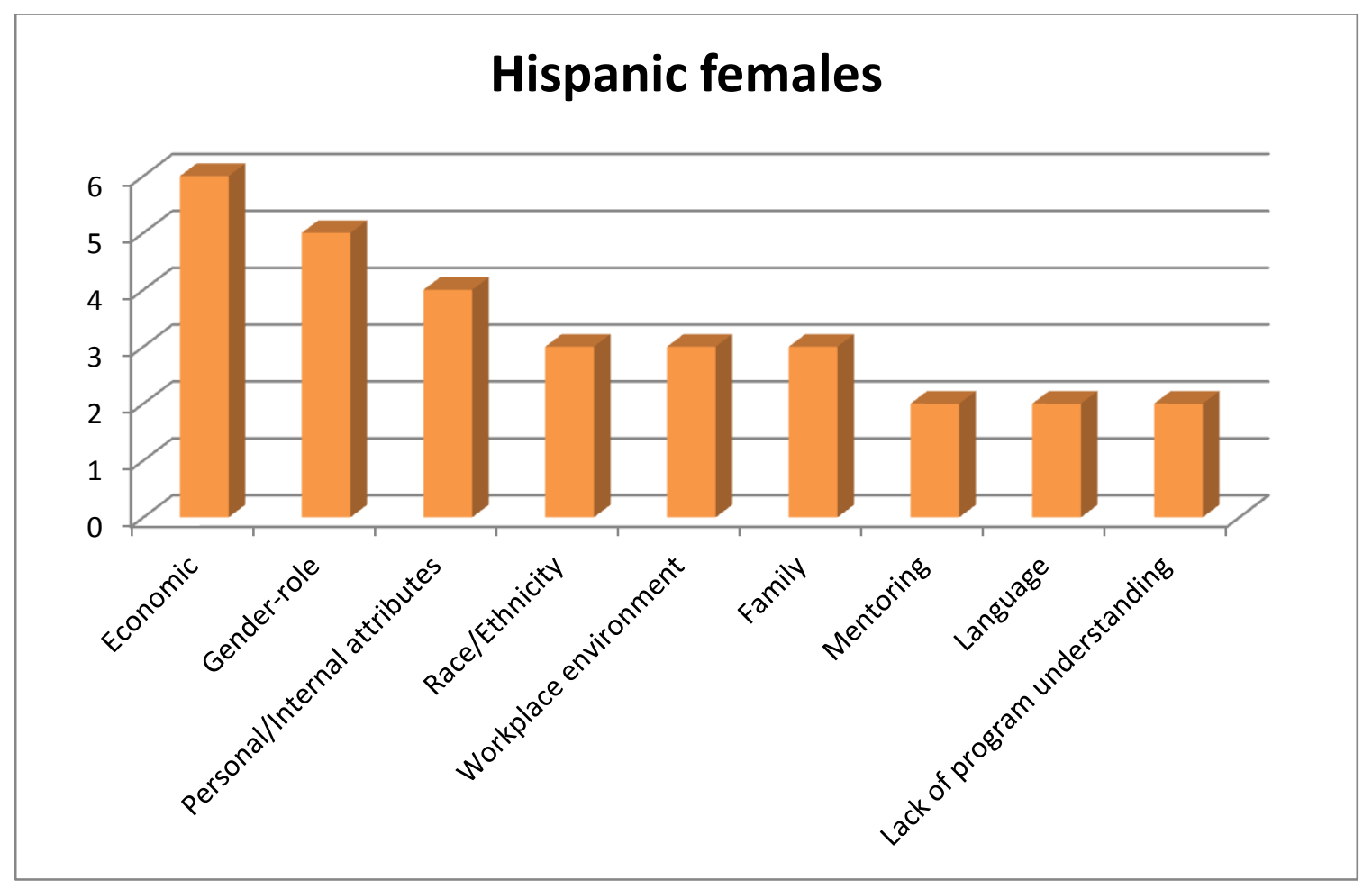


Figure 5-5

Frequency of Reported Barriers for Blacks

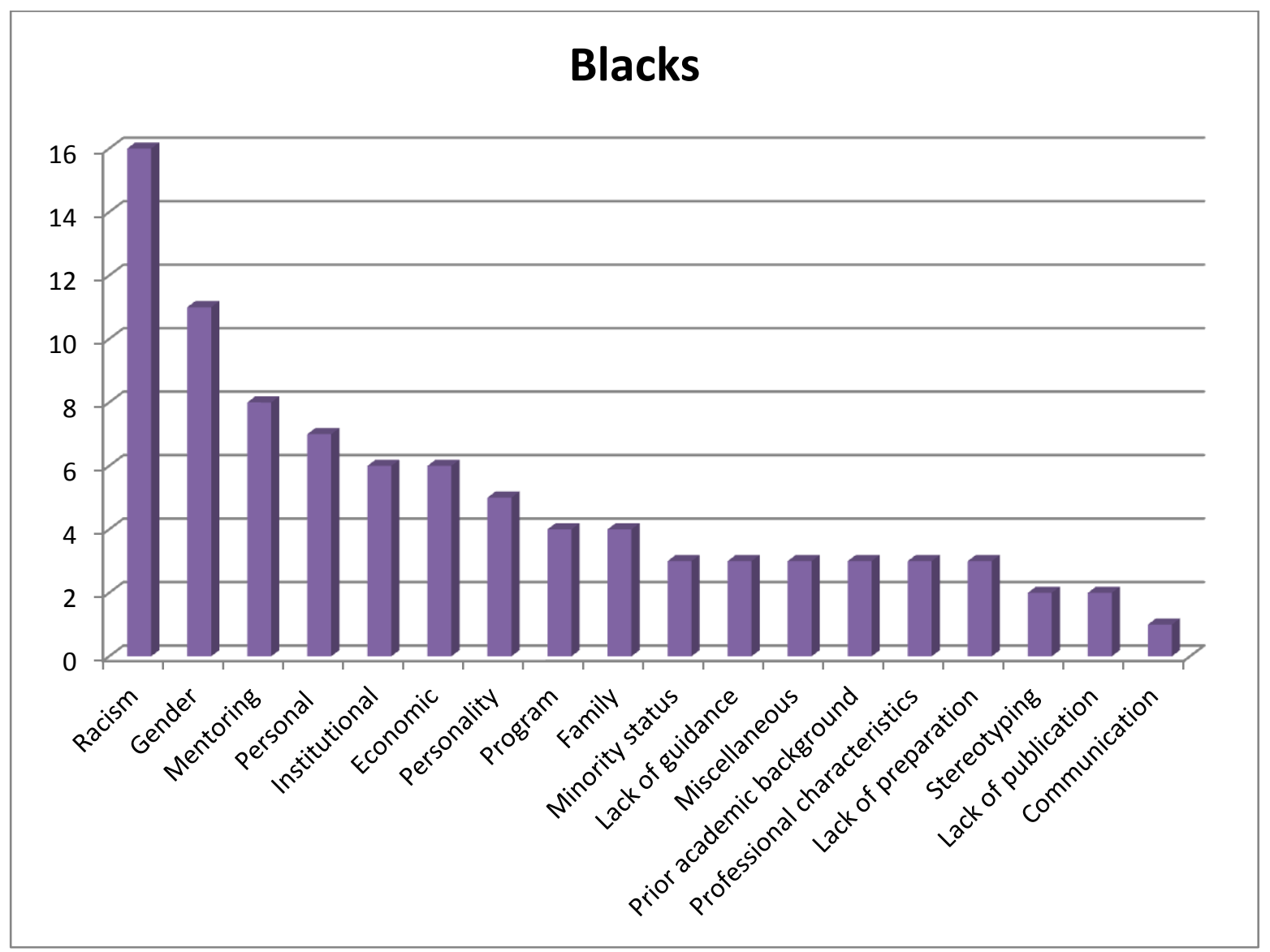


Figure 5-6

Frequency of Reported Barriers for Hispanics

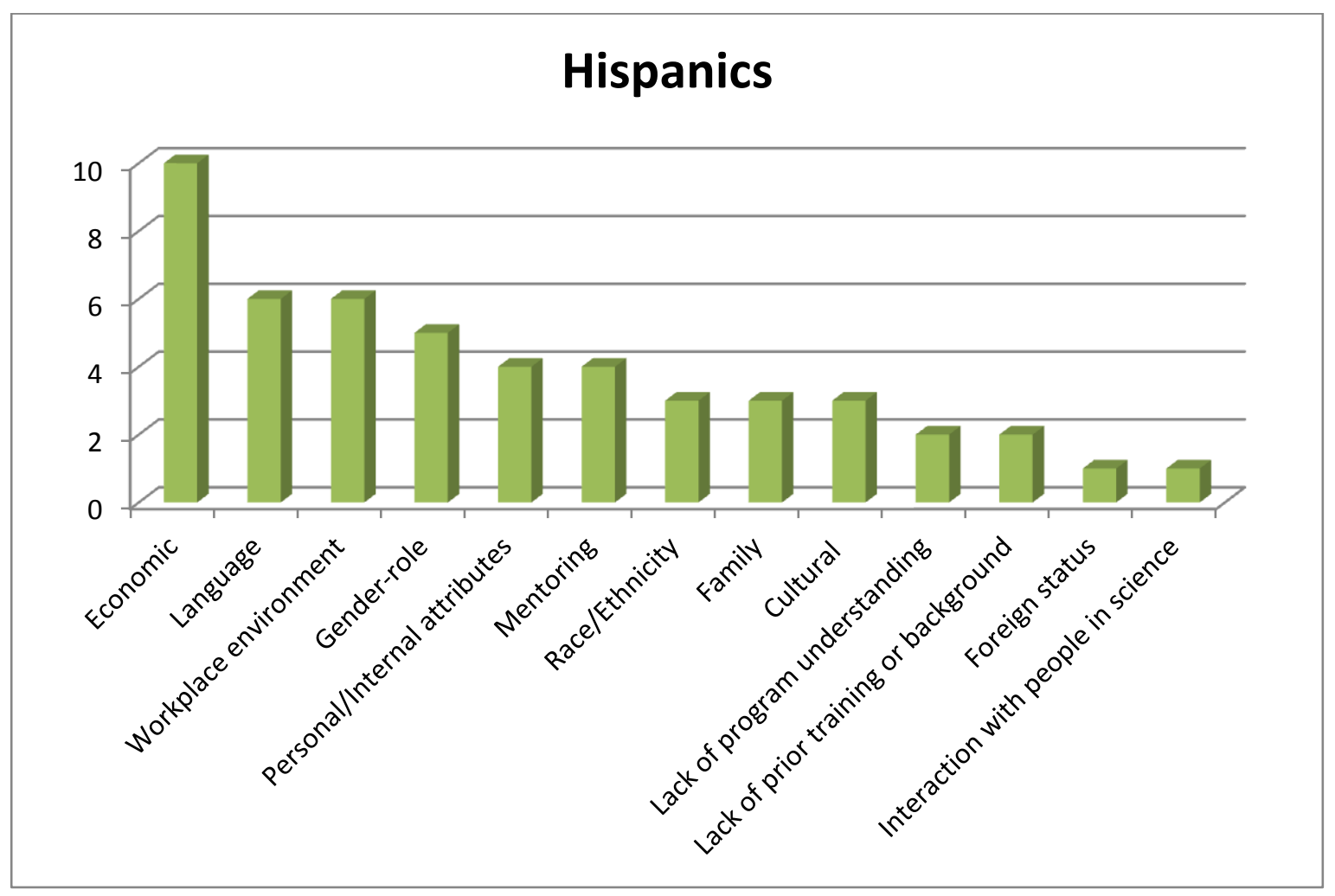


Figure 5-7

Frequency of Reported Barriers for Black Males

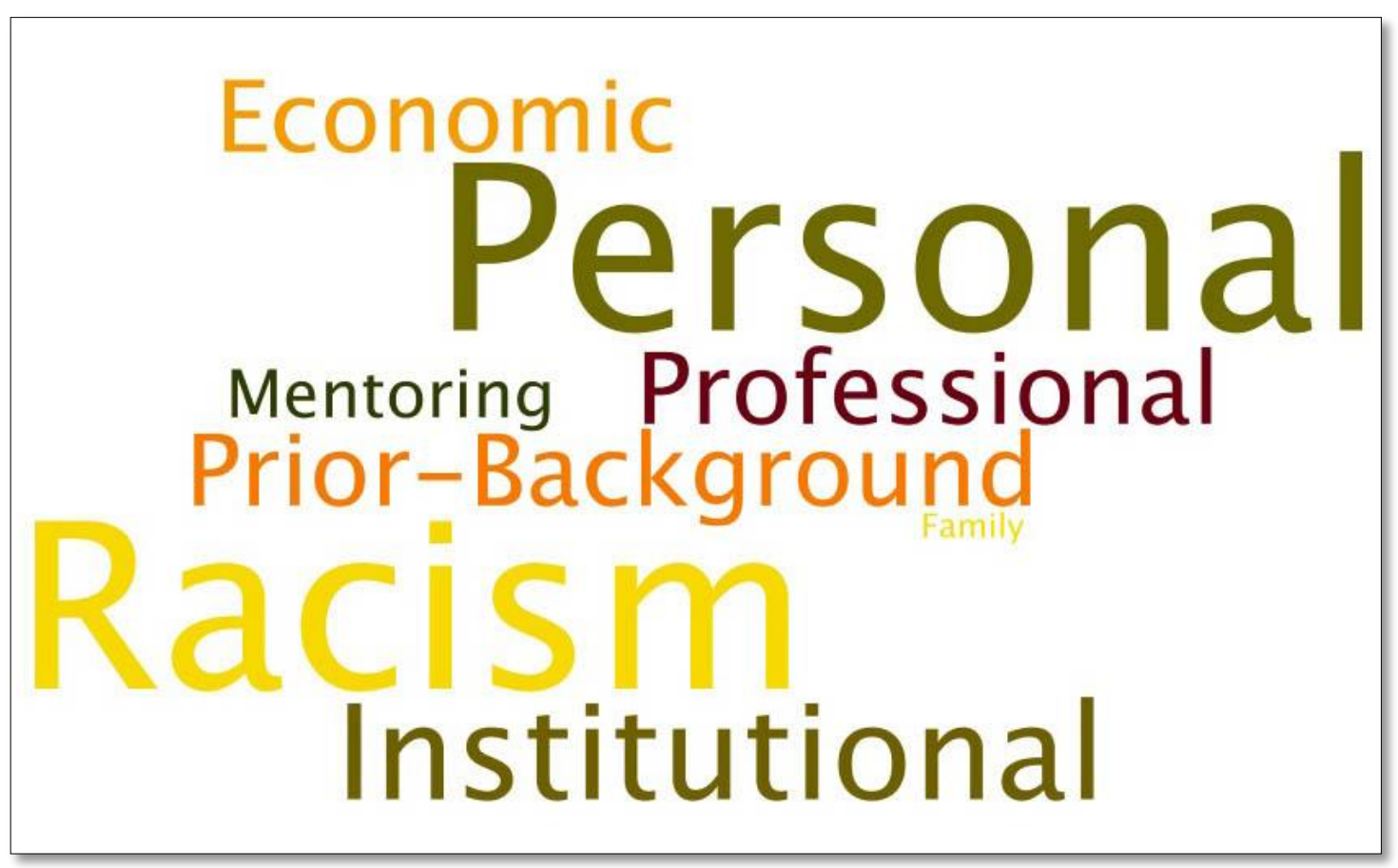


Figure 5-8

Frequency of Reported Barriers for Black Females

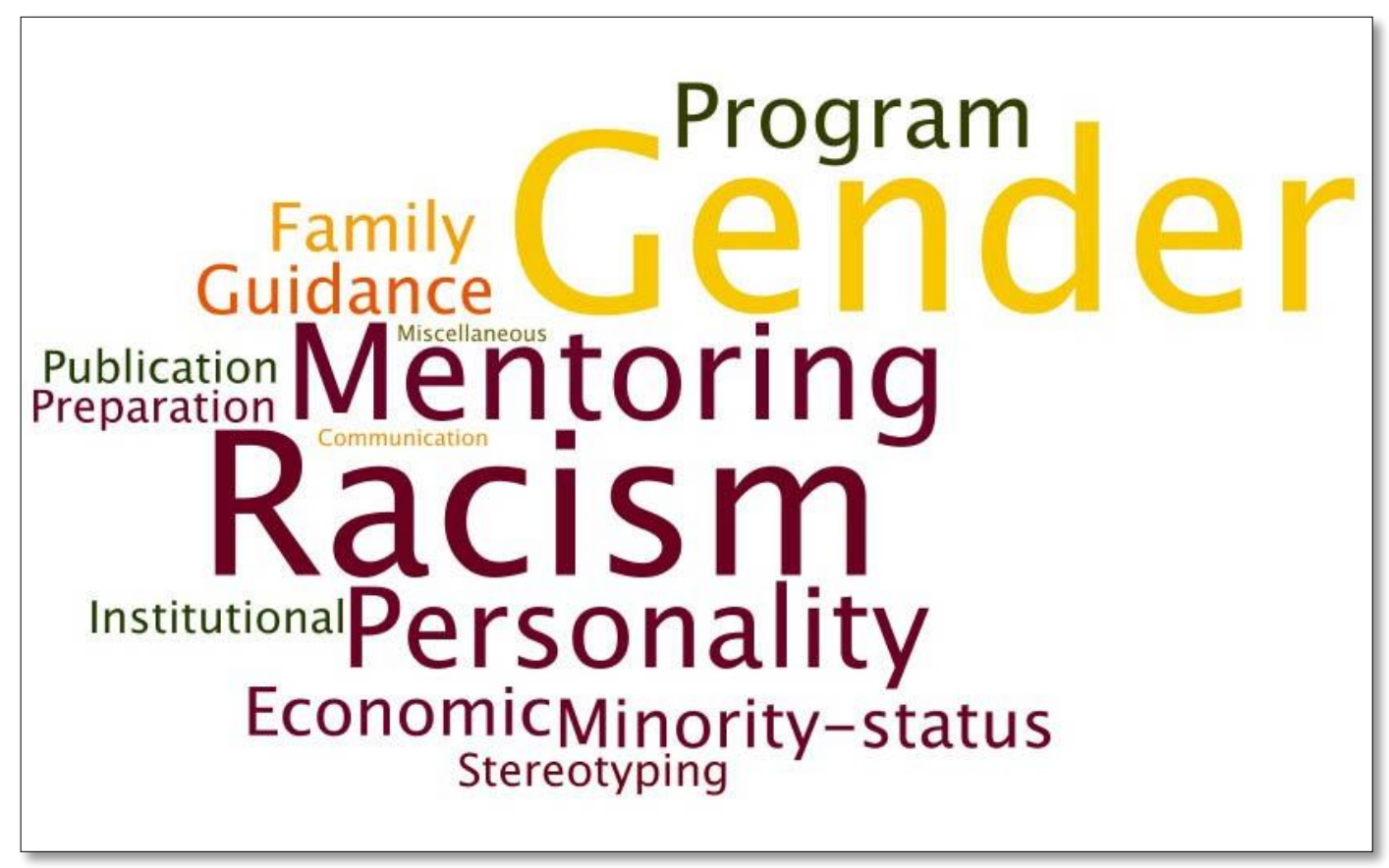


Figure 5-9

Frequency of Reported Barriers for Hispanic Males

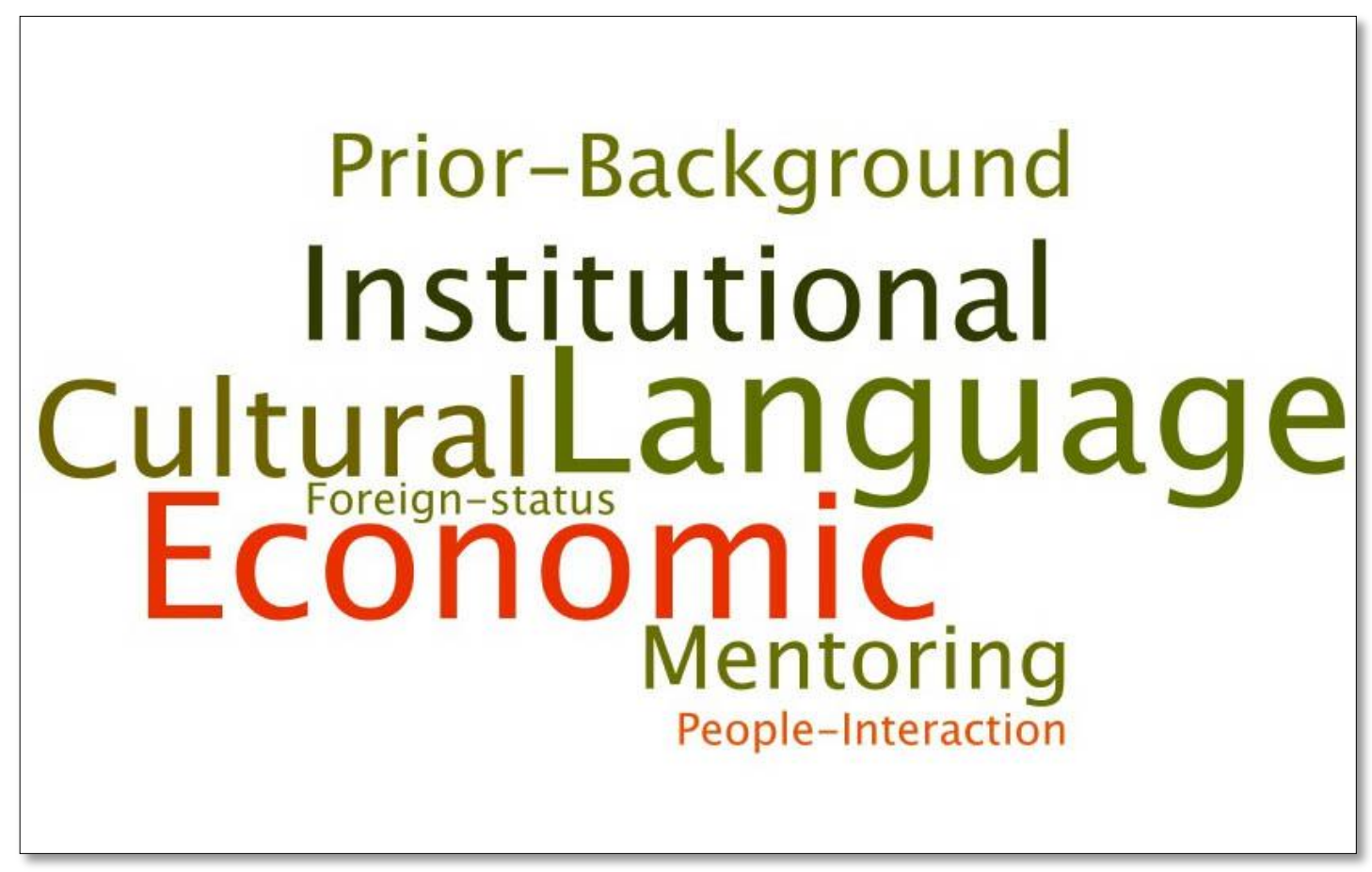


Figure 5-10

Frequency of Reported Barriers for Hispanic Females

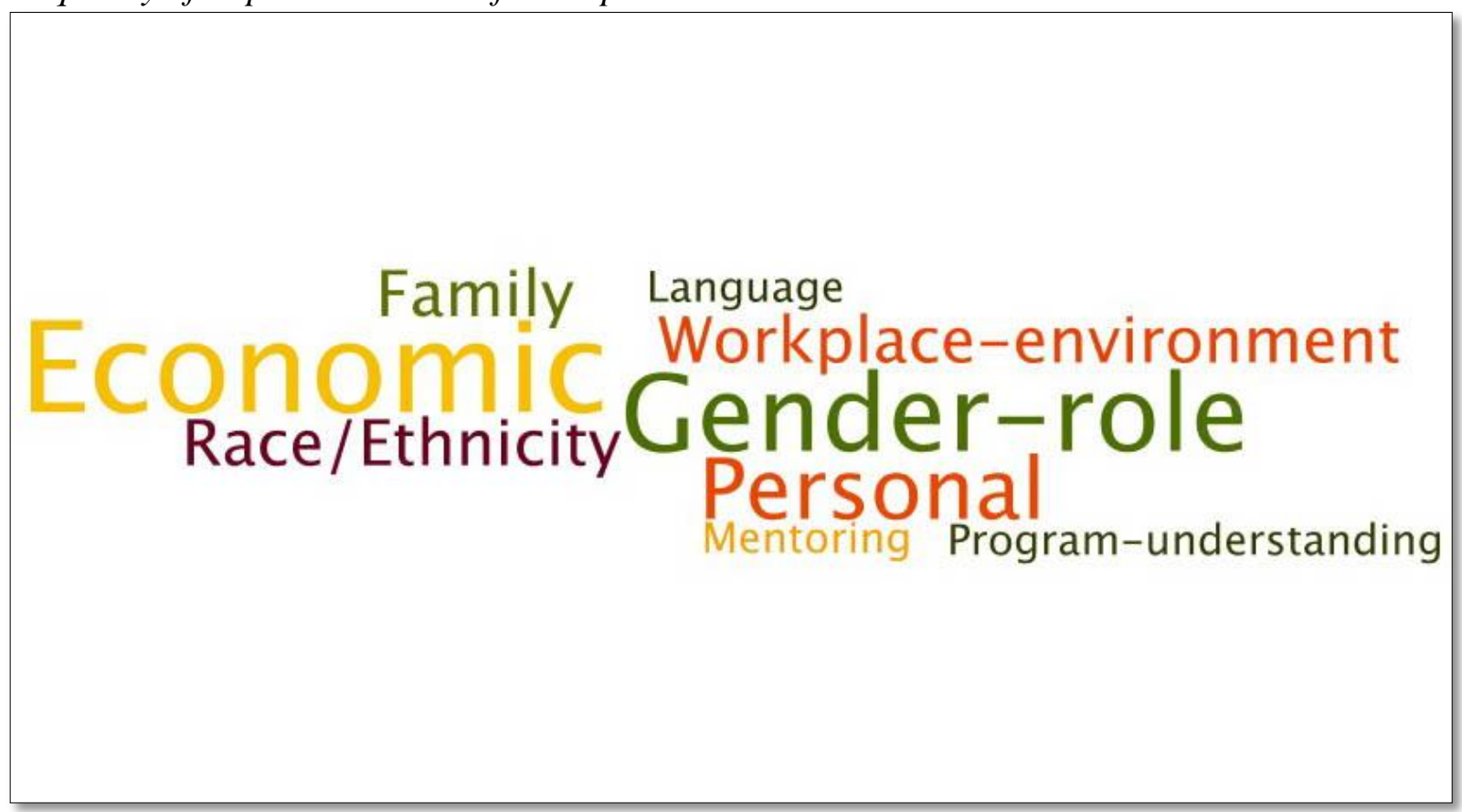


Figure 5-11

Frequency of Reported Barriers for Black Males and Females

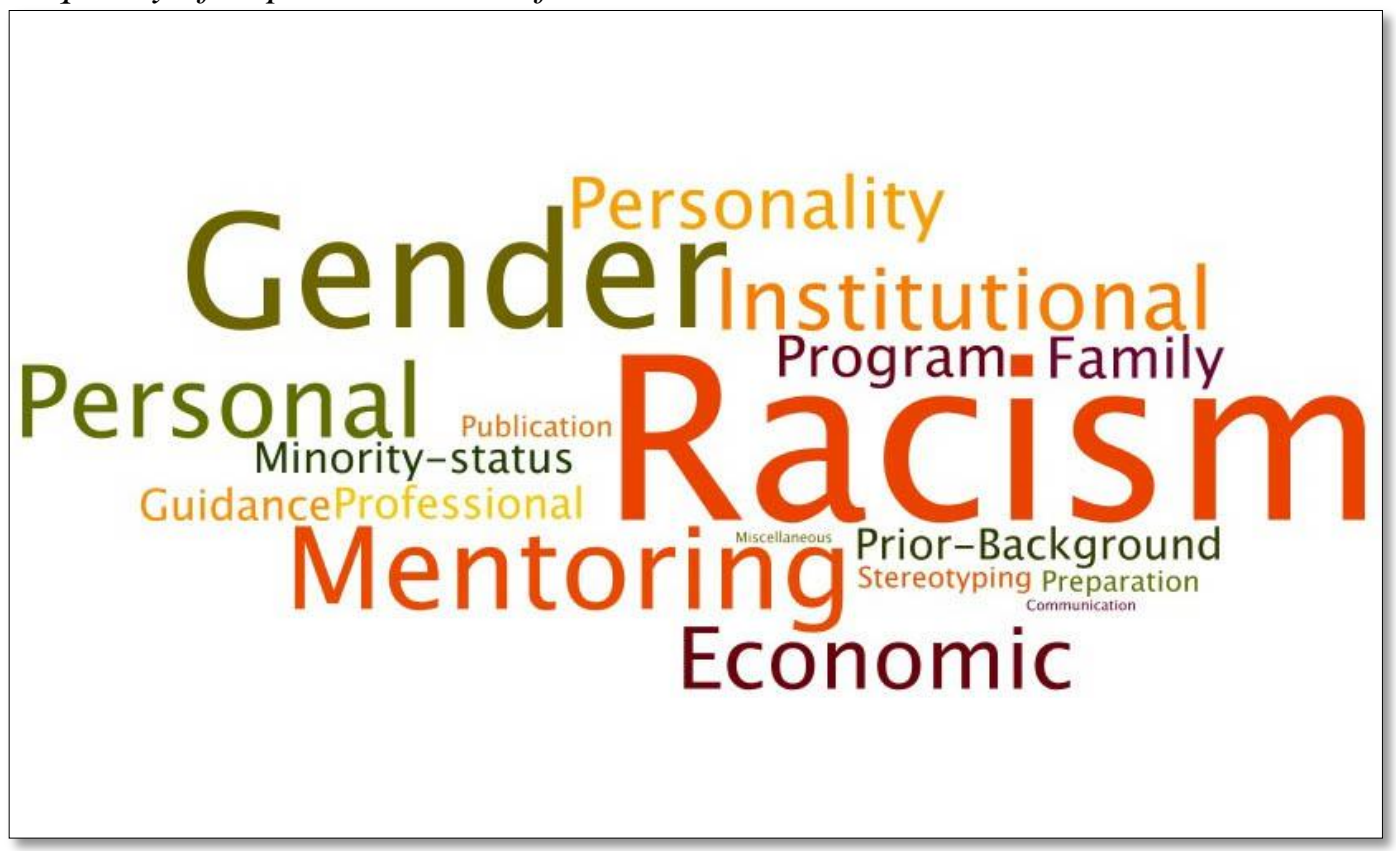


Figure 5-12

Frequency of Reported Barriers for Hispanic Males and Females

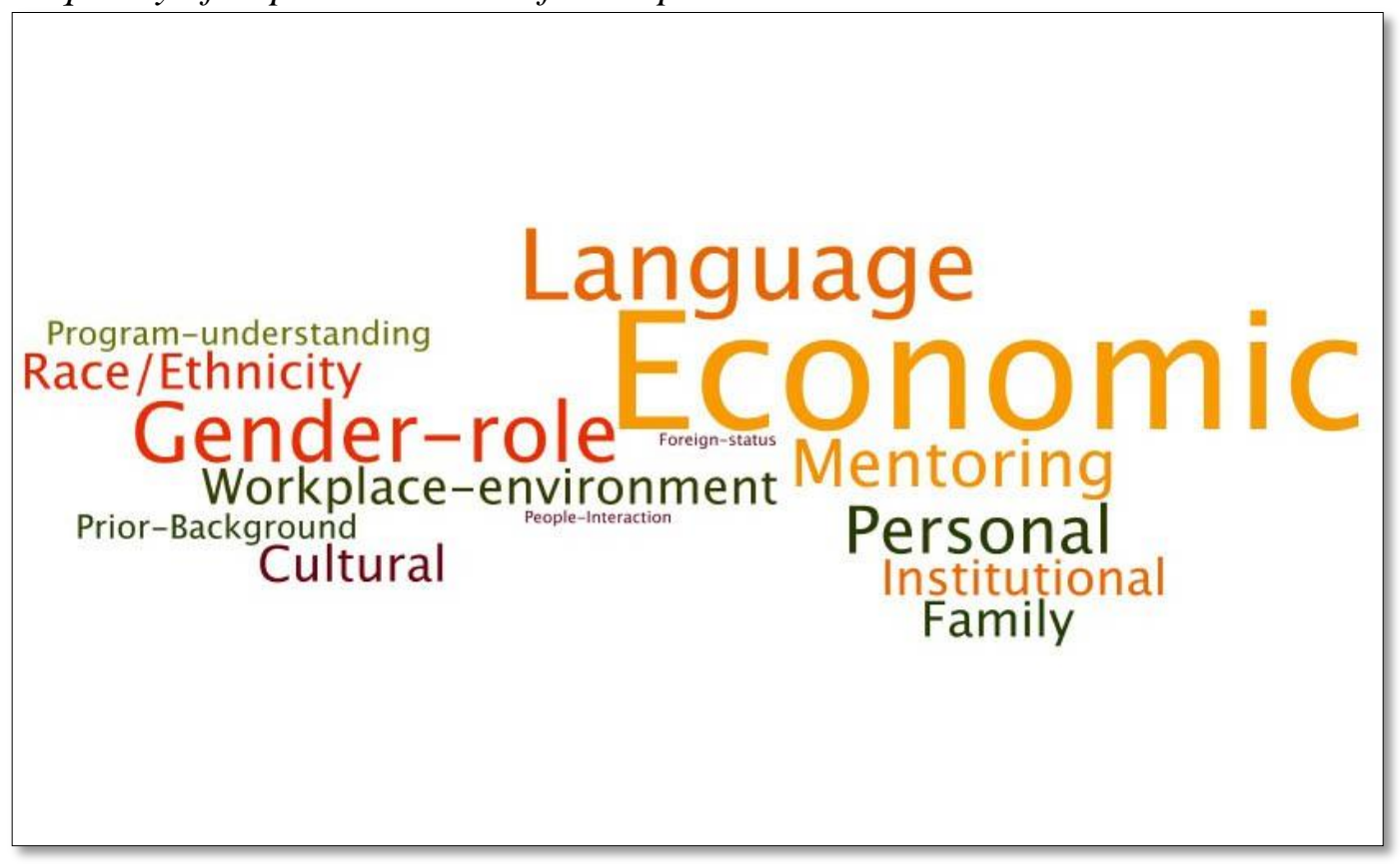




\section{CHAPTER 6}

\section{DISCUSSION AND IMPLICATIONS}

The overall focus of this dissertation has been to examine gender-role barriers for females, as well as barriers for underrepresented racial/ethnic minorities in biomedical research and medical programs. The gender-related research question sought to examine how women who are either currently enrolled or graduated from biomedical research or medical programs described their gender-roles in childbearing and childrearing as barriers to their success in the program. It further examined the strategies described by women to overcome such barriers. The race/ethnicity-related research question examined the barriers Black and Hispanic males and females face as underrepresented groups in medical schools and biomedical research institutions, and the challenges these barriers pose to their success as individuals in the program.

To examine each of these questions, data was qualitatively analyzed using a grounded theory approach that resulted in the creation of two distinct theories for gender and race. The data were drawn from semi-structured interviews from the qualitative component of Project TrEMUR, a mixed-method study. For the gender-related research question, 40 out of 118 interviews of females across different programs, races and ethnicities, and geographic locations in the U.S. were analyzed for gender-role barriers. This is because when 118 females were asked about the nature of the barriers they faced, 
that challenged their success in the program, 40 of them specifically reported gender-role barriers. For the race/ethnicity-related research question, interview data were analyzed from 56 Blacks (18 males, 38 females) and 26 Hispanics (10 males, 16 females) across different programs and geographic locations in the U.S. Overall, 122 interviews were qualitatively analyzed (40 for the gender-related research question, 82 for the race/ethnicity-related research question).

The data analysis began with a descriptive analysis of the demographics of the 122 interviewees for gender, race/ethnicity, degree program affiliation, geographic location of the program type school, current position, age distribution, and year-wise distribution of female students currently in the program (presented as descriptions, tables, and figures). Following that, interview transcripts were analyzed using a grounded theory approach. This dissertation aimed to interpret reality from the perspective of individuals through their lived experiences. Sentences and paragraphs in each of the interview transcripts were analyzed for emergent codes that fit the research questions. As a result, themes emerged at successive stages of data analysis based on concrete evidence in the data. These themes tied together to form the major theories of this study.

For the gender-related question, the analysis explored both gender-role barriers and strategies to overcome such barriers based on the interviews. As a result, the Condition-Process-Outcome theoretical framework emerged from the data. According to this theoretical framework, certain barriers can be categorized as "conditions" that lead to the "process" of gender-role barriers. Simultaneously, certain barriers are the "outcomes" of the "process" of gender-role barriers. Based on this data, the majority of the barriers could be treated as "conditions" or "outcomes", depending on the perspective of the 
participants. For example, while mentoring barriers (conditions) could make women delay their pregnancy or defer starting a family (process), women with responsibilities of children could also face mentoring barriers (outcome) as a result of their gender-role, where their mentors were not receptive or appreciative of their responsibilities as caregivers and did not adequately mentor them through their career milestones. The distinction between conditions and outcomes is important, even when looking at the same barrier. This is because individuals, institutions, and society often focus on the symptoms and not the sources of barriers. The findings of this study indicate that it is as important to focus on the conditions as it is to focus on the outcomes. In fact, one can argue that timely treatment of the condition is even more important than focusing on the outcomes, since the model shows a causal linkage between the three components. Thus, by mitigating barriers at the "conditions" level, one would automatically reduce the barriers at the "outcome" level. These strategies can be used as a roadmap for administrators and policy makers to handle issues related to gender-role barriers in women. This approach is unique and has not been studied in the field of medicine and biomedical research before. The approach used in this Condition-Process-Outcome theoretical framework could be used effectively to address the barriers of the workforce.

The Condition-Process-Outcome theoretical framework relates to the theory of socialization, whereby individuals acquire or develop certain knowledge, skills, and dispositions that help them integrate into professions, workforces or societies (Brim \& Wheeler, 1966, p.3). Thus, women professionals who socialize and seek support from families, institutions, mentors and advisors, colleagues, and peers would find it easier to transition into the workforce, being more equipped to handle barriers that can cause long- 
term effects like attrition from the field. The theory of socialization stems from the belief that individuals can acquire knowledge, skills, the ability to succeed or the desire to integrate into the workforce by seeking organizational membership (Van Maanan, 1976). Timely intervention to mitigate or remove barriers will prevent women from feeling excluded or lacking resources to handle their professional and personal challenges. Socializing networks will help women (including URMs) to integrate into and succeed in the field of research and academic medicine (Jackson, et. al., 2003; Lyons, Scroggins, \& Rule, 1990; Nettles, 1990), addressing factors associated with their persistence or attrition in the program (Golde, 2000; Seymour \& Hewitt, 1997). Organizational socialization and gender socialization would be useful to support women in their academic and professional pursuits.

For the race/ethnicity-related research question, the analyses involved first level analysis of Hispanic males, Hispanic females, Black males, and Black females, followed by a second-level analysis of the same sub-sample, stratified by race/ethnicity (Hispanics versus Blacks). As a result of this analysis, the Individual-Institutional theoretical framework emerged from the data. According to this theoretical framework, certain barriers are specific to the individuals, for example, their gender, race, citizenship status, and family background. There are other barriers that are primarily institutional in nature, such as, mentorship barriers, structure of the program, unfriendly workplace environment, and funding situations. However, barriers are social conditions that seldom occur in isolation. Hence, most of the barriers experienced by an individual are as a result of the interaction between their individual and institutional characteristics. For example, an individual who is denied certain opportunities by their institution, as a result of their 
individual characteristics such as race, citizenship status, or gender faces barriers as a result of the interaction between individual and institutional attributes. This is an important distinction, as it reinforces the belief that barriers are but certain conditions or situations that seldom occur in isolation, but happen due to the constant interaction between institutions and the self.

This finding relates to the Cultural-Ecological Theory (Ogbu \& Simons, 1998) and explains how the URMs make sense of opportunities or barriers to success in the workforce. Ogbu \& Simons (1998) indicate that the minority groups of color may belong to voluntary (immigrant) or involuntary (nonimmigrant) communities. While voluntary minorities have willingly relocated to a country for reasons of better opportunities in life compared to their home country (Hispanics in this study), involuntary minorities have a history of being forcibly conquered, colonized, or enslaved by the society permanently against their will (Blacks in this study). Interestingly, the barriers reported by each group in this study are also qualitatively different in nature. Further, in cultural-ecological theory, the minority school performance considers ecology as their environment and the culture as the way individuals make sense of the environment and behave in it. Additionally, minority school performance is guided by two major factors, the system (the different ways in which society and the schools treat minorities) and the community forces (how minorities perceive and make sense of schooling due to the treatment they receive) (Ogbu, 1987; Ogbu, 1990). The individual-institutional theoretical framework of barriers builds on the cultural-ecological theory, and augments it by indicating that barriers are conditions that usually do not occur in isolation, but result from an interaction between the individual and the environment. Further, the cultural-ecological theory 
indicates that the disparity in school performance, between immigrant and non-immigrant minorities, can be partially explained by community forces (Ogbu, 1999). The findings from this dissertation add to the argument by indicating that the barriers of immigrant and non-immigrant minorities are qualitatively different, and a "one size fits all" approach is not useful to address those barriers. Most importantly, since conditions of barriers are mostly created due to different interacting forces, this could be useful in understanding how to mitigate those barriers. For example, racism is one such barrier that should be addressed, not just institutionally (by making organizations more tolerant and promoting cross-cultural competency), but also individually by helping individuals develop their self-confidence and sense of worth early on (since some participants in this study indicated self-inflicted bias and racism). Another example is the language barriers reported by Hispanic students. Intervention is needed not only institutionally, but also at the individual level. In fact, in terms of timeline, institutional interventions occur much after individual interventions. While organizations devise policies for institutional support, parents, families, and society can help in individual intervention very early in life. Another example of this would be gender-role barriers, which should be addressed not just by institutional intervention (for example, by providing daycare facilities and better implementation of maternity leave policies), but also by personal interventions through support from spouse and family. Since most conditions of barriers do not occur in isolation, it would be important to lean in and seek support from self and one's immediate surroundings, in addition to seeking support from the workplace. These findings can be used as a roadmap for institutions, as well as individuals and families to support URMs in the workforce. 
The strength of this dissertation lies in the in-depth investigation of gender barriers and barriers of the two most underrepresented racial/ethnic minorities (Blacks and Hispanics) not only in STEM fields, but specifically in the field of medicine and biomedical research. A qualitative method of inquiry was the most suitable to provide a better understanding of the barriers of specific gender and races/ethnicities, and to address each of the research questions. This was achieved by an in-depth understanding of a specific phenomenon based on emergent themes. As mentioned, the strength of qualitative research also lies in providing depth and detail to understand specific phenomenon, as specified in the research questions, through personally lived experiences. The phenomenon of facing and overcoming barriers was studied with minimal a priori assumptions or expectations, so that the findings could emerge from the data and were not preconceived. Further, a sample of 122 interviews, representing varied demographics of gender, race/ethnicity, age, degree program, and geographic locations, strengthened the analyses. This study contributed to our understanding of the overall landscape of barriers faced by a specific demographic of students and post-degree professionals in medicine and biomedical research.

The investigation is timely, since the retention, promotion, and advancement of women to leadership positions in academic medicine are issues (McPhillips et al., 2007). Although female students are not underrepresented in the medicine and biomedical pipeline, their advancement into higher faculty and leadership positions is an issue (AAMC, 2012; Files et al., 2008; Powell et al., 2010). Since the period of career advancement also coincides with their reproductive age, women find it challenging to balance family and succeed in their professional lives (Gander et al., 2010; McPhillips et 
al., 2007). Further, Blacks and Hispanics are the two largest underrepresented racial/ethnic minority groups in the U.S., who experience several barriers to their success and retention in the pipeline (NSF, 2011). While most studies tend to aggregate the barriers of underrepresented racial and ethnic minorities together, few studies differentiate between specific barriers of Blacks and Hispanics, or tend to compare the barriers in the same study.

The results from this study provide an in-depth understanding of some of the issues students and post-degree professionals face that challenge their recruitment, retention, and promotion in the pipeline. In a country that has as much racial, ethnic, and cultural diversity as the U.S. does, it is imperative that the workforce be prepared to meet the needs of a diverse population, and strive toward better access to quality healthcare, especially for the underserved population. One of the many ways of improving workforce diversity would be by addressing the barriers individuals in the workforce face, especially individuals from the underrepresented groups that challenge their success in their training. These issues need to be addressed at the individual, institutional, and policy level. This study incorporates two separate components, namely a gender component and a racial/ethnic component to examine these barriers. While one would rightly argue about comparing the minority experiences to the experiences of the non-minority, this study argues that it is also important to understand the experiences unique to each minority group, instead of aggregating different minority populations as one group. While existing literature has focused on comparing Whites to minorities, it is important to investigate whether there are differences in the experiences of Blacks versus Hispanics in the pipeline. This is useful in order to understand the ways to tailor a program, based on its 
racial, ethnic, and cultural demographics. Furthermore, in devising strategies to ameliorate gender-role barriers, institutions would benefit by focusing on specific program components (for example, better mentoring programs or better strategies to ensure work/life balance) that will attract and retain more females in the pipeline as both students and faculty, also ensuring that women are able to compete for and be promoted into higher positions of leadership. The discussion that follows will focus on the findings from each research question, the potential implications of the study, a list of recommendations based on the findings of this study, the limitations of this research, and proposed future steps to continue this line of investigation.

\section{Findings from Chapter 4}

Chapter 4 investigated the gender-role barriers reported by female students and graduates in various programs of medicine and biomedical research across the country. Forty out of 118 female participants or about one-third of the sample (27 graduates and 13 students), reported facing some form of gender-role barriers in the program. The chapter is divided into three sections: Section 1 provides a descriptive demographic analysis of the sample of females who reported facing gender-role barriers and overcoming them. Section 2 describes the specific gender-role barriers, leading to the development of the Condition-Process-Outcome theoretical framework. Section 3 describes reported strategies to overcome those gender-role barriers.

In section 1, we found that while post-degree professionals who reported barriers mostly hailed from the $\mathrm{PhD}$ programs, students who reported barriers were mostly from the $\mathrm{MD} / \mathrm{PhD}$ programs. The racial group of women who reported the highest number of gender-role barriers was Whites followed by Blacks, which could be reflective of the 
proportion of women interviewed in each racial/ethnic group. The women who reported such barriers were in institutions spread out geographically across the U.S. However, what is most interesting is their distribution of age. A frequency count of age groups in 10 year intervals, revealed that most women who reported gender-role barriers belonged to the age group of 30-39 years (followed by 20-29 years and 40-49 years), which coincides with the peak reproductive age range of a woman. However, when examining the same group based on age groups of five year intervals, most women who reported gender-role barriers belonged to the age group of 30-34 years followed by 25-29 years. However, there was a spike in the age range of 44-49 years. While this finding is far from associative, it might be indicative of a group of women in their advanced maternal age who are still struggling with work/life balance and career advancement. Interestingly, this also coincides with the age group of professionals in their forties who seek promotion to senior ranks of higher administrative and decanal positions. Thus, interventions need to be age-specific in order to retain women in the field and ensure that they are promoted and receive tenure at par with men. While interventions for younger women, those in their twenties and thirties facing gender-role barriers, could be through support in caring for their children, intervention for those women in their forties could involve ensuring that they have enough support to gain promotion and seek professional advancement milestones. In addition, the average age of the female participants who reported genderrole barriers is 38 years. Within this group, the average age of post-degree professionals is 43.2 years and the average age of students is 27.2 years.

In section 2 , some of the most frequently reported gender-role barriers, according to this study, are: Conflict with mentors and advisors, time constraints arising due to 
work and family responsibilities, set societal and family expectations, institutional and departmental barriers, age, work/life balance, and maternity leave. While some of the barriers are personal (for example, age or lack of support from spouse) or societal (for example, set expectations), many barriers are institutional (for example, lack of support from mentors). In fact, rather than isolating and compartmentalizing barriers as personal, societal, or institutional, it might be prudent to view barriers as challenging situations arising due to a combination of personal and institutional situations (for example, a lack of professional networking opportunities arising due to lack of institutional support, as well as lack of support from spouse or family). The Condition-Process-Outcome theoretical framework will be useful in this case to identify, isolate and address those barriers.

In section 3, the reported strategies to overcome gender-role barriers included interventions at the individual, family, and institutional levels. It is not surprising that most of the suggested interventions from this study include making judicious professional choices that support career advancement. Some of the most frequently reported professional strategies to overcome gender-role barriers, according to this study, include: Seeking support from mentors, choosing the right specialty, choosing academia, choosing to work for institutions and people that support work/life balance, and seeking avenues of professional networking.

\section{Findings from Chapter 5}

Chapter 5 investigated the barriers reported by Hispanic (10 male, 16 female) and Black (18 male and 38 female) students and post-degree professionals, in various programs of medicine and biomedical research across the country. The analyses started 
by individually examining the barriers from all four sub-groups (Hispanic male, Hispanic female, Black male, and Black female). Then the analyses aggregated the barriers groupwise (using frequency counts) to examine the barriers reported by Hispanics versus Blacks in this study.

Based on this study, the most frequently reported barriers for Hispanic males are economic barriers, language barriers, and cultural barriers. The most frequently reported barriers for Hispanic females are economic barriers, gender-role barriers, and personal barriers. Further, the most frequently reported barriers for Black males are racism, personal barriers, and institutional barriers. The most frequently reported barriers for Black females are gender, racism, and mentoring. There is a distinction between gender barriers and gender-role barriers, based on this data. While gender barriers indicate any kind of barrier reported by women, that is specific to their gender, gender-role barriers indicate specific gender barriers where women report facing challenges to their professional advancement due to childbearing and their role in taking care of their family.

The most frequently reported barriers for Hispanics are economic barriers, language barriers, and institutional barriers. In comparison, the most frequently reported barriers for Blacks include racism, gender barriers, and mentoring barriers. Based on these comparative analyses, it is evident that the barriers faced by these two groups of minorities may not be similar in nature. However, the findings are specific to this dataset, and should be interpreted with caution. These findings hint at some of the questions worth considering for future studies: Are underrepresented minority experiences different across genders? Do Hispanics face the same barriers to success in the pipeline that Blacks do? Should policy implementation take into consideration that interventions for 
Historically Black colleges and universities (HBCUs) may or may not necessarily be the same for Hispanic-serving institutions (HSIs)? These are some of the questions that guided the aims of the racial/ethnic component of this dissertation.

Further, these barriers could be identified, isolated, and addressed using the Individual-Institutional theoretical framework, which explains the occurrence of barriers due to the interaction of various individual and institutional factors. Additionally, the trend of age of the participants in this study (Figure 3-11) indicates that, while Blacks belong to all age groups, Hispanics belong to relatively younger age groups (mostly in their twenties and thirties). If this is also the case for the age distribution of URMs in the workforce, then interventions designed to retain URMs in the field should be agespecific. For example, in this study, while racism is a barrier that Blacks have reported facing in all age groups (as students as well as post-degree professionals), economic barriers have been reported mostly by Hispanics at a younger age, when they were making decisions about choosing an institution, or choosing a particular kind of job at the beginning of their career.

The intent of these qualitative analyses was purely to indicate trends based on the data, and not to make any associative, inferential or causal claims, or generalize the findings in a larger social context.

\section{Implications from the Study}

Based on the study, several implications can be derived within the context of barriers to success in the pipeline. The implications for each component of this dissertation are discussed separately.

Gender-role driven implications: Based on the results from Chapter 4, certain 
implications are evident. First, more women post-degree professionals are reporting facing gender-role barriers, compared to women students. In this study, approximately one out of every two female post-degree professional and one out of every five female students discussed either a gender-role barrier, or shared their experiences of getting support to overcome those barriers. This brings certain questions in the researchers' mind. Is it because of age or being at certain stages in the professional front that more post-degree professionals are reporting barriers compared to students? How do these findings relate to existing literature? Existing literature indicates that, although recruitment of women in medicine and biomedical research pipeline is not an issue, their retention, promotion, and advancement to leadership positions is. Women in medicine and biomedical research take longer to advance their careers, and the percentage of successful women decreases up the leadership hierarchy in academic medicine (AAMC, 2012; McPhillips et al., 2007). If there seems to be a gender difference in the preparation of women to serve in the workforce, do gender-role barriers contribute to the issue, and if so, then to what extent? The second implication stems from the finding in this study that mentoring barriers are the most frequently reported gender-barriers, and good mentorship strategies are also most frequently reported by women participants as interventions to overcome gender-role barriers. The implications from this analysis seem to favor more effective mentoring strategies. This can drive future research studies to address genderrole barriers, and based on additional studies, it would certainly be worth the effort for institutions to invest in more effective mentoring strategies for students, as well as postdegree professionals.

Race/Ethnicity driven implications: The findings from Chapter 5 indicate certain 
distinct implications. First, based on this study, it is clear that barriers for Hispanics are qualitatively different from barriers for Blacks in the pipeline. Due to the strength in number and demographic diversity in the data, the findings provide a snapshot of barriers for racial/ethnic minorities across different stages in their career (students, postdoctoral researchers, scientists, non-scientists, and faculty). Secondly, in this study Blacks have reported facing racism issues, and gender barriers (for Black women) as well as mentoring barriers more than any other barriers. On the other hand, the barriers mostly reported within the Hispanic sample are economic barriers and language barriers. This necessitates future research studies to understand if this is a localized finding, specific to this study, or if it could be applied to a broader setting. Certainly, if institutions are allocating their resources for interventions, it would be important to remember that the “one size fits all" strategy might not be effective, and there is value in judiciously strategizing interventions based on the demographics of an institution.

\section{Recommendations from the Study}

Based on the knowledge gained from the findings of this study, several recommendations for the workforce are proposed:

\section{Recommendations for Gender-role Barriers}

Recommendation 1: Using the Conditions-Process-Outcome theoretical framework to study barriers in the field and to devise interventions accordingly. As described, understanding the conditions or sources of the barriers is as important as understanding the outcomes or the symptoms of the issues, and the theoretical framework developed from this study would act as a guideline or roadmap for administrators, practitioners and policy makers to address and mitigate barriers. 
Recommendation 2 (Strengthening mentoring relationships): Institutions should make an effort to connect female students and young faculty to more senior female mentors or role models who have navigated similar professional territories while successfully balancing work and family life, and are available to share their experiences and strategies. Additionally, it would benefit individuals to be assigned to a secondary, "non-academic" advisor, either within or outside the department, who would be a good resource to advise on professional and personal matters. Most importantly, every effort should be made to establish mentoring support and ensure that individuals are paired up with mentors based on similarities of interests and professional goals. Additionally, mentoring efforts from faculty should be recognized and rewarded, so that more professionals who are experienced in the field are motivated to act as mentors.

Recommendation 3 (Institutional support): Establishing institutional support networks and resources would be useful in ameliorating some of the burdens associated with balancing work and family life for women. For example, on-site daycare facilities, after hour childcare facilities, more well-defined maternal leave allowances, and network groups for mothers would go a long way in supporting women who strive to balance a family life with work.

Recommendation 4 (Working part-time): Institutions should be open to the option of women with families working part time, and offer them the same resources and support they require to be able to work that full time professionals have available. These include, and are not restricted to, access to research facilities, conference presentation opportunities, networking opportunities, relaxed tenure requirements, opportunities for 
seeking supportive mentoring relationships, and working in an environment free from bias or prejudice against women who also shoulder family responsibilities.

Recommendation 5 (Age-specific interventions): Age-specific interventions should be devised, not only for women who are in their twenties and thirties and struggling with work/life balance, but also for women in their forties and fifties who are senior in the workforce and striving to get promoted to higher academic ranks.

\section{Recommendations for URMS}

Recommendation 1: Using the Individual-Institutional theoretical framework to study barriers in the field and devise interventions accordingly. As discussed, most barriers for URMs occur due to the interaction between individual and institutional characteristics, and studying either in isolation may not yield desired results. The theoretical framework developed from this study would act as a guideline or roadmap for administrators, practitioners and policy makers to mitigate barriers.

Recommendation 2: Non-native English speakers in this study reported lack of fluency in English as a barrier to writing and oral communication. When participants felt unable to communicate their research experiences adequately to their colleagues/mentors, they perceived themselves as being unable to succeed professionally, regardless of the program in which they were training. Efforts to retain students in the workforce (including underrepresented minorities and non-native English speakers) should include opportunities for them to develop their communication skills through mentored participation in research presentations and manuscript preparation.

Recommendation 3: Exclusion and isolation for underrepresented minorities is often aggravated by perceptions of bias, stereotyping, impostor syndrome, and several 
racial, ethnic, and cultural barriers. Institutions should be cognizant that this phenomenon could be pervasive in the programs, and should be sensitive to the needs of people from different racial/ethnic backgrounds and cultures.

Recommendation 4 (Age-specific interventions): Age-specific interventions should be devised for URMs, because specific barriers they face could be attributed to their age group.

These recommendations are based on the findings of this qualitative study. In addition, a logical step for future research would include designing quantitative studies that examine barriers to success in the field. While qualitative studies provide an in-depth understanding of a research area, based on lived-in experiences, context, and meaningmaking, and are useful for early stages of a study to explore emergent themes, quantitative studies allow for the measurement of data using statistical models, and even allow for further investigation into associations, causations, and interactions. Quantitative research makes allowances to examine a larger sample of the population that is otherwise not possible through qualitative studies. Qualitative studies that are supported by quantitative findings often complement one another, strengthen the overall findings, and uniquely address a problem using a mixed-methods lens.

Additionally, an important future step would be to analyze barriers reported by Whites, and compare those findings with the barriers of the racial/ethnic minorities. As indicated, this dissertation aimed to understand the nuances of barriers within two minority sub-groups. This was motivated not only by a dearth in research literature of the same issue, but also because this qualitative study employed a large enough sample size to be able to make a qualitative comparison between two minority sub-groups. The 
findings from the current study add to our understanding of minority barriers, establishing from the data that the barriers vary across the two largest minority groups. Existing research on URMs tend to cluster their barriers, or individually study specific minority groups, but there are few studies that compare the barriers within individual URM groups. Using a non-minority comparison group would add to our understanding about whether some barriers are specific to a group, or are prevalent across the larger population.

\section{Limitations of the Study}

Several limitations were identified, related to the dataset, the methodology used, and the design and analyses of this study. First, this study suffers from mono-method error, where interviews were the sole method of data collection. However, given the nature of the research topic, it is not possible to use additional methods of data collection, such as observations, to study barriers. Second, for the gender-role barriers, we do not know how the experiences of females compare to those of males in the same programs. Fortunately, the data from male interviews exists, but were not analyzed for this particular study that meant first to understand the experiences of a particular gender without comparisons. So in future, the scope of this study can be extended to compare the gender-role barriers for men and women. Similarly, this study compares the barriers of the two larger underrepresented minority groups of Hispanics and Blacks, but does not provide information on how the findings compare to those barriers reported by White males and females. Again, fortunately enough, data from other racial groups like Whites and Asians exist, and a future endeavor would be to make comparisons between minority and non-minority groups, which were beyond the scope or focus of the current study. 
Additionally, careful attention has been given to the interpretation of findings, knowing that the findings are based on the data, and should not be generalized to a larger population. Further, this study does not interview participants who left the field entirely because of barriers. While there is data from students and post-degree professionals who are currently in the field, this study cannot address the problem of attrition using data from people who are no longer in the field. During data collection, the research team tried contacting people no longer in the field, but they were not willing to participate in the study. One way of addressing this barrier would be to follow up with the current participants in future, to see if they persisted in the field, and collect interview data from participants who might have chosen to leave the field by then. This would involve a longitudinal study design for a future study.

Despite the several limitations in this study, the findings are indicative of the nature and structure of the institutions, and provide educated cues to design a large-scale quantitative study. In conclusion, these limitations are avenues to further future research in the specific area. 


\section{REFERENCES}

Agrawal, J. R., Vlaicu, S., \& Carrasquillo, O. (2005). Progress and pitfalls in underrepresented minority recruitment: perspectives from the medical schools. Journal of the National Medical Association, 97(9), 1226.

Andriole, D. A., \& Jeffe, D. B. (2012). The Road to an Academic Medicine Career: A National Cohort Study of Male and Female US Medical Graduates. Academic Medicine, 87(12), 1722-1733.

Andriole, D. A., Whelan, A. J., \& Jeffe, D. B. (2008). Characteristics and career intentions of the emerging MD-PhD workforce. Journal of the American Medical Association (JAMA), 300(10), 1165-1173.

Association of American Medical Colleges. (2012). Women in U.S. Academic Medicine: Statistics and Benchmarking Report 2011-2012. Retrieved from https://members.aamc.org/eweb/DynamicPage.aspx?Action=Add\&ObjectKeyFro $m=1$ A83491A-9853-4C87-86A4F7D95601C2E2 $\&$ WebCode $=$ PubDetailAdd $\&$ DoNotSave $=$ yes $\&$ ParentObject $=\mathrm{Ce}$ ntralizedOrderEntry\&ParentDataObject=Invoice\%20Detail\&ivd_formkey=69202 792-63d7-4ba2-bf4e-a0da41270555\&ivd_prc_prd_key=6BFDFBCB-D8B44259-9697-A2D8C0D6F4A3. Accessed January 23 ${ }^{\text {rd }}$, 2013. 
ATLAS.ti. (Version 6.2.27). (1999). [Computer software]. Berlin: Scientific Software Development.

Barbee, E. L. (1993). Racism in US nursing. Medical Anthropology Quarterly, 7(4), 346362.

Beagan, B. L. (2003). 'Is this worth getting into a big fuss over?' Everyday racism in medical school. Medical Education, 37(10), 852-860.

Betancourt, J.R., Green, A.R., Carrillo, J.E., \& Ananeh-Firempong, O. (2003). Defining cultural competence: a practical framework for addressing racial/ethnic disparities in health and health care. Public Health Reports, 118, 293-302.

Blascovich, J., Spencer, S. J., Quinn, D., \& Steele, C. (2001). African Americans and high blood pressure: The role of stereotype threat. Psychological Science, 12, 225-229.

Bonilla-Silva, E., \& Dietrich, D. (2011). The sweet enchantment of color-blind racism in Obamerica. The Annals of the American Academy of Political and Social Science, 634(1), 190-206.

Borges, N. J., Navarro, A. M., \& Grover, A. C. (2012). Women physicians: Choosing a career in academic medicine. Academic Medicine, 87(1), 105.

Borges, N.J., Navarro, A.M., Grover, A., \& Hoban, J.D. (2010). How, when, and why do physicians choose careers in academic medicine? A literature review. Academic Medicine, 85, 680-686.

Bright, C. M., Duefield, C. A., \& Stone, V. E. (1998). Perceived barriers and biases in the medical education experience by gender and race. Journal of the National Medical Association, 90(11), 681. 
Brim, O. G., Jr. \& Wheeler, S. (1966). Socialization after childhood: Two essays. New York: John Wiley \& Sons, Inc.

Brown, J. B., Fluit, M., Lent, B., \& Herbert, C. (2011). Seeking balance: The complexity of choice-making among academic surgeons. Academic Medicine, 86(10), 12881292.

Buckley, L.M., Sanders, K., Shih, M., Kallar, S., \& Hampton, C. (2000). Obstacles to promotion? Values of women faculty about career success and recognition. Academic Medicine, 75, 283-288.

Burgess, D. J., Joseph, A., van Ryn, M., \& Carnes, M. (2012). Does Stereotype Threat Affect Women in Academic Medicine? Academic Medicine, 87(4), 506.

Burgess, D.J., Warren, J., Phelan, S., Dovidio, J., \& van Ryn, M. (2010). Stereotype threat and health disparities: What medical educators and future physicians need to know. Journal of General Internal Medicine, 25(2), 169-177.

Butts, G. C., Hurd, Y., Palermo, A. G. S., Delbrune, D., Saran, S., Zony, C., \& Krulwich, T. A. (2012). Role of Institutional Climate in Fostering Diversity in Biomedical Research Workforce: A Case Study. Mount Sinai Journal of Medicine: A Journal of Translational and Personalized Medicine, 79(4), 498-511.

Cameron, C., Chang, S., \& Pagel, W. (2011). Scientific English: A program for addressing linguistic barriers of international research trainees in the United States. Journal of Cancer Education, 26, 72-78. doi:10.1007/s13187-010-0143-5

Cameron, C., Zhao, H., \& McHugh, M. (2012). Perspective: Publication ethics and the emerging scientific workforce: Understanding “plagiarism” in a global context. Academic Medicine, 87, 51-54. doi:10.1097/ACM.0b013e31823aadc7 
Carr, P. L., Ash, A. S., Friedman, R. H., Scaramucci, A., Barnett, R. C., Szalacha, L., Palepu, A., \& Moskowitz, M. A. (1998). Relation of family responsibilities and gender to the productivity and career satisfaction of medical faculty. Annals of Internal Medicine, 129(7), 532-538.

Chang, M. J., Cerna, O., Han, J., \& Sàenz, V. (2008). The contradictory roles of institutional status in retaining underrepresented minorities in biomedical and behavioral science majors. The Review of Higher Education, 31(4), 433-464.

Chang, M. J., Eagan, M. K., Lin, M. H., \& Hurtado, S. (2011). Considering the impact of racial stigmas and science identity: Persistence among biomedical and behavioral science aspirants. The Journal of Higher Education, 82(5), 564-596.

Charmaz, K. (2006). Constructing grounded theory: A practical guide through qualitative analysis. Sage Publications Limited.

Charmaz, K. (1983). The grounded theory method: An explication and interpretation. In R. Emerson (Ed.), Contemporary field research (pp. 109-126). Boston: Little, Brown.

Cohen, J. J. (1998). Time to shatter the glass ceiling for minority faculty. JAMA: The Journal of the American Medical Association, 280(9), 821-822.

Colletti, L. M., Mulholland, M. W., \& Sonnad, S. S. (2000). Perceived obstacles to career success for women in academic surgery. Archives of Surgery, 135(8), 972.

Cooper, L. A., \& Powe, N. R. (2004). Disparities in patient experiences, health care processes, and outcomes: the role of patient-provider racial, ethnic, and language concordance. Commonwealth Fund. 
Cora-Bramble, D., Zhang, K., \& Castillo-Page, L. (2010). Minority faculty members' resilience and academic productivity: are they related? Academic Medicine, 85(9), 1492-1498.

Corbie-Smith, G., Thomas, S. B., Williams, M. V., \& Moody-Ayers, S. (1999). Attitudes and beliefs of African Americans toward participation in medical research. Journal of General Internal Medicine, 14(9), 537-546.

Corbin, J. M., \& Strauss, A. (1990). Grounded theory research: Procedures, canons, and evaluative criteria. Qualitative Sociology, 13(1), 3-21.

Corbin, J. M., \& Strauss, A. L. (1988). Unending work and care: Managing chronic illness at home. San Francisco: Jossey-Bass Publishers.

Cox, L. (2010). The Role of Old-Fashioned Racism: Disaggregating Symbolic Racism in the United States (Doctoral dissertation, Faculty of the Louisiana State University and Agricultural and Mechanical College in partial fulfillment of the requirements for the degree of Master of Arts in The Department of Political Science by Leslie Cox BA, Louisiana State University).

Creswell, J. W. (1998). Qualitative inquiry and research design: Choosing among five traditions. Thousand Oaks, CA: Sage.

Creswell, J. W. (2012). Educational research: Planning, conducting, and evaluating quantitative and qualitative research (4th ed.). Boston, MA: Pearson Education, Inc.

Creswell, J. W. (2012). Qualitative inquiry and research design: Choosing among five approaches. SAGE Publications, Incorporated. 
Cropsey, K. L., Masho, S. W., Shiang, R., Sikka, V., Kornstein, S. G., \& Hampton, C. L. (2008). Why do faculty leave? Reasons for attrition of women and minority faculty from a medical school: Four-year results. Journal of Women's Health, 17(7), 1111-1118.

Daley, S., Wingard, D. L., \& Reznik, V. (2006). Improving the retention of underrepresented minority faculty in academic medicine. Journal of the National Medical Association, 98(9), 1435.

Dannels, S., McLaughlin, J., Gleason, K. A., McDade, S. A., Richman, R., \& Morahan, P. S. (2009). Medical school deans' perceptions of organizational climate: useful indicators for advancement of women faculty and evaluation of a leadership program's impact. Academic Medicine, 84(1), 67-79.

de los Santos, A. G., \& de los Santos, G. E. (2003). Hispanic-serving institutions in the $21^{\text {st }}$ century: Overview, challenges, and opportunities. Journal of Hispanic Higher Education, 2, 377-391.

DesRoches, C. M., Zinner, D. E., Rao, S. R., Iezzoni, L. I., \& Campbell, E. G. (2010). Activities, productivity, and compensation of men and women in the life sciences. Academic Medicine, 85(4), 631.

Dong, Y.R. (1998). Non-native graduate students' thesis/dissertation writing in science: Self-reports by students and their advisors from two U.S. institutions. English for Specific Purposes, 17(4), 369-390. doi:10.1016/S0889-4906(97)00054-9

Dyrbye, L. N., Thomas, M. R., Eacker, A., Harper, W., Massie Jr, F., Power, D. V., ... \& Shanafelt, T. D. (2007). Race, ethnicity, and medical student well-being in the United States. Archives of Internal Medicine, 167(19), 2103. 
Eccles, J. S. (1987). Gender roles and women's achievement-related decisions. Psychology of Women Quarterly, 11, 135-172.

Erickson, F. (1992). Why the clinical trial doesn't work as a metaphor for educational research: A response to Schrag. Educational Researcher, 21(5), 9-11.

Erickson, F. (1986). Qualitative methods in research on teaching. In M. Wittrock (Ed.), Handbook of research on teaching (3rd ed.) (pp. 119-161). New York, NY: Macmillan.

Fang, D., Moy, E., Colburn, L., \& Hurley, J. (2000). Racial and ethnic disparities in faculty promotion in academic medicine. JAMA: The Journal of the American Medical Association, 284(9), 1085-1092.

Feinberg, J. (2013). Wordle. Retrieved from http://www.wordle.net/

Files, J.A., Blair, J.E., Mayer, A.P., \& Ko, M.G. (2008). Facilitated peer mentorship: A pilot program for academic advancement of female medical faculty. Journal of Women's Health, 17(6), 1009-1015.

Finch, S.J. (2003). Pregnancy during residency: a literature review. Academic Medicine, $78(4), 418-428$.

Fischer, C. T. \& Wertz, F. J. (1979). Empirical phenomenological analyses of being criminally victimized. Duquesne studies in phenomenological psychology, 3, 135158.

Fox, G., Schwartz, A., \& Hart, K. (2006). Work-family balance and academic advancement in medical schools. Academic Psychiatry, 30(3), 227-234.

Gall, M. D., Gall, J. P., \& Borg, W. R. (2007). Educational research: An introduction (8th ed.). Boston, MA: Pearson Education. 
Gander, P., Briar, C., Garden, A., Purnell, H., \& Woodward, A. (2010). A gender-based analysis of work patterns, fatigue, and work/life balance among physicians in postgraduate training. Academic Medicine, 85, 1526-1536.

Gardner, J. (2005). Barriers influencing the success of racial and ethnic minority students in nursing programs. Journal of Transcultural Nursing, 16(2), 155-162.

Giorgi, A. (1970). Psychology as a human science. New York, NY: Harper \& Row.

Giorgi, A., \& Giorgi, B. (2003). The descriptive phenomenological psychological method. In P. Camic, J. Rhodes, \& L. Yadley (Eds.), Qualitative research in psychology: Expanding perspectives in methodology and design (pp. 275-297). Washington, DC: American Psychological Association Press.

Glaser, B. G. (1978). Theoretical sensitivity: Advances in the methodology of grounded theory (Vol. 2). Mill Valley, CA: Sociology Press.

Glaser, B. G., \& Strauss, A. L. (1967). The discovery of grounded theory: Strategies for qualitative research. Aldine de Gruyter.

Golde, C. M. (2005). The role of the department and discipline in doctoral student attrition: Lessons from four departments. The Journal of Higher Education, 76(6), $669-700$.

Golde, M. (2000). Should I stay or should I go? Student descriptions of the doctoral attrition process. Review of Higher Education, 23, 199-227.

Guba, E. G., \& Lincoln, Y. S. (1994). Competing paradigms in qualitative research. In N. K. Denzin, \& Y. S. Lincoln (Eds.), Handbook of qualitative research. Thousand Oaks, CA: SAGE Publications, Inc. 
Guilford, W.H. (2001). Teaching peer review and the process of scientific writing. Advances in Physiology Education, 25(3), 167-175.

Harris, T.R., Bransford, J.D., \& Brophy, S.P. (2002). Roles for learning sciences and learning technologies in biomedical engineering education: A review of recent advances. The Annual Review of Biomedical Engineering, 4, 29-48. doi:10.1146/annurev.bioeng.4.091701.125502

Harrison, R. A., \& Gregg, J. L. (2009). A time for change: An exploration of attitudes toward part-time work in academia among women internists and their division chiefs. Academic Medicine, 84(1), 80-86.

Henry, P. J., \& Sears, D. O. (2002). The symbolic racism 2000 scale. Political Psychology, 23(2), 253-283.

Hewlett, S. A. (2004). Fast-Track Women and the Quest for Children. Sexuality, Reproduction and Menopause 2(1), 15-18.

Jackson, V. A., Palepu, A., Szalacha, L., Caswell, C., Carr, P. L., and Inui, T. (2003). "Having the right chemistry": A qualitative study of mentoring in academic medicine. Academic Medicine, 78(3), 328-334.

Jeffe, D.B., \& Andriole, D.A. (2011). A national cohort study of MD-PhD graduates of medical schools with and without funding from the National Institute of General Medical Sciences' Medical Scientist Training Program. Academic Medicine, 86(8), 953-961.

Jones, C. P. (2000). Levels of racism: a theoretic framework and a gardener's tale. American Journal of Public Health, 90(8), 1212. 
Keller, J., \& Dauenheimer, D. (2003). Stereotype threat in the classroom: Dejection mediates the disrupting threat effect on women's math performance. Personality and Social Psychology Bulletin, 29(3), 371-381.

Kvale, S. (2007). Doing interviews. Thousand Oaks, CA: SAGE Publications, Inc.

Kvale, S., \& Brinkmann, S. (2009). Interviews: Learning the craft of qualitative research interviewing. Sage Publications, Incorporated.

Lakhan, S.E. (2003). Diversification of U.S. medical schools via affirmative action implementation. BMC Medical Education, 3, 1-6.

Lee, K.B., Vaishnavi, S.N., Lau, S.K.M., Andriole, D.A., \& Jeffe, D.B. (2009). Cultural competency in medical education: Demographic differences associated with medical student communication styles and clinical clerkship feedback. Journal of the National Medical Association, 101(2), 116-126.

Legassie, J., Zibrowski, E. M., \& Goldszmidt, M. A. (2008). Measuring resident wellbeing: impostorism and burnout syndrome in residency. Journal of general internal medicine, 23(7), 1090-1094.

Lonie, J.M. (2010). Learning through self-reflection: Understanding communication barriers faced by a cross-cultural cohort of pharmacy students. Currents in Pharmacy Teaching and Learning, 2, 12-19. doi:10.1016/j.cptl.2009.12.002

Lovitts, B. E. (2001). Leaving the ivory tower: The causes and consequences of departure from doctoral study. Lanham: Rowman \& Littlefield.

Lovitts, B. E., \& Nelson, C. (2000). The hidden crisis in graduate education: Attrition from Ph.D. programs. Academe, 86(6), 44-50. 
Lyons, W., Scroggins, D. and Rule, P. B. (1990). The mentor in graduate education. Studies in Higher Education, 15(3), 277-285.

Mahoney, M. R., Wilson, E., Odom, K. L., Flowers, L., \& Adler, S. R. (2008). Minority faculty voices on diversity in academic medicine: Perspectives from one school. Academic medicine: Journal of the Association of American Medical Colleges, 83(8), 781.

Marshall, C., \& Rossman, G. B. (2006). Designing qualitative research (4th Ed.). Thousand Oaks, CA: Sage Publications, Inc.

Marshall, C. \& Rossman, G.B. (1995). Designing qualitative research. Thousand Oaks, CA: SAGE Publications.

Mason, M.A., \& Goulden, M. (2004). Do babies matter (part II)? Closing the baby gap. Academe, 90, 11-15.

Maume, D. J. (2006). Gender differences in restricting work efforts because of family responsibilities. Journal of Marriage and Family, 68(4), 859-869.

Maxwell, J. A. (2005). Qualitative research design: An interactive approach $\left(2^{\text {nd }}\right.$ ed.). Thousand Oaks, CA: SAGE publication.

McGrail, M.R., Rickard, C.M., \& Jones, R. (2006). Publish or perish: A systematic review of interventions to increase academic publication rates. Higher Education Research and Development, 25(1), 19-35. doi:10.1080/07294360500453053

McPhillips, H.A., Burke, A.E., Sheppard, K., Pallant, A.., Stapleton, F.B., \& Stanton, B. (2007). Toward creating family-friendly work environments in pediatrics: Baseline data from pediatric department chairs and pediatric program directors. Pediatrics, 119(3), 596-602. 
Meneghini, R., \& Packer A.L. (2007) Is there science beyond English? European Molecular Biology Organizations Reports, 8(2), 112-116. doi:10.1038/sj.embor.7400906

Miles, M. B., \& Huberman, A. M. (1994). Qualitative data analysis: An expanded sourcebook (2nd Ed.). Thousand Oaks, CA: Sage Publications, Inc.

Missing persons: Minorities in the Health Professions. (2004). A Report of the Sullivan Commission on Diversity in the Health Workforce. Retrieved from http://depts.washington.edu/ccph/pdf_files/Sullivan_Report_ES.pdf

Mitchell, D. A., \& Lassiter, S. L. (2006). Addressing health care disparities and increasing workforce diversity: the next step for the dental, medical, and public health professions. Journal Information, 96(12).

Moustakas, C. (1994). Phenomenological research methods. Thousand Oaks, CA: Sage Publications, Inc.

Muslin, A.J., Kornfeld, S., \& Polonsky, K.S. (2009). The physician scientist training program in internal medicine at Washington University School of Medicine. Academic Medicine, 84, 468-471.

National Institute of General Medical Sciences (NIGMS). Medical Scientist Training Program. Bethesda, MD: National Institutes of Health. Available at: http://www.nigms.nih.gov/Training/InstPredoc/PredocOverview-MSTP.htm. Accessed October 11, 2012.

National Science Foundation. (2011). Women, minorities, and persons with disabilities in science and engineering: 2011. Retrieved from http://www.nsf.gov/statistics/wmpd/pdf/nsf11309.pdf 
Nettles, M. T. (1990). Success in Doctoral programs: Experiences of minority and white students. American Journal of Education, 98(4), 494-522.

Nivet, M.A., Taylor, V.S., VS, Butts, G.C., Strelnick, A.H., Herbert-Carter, J., FryJohnson, Y.W., Smith, Q.T., Rust, G., \& Kondwani, K. (2008). Diversity in academic medicine no. 1 case for minority faculty development today. Mount Sinai Journal of Medicine, 75, 491-498.

Nonnemaker, L. (2000). Women physicians in academic medicine: /new insights from cohort studies. The New England Journal of Medicine, 342, 399-405.

Nosek, B. A., Smyth, F.L., Sriram, N., Linder, N. M., Devos, T., Ayala, A., et al. (2009). National differences in gender-science stereotypes predict national sex differences in science and mathematics achievement. Proceedings of the National Academy of Sciences, USA 106(26), 10593-10597. doi:10.1073/pnas.0809921106

Nugent, K. E., Childs, G., Jones, R., \& Cook, P. (2004). A mentorship model for the retention of minority students. Nursing Outlook, 52(2), 89-94.

Odom, K.L., Roberts, L.M., Johnson, R.L., \& Cooper, L.A. (2007). Exploring obstacles to and opportunities for professional success among ethnic minority medical students. Academic Medicine, 82(2), 146-153.

Ogbu, J.U. (1987). Variability in minority school performance: A problem in search of an explanation. Anthropology and Education Quarterly 18, 312-334.

Ogbu, J.U. (1990). Cultural models and educational strategies of non-dominant people. The 1989 Catherine Molony Memorial Lecture, City College of New York. 
Ogbu, J. (1999). Beyond language: ebonics, proper English, and identity in a BlackAmerican speech community. American Educational Research Journal, 36(2), $147-184$.

Ogbu, J.U., \& Simons, H.D. (1998). Voluntary and involuntary minorities: A culturalecological theory of school performance with some implications for education. Anthropology \& Education Quarterly, 29(2), 155-188.

Oriel, K., Plane, M. B., \& Mundt, M. (2004). Family medicine residents and the impostor phenomenon. Family Medicine-Kansas City, 36(4), 248-252.

Osborne, J. W. (2001). Testing stereotype threat: Does anxiety explain race and sex differences in achievement? Contemporary Educational Psychology, 26(3), 291310.

Page, K. R., Castillo-Page, L., \& Wright, S. M. (2011). Faculty diversity programs in US medical schools and characteristics associated with higher faculty diversity. Academic Medicine, 86(10), 1221.

Palda, V. A., \& Levinson, W. (2009). Commentary: The right time to rethink part-time careers. Academic Medicine, 84(1), 9-10.

Peek, M. E., Kim, K. E., Johnson, J. K., \& Vela, M. B. (2013). “URM Candidates Are Encouraged to Apply": A National Study to Identify Effective Strategies to Enhance Racial and Ethnic Faculty Diversity in Academic Departments of Medicine. Academic Medicine, 88(3), 405-412.

Peterson, N. B., Friedman, R. H., Ash, A. S., Franco, S., \& Carr, P. L. (2004). Faculty Self-reported Experience with Racial and Ethnic Discrimination in Academic Medicine. Journal of General Internal Medicine, 19(3), 259-265. 
Phelan, S. (1988). Pregnancy during residency. 1. The decision to be or not to be. Obstetrics \& Gynecology, 72, 425-431.

Powell, D., Scott, J. L., Rosenblatt, M., Roth, P. B., \& Pololi, L. (2010). Commentary: a call for culture change in academic medicine. Academic Medicine, 85(4), 586.

Price, E. G., Powe, N. R., Kern, D. E., Golden, S. H., Wand, G. S., \& Cooper, L. A. (2009). Improving the diversity climate in academic medicine: faculty perceptions as a catalyst for institutional change. Academic medicine: journal of the Association of American Medical Colleges, 84(1), 95.

Price, E. G., Gozu, A., Kern, D. E., Powe, N. R., Wand, G. S., Golden, S., \& Cooper, L. A. (2005). The role of cultural diversity climate in recruitment, promotion, and retention of faculty in academic medicine. Journal of General Internal Medicine, 20(7), 565-571.

Richardson, J. T. E. (1999). The concepts and methods of phenomenographic research. Review of Educational Research, 69(1), 53-82.

Rossman, G. B., \& Rallis, S. F. (2012). Learning in the field. An introduction to qualitative research $\left(3^{\text {rd }}\right.$ ed.). Thousand Oaks, CA: SAGE Publications, Inc.

Santiago, D.A., \& Brown, S. (2004). Federal policy and Latinos in higher education. Washington, DC: Pew Hispanic Center.

Sayres, M., Wyshak, G., Denterlein, G., Apfel, R., Shore, E., \& Federman, D. (1986). Pregnacy during residency. The New England Journal of Medicine, 314, 418-423.

Schouten, B.C., \& Meeuwesen, L. (2006). Cultural differences in medical communication: A review of the literature. Patient Education and Counseling, 64, 21-34. doi:10.1016/j.pec.2005.11.014 
Schwartz-Shea, P \& Yanow, D. (2012). Interpretive research design: Concepts and processes. New York, NY: Routledge.

Seidman, I. E. (1998). Interviewing as qualitative research: A guide for researchers in education and the social sciences (2nd Ed.). New York, NY: Teachers College Press.

Seymour, E., \& Hewitt, N. (1997). Talking about leaving: Why undergraduates leave the sciences. Boulder, CO: Westview.

Shauman, K. A., \& Xie, Y. (1996). Geographic mobility of scientists: sex differences and family constraints. Demography, 33(4), 455-468.

Shavers, V. L., Fagan, P., Lawrence, D., McCaskill-Stevens, W., McDonald, P., Browne, D., ... \& Trimble, E. (2005). Barriers to racial/ethnic minority application and competition for NIH research funding. Journal of the National Medical Association, 97(8), 1063.

Shih, M., Pittinsky, T. L., \& Ambady, N. (1999). Stereotype susceptibility: Identity salience and shifts in quantitative performance. Psychological Science, 10, 80-83.

Shollen, S. L., Bland, C. J., Finstad, D. A., \& Taylor, A. L. (2009). Organizational climate and family life: How these factors affect the status of women faculty at one medical school. Academic Medicine, 84(1), 87-94.

Snyder, D. J., \& Bunkers, S. J. (1994). Facilitators and barriers for minority students in master's nursing programs. Journal of Professional Nursing, 10(3), 140-146.

Spencer, S. J., Steele, C. M., \& Quinn, D. M. (1999). Stereotype threat and women's math performance. Journal of Experimental Social Psychology, 35, 4-28.

Steele, C. M. (1997). A threat in the air: How stereotypes shape intellectual identity 
and performance. American Psychologist, 52, 613-629.

Steele, C. M., \& Aronson, J. (1995). Stereotype threat and the intellectual test performance of African Americans. Journal of Personality and Social Psychology; Journal of Personality and Social Psychology, 69(5), 797.

Stein, E. L., Weidman, J. C. (1989). Socialization in graduate school: A conceptual framework. The Annual Meeting of the Association for the Study of Higher Education (pp. 1-22). Atlanta, GA.

Strauss, A., \& Corbin, J. (1994). Grounded theory methodology: An overview. In N. Denzin \& Y. Lincoln (Eds.), Handbook of qualitative research (pp. 273-285). Thousand Oaks, CA: Sage.

Strauss, A., \& Corbin, J. (1990). Basics of qualitative research: Grounded theory procedures and techniques. Thousand Oaks, CA: SAGE Publications.

Tamburrino, M.B., Evans, C.L., Campbell, N.B., Franco, K.N., Jurs, S.G., \& Pentz, J.E. (1992). Physician pregnancy: male and female colleagues' attitudes. Journal of American Medical Women's Association, 47, 82-84.

Turner, C. S. V. (2002). Women of color in academe: Living with multiple marginality. The Journal of Higher Education, 73(1), 74-93.

Valcarcel, M., Diaz, C., \& Santiago-Borrero, P. J. (2006). Training and retaining of underrepresented minority physician scientists- a Hispanic perspective: NICHDAAP workshop on research in neonatology. Journal of Perinatology, 26, S49S52.

van Kaam, A. (1959). Phenomenal analysis: Exemplified by a study of the experience of "really feeling understood." Journal of Individual Psychology, 15, 66-72. 
Van Maanen, J. (1976). Breaking in: Socialization to work. In R. Dublin (ed.), Handbook of work, organization, and society (pp.67-130). Chicago: Rand McNally.

Varki, A., \& Rosenberg, L.E. (2002). Emerging opportunities and career paths for the young physician-scientist. Nature Medicine, 8(5), 437-439.

Villablanca, A.C., Beckett, L., Nettiksimmons. J., \& Howell, L.P. (2011). Career flexibility and family-friendly policies: An NIH-funded study to enhance women's careers in biomedical sciences. Journal of Women's Health, 20(10), 1485-1496. doi: 10.1089/jwh.2011.2737

Weidman, J. C., Twale, D. J., \& Stein, E. L. (2001). Socialization of graduate and professional students in higher education: A perilous passage? ASHE-ERIC Higher Education Reports, 28(3), 1-112.

White, F.S., McDade, S., Yamagata, H., \& Morahan, P.S. (2012). Gender-related differences in the pathway to and characteristics of U.S. medical school deanships. Academic Medicine, 87(8), 1015-1023.

Willett, L.L., Wellons, M.F., Hartig, J.R., Roenigk, L., Panda, M., Dearinger, A.T., Allison, J., \& Houston, T.K. (2010). Do women residents delay childbearing due to perceived career threats? Academic Medicine, 85(4), 640-646.

Wong, E. Y., Bigby, J., Kleinpeter, M., Mitchell, J., Camacho, D., Dan, A., \& Sarto, G. (2001). Promoting the advancement of minority women faculty in academic medicine: the National Centers of Excellence in Women's Health. Journal of Women's Health \& Gender-Based Medicine, 10(6), 541-550. 
Xu, G., Fields, S. K., Laine, C., Veloski, J. J., Barzansky, B., \& Martini, C. J. (1997). The relationship between the race/ethnicity of generalist physicians and their care for underserved populations. American Journal of Public Health, 87(5), 817-822.

Yedidia, M. J., \& Bickel, J. (2001). Why aren't there more women leaders in academic medicine? The views of clinical department chairs. Academic Medicine, 76(5), 453.

Young-Shumate, L., Kramer, T., \& Beresin, E. (1993). Pregnancy during graduate medical training. Academic Medicine, 68, 792-799. 


\section{APPENDICES}

\section{Appendix A: \\ Informed Consent Agreement}

\section{Please read this consent agreement carefully before you decide to participate in the study.}

Purpose of the research study: The purpose of the study is to better understand the factors that contribute to the decisions making of the members of the $\mathrm{MD} / \mathrm{PhD}$ community at various stages in their career paths. There are a wide range of paths that members can take, varying from doctors to researchers to opting for altogether different areas of work. By better understanding the factors that influence persistence and attrition in various aspects of these fields, we hope that policy decisions can be informed to create optimal conditions for an equitable system.

What you will do in the study: We are seeking participants to help us isolate the factors that propelled them forward or steered them differently within their fields of study. To this end, participants will be asked to answer various questions in a private setting with a researcher from the project. During the interview, you can skip any question that makes you uncomfortable and you can stop the interview at any time.

Time required: The study will require about 1 hour of your time.

Risks: One potential risk of participation in this study is a loss of confidentiality regarding your interview responses. To minimize this risk, data will be coded and stripped of any identifying information that would link the data file to you. The researchers will have no means of identifying individuals within the data set.

Benefits: There are no specific benefits to you as an individual for participating in this research study. However, this study will help us understand the contributing factors that lead to entry, success, and long term careers in the biomedical research field.

Confidentiality: The information that you give in the study will be handled confidentially. Your information will be assigned a code number. The list connecting your name to this code will be kept in a locked file. When the study is completed and the data have been analyzed, this list will be destroyed. Your name will not be used in any report. Materials will be destroyed seven years after the data are collected. 
Voluntary participation: Your participation in the study is completely voluntary.

Right to withdraw from the study: You have the right to withdraw from the study at any time without penalty. Your tape will be destroyed should you decide to withdraw.

How to withdraw from the study: If you want to withdraw from the study, tell the interviewer to stop the interview. There is no penalty for withdrawing. If you would like to withdraw after your materials have been submitted, please contact Dr. Robert Tai.

Payment: You will receive no payment for participating in the study.

If you have questions about the study, contact:

Robert Tai, Ed.D.

209 Bavaro Hall

Curry School of Education

450 Emmet St.

University of Virginia, Charlottesville, VA 22904-4261

Telephone: (434) 924-0840

rht6h@virginia.edu

If you have questions about your rights in the study, contact:

Tonya R. Moon, Ph.D.,

Chair, Institutional Review Board for the Social and Behavioral Sciences

One Morton Dr Suite 500

University of Virginia, P.O. Box 800392

Charlottesville, VA 22908-0392

Telephone: (434) 924-5999

Email: irbsbshelp@virginia.edu

Website: www.virginia.edu/vpr/irb

\section{Agreement:}

I agree to participate in the research study described above.

Signature:

Date:

Printed Name:

You will receive a copy of this form for your records. 


\section{Appendix B:}

\section{Interview Protocols}

\section{Before you begin:}

- Check the proper functioning of all recording equipment prior to the interview. At the beginning of the session I will:

- Introduce myself to the participant and thank him or her for taking the time to participate.

- If an in-person interview is being conducted, ask the interviewee to read the informed consent form. If a telephone interview is being conducted, read highlighted sections of the consent form to the interviewee.

- If an in-person interview is being conducted, obtain signatures for two copies of the consent form and provide interviewee with one copy of consent form for his or her records. If a telephone interview is being conducted, ask the interviewee to print and sign one copy of the consent form that was sent to them via e-mail, and mail the signed copy to us at the address provided in the e-mail message. Also offer to send them hard copies of the form via U.S. mail, along with a selfaddressed, stamped envelope in which they may return a signed copy of the consent form.

- Thank you for agreeing to participate. Typically these interviews last about 45-60 minutes.

- Explain the process of recording the interview.

- To facilitate my note-taking, I would like to digitally record our conversation today. Only members of our research team will be privy to the recordings, which will be stored in a secure file until they are transcribed and destroyed.

- The purpose of this interview is for me to learn about you and your educational and career choices. If I ask you anything that you do not feel comfortable answering please feel free to tell me that you do not want to answer that question. Do you have any questions for me before we begin?

- Begin recording.

- Ask participant to state "I agree" if they understand and agree to everything on the consent form. 


\section{a. Interview Protocol for Faculty and Researchers}

Interviewee:

Date of interview:

The following questions will be used as a guide. Some may not be asked if the answer is gleaned from a previous response. Follow-up probes may be used in the context of each interview to elicit greater detail and information.

1. First, I need to ask you a few quick questions.

a. What is the name of the institution where you were enrolled in your $\mathrm{MD} / \mathrm{PhD}$ program?

b. Was that an MSTP program?

c. What is your gender?

d. What is the ethnic group that best describes you?

e. What is your age?

f. What is the name of the institution where you obtained your undergraduate degree?

g. What was your undergraduate major?

2. Tell me a little bit about what you do as [name current position].

3. At what point in your life, as a child or as an adult, do you first remember actively considering a career in medicine, science or science research?

4. How did you decide to pursue a career in academia or research? What steps did you take in order to pursue this career?

5. Tell me about your expectations going into academia or research after graduate school. In what ways did your work meet, or differ from, your expectations?

6. How did you know that you were ready to be an independent researcher?

7. Tell me about your interactions with others in your field. [Note: For clarification about "interactions," explain that we are interested in knowing more about the nature of their personal and professional relationships with peers or colleagues.]

8. Tell me about your experiences with advising or mentoring you may have received, as a student or as a professional.

a. Did you have an advisor or mentor in graduate school, or at the start of your career? If so, tell me about them.

b. How did you end up working with this advisor or mentor?

c. How was this advisor or mentor involved in your career decision-making? 
9. Tell me about any supports or preparation that you received as a student or during your early career, which might have been beneficial for you when you first entered your field. [e.g., research experience in high school, as an undergraduate, or in summer programs elsewhere (name of institution/type and duration of program); career counseling; or academic mentoring/advising...]

10. Tell me about any supports or preparation that you did not receive as a student or during your early career, which might have been beneficial for you coming into your field.

11. Were there any specific barriers that you felt you needed to overcome in order to succeed in your field?

12. Describe any barriers that, while perhaps not barriers for you, you saw as barriers to the experiences of others in your field.

13. Was there a critical moment or specific experience that precipitated your decision to seek a career in academia or research? If so, what was it?

14. Looking back at your own past educational experiences, were there one or two things that -- had they happened differently -- might have led you to choose some other career path?

a. Have you thought about discontinuing your current career path at any point? If yes, why were you considering leaving and what made you decide to continue on your current career path rather than leaving?

15. What advice would you give to someone who is considering a career in academia or research?

16. Is there anything else about your background or experiences that you would like to add?

17. Do you have any questions for me?

18. Is there anyone else you would suggest that we talk to for this project? Would you mind sharing our email address with them, so they can contact us if they'd be interested in doing an interview?

19. Would you like to be considered for participation in future studies?

- I will thank the participant for his or her time and insights. 


\section{b. Interview Protocol for Former Biomedical Researchers}

Interviewee:

Date of interview:

The following questions will be used as a guide. Some may not be asked if the answer is gleaned from a previous response. Follow-up probes may be used in the context of each interview to elicit greater detail and information.

1. First, I need to ask you a few quick questions.

a. What is the name of the institution where you were enrolled in your $\mathrm{MD} / \mathrm{PhD}$ program?

b. Was that an MSTP program?

c. What is your gender?

d. What is the ethnic group that best describes you?

e. What is your age?

f. What is the name of the institution where you obtained your undergraduate degree?

g. What was your undergraduate major?

2. Tell me a little bit about what you currently do professionally.

3. At what point in your life, as a child or as an adult, do you first remember actively considering a career in medicine, science or science research?

4. How did you decide to pursue a biomedical research career? What steps did you take to pursue this career?

5. Tell me about your expectations going into the field. In what ways did your work meet, or differ from, your expectations?

6. How did you know when you were ready to be an independent researcher?

7. Tell me about your interactions with others in your field. [Note: For clarification about "interactions," explain that we are interested in knowing more about the nature of their personal and professional relationships with peers or colleagues.]

8. Tell me about your experiences with advising or mentoring, from professors, peers, or professional colleagues. 
9. Tell me about any supports or preparation you received as a student or during your early career, which might have been beneficial for you coming into the field as a novice scientist. [e.g., research experience in high school, as an undergraduate, or in summer programs elsewhere (name of institution/type and duration of program); career counseling; or academic mentoring/advising...]

10. Tell me about any supports or preparation that you did not receive as a student or during your early career, which might have been beneficial for you coming into the field as a novice scientist.

11. Were there any specific barriers that you felt you needed to overcome in order to succeed in your field?

12. Describe any barriers that, while perhaps not barriers for you, you saw as barriers to the experiences of others in your field.

13. Tell me about the process of deciding to leave biomedical research.

a. Was there a critical moment or specific experience that precipitated your decision to leave your field? If so, what was it?

14. Looking back, what could have happened differently that would have led you to stay in your field?

15. What advice would you give to someone who is considering a career in biomedical research?

16. Is there anything else about your background or experiences that you would like to add?

17. Do you have any questions for me?

At the end of the interview

18. Is there anyone else you would suggest that we talk to for this project?

a. Would you mind sharing our email address with them, so they can contact us if they'd be interested in doing an interview?

19. Would you like to be considered for participation in future studies?

- I will thank the participant for his or her time and insights. 


\section{c. Interview Protocol for Former Students}

Interviewee:

Date of interview:

The following questions will be used as a guide. Some may not be asked if the answer is gleaned from a previous response. Follow-up probes may be used in the context of each interview to elicit greater detail and information.

1. First, I need to ask you a few quick questions.

a. What is the name of the institution where you were enrolled in the $\mathrm{MD} / \mathrm{PhD}$ program?

b. Were you enrolled in an MSTP program?

c. What is your gender?

d. What is the ethnic group that best describes you?

e. What is your age?

f. What is the name of the institution where you obtained your undergraduate degree?

g. What was your undergraduate major?

2. Tell me a little bit about what you are currently doing [academically or professionally].

3. At what point in your life, as a child or as an adult, do you first remember actively considering a career in medicine, science or science research?

4. How did you decide to pursue a [graduate or medical] degree?

5. What were the factors you considered when applying to $\mathrm{MD} / \mathrm{PhD}$ programs?

a. How did you find out about graduate/medical programs? How did you select the program you chose to attend?

b. Did you visit programs during the admissions process? If yes, in what ways did those visits impact selection of your program?

c. What kind of advice or help did you receive from your undergraduate program/institution/advisor?

6. Tell me about your expectations going into the program. [If participant asks which "program" we are referring to (e.g., MD vs. PhD), ask them to discuss both.]

a. In what ways did the program meet, or differ from, your expectations?

7. To what extent did you gain hands-on research experience while you were in your program? 
a. Describe research experiences in your former $\mathrm{MD}, \mathrm{PhD}$, or $\mathrm{MD} / \mathrm{PhD}$ program.

b. Describe research experience(s) you had as an undergraduate [Note if it is a specific summer research program or programs].

8. Tell me about your interactions with other people in your program. [Note: For clarification about "interactions, " explain that we are interested in knowing more about the nature of their personal and professional relationships with peers or colleagues.]

9. Tell me about your interactions with others in your field, while you were in the program. [If participant asks for clarification, ask them to consider peers in other departments, collaborators at the other institution, interactions at conferences, etc.]

10. Tell me about your experiences with advising or mentoring, from professors or peers, in your program. Did you have a say in selecting your former advisor?

11. How much did your family understand about what you were doing in graduate school?

12. Tell me about any supports or preparation you received prior to your graduate program, that helped prepare you for your graduate program. [e.g., research experience in high school, as an undergraduate, or in summer programs elsewhere (name of institution/type and duration of program); career counseling; or academic mentoring/advising]

13. Tell me about any supports or preparation that you did not receive prior to your graduate program, which might have helped prepare you for your graduate program.

14. Beyond programmatic rigor, tell me about any specific barriers that you felt you needed to overcome in order to succeed in the graduate program.

15. Describe any barriers that you observed during your course of study that, while perhaps not barriers for you, you saw as barriers to the experiences of others.

16. Who was your support system outside of your program?

17. Tell me about the process of deciding to leave the graduate program.

a. Was there a critical moment or specific experience that precipitated your decision to leave the program? If so, what was it? 
18. Looking back, what could have happened differently that would have led you to stay in the program?

19. Knowing what you know now about graduate school, would you have made the same choices? If not, what choices would you change?

20. What was your career goal going into your graduate program?

a. Did that goal change after you entered the program? If yes: How did your career goal change, and why?

21. Is there anything else about your background or experiences that you would like to add?

22. Do you have any questions for me?

At the end of the interview

23. Is there anyone else you would suggest that we talk to for this project?

a. Would you mind sharing our email address with them, so they can contact us if they'd be interested in doing an interview?

24. Would you like to be considered for participation in future studies?

- I will thank the participant for his or her time and insights. 


\section{d. Interview Protocol for Students}

Interviewee:

Date of interview:

The following questions will be used as a guide. Some may not be asked if the answer is gleaned from a previous response. Follow-up probes may be used in the context of each interview to elicit greater detail and information.

1. First, I need to ask you a few quick questions.

a. What is the name of the institution you currently attend?

b. Are you in an MSTP program?

c. What is your gender?

d. What is the ethnic group that best describes you?

e. What is your age?

f. What is the name of the institution where you obtained your undergraduate degree?

g. What was your undergraduate major?

2. Tell me a little bit about your current academic program.

a. What phase of your program are you in (e.g., first year of medical school, third year of $\mathrm{PhD}$ program)?

b. If $\mathrm{MD} / \mathrm{PhD}$, what is the program structure (e.g., 2-4-2); how does moving between phases of the $\mathrm{MD} / \mathrm{PhD}$ program work?

3. At what point in your life, as a child or as an adult, do you first remember actively considering a career in science or medicine?

4. How did you decide to pursue a [graduate or medical] degree?

5. What were the factors you considered when applying to programs?

a. How did you find out about graduate/medical programs? How did you select your program?

b. Did you visit programs during the admissions process? If yes, in what ways did those visits impact selection of your program?

c. What kind of advice or help did you receive from your undergraduate program/institution/advisor?

6. Tell me about your expectations coming into the program. [If participant asks which "program" we are referring to (e.g., MD vs. PhD), ask them to discuss both.]

a. In what ways has the program met, or differed from, your expectations?

7. Tell me about your hands-on research experiences so far? 
a. Describe research experiences in your current $\mathrm{MD}, \mathrm{PhD}$, or $\mathrm{MD} / \mathrm{PhD}$ program.

b. Describe research experience(s) you had as an undergraduate [Note if it is a specific summer research program or programs].

8. Tell me about any supports or preparation you received prior to your program, that helped prepare you for your program. [e.g., research experience in high school, as an undergraduate, or in summer programs elsewhere (name of institution/type and duration of program); career counseling; or academic mentoring/advising]

9. Tell me about any supports or preparation that you did not receive prior to your program, that you feel might have helped prepare you for your graduate program.

10. Beyond programmatic rigor, tell me about any specific barriers that you felt you needed to overcome in order to succeed in your program.

11. Describe any barriers that you have observed during your course of study that, while perhaps not barriers for you, you see as barriers to the experiences of others?

12. Tell me about your interactions with other people in your program. [Note: For clarification about "interactions," explain that we are interested in knowing more about the nature of their personal and professional relationships with peers or colleagues.]

a. How do people in your program treat one another?

13. Tell me about your interactions with others in your field.

[If participant asks for clarification, ask them to consider peers in other departments, collaborators at other institution, interactions at conferences, etc.]

14. Tell me about your experiences with advising or mentoring - from professors or peers -- in your program so far.

a. Did you have a say in selecting your advisor?

15. How much does your family understand about what you do in graduate school?

16. Who is your support system outside of your program?

17. Looking back at your own past experiences, were there one or two things that -had they happened differently -- might have led you to choose some other educational path that did not involve obtaining a [graduate or medical] degree?

18. What was your career goal coming into your program?

a. Has that goal changed since you entered the program?

i. If yes: How has your career goal changed, and why? 
19. Knowing what you know now about [graduate or medical school], would you make the same choices? If not, what choices would you change?

20. Is there anything else about your background or experiences that you would like to add?

21. Do you have any questions for me?

At the end of the interview

22. Is there anyone else you would suggest that we talk to for this project? This can include people you know at your institution, or at other schools, or students who have left your program.

a. Would you mind sharing our email address with them, so they can contact us if they'd be interested in doing an interview?

23. Would you like to be considered for participation in future studies?

- I will thank the participant for his or her time and insights. 